\title{
Regional Variation in New Zealand English: The Taranaki Sing-song Accent
}

\author{
by
}

\section{Helen Ainsworth}

\author{
A thesis \\ submitted to Victoria University of Wellington \\ in fulfilment of the \\ requirements for the degree of \\ Doctor of Philosophy
}

School of Linguistics and Applied Language Studies

Faculty of Humanities and Social Sciences

Victoria University of Wellington 
Although lay people confidently assert the existence of regional varieties of New Zealand English, linguists have produced very little evidence to support such claims. There are vocabulary items special to, or favoured by, the people of Southland and the West Coast of the South Island; there are traces of non-prevocalic $/ \mathrm{r} /$ in Southland and Otago; and there are regional differences in the playground language of New Zealand school children. Attempts to identify further differences between regions have generally not been successful. In most cases linguistic evidence has pointed to either social class or ethnic variation, but not to regional variation.

Nevertheless, many New Zealanders assert that a Taranaki variety of New Zealand English exists. This study was designed to test the validity of the claim by comparing samples of New Zealand English from Taranaki with samples from Wellington. The Taranaki sample included speakers from New Plymouth (population 50,000) and the South Taranaki dairy farming community. The Wellington sample was drawn from the Greater Wellington region extending from Porirua in the north to suburbs on the southern coast of the city. Interviewees were located by the social network approach, otherwise known as the 'friend of a friend' approach advocated by Lesley Milroy $(1980,1987 a)$. An index of rural orientation was devised to indicate the degree to which a speaker was oriented towards town or country. This proved helpful in distinguishing between genuinely regional differences, and rural versus urban differences. Factors of gender and age were also considered.

It has been claimed that Taranaki English has a 'sing-song' quality, suggesting that an investigation of the intonation of Taranaki speakers would be worthwhile. Comparing features of the intonation of a Taranaki sample with a Wellington sample, this thesis attempts to isolate and measure what contributes to the 'sing-song' perception of Taranaki English. 'Singsong' in this context was taken to mean that the speaker had dynamic pitch; in other words their speech was characterised by a lot of movement up and down in pitch. Auditory analysis of speech samples was undertaken, and intonation features were derived from that analysis. Averaging the number of times a speaker changed pitch direction in each intonation group and then in each accent unit provided global measures of changes in pitch direction. Analysis of nuclear accents gave an indication of whether speakers favoured tunes which were characterised by pitch movement. And analysis of the manner in which accents were approached, whether with a boosted step up in pitch, or with a more standard onset, provided a narrower focus on the amount of pitch movement present.

Results indicated that, in general, most Taranaki speakers in the sample showed more pitch dynamism than the Wellingtonians; for some features the males showed more pitch dynamism than the females; and, overall, the elderly speakers showed more pitch dynamism than the younger speakers. There were, however, important exceptions to these generalisations. Factors of Location, Gender and Age interacted significantly for all but one of the features examined and there were clear indications that intonational patterns are undergoing change in both regions studied. Explanations for the exceptional cases are explored in the thesis, and sociolinguistic, social network and geolinguistic theories provide possible clues as to the sources of the differences.

Evidence of differences in the degree of pitch dynamism present in the intonation of the Taranaki and Wellington speakers supports claims about regional variation in New Zealand English intonation, but it does not in itself prove the existence of a uniquely Taranaki or a uniquely Wellington way of speaking English. 
I am deeply indebted to my supervisors Professor Janet Holmes and Dr Paul Warren. Janet has been an encouraging mentor over many years. I thank her for her enthusiastic support of this project, for moral support when the going got tough, and for understanding when deadlines could not be met. I have benefited greatly from her insights and thoughtful comments. I am grateful to Paul for teaching me most of what I know about intonation, for his patience in lending me his ears to check my auditory assessments, for help in statistical matters, and for many invaluable suggestions and criticisms of my work.

I am grateful to Dinah Priestley for calling my attention to the 'sing-songy' quality of Taranaki speech. I am also grateful for her generosity in allowing me to use her oral history tapes. Thank you to the Oral History Centre of the Alexander Turnbull Library in Wellington for releasing these tapes for analysis.

I thank the Wellington Archive of Spoken English for the use of ten of the Porirua Project tapes.

Seminar and conference audiences have provided me with much valuable input. I am grateful for the helpful comments of LALS staff, fellow students and the many other people who have taken an interest in this project.

I thank Bernadette Vine for proof reading my writing.

I am indebted to my friends and family for their encouragement and support over the years. Their tolerance and understanding has been much appreciated. I am especially grateful to Jim Baltaxe for computer support, help with figures, diagrams, and maps, the final compilation of material, acting as a sounding board for ideas and much more besides.

I am grateful to Victoria University of Wellington and the VUW Alumni Association for their financial support.

I owe a specially big thank you to the friendly people of Taranaki and Wellington who gave of their precious time, welcoming me into their homes and offices, and allowing me to tape record their speech. If it were not for their generosity, this project would not have been possible. I also thank my friends, colleagues and extended family for providing contacts in Taranaki and Wellington, setting the whole snow ball rolling.

And finally, pats on the back for the dog who insisted on daily beach walks - there's nothing like Cook Strait air for clearing the head. 


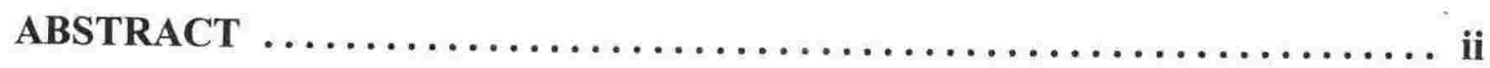

ACKNOWLEDGEMENTS $\ldots \ldots \ldots \ldots \ldots \ldots \ldots \ldots \ldots \ldots \ldots \ldots \ldots \ldots \ldots \ldots \ldots \ldots$ iii

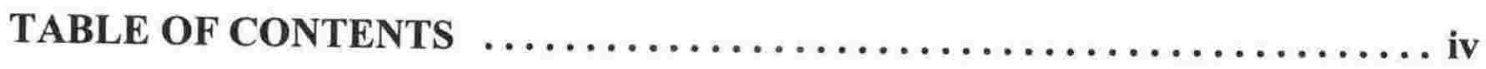

FIGURES $\ldots \ldots \ldots \ldots \ldots \ldots \ldots \ldots \ldots \ldots \ldots \ldots \ldots \ldots \ldots \ldots \ldots \ldots \ldots \ldots \ldots \ldots$, vii

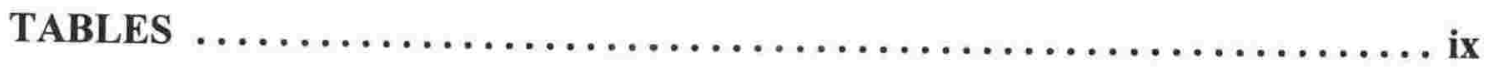

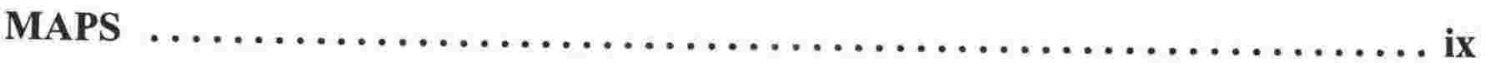

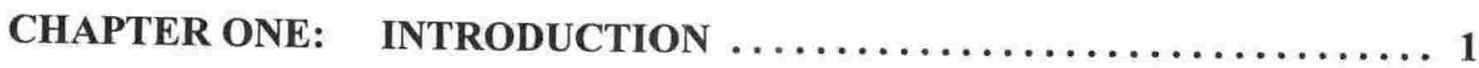

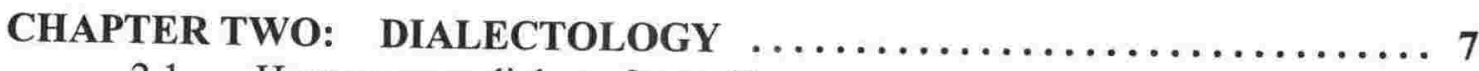

$2.1 \quad$ How are new dialects formed? $\ldots \ldots \ldots \ldots \ldots \ldots \ldots \ldots \ldots \ldots \ldots \ldots$

2.1.1 British dialects spoken in New Zealand in the nineteenth century

2.1.2 Dialect mixture $\ldots \ldots \ldots \ldots . . . . .9$

2.1.3 Determinism in new dialect formation .................. 10

2.1 .4 The role of children in new dialoc fo ............... 12

2.1.4 The role of children in new dialect formation ........... 13

2.1 .5 Law of swamping .......................... 14

2.1.6 Comparison of New Zealand English features with British dialect

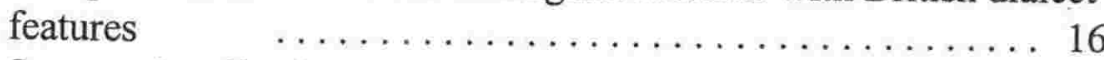

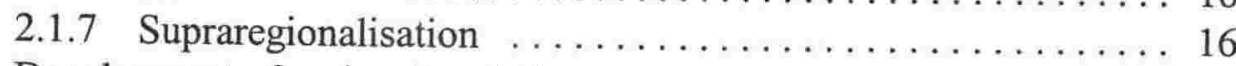

2.2 Development of regional variation $\ldots \ldots \ldots \ldots \ldots \ldots \ldots \ldots \ldots \ldots$

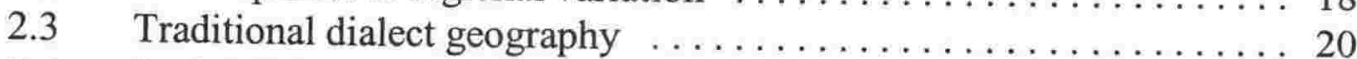

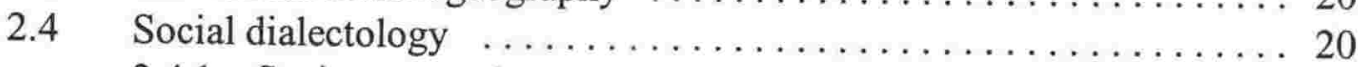

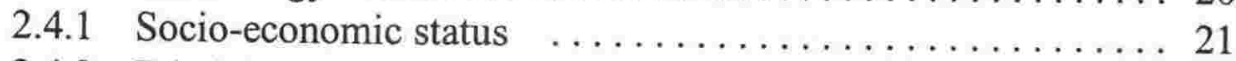

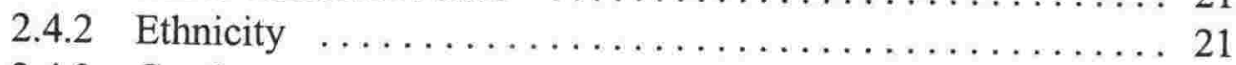

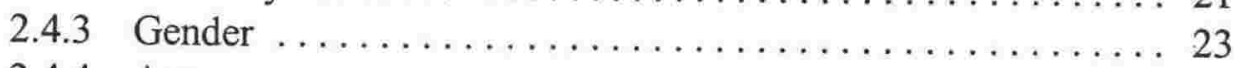

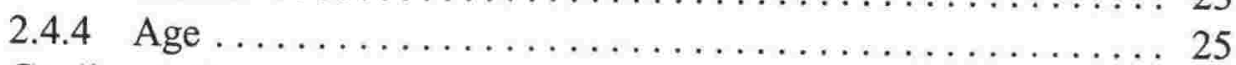

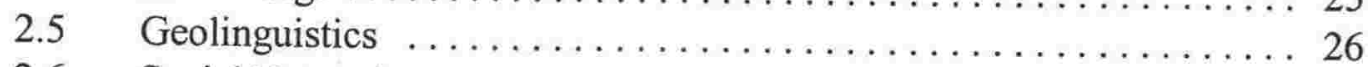

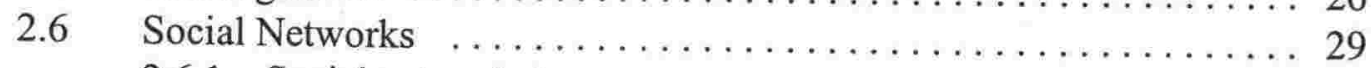

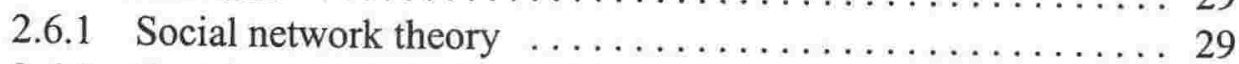

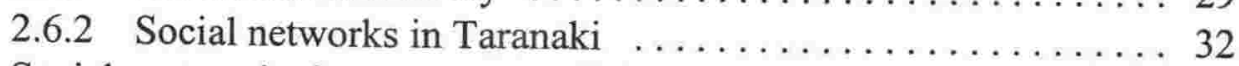

2.7 Social contructionist approach to dialectology $\ldots \ldots \ldots \ldots \ldots \ldots \ldots . \ldots \ldots$

2.7.1 Expression of gender and social class $\ldots \ldots \ldots \ldots \ldots \ldots \ldots . \ldots \ldots$

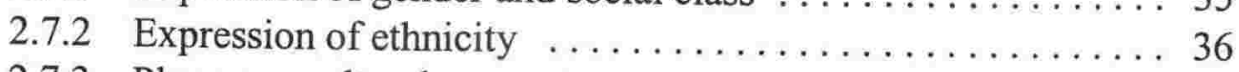

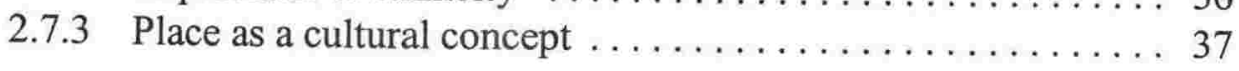

CHAPTER THREE: EVIDENCE OF REGIONAL VARIATION IN NEW

ZEALAND ENGLISH $\ldots \ldots \ldots \ldots \ldots \ldots \ldots \ldots \ldots \ldots \ldots \ldots, 40$

$3.1 \quad$ Folk linguistic approach - perceptual dialectology $\ldots \ldots \ldots \ldots \ldots, 40$

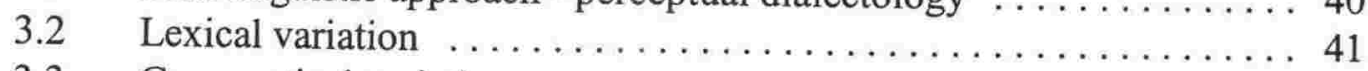

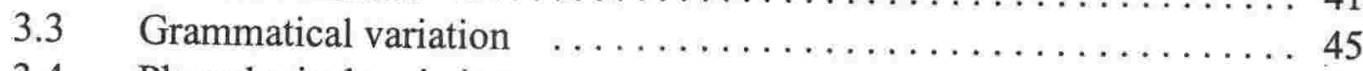

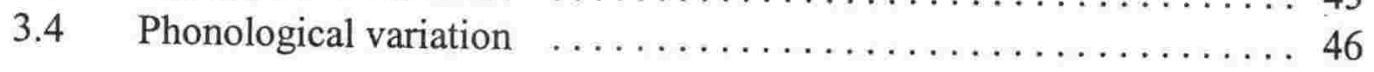


4.1 Ladd's taxonomy of intonational differences $\ldots \ldots \ldots \ldots \ldots \ldots 52$

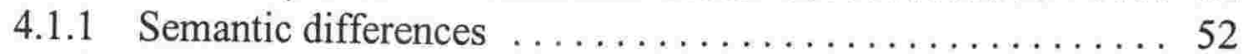

4.1 .2 Systemic differences $\ldots \ldots \ldots \ldots \ldots \ldots \ldots \ldots \ldots \ldots \ldots$

4.1.2.1 Overall percentage of rises ................ 54

4.1.2.2 Prosodic features of conversational turn endings .... 54

4.1.2.3 Placement of base-line .................... 55

4.1.2.4 Closed versus open tone meanings $\ldots \ldots \ldots \ldots \ldots 55$

4.1.3 Realisational differences $\ldots \ldots \ldots \ldots \ldots \ldots \ldots \ldots \ldots 656$

4.1.3.1 Peak lag .......................... 56

4.1.3.2 Alignment of rises $\ldots \ldots \ldots \ldots \ldots \ldots \ldots \ldots . \ldots 57$

4.1.3.3 Pitch movement on unaccented syllables $\ldots \ldots \ldots . .57$

4.1.4 Phonotactic differences ........................ 57

4.2 Methodologies used to establish intonational variation $\ldots \ldots \ldots \ldots . . . \ldots 58$

4.2.1 Impressionistic/qualitative studies $\ldots \ldots \ldots \ldots \ldots \ldots 58$

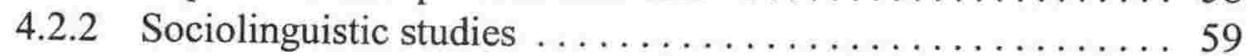

4.2.2.1 Comparison of nuclear tones $\quad \ldots \ldots \ldots \ldots \ldots \ldots 59$

4.2.2.2 Comparison of intonation tunes ............. 60

4.2.2.3 Comparison of HRT usage . . . . . . . . . . . . 61

4.2.2.3.1 Age $\ldots \ldots \ldots \ldots \ldots \ldots \ldots, 61$

4.2.2.3.2 Gender .................. 61

4.2.2.3.3 Ethnicity $\ldots \ldots \ldots \ldots \ldots \ldots 62$

4.2.2.3.4 Social class $\ldots \ldots \ldots \ldots \ldots \ldots 62$

4.2.2.3.5 Discourse context .............6 63

4.2.2.4 Gender comparisons ....................... 64

4.2.2.4.1 Stereotypes .................. 64

4.2.2.4.2 Pitch range $\ldots \ldots \ldots \ldots \ldots \ldots 65$

4.2.2.4.3 Pitch dynamism ............... 66

4.2.2.4.4 Other studies which confirm speaker stereotypes ................ 67

4.2.3 Psycholinguistic/experimental methodology ............. 69

$4.3 \quad$ Research questions ................................. 70

CHAPTER FIVE: METHODOLOGY $\ldots \ldots \ldots \ldots \ldots \ldots \ldots \ldots \ldots, 73$

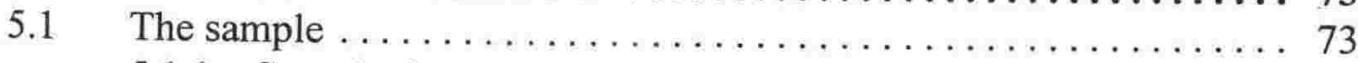

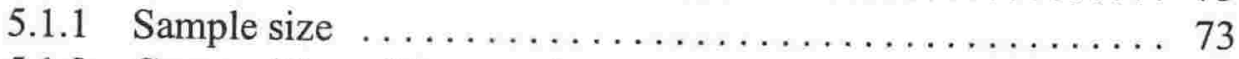

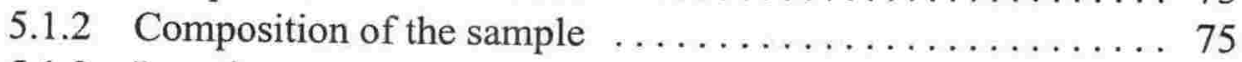

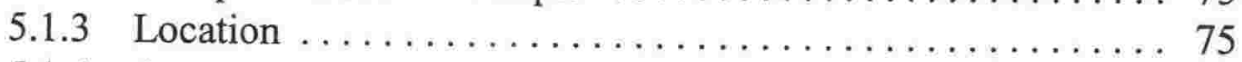

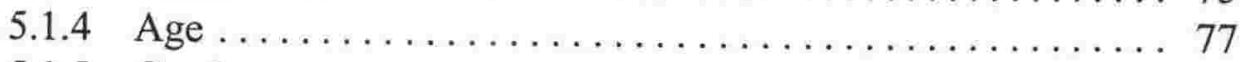

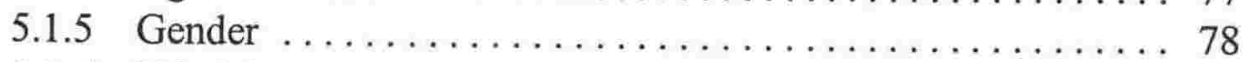

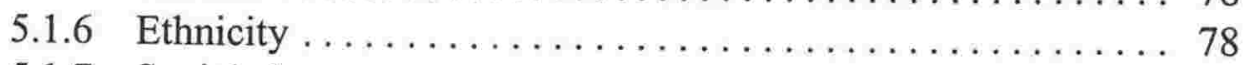

$5.1 .7 \quad$ Social class $\ldots \ldots \ldots \ldots \ldots \ldots$
0

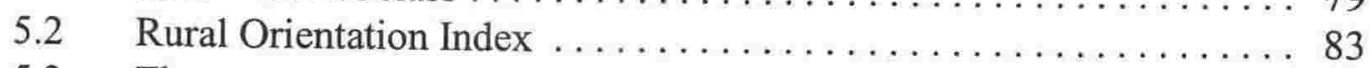

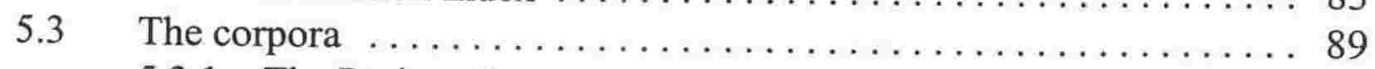

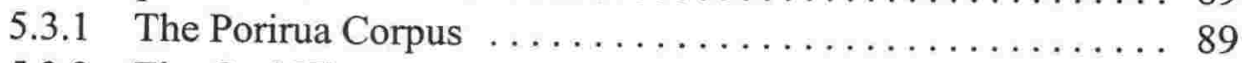

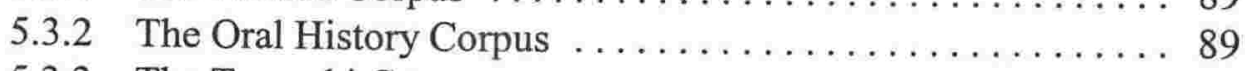

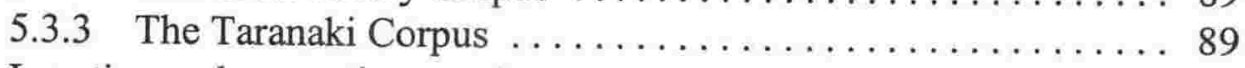

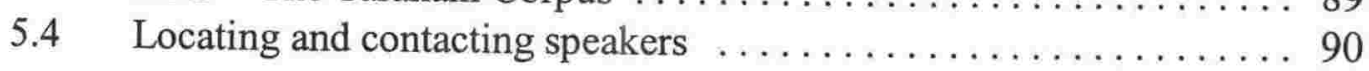




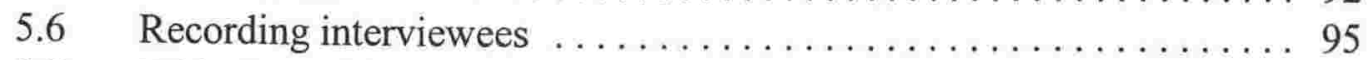

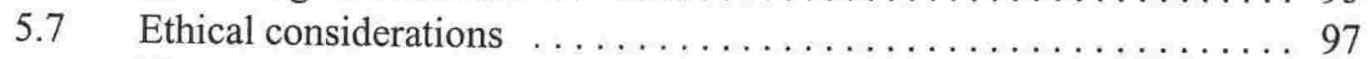

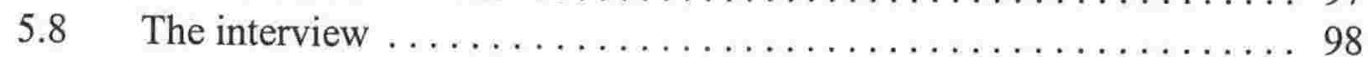

5.8.1 Language questions . . . . . . . . . . . . . . . . . . . . . 99

5.8.2 British and American lexical items ................ 100

5.8 .3 L-vocalisation ............................ 100

$5.8 .4 \mathrm{Rural} / \mathrm{Urban}$ orientation questions $\ldots \ldots \ldots \ldots \ldots \ldots \ldots \ldots, 100$

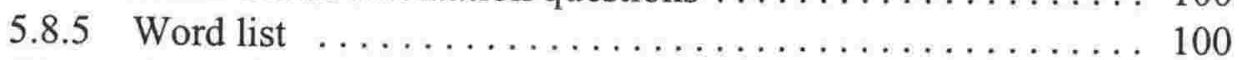

5.8.6 General conversation ............................ 101

5.8.7 Demographic information ....................... 102

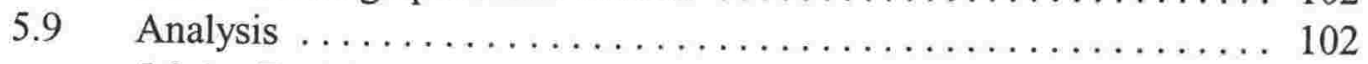

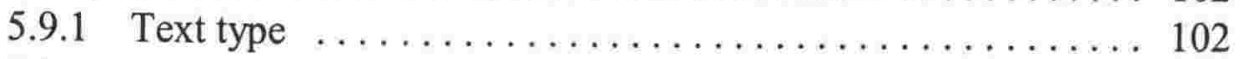

5.9 .2 Transcription of data ............................ 104

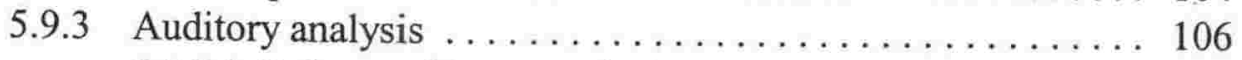

5.9.3.1 Orthographic transcription ............... 106

5.9.3.2 Intonation group boundaries $\ldots \ldots \ldots \ldots \ldots \ldots . \ldots 106$

5.9.3.3 Identification of accent units . . . . . . . . . . . . . 107

5.9.3.4 Description of accent units ................. 108

5.9.3.5 Structure of intonation groups .............. 108

5.9.3.6 Declination .............................. 109

5.9.3.7 Prosodic features transcribed ............... 110

5.9.4 Quantitative analysis of data $\ldots \ldots \ldots \ldots \ldots \ldots \ldots \ldots . \ldots 111$

5.9.4.1 Length of intonation groups

5.9.4.2 Changes in pitch direction per intonation group and per accent unit .......................... 112

5.9.4.3 Nuclear accents . . . . . . . . . . . . . . . . . . . . 113

5.9.4.4 Non-nuclear accents ...................... 114

5.9.4.5 Falling accents with boosted onsets (nuclear and non-

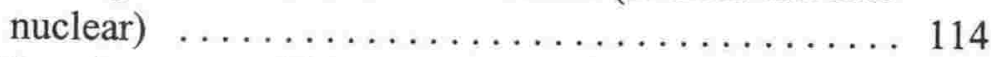

5.9.4.6 Level accents with boosted onsets (nuclear and non-

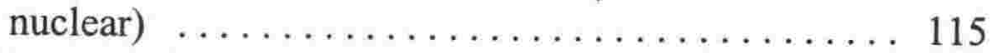

5.9.4.7 Statistical analysis $\ldots \ldots \ldots \ldots \ldots \ldots \ldots \ldots . \ldots \ldots$

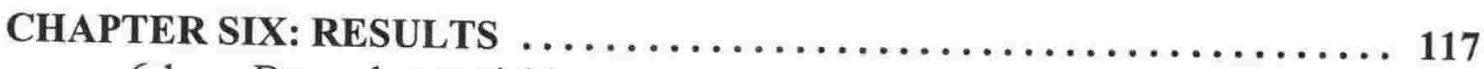

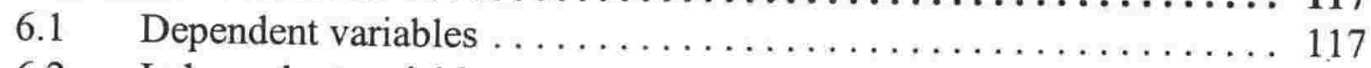

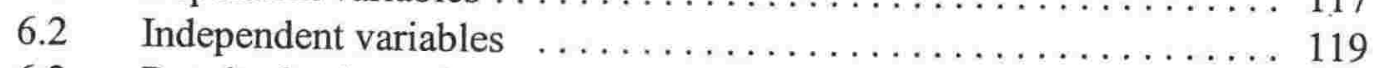

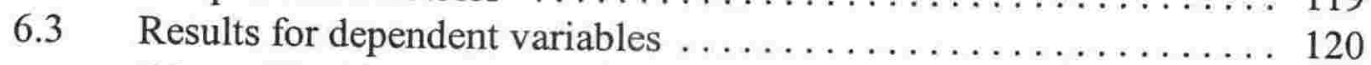

6.3.1. Significant Main Effects of Location . . . . . . . . . . . . . . 128

6.3.2 Significant Main Effects of Gender ................. 130

6.3.3 Significant Main Effects of Age $\ldots \ldots \ldots \ldots \ldots \ldots \ldots \ldots 131$

6.3.4 Significant Interactions of Location and Gender .......... 133

6.3.5 Significant Interactions of Location, Gender and Age . . . . . 135

$6.4 \quad$ Summary of results $\ldots \ldots \ldots \ldots \ldots \ldots \ldots \ldots \ldots \ldots \ldots \ldots \ldots$

6.5 Correlation of rural orientation index scores with intonational features 
CHAPTER SEVEN: DISCUSSION $\ldots \ldots \ldots \ldots \ldots \ldots \ldots \ldots \ldots \ldots \ldots \ldots, 140$

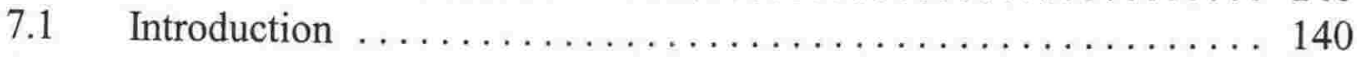

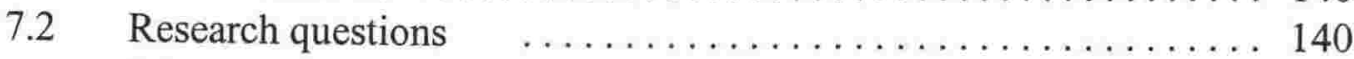

7.2.1 Rules for pitch dynamism $\ldots \ldots \ldots \ldots \ldots \ldots \ldots \ldots . \ldots \ldots 14$

7.2.2 Exceptions to the rules ....................... 141

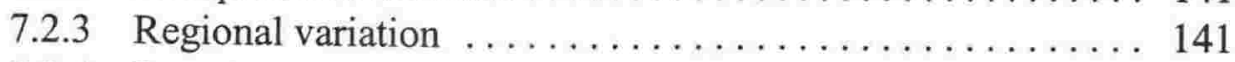

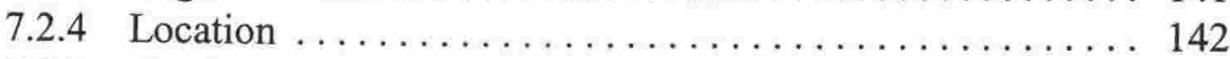

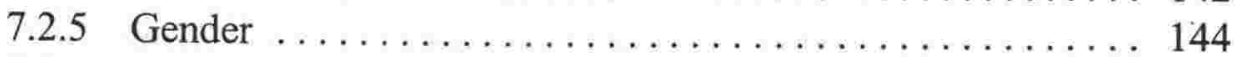

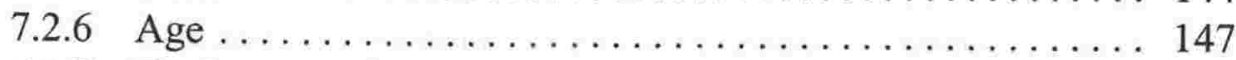

7.2.7 Explanations for exceptional cases $\ldots \ldots \ldots \ldots \ldots \ldots . \ldots 148$

7.2 .8 Social networks . . . . . . . . . . . . . . . . . . . . . . . 149

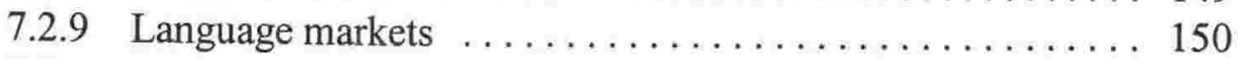

7.2 .10 Changes old and new $\ldots \ldots \ldots \ldots \ldots \ldots \ldots \ldots \ldots \ldots \ldots \ldots$

7.2.11 'Standard' versus 'non-standard' intonation . . . . . . . . . 154

7.2 .12 Social status . .......................... 154

7.2.13 Non-conformity, social mobility and innovation ........ 155

7.2 .14 Gender socialisation ......................... 156

7.2.15 Impact of socio-economic and ideological changes ...... 156

7.2.16 Summary of explanations ...................... 157

7.2.17 Rural versus urban orientation .................. 159

7.2 .18 Regional variation revisited $\ldots \ldots \ldots \ldots \ldots \ldots \ldots \ldots \ldots$

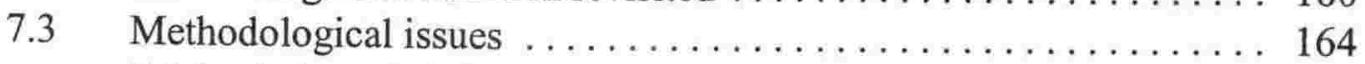

7.3.1 Index of pitch movement ..................... 164

7.3.2 Relative indexicality of features $\ldots \ldots \ldots \ldots \ldots \ldots \ldots$

7.3.3 Use of narrative texts . ..................... 167

7.3.4 Ladd's taxonomy of intonational differences ............ 168

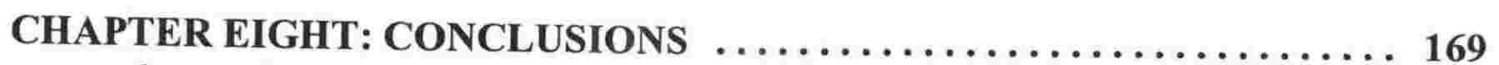

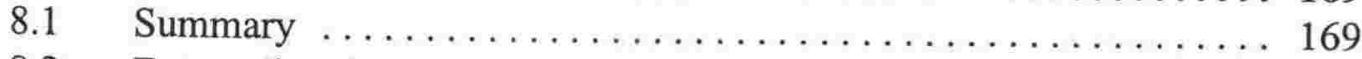

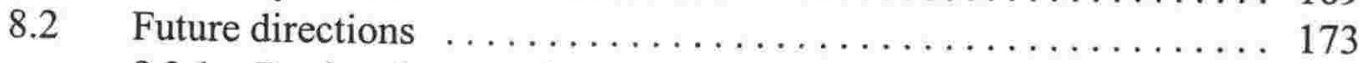

8.2 .1 Regional comparisons .......................... 173

8.2 .2 Possible sources of difference $\ldots \ldots \ldots \ldots \ldots \ldots \ldots \ldots . . \ldots \ldots$

8.2.3 Trajectory of change $\ldots \ldots \ldots \ldots \ldots \ldots \ldots \ldots \ldots \ldots \ldots$

8.2.4 Acoustic analysis . . . . . . . . . . . . . . . . . . . 175

8.2.5 Gender differences in intonation . . . . . . . . . . . . 176

8.2 .6 Lexical variation $\ldots \ldots \ldots \ldots \ldots \ldots \ldots \ldots \ldots \ldots \ldots$

8.3 Contribution of this thesis to social and regional dialectology .... 176

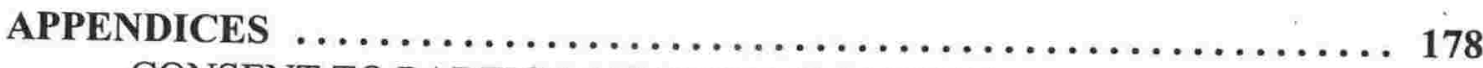

CONSENT TO PARTICIPATION IN RESEARCH $\ldots \ldots \ldots \ldots \ldots \ldots \ldots$

INTERVIEW SCHEDULE $\ldots \ldots \ldots \ldots \ldots \ldots \ldots \ldots \ldots \ldots \ldots \ldots \ldots \ldots \ldots \ldots$

BIBLIOGRAPHY OF WORKS CONSULTED .................... 197 


\section{FIGURES}

$5.1 \quad$ New Zealand Socioeconomic Index Scores . . . . . . . . . . . . . . . . 83

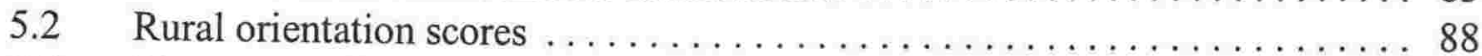

5.3 Placement of intonation group boundaries . . . . . . . . . . . . . . 107

5.4 Location of accent units . . . . . . . . . . . . . . . . . . . . . . . . . 107

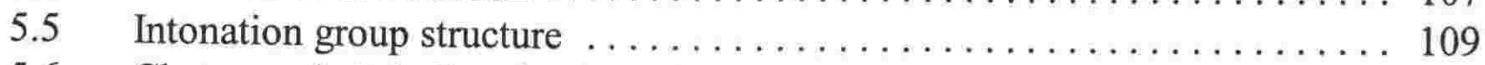

5.6 Changes of pitch direction in an intonation group ................ 113

\section{Significant Main Effects of Location}

6.1 Average changes of pitch direction per intonation group $\ldots \ldots \ldots \ldots \ldots 128$

6.2 Average changes of pitch direction per accent unit $\ldots \ldots \ldots \ldots \ldots \ldots .128$

6.3 Percent of nuclear accents with moving pitch $\ldots \ldots \ldots \ldots \ldots \ldots \ldots \ldots \ldots \ldots$

6.4 Percent of non-nuclear accents with moving pitch $\ldots \ldots \ldots \ldots \ldots \ldots . \ldots 128$

6.5 Percent of falling accents with boosted onsets . . . . . . . . . . . . . . . . . 129

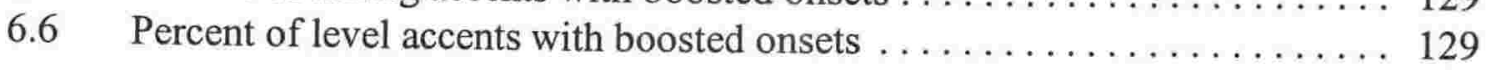

\section{Significant Main Effects of Gender}

6.7 Average changes of pitch direction per accent unit . . . . . . . . . . . . . 130

6.8 Percent of complex nuclear accents ........................... 130

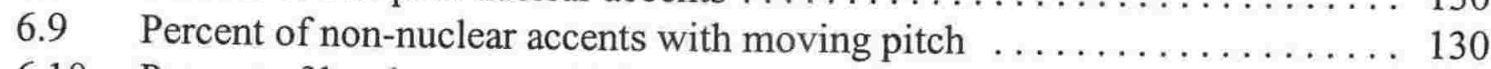

6.10 Percent of level accents with boosted onset .................. 130

\section{Significant Main Effects of Age}

6.11 Average changes of direction per intonation group $\ldots \ldots \ldots \ldots \ldots \ldots . \ldots 131$

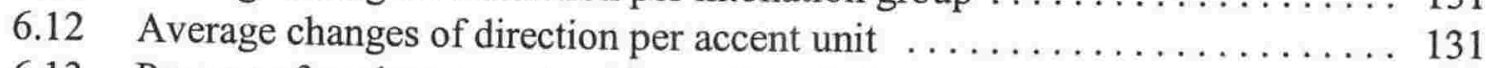

6.13 Percent of nuclear accents with moving pitch $\ldots \ldots \ldots \ldots \ldots \ldots \ldots \ldots \ldots \ldots \ldots$

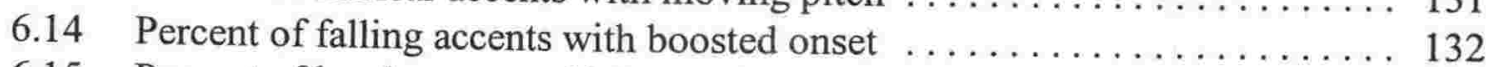

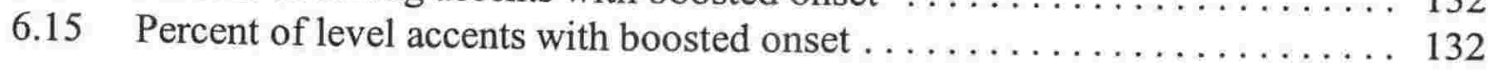

\section{Significant Interactions of Location and Gender}

6.16 Average change of pitch direction per intonation group $\ldots \ldots \ldots \ldots \ldots . \ldots 133$

6.17 Average change of pitch direction per accent unit $\ldots \ldots \ldots \ldots \ldots \ldots \ldots . . \ldots \ldots$

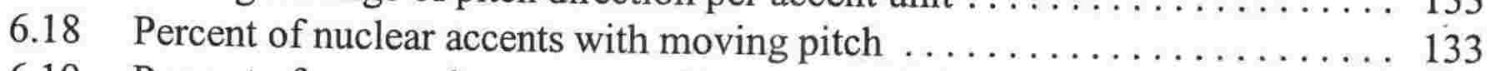

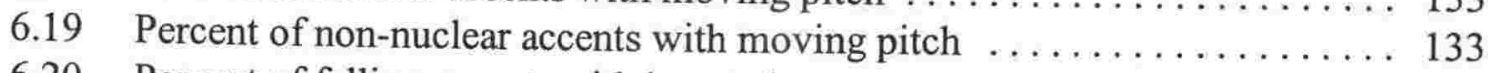

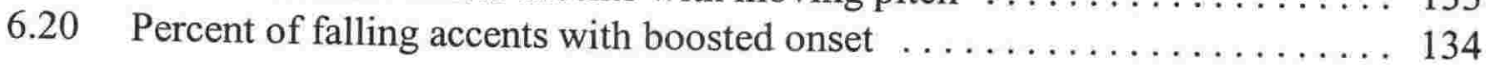

\section{Interactions of Location, Gender and Age}

6.21 Average changes of pitch direction per intonation group $\ldots \ldots \ldots \ldots \ldots . . \ldots 135$

6.22 Average changes of pitch direction per accent unit $\ldots \ldots \ldots \ldots \ldots \ldots \ldots . . \ldots \ldots$

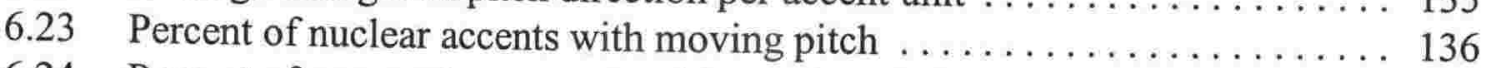

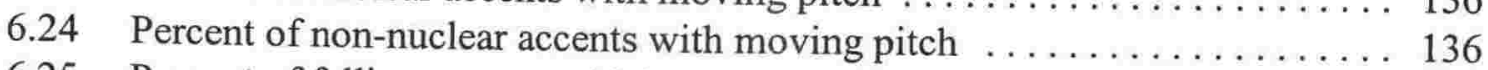

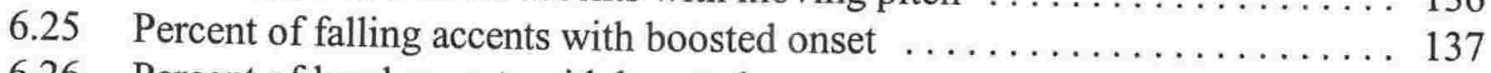

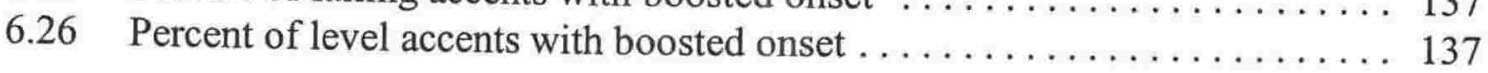




\section{TABLES}

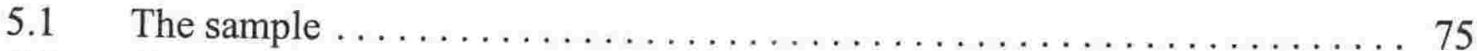

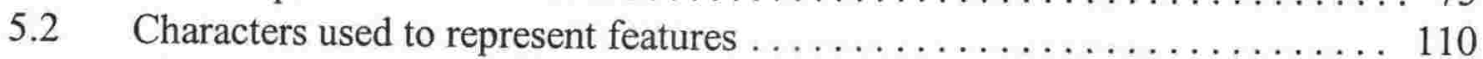

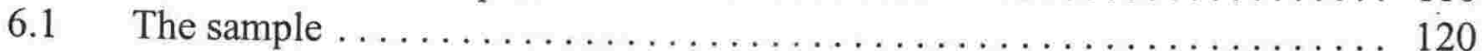

7.1 Differences between young South Taranaki males and females ........ 149

\section{MAPS}

$1 \quad$ New Zealand

2 North Island 


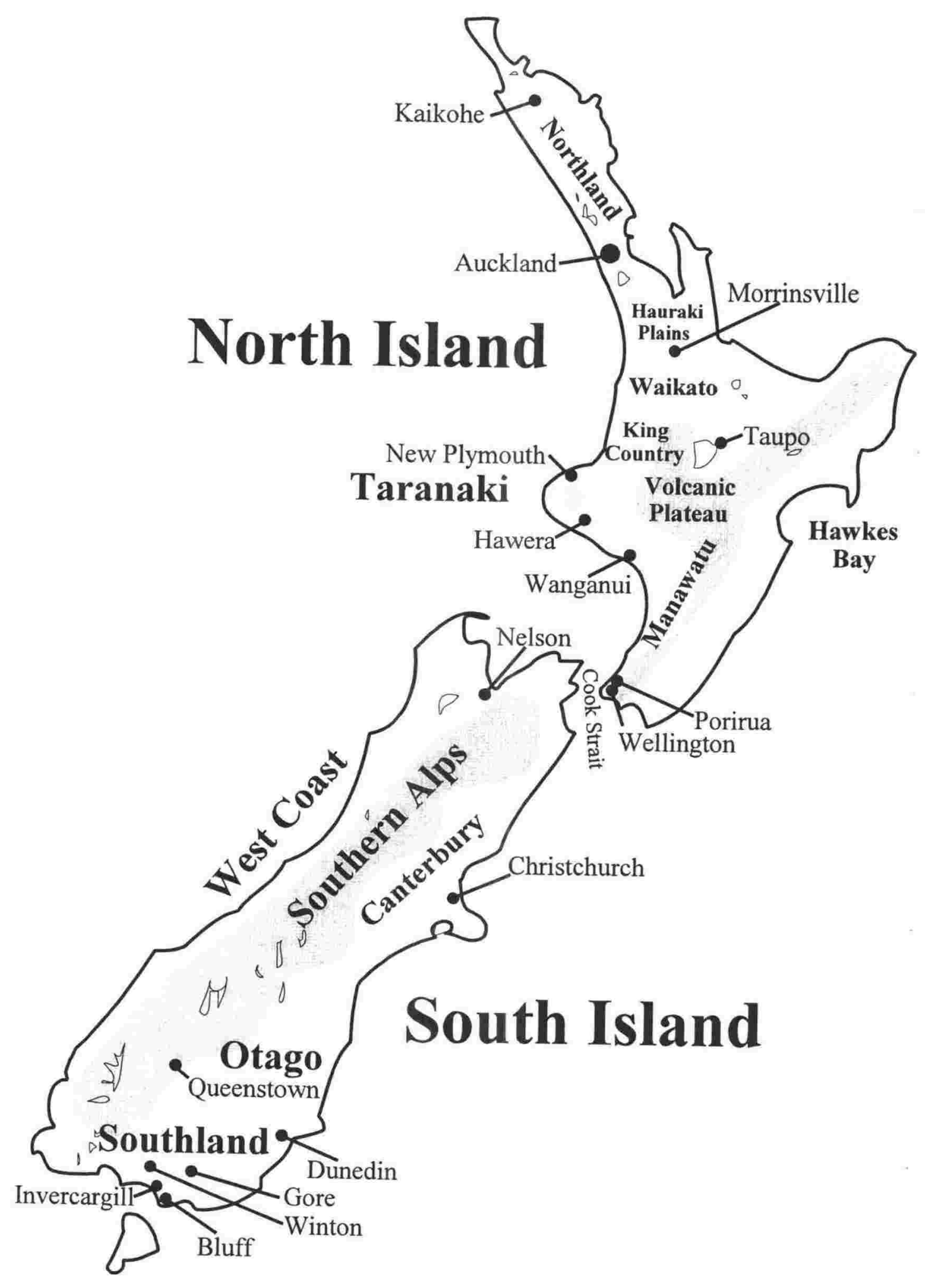

Map 1. New Zealand 
'I was talking to a lady in Karori and she said, "You're from Taranaki, aren't you? I can tell by the way you talk."'

'When we went on a school trip to St Pats Silverstream I was aware my friend and I sounded different to the other debaters. I didn't know we were different till then.'

'My family have me on when I go back to Stratford. They say I talk differently now.'

These are the words of friends and acquaintances born and bred in Taranaki and now resident in Wellington. None has linguistic training and each has a perception that Taranaki speech is distinctive, a view which has long been popular amongst other New Zealanders. 'No-one else can say "Taranaki gate” as a Taranaki person can,' wrote Rhona Davis, Chairman of the New Zealand Speech Board, to The New Zealand Listener, 30 April 1977.

Until recently there has been little systematic scholarly research into regional variation in New Zealand English. There has been an assumption amongst linguists that such variation is nonexistent, or at most, minimal, with the exception of the English spoken by Southlanders. As a consequence lay perceptions such as those expressed above have not been taken very seriously.

Curiosity as to the basis for these lay opinions attracted me to my thesis topic. I wanted to investigate whether or not regional variation, and, more specifically, a Taranaki variety, existed in New Zealand English.

Taranaki was selected for study in part because of folk perceptions of the type quoted at the beginning of this chapter and in part because Taranaki has become the focus of derogatory cultural stereotyping. This is conveyed in the ironic use of the adjective 'Taranaki' as in 'Taranaki topdressing' meaning 'cow manure', 'Taranaki sunshine' meaning 'rain' and 'Taranaki bullshit' meaning 'excessive boasting'. Such cultural stereotyping, based on the predominance of dairy farming in the area, may have given rise to perceived linguistic differences. The region is to some extent isolated from other 
areas of the North Island. The most direct route from North to South and vice versa is via the centre of the island and not via Taranaki. Surfies, gardening enthusiasts, trampers, mountaineers, milk tanker drivers and extended family members might have reason to go there, but, as one of my interviewees commented, 'People don't come to New Plymouth for work, and people from New Plymouth go elsewhere to find it.' Michael Smither, a notable Taranaki artist is quoted as saying 'New Plymouth is so isolated, it's a law unto itself' (The Dominion Post, 12 November 2004). This view may be a little exaggerated, but it is plausible that the relative isolation of the area during its one hundred and sixty odd years of English speaking settlement may have allowed the development of some variation in speech. Happily, for ease of data collection, and my credibility as an interviewer, I had spent seven years of my early adulthood in New Plymouth, the major urban centre in the region, and I had friends and acquaintances who were able to put me in touch with potential interviewees. The Taranaki sample consisted of people from both New Plymouth and the South Taranaki dairy farming community.

Wellington was selected as a contrast largely for reasons of convenience. Two excellent corpora of spoken English were available for analysis (the Porirua Corpus collected by Holmes, Bell and Boyce in the 1990's and material from the 'Coastal Voices of New Zealand' oral history project recorded by Dinah Priestley also in the 1990's). As a Wellingtonian myself I had plenty of contacts who could introduce me to additional interviewees.

A good proportion of the population of Wellington tends to be rather transient as is to be expected of an administrative capital. The city is situated in the centre of New Zealand on the south coast of the North Island and is a major transport hub for air, sea and land traffic. This being the case, there is probably more scope for face to face interaction with people from outside the region than there is in Taranaki. There is therefore less likelihood of Wellingtonians having developed a uniquely Wellington way of speaking English. In other words they are more likely to speak 'standard' New Zealand English, whatever that may be. It seemed that there could well be differences in the speech of these two very different regions. 
The intonation patterns of the two regions were chosen for comparison for reasons which are outlined in Chapter 4 of this thesis. The systematic study of intonation is relatively new in New Zealand and the focus until recently has been on the highly salient intonational feature in New Zealand English commonly known as the High Rising Terminal (HRT). I chose to look beyond the HRT in this thesis and took as my starting point the lay description given to me by Priestley (personal communication) of Taranaki English as 'sing-songy'. I interpreted 'sing-songy' to mean intonation characterised by frequent pitch movement up and down in a manner reminiscent of singing. In Chapters 5 and 6 I outline how I went about measuring and comparing 'sing-songiness' or 'pitch dynamism' in the speech of individual speakers.

The research project was designed according to sociolinguistic principles and these principles are reflected in the research questions addressed in the thesis. My reasons for asking these particular questions with their focus on the factors of Location, Gender, Age and urban or rural orientation are presented in Section 4.3, at the end of the literature review. In brief, the reasons are as follows: curiosity as to the basis for lay opinions concerning regional variation in New Zealand English led to the first question. The two locations chosen for comparison were of interest because of lay impressions expressed concerning variation, the geographical position of the locations concerned and sociological differences between the two locations. Comparison between male and female speakers was of interest because of known gender differences in intonation patterns. A concern to know if there was any evidence of change over time led to the comparison of the intonation patterns of two widely different age groups. Finally, I wished to distinguish between rural versus urban differences and authentically regional differences. An understanding of what constituted rural versus urban variation was therefore necessary.

The following are the research questions addressed:

- Is there regional variation in New Zealand English intonation?

- Does Taranaki English possess intonational features which distinguish it from the English spoken in Wellington? 
- Are there intonational differences in the English spoken by male and female speakers in Taranaki and Wellington?

- Is there any evidence of change over time in the intonation of speakers from Taranaki and Wellington?

- Are there intonational differences between urban and rurally oriented speakers in Taranaki and Wellington?

After close examination of the social distribution of seven intonational features selected for analysis, answers to the research questions appeared at first sight to be reasonably clear. All five questions could be answered in the affirmative. But analysis of variance showed that the situation was actually rather more complex.

Results of the analysis of variance undertaken showed that:

- For six of the seven intonational variables studied there were main effects of Location, with speakers from Taranaki displaying more pitch dynamism than Wellingtonians.

- For four of the variables studied there were main effects of Gender. For two of these four variables the men showed more pitch dynamism than the women and for the other two, women had higher scores than the men.

- $\quad$ For five of the variables studied there were main effects of Age, the elderly speakers displaying more pitch dynamism than the younger speakers.

- Four of the variables studied correlated positively with high rural orientation scores. 
There were, however, complex interactions of Location, Gender and Age for six of the seven variables studied and the picture which emerges is murkier than might at first appear. The fact that not all sample groups behaved as one might expect from the main effects outlined above indicates that these intonational features may be undergoing change and the behaviour of some groups provides us with clues as to which people are responsible for the changes.

Of particular interest is the contrast between the intonation patterns of the young South Taranaki dairy farming men and the young South Taranaki dairy farming women. In this thesis I argue that the young South Taranaki men express their unique Taranaki identity by retaining the dynamic pitch patterns typical of their Taranaki elders while the young South Taranaki dairy farming women adopt the more level intonation patterns typical of other New Zealanders.

I also argue that the difference between the intonation patterns of the Taranaki and Wellington speakers in the sample is genuinely regional and not simply a rural versus urban distinction.

Finally, I acknowledge that evidence of differences in the degree of pitch dynamism present in the intonation of the Taranaki and Wellington speakers supports claims about regional variation in New Zealand English intonation, but it does not in itself prove the existence of a uniquely Taranaki or a uniquely Wellington way of speaking English. Considerably more research is needed before such claims can be made.

The thesis is structured as follows:

In Chapters 2, 3 and 4 literature concerning regional and social dialectology, regional variation in New Zealand English, and research into intonational variation is reviewed. Theories of how dialects are formed are outlined in Chapter 2 as are methodologies employed by dialectologists for establishing the existence of linguistic variation and the reasons for such variation. Methodologies examined include traditional dialect geography, and social dialectology including social network theory, geolinguistics, social constructionism and ethnography. The literature on regional variation in New 
Zealand English is reviewed in Chapter 3. This review begins with the folk linguistic approach to the subject, then studies of lexical, grammatical and phonological variation are surveyed. Chapter 4 reviews research into intonational variation. The chapter begins with my reasons for focussing on intonation as a possible area of regional variation in New Zealand English. Different methodologies used by researchers in the comparison of varieties of English intonation are reviewed. The literature on HRTs, the particularly well known New Zealand feature of intonation, is surveyed, as is the literature on gender comparison in intonation. At the end of Chapter 4 I restate the research questions which underpin this thesis, and I outline the reasons for asking these particular questions drawing on the contents of the preceding literature review.

The sociolinguistic method used for seeking evidence of possible regional variation in New Zealand English intonation is described in Chapter 5, as is the method used for transcribing patterns of pitch movement. The seven intonational features selected for analysis are described and the statistical analysis undertaken outlined.

The primary results of the thesis are listed in Chapter 6 and the variation associated with each of the intonational features is examined.

The results are interpreted in Chapter 7 with links drawn between the individual findings. Insights gained from other studies are used to clarify some of the more complex findings.

Finally, the major findings and conclusions of the thesis are summarised in Chapter 8 . Ideas for future research in the area are indicated. I conclude with a note on the contribution this thesis makes to the fields of regional and social dialectology. 


\section{CHAPTER TWO: DIALECTOLOGY}

'You can spot an Irishman or a Yorkshireman by his brogue. I can place any man within six miles. I can place him within two miles of London. Sometimes within two streets' (Shaw 1941:26).

Henry Higgins (Shaw, Pygmalion, Act 1), with his superb ear for the nuances of variation in British English, here boasts of his skills as a phonetician. He is portrayed in Shaw's popular play as a dedicated dialectologist, based in part on Henry Sweet, the real life phonetician and a contemporary of Shaw. In the global village of today, placing people - regionally, socially and ethnically, by the way in which they speak, is more than ever an interesting, not to say challenging, occupation. A challenging task because of the relative ease with which people can now move from one country to another across the planet, and because of advances in communications technology which give us increased exposure to different language varieties. Given the world's exposure to mass media, some might say it is surprising that linguistic variation continues to exist, but there is no doubt that it does, and the field of dialectology is as relevant as it ever was.

During the latter half of the nineteenth century and the first half of the twentieth century dialectology principally involved the study of regional variation. With the increase in social and geographical mobility of the second half of the twentieth century, came a change in emphasis from regional to social variation, and factors such as social class, age, gender and ethnicity were found to correlate with linguistic differences among speakers. The present dialectological study incorporates elements of both regional and social variation. It is also informed by the discipline known as geolinguistics which takes note of the influence of face to face communication, ie. who speaks to whom, and how often such interactions take place, and which features of day to day existence favour face to face communication and which features impede it.

In this chapter I consider how dialects are formed, with particular reference to the formation of New Zealand English. I then examine different approaches to the study of regional variation in English: firstly, the traditional approach of dialect geography; secondly, social dialectology, including social network theory and geolinguistics; and 
then thirdly, I consider recent ethnographic approaches to social and regional dialectology. This thesis draws on each of these approaches to varying degrees, though the basic design is consistent with the sociolinguistic principles developed by Labov in the United States (Labov 1972a,b,c) and Trudgill and Milroy and Milroy in Great Britain (Trudgill 1974; L. Milroy 1980, 1987a, 1987b: J.Milroy \& L.Milroy 1985) and adopted and refined by many others since.

\subsection{How are new dialects formed?}

I begin this review with an examination of the process of dialect formation in general, in order to shed light on the formation of possible regional variation in New Zealand English.

I use the term dialect as Wolfram used it (1997:107) to refer to

'any regional, social or ethnic variety of a language. The language differences associated with dialect may occur on any level of language, thus including pronunciation, grammatical, semantic, and language use differences.'

\section{New dialect formation refers to}

'a linguistic situation which arises when there is a mixture of dialects leading to a single new dialect which is different from all inputs. In the context of New Zealand, new dialect formation took place after initial immigration of speakers from different regions of the British Isles. This was a process of dialect mixture in which, over just a few generations, a clearly focused variety arose which was then fairly uniform and distinct from any other existing varieties of the language in question' (Hickey 2003:214).

Theories as to how dialects form and specifically how New Zealand English developed have been the subject of considerable debate. Outlined below are some of the more recent contributions to the subject. I begin with a consideration of the original linguistic input to the variety which was to become modern day New Zealand English. 
The dearth of linguistic information about the early European immigrant population of New Zealand has been lamented because such information could have provided important clues as to the original linguistic features which went into the make up of present day New Zealand English (Bauer 2000:40). Full shipping listings of immigrants do not exist and sometimes point of embarkation is the only information available about immigrants (Bauer 2000:40). What is known, however, is that in the early years of European settlement the mixture of different English dialects spoken in New Zealand was not uniform throughout the country, some regions of New Zealand being settled by immigrants from relatively restricted areas of Britain. For instance in the 1840's and 50's the New Zealand Company brought settlers to Wellington and Nelson from London and nearby counties, and the Plymouth Company brought people from the South Western counties of Britain, principally Cornwall, Devon and Dorset, to New Plymouth in Taranaki. Scottish free-church emigrants settled in Otago and Southland, AngloCatholics in Canterbury. In 1851 thirty one percent of Auckland's population was of Irish extraction compared with only two percent of Wellington's population. The gold rushes of the 1860's brought thousands of Australians to Otago and the West Coast of the South Island (Sinclair 2000). However, 'the regional dialects of the immigrants have not obviously given rise to corresponding regional dialects in New Zealand' (Bauer 2000:41) with the exception of the English spoken in Southland and in parts of Otago which shows traces of the original Scottish input dialects (Bartlett 1992, 2003).

McKinnon (1997) provides census based figures for New Zealanders born in English speaking countries who were born before 1881 as follows (percentages calculated by Trudgill et al 2000:303):

$\begin{array}{ll}\text { England } & 49 \% \\ \text { Scotland } & 22 \% \\ \text { Ireland } & 20 \% \\ \text { Australia } & 7 \% \\ \text { Wales } & 1 \% \\ \text { N. America } & 1 \%\end{array}$

The major areas of immigration from England were: Cornwall, Devon, Gloucestershire, Warwickshire, Oxfordshire, Hampshire, Surrey, Sussex, Kent, Essex and Middlesex 
(including London), the cause of emigration often being specific to particular areas. Miners and their families left Cornwall, for example, when the copper and tin mining industries went into decline.

While other languages spoken in New Zealand, most particularly Maori, contributed to the dialect mix from which New Zealand English arose, the British English dialects of the dominant group of immigrants clearly had the greatest influence on the end result.

\subsubsection{Dialect mixture}

Trudgill (1986) examines what happens when mutually intelligible dialects come into contact in social contexts such as the growth of colonies, the development of new towns and in situations of rapid urbanisation. After analysis of case studies he distinguishes three different chronological stages in the process of new dialect formation. The three stages correspond roughly to three successive generations of speakers. In the first stage rudimentary levelling occurs with the initial contact of speakers of different regional and social varieties, the second stage is characterised by extreme variability and further levelling and in the third stage, focussing occurs with the new dialect appearing as a 'stable, crystallised variety' (Trudgill et al 2000:307). Some other researchers who have adopted Trudgill's approach to the study of dialect formation include Kerswill and Williams who studied new dialect formation in the new town of Milton Keyes in the United Kingdom (Kerswill 1996, 2001; Kerswill \& Williams 2000; Williams \& Kerswill 1999); Britain who looked at the formation of dialect in the English fens (Britain 1991, 1997); and Sudbury (2001) who investigated the English spoken in the Falkland Islands.

The above theory was applied to analysis of the development of New Zealand English by Trudgill and fellow researchers at the University of Canterbury (Trudgill et al 2000, Gordon et al 2004). For their study of the origins of New Zealand English (known as the ONZE project), the researchers utilised recordings made between 1946 and 1948 by the Mobile Disc Recording Unit of the National Broadcasting Corporation of New Zealand. The recordings were of pioneer reminiscences of people in small towns throughout New Zealand. The speech of people who were children of the first European settlers in New 
Zealand and who were born between 1850 and 1900 was analysed. The authors give as one example of possible evidence of first stage, rudimentary levelling, the absence in their data of the merging of $/ \mathrm{v} /$ and $/ \mathrm{w} /$ as $/ \mathrm{w} /$, where village becomes willage, a feature of many nineteenth century southern English dialects. The variability of the second stage is demonstrated by individuals who have acquired features from a range of dialects spoken in their speech community. They cite one individual of Scottish parentage who has linguistic features of Scottish, Irish and southwest English origin. An example of evidence of second stage levelling is the near absence in the data of the use of the FOOT vowel in the lexical set of STRUT. According to McKinnon (1997) most English immigrants to New Zealand were from southern regions of England. The use of the FOOT vowel in the STRUT lexical set is a feature of northern English dialects to which second generation English speaking New Zealanders would have had little exposure (Trudgill et al 2000:307).

The reduction of variants that accompanies focussing, Trudgill's third stage of new dialect formation, takes place via the process of koineization (Trudgill 1986:126). The term koine is derived from the Greek word meaning 'common'. Koine was the variety of Greek that became the lingua franca of the Mediterranean basin.

Koineization is defined as 'the process which leads to mixing of linguistic subsystems, that is, of language varieties which either are mutually intelligible or share the same genetically related superposed language. It occurs in the context of increased interaction among speakers of these varieties' (Siegel 1985:375). A koine is 'the stabilized composite variety which results from this process. Formally a koine is characterized by a mixture of features from the contributing varieties, and at an early stage of development, it is often reduced or simplified in comparison to any of these varieties. It may also become the primary language of amalgamated communities of these speakers' (Siegel 1985:376).

An immigrant koine develops in an amalgamated immigrant community and often is the primary language of the first generation born in this community. Regional koines develop as lingua franca of geographical areas in which different regional dialects are 
spoken. They can become expanded and eventually become regional standards (Siegel 1985:376).

Trudgill expands on the concept of koineization. It comprises the processes of dialect mixing, levelling and simplification. Levelling involves the loss of 'linguistically marked and demographically minority variants' (Trudgill et al 1998:37). Localisms tend to be suppressed in favour of features which are more common or well known. But, by means of simplification, 'even minority forms may be the ones to survive if they are linguistically simpler, in the technical sense' and 'even forms and distinctions that are present in all contributory dialects may be lost'(Trudgill et al 1998:38).

After koineization reallocation can occur. 'Variants originally from different regional dialects may in the new dialect become social-class variants, stylistic variants, or, in the case of phonology, allophonic variants' (Trudgill et al 1998:38). Bauer (1994:423) provides examples of this phenomenon in New Zealand English. One such example is the use of voiced intervocalic / $t /$ in words like beauty used as an expression of approval. This may have originated in part from one of the southwestern English input dialects. Another example is the retention of aspirated / $t /$ as a prestige form.

\subsubsection{Determinism in new dialect formation}

By comparing features of the speech of New Zealanders born between 1850 and 1900 with the speech of modern day New Zealanders, Trudgill et al (2000) arrived at a deterministic theory as to which features of speech used by people at the second stage of new dialect formation were likely to be selected by people at the third, or focussing, stage of dialect formation. They argued that dialect mixture and new dialect formation are not haphazard processes and that 'given sufficient linguistic information about the proportions of speakers of the different dialects, it is possible to make predictions about what the outcome of the mixture will be' (Trudgill et al 2000:299). They also claimed to 'have arrived at a probabilistic solution to the problem of randomness in the transmission of dialect features from one generation to another in such situations' (Trudgill et al 2000:299). 
The following is an example used by the researchers to demonstrate that the majority wins out. $/ \mathrm{h} /$-dropping in words such as hammer, hill and house has not survived in modern New Zealand English although it was a feature of the speech of $25 \%$ of the speakers in their recorded data. $/ \mathrm{h} /$ dropping is normal in vernacular varieties in London and the southeast of England generally but is not present in the Irish, Scottish, Northumbrian, West Country and peripheral East Anglian variants which were in the majority in the dialect mixture in New Zealand at the time. The majority of their second stage informants used $/ \mathrm{h} /$ and this was because of "the presumed majority status of the variants in the dialects brought to New Zealand by immigrants from different parts of the British Isles at the first stage' (Trudgill et al 2000:310). The researchers subsequently examined the occurrence of tokens of $/ \mathrm{h} /$ dropping as well as the percentage of speakers who $/ \mathrm{h} /$ dropped and found a low rate of usage. Both factors contributed to the rapid disappearance of the feature in New Zealand English. It was concluded that, 'it is not enough to consider how many speakers use a particular variant. We also have to consider the degree to which they use it' (Gordon et al 2004:241).

\subsubsection{The role of children in new dialect formation}

In a study of new dialect formation in the English New Town of Milton Keynes, Kerswill and Williams (2000) stressed the important role children, particularly those verging on adolescence, play in the focusing of new dialects. They found that if there is a high proportion of children present in the early years of dialect formation and if they are able to form close social networks with each other, new linguistic norms are readily formed.

'Children presumably take the diverse adult models as a part of their input; but given the opportunity, they will begin quite rapidly to form new, more focused varieties - which may contain further changes, including simplificatory processes, not foreshadowed in their parents' speech' (Kerswill \& Williams 2000:110).

The role of the younger generation in the focusing stage of new dialect formation is also noted by Hickey (2003). He believes that New Zealand English evolved from a mixture of dialects of English from the British Isles but considers that the position of Trudgill et al - that numerical superiority of variants is the main reason for the survival of some features and the rejection of others - is in need of 'further nuancing' (Hickey 2003:213). 
He would include in the process 'speakers' active, though unconscious, participation in the forging of the new variety and a more differentiated assessment of the status of the main ethnic groups in New Zealand society in the second half of the nineteenth century' (Hickey 2003:213). New Zealanders involved in the focusing stage of the formation of the New Zealand English dialect would, as young people, have recognised which variants were more innovative and which were more conservative and would have been likely to opt for the more innovative variants. 'Which individuals use what variants in what situations gives speakers of the young generation at any point in time the necessary information about what to favour as dynamic members of their society' (Hickey 2003:232). The lack of influence of Irish English on New Zealand English is explained by Hickey with reference to the large percentage of Irish, as opposed to Scottish or English, immigrants who arrived in New Zealand as unmarried adults (Irish - 60.8\%, Scottish - 33.4\%, English - 25\%) and the small number of married couples who arrived with children (34.4\%) (Akenson 1990). In other words, most children of Irish parents were born in New Zealand and would have been exposed to, and influenced by, the embryonic New Zealand English dialect spoken by other children from a young age. This is one proposed reason for the apparent lack of Irish features in New Zealand English today.

\subsubsection{Law of swamping}

Another perspective on new dialect formation is provided by Lass (1987). His Law of Swamping is formulated as follows:

'(i) In cases of mixed input to an ETE [Extra Territorial English], whatever the original demography, the output is (a) southern, and (b) more eastern than western.

(ii) Whatever the size of the non-southern input, it will normally leave only unsystematic relics (eg. odd lexical items, idioms, or minor constructions); there will rarely be larger-scale structural effects (eg. in the system of phonemic oppositions)' (Lass 1987:269).

By this law the tendency for Australians, New Zealanders and South Africans to speak varieties of English similar to that spoken in Southern England could be accounted for by the swamping of the minority Scottish, Irish and Northern English varieties present in the input dialects by the majority southeastern British dialects present. 
It has been suggested that the source of the swamping might be the fact that there was in general 'an attitudinal bias in favour of variants which sounded as though they might come from the southeast of England,' forms from the north of England being considered 'barbarous'(Bauer 1994:423). As Lass says, 'Essentially southern [English] dialect-types have been institutionalised as standard since the $15^{\text {th }}$ century or so, and this has had its effects on Extra Territorial Englishes as well'(Lass 1987:255).

European settlers in New Zealand did not on the whole deliberately reject the society in which they had been raised. They had settled in a new land because they wanted to prosper, to get on in life and they clung to the values and attitudes of their parent society. Governor Grey's wife reflects these attitudes in an approving letter to a South Australian correspondent during a visit to New Plymouth in February 1850. 'This is a . lovely country, the finest agricultural country you can imagine with the nicest quietest, most simple, rural population you can imagine out of dear old England, and almost all of them from my own West Countree and it is a pleasure to hear the old Dorsetshire farmers speak of my dear father. We have too the friendliest church and some of the nicest schools in the Colony' (quoted in Graham 1981:119).

The settlers were predominantly from labouring and working class backgrounds (Graham 1981:116). Getting on in life would have entailed the valuing of and adoption of something approximating the English standard which would presumably have helped them 'get on in life' back 'Home'.

Presumably 'swamping' was responsible for the current near absence of non-prevocalic $/ \mathrm{r} /$ in the speech of Taranaki where the founding English settlers were from the South West of England. Virtually all traces of their/r/-ful English have now vanished, though in my interview data there are two instances of $/ \mathrm{r} /$ occurring at the end of the first syllable and word finally in fertiliser and another of $/ \mathrm{r} /$ word finally in tractor. Interestingly, both these words could be termed 'farming' words. Researchers in the ONZE project found that, 'Farming words and mining words, in particular, were much more resistant to /r/-loss than other types of words for a number of the Mobile Unit speakers' (Gordon et al 2004:279). It could be argued that, where Taranaki English is concerned, both Trudgill's and Lass's positions are correct. As more and more speakers 
of non-rhotic varieties of English moved into Taranaki, non-pre-vocalic / $\mathrm{r} /$ would have become more marked as a feature and it would have been subject to levelling processes. At the same time the population became increasingly educated throughout the nineteenth century (compulsory, free schooling for all children was instituted in 1877) and people aspiring to get on in life would have felt inclined to adopt speech patterns which more closely approximated what they saw as the standard English of the South East of England. The /r/-ful English of the people from the rural South West would have been swamped by the /r/-less English of speakers of other varieties.

\subsubsection{Comparison of New Zealand English features with British dialect features}

By tracing New Zealand English words listed in The Dictionary of New Zealand English (Orsman 1997) as being of British dialectal origin, back through British dialect dictionaries to their places of origin in the United Kingdom, Bauer (2000) confirmed the very mixed origins of New Zealand English. The exercise showed an even spread of dialect attributions throughout Britain. In an analogous exercise he compared a set of eighteen New Zealand English phonological traits with traditional dialect pronunciations in England and found many features from both the southwest and the southeast of England (Bauer 1999). By no means all variants which survive in present day New Zealand English have been swamped by southeastern variants and Bauer therefore cautions against appealing to swamping as the sole explanation for the formation of New Zealand English.

\subsubsection{Supraregionalisation}

An alternative approach to new dialect formation, which also explains the present apparent lack of regional variation in New Zealand English, is given by Hickey (2003). He invokes a phenomenon which he labels supraregionalisation and it is this phenomenon, rather than focusing, which he says is behind the lack of variation.

He defines supraregionalisation as: 
'a process where by dialect speakers progressively adopt more and more features of a non-regional variety which they are in contact with. There does not have to be direct speaker contact; indirect exposure to the non-regional variety can be sufficient. Supraregionalisation is distinct from accommodation which does require such contact and it is different from dialect levelling in which the input varieties lose salient or minority variants, resulting in a new mixture not present before. Dialect levelling can be assumed to have taken place in the areas of high density in New Zealand prior to both koineisation and supraregionalisation' (Hickey 2003:236).

Speakers acquire supraregional forms through exposure to mass media, and as a result of physical, social and occupational mobility. The population of New Zealand has traditionally been characterised by mobility. Gardner (1999:50) referred to New Zealand's 'untidy past', describing it as 'a game of regional snakes and ladders'. 'Historical community in New Zealand,' he said 'may mean a rather solid core, and a large fluid overlay' (Gardner 1999:50). However, in spite of mobility, the all pervading presence of the mass media, and the existence of compulsory education since 1877 , there is evidence of variation in modern day New Zealand English (see Section 2.4 and Chapter 3). This suggests the presence of opposing forces which may yet prove to be stronger than supraregionalisation. The importance of social factors relevant to variation will be examined in Section 2.4.

ONZE project researchers also looked beyond the theory of determinism and 'the sheer weight of numbers' in dialect formation and found that social factors needed to be considered for the effect they had on the process of new dialect development. They found, for example, that women were in the lead in almost every change, that 'mixed towns [led] over more homogeneous towns such as the Scottish settlements, where forms like rhoticity survived longer' (Gordon et al 2004:257) and that in certain circumstances 'speakers' families [could] have a highly influential role' (Gordon et al 2004:286).

Having considered some proposals concerning the process by which several British dialects merged into a single, all but regionally homogeneous dialect, New Zealand English, I turn now to the question of how regional diversification might occur, or have already occurred, within New Zealand. I consider in greater detail evidence for the existence of regional variation in New Zealand English in Chapter 3. 
It is acknowledged that people speak differently in the Southland/Otago region of New Zealand, the most salient phonetic feature of their speech being their usage of nonprevocalic /r/ which is not shared by most other New Zealanders. This variety seems to have developed separately, but alongside the majority New Zealand English variety and could be seen as a 'competing koine' (Bauer \& Bauer 2002a:173). Its development has been attributed to the input of Scottish settlers in the region (Bartlett 1992, 2003).

It is theoretically possible that other regional varieties could have arisen at the same time as the New Zealand English dialect which is spoken by the majority of New Zealanders, particularly given the early settlement patterns of New Zealand referred to in Section 2.1.1 above. The elusiveness of these as yet hypothetical varieties could be accounted for by their lack of stigmatised or salient features of the type found in the Southland/Otago region. In other words, they may exist but noone has as yet noticed them. Which begs the question, if people in a given region are not aware of the specialness of their speech, how can they be said to speak a dialect which is different to the dialects which surround their region? At what point do differences become sufficiently critical for it to be said that a separate regional dialect exists? Another possibility is that such variation has existed in the past but is disappearing or has already disappeared under the levelling pressure of the standard New Zealand English koine and any observed variation would then be a remnant. The instances of non-prevocalic $/ \mathrm{r} / \mathrm{in}$ my Taranaki corpus (see Section 2.1.5 above) could be a case in point.

If, however, it is accepted that, aside from the competing Southland/Otago variety, New Zealand English developed into a single, homogeneous koine, it is to be expected that in time that koine will itself change and develop new offshoots. There is considerable sociolinguistic evidence that different social and ethnic varieties of New Zealand English have emerged over the past few decades (eg. Bayard 1987; Holmes et al 1991; Warren \& Bauer 2004). There is evidence of language change in progress with younger people using more innovative features than their elders and there is also evidence of ethnic and gender differences in the way New Zealanders speak. (See Section 2.4 for more detail on social, ethnic, generational and gender variation in New Zealand 
English). It would seem that more time is required for the development of recognisable, new regional varieties.

The existence of regionalisms has been established by L. Bauer and W. Bauer in a study of words used by New Zealand children in the school playground (Bauer \& Bauer $2000 \mathrm{~b}, 2001,2002 \mathrm{a}, \mathrm{b}, 2003)$. They classified the lexical items which were found to belong to different regions according to whether they were innovations or retentions and explored what happens when there are competing forms. Three distinct dialect regions emerged from the study: northern, central and southern. (A more detailed description follows in Section 3.2). The researchers admit the possibility that the differences found may be age-graded and that there is no evidence as yet of matching adult regional variation. For a new regional dialect to arise, 'the language of adjacent areas will have to become radically different, or start to move in different directions' (Bauer \& Bauer 2002a:191). This implies the need for a considerable time lapse.

'regional dialects demand not only the development of a national koine, but the development of two or more regional koines (each less well-defined than the national koine) which, through the operation of a number of (apparently) random choices have come to move apart from each other'(Bauer \& Bauer 2002a:191).

They also point out that 'until it is clear what the national koine is, it is very difficult to recognise minor local deviations from the national standard'(Bauer \& Bauer 2002a:191).

So in order to say that a specifically Taranaki and/or Wellington regional dialect has formed, it will be necessary to (a) provide evidence of variation which is special to the region concerned and (b) demonstrate that the varieties in question have moved away from 'standard' New Zealand English (whatever that may be).

Having considered the processes by which dialects are formed, I turn now to methodologies used by dialectologists to establish (a) the existence of linguistic variation and (b) the reasons for such variation. Since the principal aim of the present project is to establish whether or not regional variation exists in New Zealand English, a review of this literature will be helpful. 


\subsection{Traditional dialect geography}

Dialectology has traditionally been associated with geographical variability in language. It had a strong historical bias as it aimed to offer a means of answering questions about the earlier history of the language. 'The main objective was to study contemporary reflexes of older linguistic forms in their natural setting, concentrating on speakers and locations which were relatively free from external influence' (Milroy 1987a:9). Fieldworkers looked for traditional vernaculars which they thought were best found in rural areas amongst the farming community. Nonmobile, older, rural males, or NORMS, to use Chambers' and Trudgill's (1980) tongue in cheek acronym, were selected as informants irrespective of other social considerations. Dialectologists were typically concerned to record and preserve older dialect forms before they became extinct (Trudgill 1983:33). They produced maps showing the broad areal limits of the phonological or lexical features chosen for study. Boundaries, indicated by isoglosses, were plotted on the maps showing where one form gave way to another. A dialect boundary was said to exist where a number of isoglosses coincided.

However, in spite of their seeming preoccupation with space, Britain (1991:203) says of the dialectologists that, for them, space 'was no more than a container, a background setting against which dialectological findings could be mapped' and 'the essential question of why two locations shared or did not share certain linguistic characteristics was not on the agenda.' In other words they were not concerned with explanation.

\subsection{Social dialectology}

Social dialectologists are not interested in either the taxonomic, 'butterfly collecting' approach of the dialect geographers or the purely abstractionist approach of linguistic theoreticians. They are interested in developing a social explanation as to why a linguistic phenomenon is present and in order to do so they seek information about its social distribution and context. Linguistic variation, they argue, is typically apparent not only within the language system itself, in its phonology, morphology, syntax and semantics, but also within its social dimensions. Exponents of this approach include, 
amongst many others, Labov (1966, 1972a,b), J.Milroy and L.Milroy (1985, 1993), Trudgill $(1974,1983)$ and Wolfram $(1991,1997)$.

Social dialect research on New Zealand English during the past three decades has taken into consideration the following social factors: socio-economic status, ethnicity, gender and age. I outline below some of the findings in this area.

\subsubsection{Socio-economic status}

One of the first research projects in New Zealand to operate within the sociolinguistic . paradigm developed by Labov in the United States in the 1960's and 1970's was undertaken by Bayard (1987) who undertook a broad spectrum, or 'scatter-shot' (to use his words) study of the speech of 144 informants most of whom were from the south of the South Island. The stigmatised diphthongs /ei/, /ai/, /au/ and /ou/, centralisation of /I/, the merging of the vowels in EAR and AIR, and vowel variants before /1/ were some of the features analysed. This work clearly demonstrated a correlation between social class and the degree of 'broadness' of speaker accent, though Bayard suggested that 'socioeconomic class in NZ is very likely better viewed as a continuum with few clearcut breaks (unlike the UK situation)' (Bayard 1987:11). A selection of other features which have since been found to correlate with social class in New Zealand English includes: -ing reduction, deletion of the perfect auxiliary have, and use of the pragmatic particle $e h$ (Holmes et al 1991); the voicing of intervocalic/t/ (Holmes 1994); and unaspirated word initial /t/ (favoured by young Pakeha, i.e. New Zealanders of European descent, working class men) (Holmes 1995a). There are problems associated with the concept of social class and different approaches have been taken to resolving them. Some of these will be outlined in Section 5.1.7.

\subsubsection{Ethnicity}

Like social class, ethnicity is a criterion by which people can be grouped and linguistic means can be used to convey group membership. In New Zealand the influence of the Maori language on English has been observed (eg. Benton 1985, 1991; King 1993; 
Holmes 1997a, Bauer \& Bauer 2000a, Macalister 2002, 2003; Warren \& Bauer 2004) and the variety which has come to be known as Maori English examined.

Maori have been found to use the pragmatic tag eh significantly more often than Pakeha (New Zealanders of European extraction) (Holmes, Bell \& Boyce 1991, Meyerhoff 1994). The high rising terminal contour (HRT) has been found to be used more frequently by Maori than Pakeha (Allan 1990, Britain 1992). Unaspirated word-initial /t/ and devoiced word-final $/ z /$ have been found to occur more frequently in the speech of Maori than in that of Pakeha (Holmes 1995a, 1996). The mora-timed rhythm of Maori and/or the quality of Maori vowels appear to have influenced the way English is spoken by some New Zealanders (Ainsworth 1993; Holmes \& Ainsworth 1996, 1997; Warren 1998).

The important role of Maori people in the creation of patterns of regional and social differentiation found in New Zealand has been stressed by the Bauers in their research on playground language in New Zealand (Bauer \& Bauer 2000a). They noted the high density of Maori people in Northern areas of New Zealand and the preponderance of low decile schools in these areas ('low decile' equating with lower socio-economic status) compared with both the central and southern regions which had a higher percentage of high decile schools. In the Northern region the researchers found instances of Maori language words (eg. pakaru meaning'damaged'), features previously established as Maori English (eg. the construction in he growled me) and vocabulary pertaining to concepts reflecting Maori norms (eg. the use of the expression I felt shame or I felt shamed (out) in reaction to being praised by the school principal. This relates to the Maori concept of whakamaa, a reaction of extreme outward embarrassment in the face of praise). These forms which are associated with the Maori population are also associated with lower socio-economic schools, and 'show strong links to either the Northern Region or the North Island or both' (Bauer \& Bauer 2000a:60). The influence of the Maori population on playground language in these areas is clear. 


\subsubsection{Gender}

A third important speaker variable in the study of language variation is gender. Linguistic differences between women and men have been documented in several studies of New Zealand English. Of particular interest is the role which New Zealand women play in the adoption of innovative features which lead to changes in the standard accent.

In a comparison of the vowels of first generation Anglophone New Zealanders born between 1864 and 1886, and twenty year old speakers of 'the General variety of New Zealand English' recorded in 1979, Maclagan (2000) found that the vowels of women in the older sample were more like the vowels of present day men and women than were the vowels of the older group of men. Maclagan concluded that,

'women led the move towards a distinct NZE accent as early as the nineteenth century and that, as they led this movement, so they helped to create the accepted norms of what is now NZE. And therefore the female gender role of creating language standards has been operating for at least a hundred years within New Zealand' (Maclagan 2000:88).

Reasons why women in New Zealand play the role they do in language change have been explored by Holmes (1997b). She noted that, 'whatever their origins, the success of particular innovations (as opposed to linguistic variants which never acquire the status of changes in the standard accent) appears to depend on their being adopted and endorsed by women' (Holmes 1997b:131). She argued that this may be because of the greater influence Pakeha women have traditionally had in matters of social etiquette since the early days of the colony, with women being 'expected to provide models of correct and refined linguistic usage' and that 'issues of language usage have long been regarded as more appropriately the concern of women than men in New Zealand' (Holmes 1997b:131). A second possible reason given for women's linguistic variants being treated as models by New Zealand society and becoming established as components of standard New Zealand English is that 'women typically interact with a wider range of social contacts than men' and 'since they are more responsive to the speech of others than men are, they are thus likely to acquire a number of linguistic variants from which innovations may develop' (Holmes 1997b:133). These innovations, being favoured by women, then become standard forms over time and by looking at 
women's usage it may be possible to predict what New Zealand English will sound like in future. The range of social contacts of the men and women in my project and their roles in society are of particular interest and will be explored in Section 7.2.

While women's role in language change has been noted, it has also been observed that 'For stable sociolinguistic variables, men use a higher frequency of nonstandard forms than women' (Labov 1990:210). Labov cites studies in support of this principle covering such stable sociolinguistic variables as nonstandard pronunciation of -ING. In other words, women have been shown to lead in linguistic changes which are new and dynamic, but lag behind men in the use of variables representing older changes which may have become 'overtly proscribed' (Labov 2001:367).

This generalisation is illustrated by Woods (1997) in a study of gender-related variation and linguistic change using real-time evidence of the development of New Zealand English. She compared the speech, recorded in 1948, of men and women who had lived most of their lives in the Otago region of New Zealand, with the speech of some of their present day descendants who continued to live in Otago, and who were recorded in the early 1990's. The speakers in both sets of recordings were aged between 60 and 87 . She analysed 30 tokens each of the MOUTH, TRAP and DRESS vowel sets for both generations of speakers. For the purposes of the study she termed the earlier generation of speakers 'first' generation and the subsequent generation 'second' generation. I shall do the same. She found that the MOUTH diphthong had become closer over time and that the first generation women were leaders in the change, but that fifty years later, when the feature had become a more established variant of New Zealand English, the second generation women were using a more open, less advanced form than the men. The vowels in TRAP and DRESS had also been raised over time with women leading the change in both cases. In the case of TRAP women of the first generation had closer articulation than the first generation men, but by the second generation the gap between the women and the men had closed. The raising of the vowel in DRESS was shown to be a more recent change and the women of the second generation were clearly leading this change. 
The above analysis illustrates three distinct stages in the diachronic development of New Zealand English as spoken in Otago with women being the first to adopt innovative features which are then adopted by men over time, at which point women may have a tendency to revert to earlier forms. Woods hypothesises that women's preferred discourse strategies may provide an explanation as to why women tend to introduce new phonological features into New Zealand English. She cites research which shows that women have been found to be more co-operative and listenerorientated in face-to-face interaction than men and that they are more accommodative to their interlocuters' needs (Woods 1997:117). She suggests that in the levelling stage of New Zealand English dialect formation her first generation women would have accommodated their speech to the linguistic features of people they were in contact with, in this case, quite possibly Australians. Australians were present in Otago, especially during the time of the gold rushes, and their dialect was characterised by raised MOUTH and TRAP vowels. She also suggests that, by way of contrast, where it is found that men are leading linguistic change it is in situations of geographic restriction and comparative lack of contact with speakers of different varieties. Labov's (1972a) analysis of the centralisation of/ay/ and /aw/ in Martha's Vineyard is a case in point. Men were in the lead in this change and it was clearly not the result of dialect mixing but rather the adoption of a form associated with conservative usage on the island. Woods also compares her findings to those of Milroy and Milroy (1993) who found that 'strictly localised' variants were most frequently used by men in their Belfast study and 'supralocal' forms were favoured by the women in their sample.

With gender known to pattern in language change in such clearly different ways, it was necessary to investigate the presence of gender differences in intonation patterns in Taranaki and Wellington English and to seek possible explanations for these differences.

\subsubsection{Age}

The main motivation in social dialectology for examining linguistic features of speakers of different age groups is to investigate possible language change in progress. Using an apparent-time model, diachronic inferences can be made about language change (see 
Section 5.1.4 for further detail). Many studies of linguistic features in New Zealand English have employed this model, tracking such changes as the merging of the diphthongs in EAR and AIR (Gordon \& Maclagan 1990, Holmes et al 1991, Batterham 1995), the emergence of the HRT in New Zealand English (Britain 1992) and increased usage of the pragmatic particle $e h$ (Meyerhoff 1994).

The study of a selection of New Zealand English vowels by Woods (1997) cited in Section 2.4.3 above, provides an example of a study of language change using a realtime model. In this study the author was able to find evidence of the development of New Zealand English over fifty years by analysing recordings of the speech of two generations of the same families, who lived in the same area, all participants being approximately the same age at the time of recording.

For practical reasons I adopted the apparent-time model for investigating the existence of language change over time in my project, although it is acknowledged that the speech of individuals will probably shift, at least to some degree, in the direction of new norms throughout their lifetimes (Gordon et al 2004:261).

\subsection{Geolinguistics}

Having considered the social factors of socio-economic class, ethnicity, gender and age in New Zealand English research, I now turn to consideration of geographical location and social space which are of prime importance in a study of regional variation in New Zealand English. Studies which correlate geographical location with linguistic features in New Zealand will be reviewed in Chapter 3. These are few in number however. Insights into regional variation can be gained from geolinguistic studies which have been undertaken in other parts of the world and a brief review of some of these follows.

Geographical insights are important in the development of theories which attempt to explain the diffusion of linguistic innovations throughout a region and beyond.

'The diffusion of changes takes place both within and across speech communities; that is, changes can spread vertically through a community from 
one social group to another, and they can spread horizontally from one location to another'( M.Gordon 2001:5).

The 'hierarchical' theory of the diffusion of linguistic innovations used by Callary (1975) and refined by Trudgill (1983) shows innovations beginning in large population centres before trickling down to smaller centres. Trudgill (1983:75) borrowed from the methodology of geography a 'gravity model' which used a mathematical measure of the level of interaction between two population centres that was based on the population of the two centres and the distance between them. Sometimes diffusion is 'contagious' with innovations spreading more uniformly across a region simply by contact among neighbouring areas (Bailey et al 1993). Both 'hierarchical' and 'contagious' diffusion theories are relevant to my findings on regional variation in New Zealand English and will be referred to later in Section 7.2.4.

Neither of the above theories appears to apply, however, in the spread of $/ 1 /$ vocalisation in Australasia. Geographic considerations were added to sociolinguistic ones in a study of $/ /$ vocalisation in six different locations in Australia and three in New Zealand (Horvath \& Horvath 2001, 2002). /1/ vocalisation was found to correlate most strongly with place in this study, there was a moderate correlation with age indicating a change in progress, and sex and social class were only weakly associated with variability. The researchers' speech locality hierarchy showed 'all New Zealand cities leading Australian cities, with Christchurch ahead of Wellington and both of them ahead of Auckland. In Australia, Adelaide and Mt Gambier [were] close and still on the side of promoting vocalization, while speakers from other Australian cities [were] less likely to vocalize $11 /$, gradually decreasing to only $7 \%$ in Brisbane' (Horvath \& Horvath 2002:41). If the hierarchical theory of the diffusion of language innovation were to apply, one would expect the language change process to have started in the city with the largest population, which is Sydney, and diffused from there down through the Australian locations finally reaching Mt Gambier, 'the lowest order speech locality in the hierarchy' (Horvath \& Horvath 2002:51). In New Zealand the change would have reached Auckland first, about the same time as it reached Melbourne and Brisbane, and then it would have spread to Wellington and Christchurch. But the geographical pattern revealed by the Horvaths does not conform in any way with the diffusion pattern down the urban hierarchy. The researchers suggested that the effects of 'place' as opposed to. 
those of 'space' needed to be examined in order to understand the geographic distribution of $/ 1 /$ vocalisation.

'Place effects refer to the ensemble of sociolinguistic conditions within a speech locality, whereas space effects refer to the relationship between speech localities. Space focuses attention on distance, proximity, or location; place addresses the effects of linguistic and social conditioning within particular speech localities. Space and place operate together in the real world, but their causal importance may vary from context to context. In some situations place effects may prevail with little or no significant space effects, and in other cases space effects prove to be significant' (Horvath \& Horvath 2002:53).

The effects of 'place' prevailed in a study of the Northern Cities Chain Shift in two small towns in Michigan undertaken by M.Gordon (2001). The predicted pattern of hierarchical diffusion did not apply, as Paw Paw, the town furthest from a large metropolitan centre, led the change, with Chelsea, which is much closer to the big cities of Detroit and Chicago, following behind. The author looked to the social dynamics of the two towns for explanation of the patterns revealed. He noted, for example, the tension created by the recent influx of city people into the town of Chelsea and a consequent reluctance amongst locals to adopt a socially marked incoming linguistic change. No such tension appeared to exist in Paw Paw and residents adopted the changes more readily.

In a survey of the English spoken in the Fens district of England, Britain (1991) found that it was the social rather than the physical aspects of spatiality which were most relevant in explaining his findings. Reclamation of the Fenlands and subsequent inmigration resulted in a dialect mixture which led to the phonological pattern known as Canadian Raising. He defined social spatiality as 'the way in which humans and space interact, how humans in the enactment of their everyday lives, colonize their surrounding environment' (Britain 1991:195). He considered the social networks of his interviewees and their 'daily routinization'. 'Routinization' was defined by Giddens (1984:376) as 'the habitual taken-for-granted character of the vast bulk of activities of day-to-day social life, the prevalence of familiar styles and forms of conduct'. It is through routines that norm enforcement is achieved and routines instill in people a sense of trust in the continuity of the object world and in the fabric of social activity (Giddens 
1984:60). Both norm enforcement and the development of trust are aspects of strong, dense social networks.

I turn now to discussion of social network theory, a theory which links regional and social variation.

'One of the benefits of [the] network-based approach is its generality. It provides a link between regional and social variation and suggests that the mechanism involved in diffusion of innovation through both geographic and social space is essentially the same' (M.Gordon 2001:7).

\subsection{Social Networks}

\subsubsection{Social network theory}

Social space, or 'place' as defined by the Horvaths in Section 2.5 above, is an important aspect of the social network theory which was developed within sociolinguistics by Milroy and Milroy (1985).

According to this theory social networks have varying degrees of density. A high density network is one where members have contact with each other independently of any one individual in the network. Networks may have clusters which have a high density. If there is more than one transactional basis for social relationships in a network, eg. an individual might have workmates who are also friends and rugby team mates, then the network can be said to be multiplex. A uniplex network tie is one where one individual relates to another in a single capacity. I have uniplex network ties with my hairdresser and dentist. The more dense and multiplex a network, the greater the likelihood of social cohesion. In such a network an individual's contacts are in contact with each other in several capacities. In a small, close community people might be related to each other, live together and work together. There will probably be a strong sense of solidarity and pressure will be exerted on members to conform to social norms. 'Densely interrelated networks...exert a function of norm reinforcement which results in the development of resistance to forces of innovation. As a consequence of this, inter-group distinctiveness is emphasised and the members of close-knit networks are insulated from outside 
influences, including mainstream linguistic values' (Bortoni-Ricardo, 1985:81). On the other hand, a weakening of network ties can produce conditions which favour language change. 'A network analysis can help to explain why a particular community successfully supports a linguistic system that stands in opposition to a legitimized, mainstream set of norms, and why another system might be less focussed or more sensitive to external influences' (Milroy \& Gordon 2003:118). It has been observed that 'Relationships in tribal societies, villages and traditional working-class communities are typically multiplex and dense, whereas those in geographically and socially mobile industrial societies tend to uniplexity and spareness' (L. Milroy, 1980:52). It has also been claimed that 'the most integrated individuals, the core members, use the regional variants most frequently' (Chambers 2003:86).

It is possible to measure the degree to which an individual is integrated into, or oriented towards a particular speech community, by devising a scale of indicators for social network strength. Care must be taken in selecting features which are to be used in the construction of such a scale as different features will be salient for different communities. There are four conditions which enrich network ties that are basically the same everywhere: kinship, proximity, occupation and friendship (Chambers 1995:75). However indices can be refined to include very community specific items.

A network approach has proved useful in a variety of social contexts. I outline some of these below.

In their study of working class speech in Belfast, the Milroys devised a scale to measure the degree of density and multiplexity in the personal networks of residents on the basis of indicators of network attributes. Particularly relevant indicators were those clustering in the areas of kinship, workmates and friends. The men, who, if employed, worked locally, seldom ventured outside the neighbourhood, and had higher network scores than the women who were much less restricted in their employment and recreation. The language of individuals and their network scores were compared to find out whether there was a correlation between a high network score and particular linguistic variations. The men, with their dense and multiplex personal networks, tended to maintain the local vernacular norms (Milroy 1987a:160). 
Language shift from Hungarian to German in the rural community of Oberwart in Austria was studied by Gal (1979). She found that a person's use of Hungarian or German could be predicted by the degree to which his or her social contacts could be regarded as 'peasants' or 'workers'. The traditional Hungarian language was favoured by peasants and the economically useful German language by salaried workers. She said that, 'Linguistic presentation of self appears to depend at least in part on the expectations of those with whom one habitually interacts'(Gal, 1979:141). The 'peasantness' of an individual's network contacts predicted the choice of Hungarian over German at least as powerfully as the speaker's own status as a peasant worker.

Social network integration and language change in progress in the rural alpine village of Grossdorf in Vorarlberg, Austria's western-most province, were the focus of research by Lippi-Green (1989). She spoke the local dialect fluently and had been an active member of the community. Consequently 'many doors were open to [her] as a linguistic field worker in a clannish community otherwise very distrustful of strangers' (Lippi-Green 1989:215). The three areas of measurement of social network density selected by her were the degree to which the individual was related to core families in the village, workplace network and voluntary association. She found that 'people who have in common high levels of integration into conservative employment networks also have in common a preference for the conservative linguistic variable'(Lippi-Green 1989:224). She suggested that workplace networks seem to be stronger norm enforcement mechanisms than clans because they are a better indicator of voluntary integration into the community, the implication being that voluntary group membership is stronger than involuntary membership.

The findings of the above three studies are particularly relevant to the sociolinguistic patterns I found in Taranaki. The young farming men in particular belonged to dense, multiplex networks, they were employed in a traditional, 'conservative' part of the workforce alongside similarly employed people and their intonation proved to be similar to that of the old people of the region.

In a study of sociolinguistic adjustment of rural migrants to an urban setting, the social network concept was operationalised rather differently by Bortoni-Ricardo (1985). She 
studied the language patterns of a group of rural immigrants in the city of Brazlandia, Brazil, who had come to the city to find work and so that their children could receive formal education. They were motivated to adopt those features of the new culture, including language, which were necessary for success. The researcher used a network approach in order to assess the extent to which speakers had moved away from the stigmatised Caipira dialect. She employed two different network measures, a network integration index and an urbanisation index. The network integration index reflected the degree to which an individual was insulated from, or integrated with, wider networks in the city. The urbanisation index measured the urbanness of a migrant's contacts according to a set of criteria which included category of work and geographic mobility. She found that people who had integrated well in the urban community tended to display the greatest movement away from the Caipira dialect (Bortoni-Ricardo, 1985:247).

Bortoni-Ricardo's methodology was of relevance to my work because one aspect of my study of regional variation in New Zealand English was to determine the degree to which Wellingtonians and people in Taranaki in both urban and rural settings were oriented to either town or country. Any linguistic differences I found between speakers from Taranaki locations and speakers from Wellington could be said to be purely rural versus urban differences and some means of separating possible regional variation from what might be a rural/urban distinction was needed. I outline in Section 2.6 .1 below some of the problems I faced in deciding the extent to which people were either rural or urban in their orientation, and the way in which I operationalised social network theory is outlined in Section 5.2.

\subsubsection{Social networks in Taranaki}

Taranaki presented particular challenges as an area for sociolinguistic study. It is made up of three districts which are largely rural in character: New Plymouth District to the north of Mount Taranaki, the mountain which dominates the region; Stratford District to the east of the mountain, and South Taranaki District to the south, as its name suggests. New Plymouth and Hawera are the only towns of any size. New Plymouth is big enough 
to be called a city with a population of 50,000 and Hawera (population 11,000) in the South Taranaki district is also undergoing rapid expansion at present.

One could imagine that rural communities of Taranaki might be classically dense and multiplex. In South Taranaki where I conducted my interviews, dairy farms predominate over other sorts of farms and they tend to pass down through the generations from father to son. A description of rural Taranaki in the 1950s would show groceries and mail being collected from the local co-op store, friends and families connected by party line telephones, everyone drinking at the local pub, people watching their own sports teams in action on local sports grounds, farmers co-operating with each other in activities such as harvesting hay, farmers transporting their own milk to the local dairy factory, people attending the local church (choice of Catholic or Protestant), families visiting the local town once a week (probably on Friday night), New Plymouth once a month and Wellington or Auckland very rarely. People had large families and women stayed home to look after them and, in many cases, they also looked after the farm accounts. This social setting is suggestive of close-knit communities with typically dense and multiplex network ties and a scene set for the development and/or maintenance of dialectal variation.

However, in recent years massive changes have taken place in rural communities, not least in Taranaki. It is difficult to say what effect, if any, there will have been on the language spoken in the area. Groceries are now bought in supermarkets in town, mail arrives via rural delivery and increasingly via the internet, people tend to shop in New Plymouth or Wanganui, they take regular trips to Wellington and Auckland, overseas holidays are common as is off-farm employment. Women are employed either off the farm or on the farm as partners in the business. There are differences in the occupations and lifestyles of those who live in the country. Alternative lifestylers attempt to live off the land, artists and crafts people find living in the country cheaper, people open their homes to paying guests and Taranaki gets its share of the tourist dollar. These changes may have resulted in less multiplex networks and the looser ties more typically found in urban settings. 
A feature of New Plymouth and Hawera, the biggest centres of population in Taranaki, is the number of farmers who choose to retire there. Many of these retirees maintain their relationships with family and friends still living in the country.

These complicating factors made it difficult to disentangle urban and rural threads in both town and country settings in Taranaki and I concluded that a network approach might help the process. The degree to which speakers in the Wellington sample were rurally oriented was also of interest as I noted that some of the elderly sample had rural connections as did one of the Wellington young men. So social networks of Wellington speakers were analysed in the same way as those of Taranaki speakers. The rural orientation index which I devised along with the rationale for indicators selected is outlined in Section 5.2 .

Social network theory looks at the effect of networks, close or open, on the individual. I look next at social constructionist methodologies which focus on the individual actively choosing from the linguistic resources available from the different social groups with which they wish to be associated. Social network theory and social constructionism are related. They differ in focus and methodology.

\subsection{Social contructionist approach to dialectology}

The social constructionist approach to dialectology advocated by Ochs (1993) explores how individuals use linguistic forms associated with particular social groups, and linguistic devices and strategies associated with or symbolising particular social dimensions or stereotypes. 'Using a more ethnographic qualitative method of analysis, this approach explores how people use language to create, construct and reinforce particular social identities' (Holmes 1997c:204). Although my research methodology was not ethnographic in approach, consideration of how people might construct their identities was important when it came to the interpretation of quantitative data. I outline below some of the ways in which social constructionist methodology has been applied by others in social dialectology. I look at how individuals have been shown to express, amongst other things, social class, gender, ethnicity, and a sense of belonging to a particular place. 
The ability to construct and express ones identity through linguistic means is learnt during childhood. As part of their socialisation children learn how to pick and choose from the linguistic resources available to them those features which will be acceptable to particular social groups. These features may be marked for gender, ethnicity or place. The importance of conforming linguistically in the primary school playground was noted by Bauer and Bauer (2001:75). They observed that,

\begin{abstract}
'the sort of language a child uses is just as important to their acceptance or rejection by their peers as their clothing and their behaviour. It is a 'uniform' they impose, an unwritten code of what is acceptable and what is not.' What is more 'there will be several different 'uniforms' in most playgrounds, and group membership will depend on the 'uniform' a child displays. To belong, you have to talk like the others in your group' (Bauer and Bauer 2001:75).
\end{abstract}

I will refer in greater detail to the study by Bauer and Bauer of New Zealand playground language in Section 3.2 .

\title{
2.7.1 Expression of gender and social class
}

The ways in which a group of Detroit high school students expressed gender and social class through membership of social groups of their own construction was explored by Eckert (2000). This group of adolescents allied themselves with the 'jocks' or 'burnouts' or adopted aspects of one or other of these cultures as suited them. By looking at their 'communities of practice' she described the social mechanisms by which local behavioural conventions and norms of language, dress etc were constructed. 'Community of practice' was defined as 'an aggregate of people who come together around mutual engagement in an endeavor. Ways of doing things, ways of talking, beliefs, values, power relations - in short, practices - emerge in the course of this mutual endeavor' (Eckert \& McConnell-Ginet1992:464). An individual can align themselves with multiple 'communities of practice' at different times and in different contexts.

The way women and men 'do' gender identity in New Zealand was demonstrated by Holmes (1997c) when she undertook discourse analysis of two conversational narratives, one between two women and the other between two men. In both narratives 
stereotypical gender identities were constructed through the speakers' choice of pragmatic particles, conversational devices and phonological variants known to be favoured by one gender or the other.

\subsubsection{Expression of ethnicity}

Several recent projects have studied ways in which different ethnic groups choose to convey their ethnicity via linguistic means.

The speech of the Lumbee Native American Indian community was studied by Wolfram and Dannenburg (1999). The Lumbee do not have reservation land and have lost their ancestral language but the researchers found that the community had developed a unique way of speaking English which was quite distinct from the English of neighbouring European Americans and African Americans.

'Of the behavioral traits that may symbolize ethnic and cultural identity, few are as symbolic as language. The current and past sociohistorical and sociocultural circumstances of the Lumbee certainly underscore their cultural and ethnic distinctiveness on a local level and beyond, and their dialect of English demonstrates that language has been integral to their construction of ethnic distinctiveness. Our sociolinguistic findings indicate Lumbee English to be a vibrant, distinctive dialect representative of a community-based culture' (Wolfram \& Dannenburg 1999:210-211).

Another researcher studying the speech of the same rural community used an ethnographic, sociohistorical methodology and observed that different groups within the community had different notions of local loyalty and expressed their sense of belonging through different language variants (Schilling-Estes 1999). For example Lumbee who prided themselves on their membership of a core Lumbee subcommunity used certain features not used by other subgroups. What appeared to be a single variant could have different meanings for different speakers and even within the speech of a single speaker, one variant could communicate several different meanings depending on the company at the time.

The development of Cajun English in rural areas of Louisiana was researched by Dubois and Horvath (2000). They were interested in the social life and social history of three 
generations of speakers of Cajun English and found links between sociohistorical aspects of the Cajun community being studied and the linguistic behaviour of each generation. The behaviour of the young men in the community was of particular interest. They chose to express their Cajunness through Cajun English features whether or not they had closed or open social networks. Only women who were deeply immersed in Cajun traditional culture and who did not work outside the home spoke Cajun English in the way that the young men did. The researchers suggested that the young men chose to display their Cajunness through language in part because there were financial advantages in doing so. Their work tended to consist of playing music to tourists in the area and acting as tour guides in the bayous. In other words it was 'cool' to be Cajun and it also paid to be Cajun.

It has been observed that increased usage of the variety known as Maori English, sometimes referred to as 'bro talk', has been parallelled by a Maori renaissance in New Zealand 'which has seen an upsurge in pride in wide-ranging aspects of Maori culture' (King 1999:36). King interviewed a group of Maori university students about their experiences and perceptions of who spoke Maori English when and where, and what they thought the functions of the variety might be. She concluded that 'for these Maori students, Maori English functions as an important emblematic marker of their group identity' (King 1999:36). Her interviewees chose to speak Maori English in some contexts and not in others depending on which aspect of their identity they wished to display.

\subsubsection{Place as a cultural concept}

The social dynamics underlying variation at the level of the individual have been studied by Johnstone and Bean (Johnstone 1999, Johnstone \& Bean 1997). The researchers viewed 'place' as a cultural rather than a geographical, physical entity and suggested that as such it could provide the individual with linguistic resources for self expression. Regional identity is situated in the same way as ethnicity is situated, 'arising on the spot in interaction as people categorize themselves and others' (Johnstone \& Bean 1997:240). 
They conducted detailed case studies of the language of ten women of different ethnicities and representing different rural and urban regions in Texas. Of particular interest were the Anglo-Texas women who typically did not think of themselves as southerners, but when it suited them they were able to use speech forms that came to Texas with southern plantation culture, including ones associated with a widely recognised image of 'Southern Belle' femininity. Speakers could either accept this way of talking or they could display resistance to it according to the persona they wished to display at the time (Johnstone 1999).

Johnstone concluded that "close attention to what region and rurality mean to people and how region and rurality can be resources for identification and self-expression shows how dialectology might help moderate sweeping claims by social and media theorists that place has become meaningless in the modern world' (Johnstone 1999).

As mentioned above my methodological approach is quantitative rather than qualitative but place as a cultural construct proved useful in the interpretation of variation in my data. In adopting this approach I follow the precedent set by Labov in his study of language patterns in the Martha's Vineyard community (Labov 1972a). In this study Labov drew on ethnographic knowledge of the island community of Martha's Vineyard for explanations for the linguistic variation which existed in the community at the time. Of major importance was the region's socio-economic history, the downturn of the fishing industry and the decline in farming and dairying with a consequent increasing reliance on tourism and summer holiday makers for income. The linguistic response amongst middle-aged men to these changes was to demonstrate their pride in being different to the incoming flood of socio-economically privileged mainlanders by maintaining the linguistic features typical of the older generation of fishermen. Those who had left the island to further their education or to join the army and who then chose to return, enthusiastically adopted local speech patterns, while those who did not intend to stay on the island adopted mainland speech norms. Four decades later Blake and Josey returned to Martha's Vineyard and undertook a synchronic analysis of the /ay/ diphthong studied by Labov (Blake \& Josey 2003). They found that the earlier linguistic pattern had undergone changes in the intervening years and argued that the changes were linked to socio-economic restructuring and resulting ideological changes taking 
place on the island. Fishermen no longer had the status they once had and young people did not have the same incentive to choose fishing as a profession. 'The economy of the island [had] been maintained primarily by tourism, with locals going from an oppositional to cooperative stance towards tourists' (Blake \& Josey 2003:481). 'The sociolinguistic findings for the present-day data base suggest that, with a change in the socio-economic structure of the Vineyard, locals' allegiance to a traditional way of life has diminished. As a consequence, there has been a decline in the linguistic marking of opposition to non-local populations' (Blake \& Josey 2003:481).

Changes in the socio-economic structure of rural Taranaki are as inevitable as they were in Martha's Vineyard. Some of the changes that have already taken place in the area were outlined in Section 2.6.1. Young men and women still choose to stay on or return to the dairy farms worked by their parents, and often their parents before them, but the industry has changed. Dairy farming is becoming less and less a family business and is increasingly becoming big business with the more successful farmers buying up neighbouring properties. The recent television and newspaper advertising campaign in this country extolling the virtues of a career in dairy farming suggests that there is now a nationwide shortage of dairy farm workers. Advertising on this scale is to my knowledge unprecedented in this sector of the farming industry. An influx of townies (NZE for town-bred people) may contribute to the demise of a rural Taranaki way of speaking in the same way that large numbers of tourists to Martha's Vineyard and a decline in traditional fishing and farming industries have led to linguistic changes in that part of the world.

Having surveyed the literature on dialect formation, and the methodologies employed by social dialectologists to establish the existence of linguistic variation and their attempts to explain such variation, I turn now to consideration of regional variation in New Zealand English. In the next chapter I review available evidence of regional variation in New Zealand English. 


\section{CHAPTER THREE: EVIDENCE OF REGIONAL VARIATION IN NEW ZEALAND ENGLISH}

In this chapter I survey approaches taken to research on regional variation in New Zealand English and outline the results of these studies. It will be apparent that attempts to identify differences between regions have generally not succeeded to date. In most cases the evidence has pointed to other sorts of variation, namely, either social class or ethnic variation. This does not mean, however, that regional differences do not exist. In more recent work researchers have been looking at different data, in different places, with rather different results.

For locations referred to in this chapter see Map 1, page x.

\subsection{Folk linguistic approach - perceptual dialectology}

Using methodology drawn from the field of perceptual dialectology which is associated with Preston and Niedzielski (Preston 1989, Niedzielski \& Preston 1999), Pamela Gordon (1997) explored the views of New Zealanders on the subject of regional accents in New Zealand. She surveyed Otago University students who had little or no linguistic training. Of the 97 respondents to the question, 'Do you think New Zealanders speak differently in different parts of New Zealand?' only two people said, 'No.' The 95 people who claimed that there were differences were asked to identify any such areas on a map of New Zealand, to give the areas labels and to describe the speech of the area. 88 of Gordons' informants identified Southland as being different. Given Southland's proximity to Dunedin where the students were resident it is not surprising that the Southland post vocalic $/ \mathrm{r} /$ was well known to them.

A number of other areas were identified and interesting lay descriptions given of these areas. Gordon noted the tendency for people to evaluate their own home area, be this Southland, Otago, Canterbury, Wellington, Taupo or Auckland, as 'normal'. Various pejorative expressions were used to describe the speech of others. According to those from other areas West Coasters have a 'harsh' accent; there is a 'lack of articulation' in the speech of Southlanders; the speech of the central North Island is 'nasal'; in Northland 
they speak with 'flattened vowels'. Class distinction was recognised: the speech of the higher socio-economic group of Canterbury was characterised by a 'plum in the mouth' accent. The influence of te reo Maori was noted, particularly in rural parts of the North Island. An urban/rural distinction was commented on, very often with respect to speed of utterance, rural speech being perceived as slower than urban speech.

Gordon drew similar conclusions to those of Bayard who had been conducting accent attitudinal surveys in New Zealand since 1986 (Bayard \& Bartlett 1996). In a survey on attitudes to language in New Zealand Bayard (1990) found that only $45 \%$ of his subjects would hazard a guess when tested with the question, 'Where do you think this speaker comes from?' with reference to a voice on a tape. The subjects who did hazard guesses as to regional origins were wildly inaccurate in their guesses for the most part and demonstrated that New Zealanders are, on the whole, no good at identifying where their compatriots come from by their accent. Gordon and Bayard were agreed that 'the stereotypes that NZE speakers attribute to regional variation are social in origin' (Bayard 1990:85). The predominant, perceived, social differences to emerge from Gordon's research were socio-economic variation, ethnic variation and a rural/urban distinction.

\subsection{Lexical variation}

The existence of small-scale differences in the use of regional vocabulary has long been acknowledged by linguists and non-linguists alike.

'Shifting from the South Island to the North .... from Invercargill all the way up to Morrinsville .... Things that stuck out most is we roll our r's, we call "luncheon" "belgium" and we call "vacuum cleaning" "luxing".' (Quoted from the Tablet, Dunedin, 21 January 1996 in Orsman 1997: 456).

Several words which may be diagnostic of Southland English arose in the course of interviews conducted by Bartlett in Southland in the early 1990's (Bartlett 1992: 10-11). Examples include:

ashet: a large plate, especially one used for meat

shaws: the tops of potato plants (or the potatoes themselves, or the complete potato plant) 
sulky: old style of pushchair in which the child faces the person who is pushing

Belgium, Belgium roll, Belgium sausage: luncheon sausage

superheater: hot water cylinder

lux: vacuum cleaner

like: kind, type (as in 'What like is it?')

mind: remember (as in 'Do you mind what the name for that plate is?')

Vocabulary items characteristic of people from the West Coast of the South Island were. identified by Durkin (1972). One of her findings was that West Coasters were often unaware that there was anything different about the way in which they used words and people from outside the region were the best informants. Primary school teachers who had come from or taught in other areas of the country were particularly helpful. A few of the words she identified were:

barber: a very cold wind

crib: a miner's lunch

lammy: a long, grey, woollen shirt worn in the bush

taipo: a weta (large insect, native to New Zealand)

from away: a person who comes from outside the West Coast is 'from away'

Playground vocabulary was the focus of research undertaken by L. Bauer and W. Bauer (Bauer \& Bauer 2000a,b, 2001, 2002a,b, 2003). They investigated expressions which 1112 year old children from 150 schools throughout New Zealand said they used whilst playing, and these expressions were mapped according to geographic distribution. The maps of children's word usage showed that three broad dialect regions (northern, central and southern) were emerging in New Zealand. The northern region extended south to the volcanic plateau in the central North Island. It often, though not always, included Taranaki on the western side of the volcanic plateau. The central region extended from Hawkes Bay on the eastern side of the plateau, through the southern North Island (sometimes including 
Taranaki) and the northern and central South Island including the main tourist areas in the Central Otago lakes area. Southland and eastern Otago formed the southern region.

Terms now used for the game which my friends and I called chasing in Wellington during the 1950's and 1960's divided New Zealand into the three regions. In the northern region it is now usually tiggy, in the central region it is tag and in the southern region it is tig. The researchers traced this regionalisation back to the 1920s. They found that the words used for the basic chasing game have changed over time but the regions have not. They concluded that 'the forces which brought the original dialect areas into being are still present' (Bauer \& Bauer 2002b:37).

Their statistical analysis also revealed the existence of subregions within the three major regions (Bauer \& Bauer 2003). Of interest to my research was the fact that Taranaki did not constitute one of these subregions, although Wellington did. Taranaki was incorporated into the large 'Central North Island' area north of the volcanic plateau extending from Taranaki in the west across the King Country and the Waikato to the Hauraki Plains in the east. Two vocabulary items were found to be special to Taranaki, the truce term twigs and the expression pinner for something which is easy. Almost exclusive use of these expressions in Taranaki suggested the existence of strong internal ties within the region. There was, however, evidence of twigs leaking northwards and there were strong resemblances between Taranaki and the King Country to the north with respect to other items. The researchers inferred the existence of longstanding ties between the regions.

They found that fans, another truce word, was exclusive to the Wellington region suggesting strong internal ties within this subregion.

To the list of words special to the Southland-Otago region cited by Bartlett (1992) can be added the children's truce term nibs. As the Bauers say, 'local pride is strong in the Southern Region, and this provides resistance to the loss of local forms' (Bauer \& Bauer 2003:106). They noted that there is pressure from the northern region in Southland and Otago as a result of northerners immigrating to the Invercargill area in search of cheaper housing and life-style. In addition to this, during the course of interviewing I did for my own project, I learnt that a number of Taranaki dairy farmers had moved to the Southland 
area in search of cheaper dairy farming land. There is also likely to be an impact from the large number of people visiting the lakes and mountains of the southern section of the central region immediately to the north.

Of the three major regions there was more evidence overall for the existence of a northern region which was separate from the rest of the country than there was for a southern region which was separate from the rest of the country. The southern region shared some features with the central region. The central volcanic plateau of the North Island seemed to provide a greater linguistic barrier than the Southern Alps which separate the West Coast of the South Island from the rest of the Island, and greater even than Cook Strait which separates the North Island from the South Island. The Bauers also observed that, 'the divide between the northern and central areas .... coincides roughly with the divide between eastern and western dialects of Maori ..., suggesting that the North Island ranges are a major physical and linguistic barrier, despite modern communications and transport' (Bauer \& Bauer 2003:16). Having lived in New Plymouth and travelled on several occasions by bus and car north, south and east from the city I can vouch for the difficulties of traversing the centre of the North Island from west to east and east to west. The roads are slow and tortuous to say the least and much more of a challenge than the road south. The road to the north is also difficult in places. Taranaki is situated in an interesting position on the border of the northern and central regions with apparently more linguistic influence coming from the north. The Bauers noted 'the large Maori population in Taranaki' and suggested that this could be the most likely explanation for the fact that Taranaki belongs to the northern region (Bauer \& Bauer 2003:103). This is still open to question however and I suspect that the links between Taranaki and the King Country may be based on rural ties rather than ethnic ties per se. Wellington sits squarely in the middle of the large central region.

These findings clearly demonstrate the existence of regional variation in New Zealand children's playground language. L. Bauer is quoted in the New Zealand Listener of 14 October 2000 (Taylor 2000) as saying, 'New Zealand may be at a turning point linguistically. The evidence from other countries is that, within three generations of British settlement, the immigrant dialects all blend into one. Then, about three generations further on, regional dialects start to emerge. The playground data suggests that New Zealand may be entering this phase.' It is probable that regional variation in playground 
vocabulary in New Zealand will continue to be confined to children. These particular children's expressions are unlikely to continue into adulthood. However, the fact that regional variation exists in this restricted area of language suggests the possibility that there could be regional variation in other aspects of language, in adult vocabulary, syntax, or phonetics/phonology. It is known that a regional variety of New Zealand English exists amongst the adults of Southland with respect to vocabulary and phonetics/phonology (Bartlett 1992, 2003), (see Sections 3.2 above and 3.4), the area coinciding roughly with the southern children's playground dialect area. It is possible, though not yet demonstrated, that adult dialects could have developed, or be in the process of developing, with boundaries at least roughly coinciding with the northern and central children's dialect areas, as well as the southern area.

If this scheme were to extend to intonational variation it appears feasible that Wellingtonians' intonation might conform with some central regional norm for intonation patterns. Where Taranaki intonation would fit in the scheme would be less clear. It could conform to the northern pattern, whatever that might be; it could be more like Wellington and the central regional pattern; or alternatively it could contribute to a linguistic subregion all of its own. The scope of my study did not permit me to draw any conclusions concerning a putative northern dialect or for that matter a southern one.

\subsection{Grammatical variation}

A few grammatical constructions have been noted as distinctive, or at least prominent, in some regions. On the West Coast of the South Island a preference for the construction 'the girl of Smith' has been noted (Durkin 1972). Reflecting the influence of the high numbers of Scottish immigrants to the south of the South Island in the nineteenth century, a preference for the use of the past participle after 'needs' and 'wants' as in 'the cat wants stroked' has been observed in Southland as has the lack of contraction of 'not' in expressions like, 'Did you not?' (Bartlett 1992: 12,13). There is obviously scope for further research in this area. 
Both non-linguists and linguists are agreed on the existence of a distinctive regional difference in the Southland/Otago area of New Zealand. The most salient feature of this variety is the post-vocalic/r/. Bartlett (1992) began researching regional variation in Southland in 1989 and he collected data from Invercargill city, Central Southland (rural areas around Winton) and Eastern Southland (rural areas to the immediate south of Gore) (see Map 1). He found considerable variation in the degree of rhoticity exhibited by speakers of Southland English, ranging from fully rhotic speakers to completely nonrhotic speakers. Older speakers in rural areas proved most likely to pronounce postvocalic /r/ wherever it occurred. Among younger speakers, where the post-vocalic /r/ occurred, it was almost always after the NURSE vowel in words like 'work' and 'first'. Bartlett's findings indicated that speech in late twentieth century Southland was becoming less rhotic, although there was some evidence that a positive attitude towards rhoticity of the NURSE vowel, seen as a badge of local identity, could be reducing the speed of the change (Bartlett 2003). Primary school children in Queenstown displayed rhoticity in interviews conducted by L.Bauer for the survey of playground language described in Section 3.2 above, adding weight to the argument that local pride may be providing resistance to the loss of local forms.

Some Southlanders have been found to favour other distinctive phonological features. Older people in Southland maintain the which/witch distinction more consistently and in a wider range of vocabulary items than do younger speakers. Variation in usage of $/ a /$ and læ/ in words like 'dance' and 'chance' has been found with some individuals using both the $/ \mathrm{a} /$ pronunciation and the /æ/ pronunciation for the same item in different parts of an interview (Bartlett 1992). The use of /hw/ as opposed to /w/, and rhoticity have been attributed to the Scottish origins of the heavier proportion of the settlers of the region (Bartlett 2003, Gordon et al 2004:218).

On the West Coast of the South Island children have been found to speak with a 'broad' accent similar to that of Christchurch children of the same socio-economic group suggesting social class rather than regional variation (Durkin 1972). 
The language of dairy farmers and the teenage sons of dairy farmers on the West Coast of the South Island and in the Manawatu region of the North Island has been compared (Hogstad 1995). Analysis of the diphthongs /ei/, /ai/, /ou/ and /au/, the diphthongisation of /i/ as /əi/, and the level of (ING) reduction, revealed that the speech of West Coast dairy. farmers was slightly 'broader' than that of the Manawatu dairy farmers. This may reflect, as Hogstad observes, the fact that the West Coast region is, as a whole, poorer than the Manawatu region and the 'broadness' of accent reflects lower socio-economic status or it could reflect regional solidarity and the farmers' desire to stress their identity as West Coasters (Hogstad 1995:83,84).

Vowels in the speech of men in Kaikohe, a rural town north of Auckland, have been acoustically analysed (Hall 1976). When these vowels were compared with those of men from Auckland city the Northland close vowels were found to be more open, the Northland open vowels were closer and the Northland back vowels were further forward than in Auckland.

A regional comparison of the front centring diphthongs EAR and AIR was undertaken by Batterham (2000:111-145). Results were compared from studies undertaken in four different New Zealand cities by different researchers at different times: in Dunedin (Bayard 1987), in Christchurch (Gordon and Maclagan 1990), in Wellington (Holmes and Bell 1992) and in Auckland (Batterham 1995). Batterham found that methodological differences between the studies made comparison difficult, but that, if she applied the methods she used in her Auckland study to all the studies, she could detect patterns of difference between regions. She concluded that a partial merger of the two diphthongs is evident in all four cities. The merger is bidirectional, towards the close variant /ij/ in Auckland and Christchurch and towards the more open variant/eə/ in Wellington. The direction of the merger in Dunedin is not known. She also noted that changes of direction had been observed in both Wellington and Christchurch but not in Auckland.

Evidence of regional speech variation was reported within Auckland by Allan and Stark (2000). They found that in certain parts of the city (in north, central and south Auckland in a strip either side of the motorway) there was a tendency for people to pronounce $/ \mathrm{s} /$ in utterance final position with a fronted dental articulation. People who lived in the east or west, further away from the motorway, were more inclined to pronounce/s/ in a non- 
fronted, less shrill sounding way. Only about half the 1243 speakers who participated in the study had the fronted /s/ so the feature could not be considered diagnostic of Aucklanders' speech though older speakers exhibited it less frequently than younger speakers, suggesting that its usage is advancing.

Having reviewed approaches taken thus far to the exploration of regional variation in New Zealand English I turn, in the next chapter, to my reasons for focussing on intonation as a possible area of regional variation. I also survey the ways in which varieties of English have been found to differ intonationally. 


\section{CHAPTER FOUR: INTONATION}

As indicated in the previous chapter, syntactic, lexical and segmental phonological/phonetic features have until now been the focus for research into possible regional variation in New Zealand English. In comparison intonation is relatively underresearched, which is surprising given the comments which have been made about aspects of New Zealand English which relate to intonation and its variation. Informants in the folk linguistic survey conducted by Gordon (1997) described Taranaki speech as whining or possessing a twang (P.Gordon 1997:18,25). Elderly women of Taranaki interviewed for an oral history project were said by their interviewer, Dinah Priestley, to have a sing-song quality to their speech (Priestley, personal communication).

This sing-song quality to intonation is noted by Abercrombie (1967) in the following observation:
'That languages, and even dialects, do not sound alike in the matter of pitch fluctuation is a matter of common knowledge; it does not take a trained ear to detect that differences exist. The accusation commonly made by one group of people about another that 'they sing when they talk' merely recognizes that they use different melodic patterns. Familiar patterns, those of the mother-tongue, go un-remarked - they are not heard in terms of musical pitch as such, but simply as immediate indications of meaning and attitude. Unfamiliar patterns, however, since they do not convey these immediate indications, are heard as pitch fluctuation, and are therefore often said to sound like singing' (Abercrombie 1967:102).

Abercrombie's observation tallies with the above assessment of Taranaki speech as 'singsongy'. Priestley, who made the comment, is a Wellingtonian. She was aware of something different in the speech of the elderly Taranaki women she interviewed and remarked that they sounded as though they were singing, the sort of comment which, according to Abercrombie, might be expected in the circumstances.

These somewhat loose 'folk' characterisations suggested that there might be something in the intonation of Taranaki speech which is distinctive. Furthermore, 'It has often been remarked that the essential auditory identity of a language [and, I would argue, a dialect, HA], the immediate impression conveyed upon a first or a passing encounter, derives 
from the character of its prosody' (Crystal 1995:174) and intonation is an important aspect of prosody.

L.Bauer (1986:251) pointed out that no studies had at that point been carried out considering intonation as a possible regionally defined variable in New Zealand English and, as far as I know, none have been carried out to date. He also noted that, 'The intonation of New Zealand English is generally speaking rather flat' (1994:391). I understand 'flat' here to mean 'having restricted variation in pitch'. Pitch is the prosodic feature most centrally involved in intonation and it relates to the listeners' judgements 'as to whether a sound is "high" or "low", whether one sound is "higher" or "lower" than another and by how much, and whether the voice is going "up" or "down"' (Cruttenden 1997:4). It is the melody of voice during speech. An assessment by a lay commentator, the Hon. Nigel Wilson Q.C. (quoted in Gordon et al 2004:68) is similar to that of Bauer. In a radio talk in 1983 he maintained that there is a 'monotonous and dull' quality to New Zealand speech, 'monotonous and dull' presumably referring to prosodic elements of speech. His explanation for this quality was, as indicated by Gordon et al, decidedly fanciful. He claimed that it was the result of 'the loss of enjoyment of life occasioned by the 1930s Depression'. In line with Bauer's and Wilson's comments, it is interesting to note that the speech of the man selected to demonstrate general New Zealand English in the Evaluating English Accents Worldwide project of Bayard et al (2001) is notable for its flat intonation. Presumably the speaker was chosen because it was thought that his speech typified that of a New Zealand male. My impression of the speech of the elderly Taranaki women recorded by Priestley was that it was characterised by a lot of pitch movement and it was not at all flat. It did not conform to what was thought to be typically New Zealand intonation and the women came from the one region of New Zealand, Taranaki. So it seemed there was a reasonable possibility that there could be regional variability in patterns of intonation in New Zealand English. Hence my decision to compare the intonation of Taranaki speakers with that of people from another region of New Zealand. Wellington was selected for contrast in part because of its status as capital city of New Zealand and in part because of the availability of a suitable corpus of material for analysis. The fact that the man with the noticeably flat intonation in the Evaluating Accents Worldwide project was a Wellingtonian also contributed to the decision. 
A further reason for my focus on intonation was the possibility suggested in the literature that prosodic features, intonational ones in particular, may be the most enduring features of speech where there are competing dialects or where one language or dialect is giving way to another. In a recent survey of the phonology of Rhondda Valleys English, Walters (2003) examined the degree to which this dialect was influenced by the Welsh language and found that suprasegmental features derived from the Welsh language such as stress, rhythm and intonation seemed more pervasive than segmental features. He concluded that, 'they may ... prove to be the most enduring, in that such features, particularly the intonational ones, can be retained in the speech of speakers who have shed all other traces of "Welsh accent"' (Walters 2003:85). Kerswill (1994) found when researching the Norwegian spoken by rural migrants to Bergen that rural speakers acquired prosodic features of the urban dialect spoken in Bergen less readily than morpholexical and segmental phonological features (Cheshire, Kerswill \& Williams 2005 f.c.) though the fact that prosodic features also play a lexical role in Norwegian could confound the issue. These findings suggest that intonation may be the most difficult aspect of a second or subsequent dialect to acquire and conversely the hardest thing to lose. In the latter stages of the process whereby one regional dialect gives way to pressures from another it may well be that intonational features could distinguish between the different regional varieties in the absence of any other easily identifiable characteristics.

Having decided that an investigation of intonation might be a good place to start in pinpointing what might or might not differentiate Taranaki speech from Wellington speech I needed a procedure which could measure the 'singsong' quality of speech. 'Singsong' was taken to refer to regular pitch movement up and down in a manner reminiscent of singing. Singing of course has other prosodic attributes such as certain rhythmic types that may or may not be found in speech. The purpose of the current investigation was to seek confirmation of the singsong impression specifically in terms of pitch dynamics, ie. in the patterns of pitch movements in speech. An account of the means used to measure 'singsonginess' will be given in Chapter 5 .

Before reporting on the regional comparison I undertook I will review what has been discovered about ways in which varieties of English differ intonationally. I will attempt to categorise differences according to the typological framework devised by Wells (1982) for segmental systems and then adapted by Ladd (1996) to distinguish intonational 
differences between and within languages. After this I will look at methodologies used to establish the existence of differences.

\subsection{Ladd's taxonomy of intonational differences}

Ladd's taxonomy consists of four possible ways in which language varieties can differ. These are:

"Semantic" differences: differences in the meaning or use of phonologically identical tunes.

"Systemic" differences: differences in the inventory of phonologically distinct tune types, irrespective of semantic differences.

"Realisational" differences: differences of detail in the phonetic realisation of what may be regarded phonologically as the same tune.

"Phonotactic" differences: differences in tune-text association and in the permitted structure of tunes.' (Ladd 1996: 119).

Ladd admits 'it is not always easy to classify specific cases' but that it is useful to be 'aware that there are different kinds of differences' (Ladd 1996:119). The description of the intonation tunes typical of New Zealand English is in its infancy so categorisation of any differences I find within the variety will necessarily be tentative only.

\subsubsection{Semantic differences}

One of the examples Ladd gives of a semantic difference is the use of the high rising intonation typical of questions sometimes used on utterances which are syntactically and functionally statements. This is commonly known as the high rising terminal (henceforth HRT) and it is a salient feature of Australasian English. The rising pitch at the end of noninterrogative intonational phrases has a fundamental frequency which varies in range and the rises can spread over a single syllable, over several syllables or over more than one word (Britain \& Newman 1992:4-8). Halliday's description of an HRT, cited in Fletcher et al (2003:2), is that 'the tune must rise to a pitch level approximately $40 \%$ higher than 
the nuclear accent' (Halliday 1967). The feature has been studied in great detail in Australia and New Zealand. It has been examined for social and contextual correlates, it has undergone testing for people's subjective evaluations, and there has been much discussion about its possible meaning. I will discuss this work in Section 4.2.2.3. The feature is not confined to Australasian English and has been observed in the United States (Ching 1982), in Canada (Paddock 1981, James et al 1989), and the United Kingdom (Cruttenden 1995).

Ladd maintains that HRT statement rises and question rises have different semantic functions but identical tunes. However, recent close analysis of HRT statements compared with yes/no questions in Australian and New Zealand Englishes reveals realisational differences in the degree and timing of the rises. Fletcher et al (2005) found in the speech of male speakers of Australian English a contrast between a lower starting point for statement rises than for question rises with no difference in the target end point of the rise. Warren and Daly (2005 f.c.) found that female speakers of New Zealand English in particular started their statement rises later than question rises. Perceptual research has shown that New Zealanders, hearing the same segmental material but uttered with differing rising patterns, are most likely to identify a rising pitch which is quick, occurs early in the accent unit and sustains a high pitch level as a question. Conversely, if the same passage has a rise which occurs late in the accent unit and which rises to the endpoint of the pitch contour it is likely to be identified as a statement (Zwartz \& Warren 2003, Warren 2005). It would seem then that in Australian and New Zealand Englishes the rising statement tunes and the rising question tunes are not necessarily always identical . and the differences may not be simply semantic. In New Zealand English at least the difference may be becoming a systemic one (Warren 2005).

\subsubsection{Systemic differences}

The Urban Northern British English inventory of phonological tunes includes a pattern of a rising accent followed by a plateau and sometimes a following slump (known as the rise-plateau-slump pitch contour) which is not shared by other varieties of English. This is an example of a systemic difference in Ladd's taxonomy (Ladd 1996:123). Urban Northern British English rises differ both phonetically and pragmatically from the HRT. The HRT tends to begin high on the accented syllable (though Warren and Daly, 2005 
f.c., have found that statement rises in their NZE data tend to rise after the accented syllable) and it keeps rising to the end of the phrase to which it is attached, whereas the rises of Urban Northern British English statement intonation are characterised by a low beginning on an accented syllable and the rise is often followed by a distinct fall. HRT statement rises have a specific meaning of checking that the listener is understanding what is being said (Britain 1992). This is not the case with Urban Northern British English rises which function as normal declaratives.

Belfast, Newcastle, Glasgow, Liverpool, Manchester and Birmingham Englishes are examples of Urban Northern British English varieties which have statement intonation which rises, or rises then falls. Different approaches have been taken to the study of the rises. I outline some of these below.

\subsubsection{Overall percentage of rises}

Jarman and Cruttenden (1976) noted the preponderance of intonation groups containing rises in Belfast English. They analysed the speech of an educated speaker of the urban dialect of Belfast and found $70 \%$ of the intonation groups analysed contained rises. Of the remainder a few had a rise-fall where the fall did not go below mid-pitch. The remaining small percentage of intonation groups had a falling tone in which the voice fell from high to mid-pitch. The frequently expressed meaning of the rises was declarative.

\subsubsection{Prosodic features of conversational turn endings}

Turn endings in conversational talk in Tyneside English were analysed by Local, Kelly and Wells (1986). A typical turn ending was characterised by a pitch step up at the end of a turn as opposed to the steep rise at the end of a typical Belfast turn-ending. Both patterns reflect the rising pattern of intonation typical of statements in Urban Northern British English. Although the New Zealand data I have analysed is not characterised by Urban Northern British English rising intonation it is interesting to note that some speakers, notably the young women, have a tendency to use stepped up level accents rather than continuous rises when they do choose to raise their pitch. 


\subsubsection{Placement of base-line}

Brown et al (1980:19) approach the comparison of the intonation of different regional varieties of English by observing the placement of the intonational base-line of unstressed syllables in relation to stressed syllables, the inclination of this base-line and the type of excursion of stressed syllables from the base-line. (Was the excursion stepped or was it contoured?) The base-line, they say, in Edinburgh Scottish English and in RP is lower in pitch than the stressed syllables. The base-line in the English spoken in Glasgow and Belfast is, however, positioned above the stressed syllables 'which occur as scoops down in pitch from this raised base-line, yielding the characteristic rising-contour pattern of Glasgow and Belfast intonation' (Brown et al 1980:19) The base-line in Edinburgh Scottish English differs from that of RP in that it remains quite flat throughout the intonation unit whilst the RP base-line sloped downwards. The effect of the flat Edinburgh base-line was that excursions from it on stressed syllables involved relatively little pitch movement or steps whereas there was more pitch movement on RP stressed syllables as the base-line declined creating contours (Brown et al 1980:20). The base-lines in these varieties of English could be said to represent systemic differences. It has been observed that the base-line of New Zealand English may be flatter than that of RP (Chris Lane: personal communication). This may or may not be true of the data I have collected in Taranaki and Wellington. I have not specifically measured base-lines in my data but it is my impression that base-lines vary from speaker to speaker in New Zealand English and I believe that if speakers have flat base-lines this is more likely to be evidence of a realisational difference than a systemic one.

\subsubsection{Closed versus open tone meanings}

Cruttenden (1997) focusses on meanings of nuclear tones and in so doing arrived at a systemic difference between Manchester English and RP. He suggests that the meanings of nuclear tones can be divided into closed and open meanings. He proposes closed as a label for those tones which are ascribed meanings of assertiveness and non-continuation. Open tones were those which have been described as having non-assertive and continuative meanings. In RP falling tones belong to the closed set and rising tones are classified as open. He makes a similar division between closed and open sets of tones in the intonation typical of the English spoken in Manchester (Cruttenden 2001:57). But in 
Manchester the closed and open sets are quite different to those of RP. Rise-slump is the basic tone in the closed category in Manchester. Cruttenden uses the term slump to refer to 'a fall from a relatively high pitch to a relatively mid pitch'. A slump is different to a fall 'where a falling contour reaches the base-line of the speaker'(Cruttenden 2001:57). Fall-level is the basic tone in the open category in Manchester. The fall-level of Manchester is differentiated from the RP fall by the fact that it maintains an elongated low tone as opposed to the final fading and lowering at the end of the RP tone. This difference is important in preventing possible confusion between the open meaning of the Manchester intonation pattern and the closed meaning of the RP contour.

\subsubsection{Realisational differences}

Ladd (1996) lists differences of tonal alignment as an example of realisational differences between and within language varieties. The pitch contour of a tone may fit the segmental aspects of an utterance differently in different varieties. I comment below on some instances of differing peak alignments:

\subsubsection{Peak lag}

Nolan and Farrar (1999) survey peak lag in the speech of people from Cambridge, Leeds, Newcastle and Belfast. Peak lag occurs where the pitch accent associated with a particular syllable is aligned not with the accented syllable but with a following unstressed syllable. F0 peaks may be aligned "not even with the immediately adjacent syllable, but delayed still further, giving rise to "extreme peak lag" (Nolan \& Farrar 1999:961). Data for analysis comes from the Intonational Variation in English (IViE) corpus (Grabe et al 1997) and consists of utterances read aloud from the story of Cinderella by forty seven speakers resident in Cambridge, Leeds, Newcastle and Belfast. In the ten utterances selected from each speaker a high pitch accent was associated with the first accented syllable. Peaks were found to be more frequently subject to lag in the data from Belfast, Newcastle and Leeds than in the data from Cambridge. Extreme lag was found to be most common in the data from Newcastle and Leeds (Nolan \& Farrar 1999: 964). 


\subsubsection{Alignment of rises}

Late alignment of rises has been found to be typical of female speech in New Zealand English in certain contexts. In an examination of rises in questions realised by intonational means in New Zealand English Warren and Daly (2000) find realisational differences between males and females. Females used larger, more rapid rises than males and the rises were aligned later with respect to text. The authors of this study also study data relating to rises realised on statements, in other words the HRTs discussed above under the heading Semantic Differences. They find that statement rises started significantly later than question rises for both males and females (Warren and Daly 2005 f.c.).

\subsubsection{Pitch movement on unaccented syllables}

Pitch movement on unaccented syllables is found in the intonation of the English spoken in Abercrave, a Welsh industrial village in the Swansea Valley (Tench 1990:140). Conversations of three men in their fifties and sixties who were born in Abercrave and had lived there all their lives were tape-recorded and analysed. 'Neutral' intonation patterns in Welsh English had more pitch movement than RP English 'neutral' patterns,. giving us another example of a realisational difference between two dialects. A high degree of pitch movement on unaccented post-tonic syllables was noted (leading to the impression of a high proportion of rise-falls), as was a high degree of pitch movement on unaccented syllables in pre-tonic position. Glissando rising was found to be very common. Tench says that it was these features which gave rise to the popular claim that Welsh people have a 'sing-song' or 'lilting' intonation. It could be argued that these features really belong in the category of phonotactic differences described in Section 4.1.4 below.

\subsubsection{Phonotactic differences}

Semantic, systemic and realisational differences in intonation are the categories of difference in Ladd's taxonomy which have attracted most attention in the literature. Phonotactic differences appear to be very similar to realisational differences and it is difficult to find illustrative examples. 
Pitch accents are normally associated with lexically stressed syllables. Ladd (1996) gives as an example of a phonotactic difference the case of a pitch accent being used in association with a lexically unstressed syllable. He cites the use of two falling declarative accents for emphasis where one accent might be expected. This is a particularly Italian trait he says. However, as a speaker of New Zealand English, I am aware that occasionally I say 'No' or 'Yes' with a double falling accent for extra emphasis and I am not alone in this.

\subsection{Methodologies used to establish intonational variation}

Intonational variation in English has been studied from several viewpoints and a variety of methodologies used to establish the existence of variation. Until recently most studies have been monodialectal, with some taking Southern Standard British or RP (Received Pronunciation) as a point of comparison. There have been many impressionistic, qualitative descriptions of the intonation of particular varieties of English and, more recently, sociolinguistic comparisons between varieties have been undertaken, as have studies with a psycholinguistic, experimental approach. I outline below a sample of studies illustrating the different approaches taken. I limit my review for the most part to research on British and Australasian English largely because of the origins of New Zealand English in British dialects and because of historical and ongoing links between New Zealand, the UK and Australia. This is not to deny possible influences of other varieties of English spoken in New Zealand, for example Maori, Pacific Nation, Asian and North American Englishes.

\subsubsection{Impressionistic/qualitative studies}

Conversational texts have been the source of data for several impressionistic analyses of intonation. When Jarman and Cruttenden (1976) described the intonation of Belfast they based their analysis on recordings of the conversational speech of a single educated speaker of an urban dialect of Belfast, checking their principal findings by reference to a second speaker of the same dialect. Wells and Peppe (1996) based their analysis of the intonational features of turn delimitation in Belfast English on a single extended extract from a conversation, which had been collected by Lesley Milroy as part of her sociolinguistic study of Belfast English in the mid-1970s. A similar approach was taken 
by Local, Kelly and Wells (1986) when they studied turn delimitation in Tyneside English. They used a conversation between two urban Tyneside families involving seven conversationalists in all, all of whom knew each other well, and the recording took place in the home of one of the families. Tape recordings of the conversations of three men in their fifties and sixties who had lived in Abercrave all their lives provided material for analysis for Tench (1990) in his study of pronunciation features of English in Abercrave in the Swansea Valley of Wales. And Cruttenden (2001) based his observations of the characteristics of nuclear tones in Manchester English on qualitative analysis of conversational data from four women who knew each other well and who were native to the area of Greater Manchester where they lived.

Impressionistic studies such as those listed above provide a good starting point for the description of the intonation of a region. But it is difficult to generalise from such findings without reference to social factors which may affect intonation patterns and until recently there has been little research undertaken on regional and/or social variation in the intonation of English using a standard sociolinguistic framework.

\subsubsection{Sociolinguistic studies}

\subsubsection{Comparison of nuclear tones}

An early, indicative sociolinguistic study of intonational variability in Tyneside speech was undertaken by Pellowe and Jones (1978) as part of the Tyneside Linguistic Survey. This survey aimed to determine the ecology of speech varieties in urban environments. Researchers on the project were interested in linguistic, social, spatial and temporal associations between varieties. The intonation of twenty speakers was studied, nine women and eleven men, aged from 17 to 70 , with occupations ranging from unskilled manual to higher supervisory. All had lived continuously on Tyneside. Proportions of different kinds of nuclear tones were compared with nuclear tones in the speech of RP speakers from the Survey of English Usage (Quirk et al 1964). The Tyneside speakers were found to have more level nuclei and fewer falls than the RP speakers. The Tyneside level tones were frequently preceded by a step up in pitch. When percentages of rises compared with falls were contrasted there was no difference between Tynesiders and RP 
speakers. There was, however, a gender difference with women, younger women in particular, using a higher percentage of rises than men.

A similarly 'broad' analysis of different kinds of nuclear tones was undertaken by Warren and Daly (2005 f.c.). They compared the newsreader speech of male RP and male New Zealand English newsreaders and found that New Zealand English newsreading speech tended to be characterised by more complex nuclear accents, rise-fall accents in particular, and fewer level nuclear accents than the RP newsreading speech. Rise-fall tunes in British English have been interpreted as expressing a range of emotions such as excitement, 


\subsubsection{Comparison of HRT usage}

Sociolinguistic methodology was employed in studies of the HRT intonation pattern in Australian English (McGregor 1980, Guy and Vonwiller 1984, Horvath 1985, Guy et al 1986, Fletcher et al 2005) and in New Zealand English (Allan 1990, Britain 1992, Britain and Newman 1992, Ainsworth 1994, Warren and Britain 2000, Fletcher et al 2005).

Age, sex, socio-economic class and ethnicity have all been examined as possible correlates of HRT usage.

\subsection{Age}

In both Australia and New Zealand age has been shown to be a significant variable. In Britain's study 20-29 year olds used HRTs over 4.5 times more than did 70-79 year olds (Britain and Newman 1992:4). Nine year olds in Ainsworth's data had a very high rate of HRT usage, 13.76\% of their tone groups containing HRTs (Ainsworth 1994:9). This is considerably higher than the $1.6 \%$ usage reported amongst $11-14$ year old children in Sydney by Guy et al (1986).

\subsection{Gender}

The reported frequency of HRT usage amongst New Zealand women is higher than that for Australian women. In a study of the speech of nine 25-35 year old women of the same social class in Levin, $3 \%$ of non-interrogative pause defined units (intonation groups were defined by pauses in this study) contained HRTs (Allan 1990:119). Britain (1992; Britain and Newman 1992) studied data from interviews which were part of the wide ranging sociolinguistic project undertaken in Porirua, an area on the north western outskirts of Wellington (Holmes et al 1991). Age, gender, ethnicity and social class were factors considered. As in Australia, women used more HRTs than men (women 3.9\%, men $1.8 \%$ ). The gender difference did not exist, however, amongst Maori men and women (Maori women 5.0\%, Maori men 5.1\%). The gender distinction in HRT usage amongst Pakeha New Zealanders was found amongst very young New Zealanders (Ainsworth 1994). Amongst four year old girls $3.54 \%$ of all tone groups contained HRTs and with four year old boys there was a much lower rate of $0.69 \%$. In a more recent piece of 
research designed to test whether audiences of different ethnicity or gender affect the use of HRTs it was found that Pakeha women used more HRTs than Pakeha men, no matter what the ethnicity or gender of their audience (Bell and Johnson 1997, reported in Warren and Britain 2000).

\subsection{Ethnicity}

Of the nine women whose speech Allan analysed, five were Pakeha and four were Maori (Allan 1990:116). The Pakeha women studied averaged 2.33\% HRT usage and Maori women averaged $3.58 \%$ usage. There was also a clear ethnic distinction in Britain's Porirua data with Maori New Zealanders using 45\% more HRTs than Pakeha New Zealanders (Britain and Newman 1992:4). Both Maori men and Maori women favoured HRT usage over Pakeha men in Bell and Johnson's study (1997). This mirrors a preference for HRT usage amongst some ethnic minorities in Australia where Italians and Greeks were shown to have higher HRT scores than Australians of British or Irish extraction (Guy et al 1986:40).

\subsection{Social class}

Social class was found to be an important factor in HRT usage in Australia with working class speakers having a higher percentage of HRT usage $(2.1 \%)$ than middle class speakers $(0.7 \%$ ) (Guy et al 1986) whereas in New Zealand there was no significant difference between working and middle class speakers (Britain and Newman 1994:4). Aspects of Ainsworth's (1994) findings suggested a similar lack of class distinction amongst young children in New Zealand. The highest user of HRTs was a pupil at a private school whereas all the other children attended a state primary school (Ainsworth 1994:11). Obviously it cannot be suggested on the basis of this one child's speech, that the HRT is a more middle class than working class feature in New Zealand English.

Current research in Australia suggests that HRT usage has now spread to a much broader cross-section of the Australian community (Fletcher et al 2005). Analysis of the speech of three females and six males participating in a MAP task included in the Australian National Database of Spoken Language (ANDOSL) shows 21\% usage of HRTs amongst the women and $25 \%$ amongst the men, though differences in the discourse context in 
which the HRTs were elicited may account to some extent for the increase in usage. (See Section 4.2.2.3.5 for details on discourse contexts studied in New Zealand). All speakers in this study were speakers of 'general' as opposed to 'cultivated' or 'broad' Australian English. 'Cultivated', 'general' and 'broad' were labels given to three linguistically defined groups of Australian English by Mitchell and Delbridge (1965). The fact that speakers of 'general' Australian English of both sexes favour HRT usage to this extent indicates that the feature is no longer confined to working class females in Australia. HRT usage has in recent times been reported in England, and Cruttenden (1997:130) comments that it is not his impression that it is a working class feature of speech in London. He says that, on the contrary, "it seems to be typical of what might be called "New Yuppies"'. There is a popular notion in England that the spread of HRT may have come about as the result of exposure to Australian television soap operas.

\subsection{Discourse context}

There are similarities with respect to findings in Australia and New Zealand as to which text types favour HRT usage. In both countries HRTs are most commonly found in narrative texts and far less often in opinion-giving texts (Guy et al 1986, Allan 1990, Britain 1992). Four year olds in Ainsworth's (1994) data used HRTs only in explanation texts, but the nine year olds had acquired the New Zealand adult pattern of a preference for using HRTs in narrative texts. Warren and Britain (2000) have refined the study of the location of HRTs by looking at exactly where they occur within narrative and opinion discourse genres. They found that they occurred most frequently in evaluation and orientation sections of narrative texts and far less often in resolution, coda and complicating action sections. They also found that where a narrative was at its most exciting, HRTs tended to occur in a series, thus heightening the listener's interest in the story. In the act of giving opinions speakers tended to use HRTs when they were providing evidence to support initiating opinions but not whilst expressing the opinion itself. 


\subsubsection{Gender comparisons}

Intonational differences between men and women have been commented on by several researchers and given that gender comparison is of importance in my research on the intonation of New Zealand English as spoken by people in Taranaki and Wellington I outline below some of the differences which have been noted in different parts of the English speaking world.

Differences in the intonation patterns of males and females have already been noted in the above summary of variation in intonation (eg. Pellowe and Jones 1978; Douglas-Cowie et al 1995, Vermillion 2003, the HRT studies cited in Section 4.2.2.3). In addition to these studies there are several more which deal specifically with gender variation.

\subsection{Stereotypes}

Several researchers have approached the investigation of gender differences with respect to intonation by looking firstly at male/female stereotypes (eg. McConnell-Ginet 1983, Henton 1989, Warren \& Daly 2000, Daly \& Warren 2001, Vermillion 2003). Stereotypically, female intonation has been described in negative terms such as 'highpitched', 'shrill', 'over-emotional' and 'swoopy' (Henton 1989: 299). These descriptors appear to be based on the speech of American women but Henton seems to imply that they apply to all women not just American women. In a more positive vein, Dutch female voices are described as 'melodious' by Tielen (1992, cited in Henton 1995:52). Women's intonation has also been characterised as 'more dynamic than men's, displaying wider ranges of pitches, more frequent and rapid shifts in pitch, and more frequently ending with a non-falling terminal than men's' (McConnell-Ginet 1983:555). These descriptions may be less emotive, but McConnell-Ginet still questions the validity of such global characterisations, saying that they are based on 'unsystematic observation and a few experimental studies in laboratory settings involving oral reading' (McConnell-Ginet 1983:555). She calls for systematic investigation to determine to what extent these male/female stereotypes are based on fact. I outline below how some researchers have addressed the issue. 


\subsection{Pitch range}

The notion of 'swoopiness' provided the focus of study for Henton. She explored what 'swoopy' might mean in terms of acoustics, firstly taking it to refer to greater overall pitch range (Henton 1989) and secondly greater pitch dynamism (Henton 1995). She reviewed data from seventeen previous acoustic studies which compared male and female pitch range in American and British English and in Swedish. She followed this up with analysis of her own recordings of the speech of five men and five women speakers of American . English.

If valid comparisons are to be drawn between the findings of different studies on the comparative pitch ranges of different groups of speakers, 'pitch range' must be clearly defined and the way in which it is measured is also critical. Pitch range, Henton said, 'may be defined as the amount by which a speaker varies around the average pitch' (Henton 1989:301). Conclusions drawn from the studies she selected for review were based on measurements in Hertz which is a linear measurement. However pitch perception is non-linear and normalisation is necessary to accommodate for lack of linearity. 'A large change in frequency at the higher absolute pitch range of a female voice is needed to produce the same perceptual effect as a smaller change in the frequency of a male voice' (Daly \& Warren 2001:86) so a non-linear measurement is particularly necessary when comparing men's and women's pitch. Henton therefore chose to convert the Hertz values in the data from studies selected for review, into logarithmic semi-tone values which preserve perceived intervals in pitch. The studies' original conclusions, based on measurements in Hertz, were that women used a wider pitch range than did men. Adopting the semi-tone scale on her own recordings and on data from the seventeen reviewed studies, Henton came to the conclusion that there was little measurable difference between men's and women's pitch ranges.

An alternative non-linear scale is the Equivalent Rectangular Bandwidth (ERB) scale, which normalises for absolute differences in male and female pitch ranges. It is based on the frequency selectivity of the human auditory system and is said to afford a perceptually realistic comparison between men's and women's pitch ranges (Hermes \& van Gestel 1991). It was adopted in a study of sex-related pitch range in Dutch (Haan \& van Heuven 1999). Pitch range in this study was defined as the difference between minimum and 
maximum pitch values over an utterance. It was found that women had larger pitch ranges in both declarative and interrogative speech than did men in both read and spontaneous speech. Final pitch movements in statements and questions were greater for women than for men. Statements were marked by bigger final falls and questions by bigger rises.

Using the same working definition of pitch range and the same measurement scale, the existence of measurable and reliable speaker-sex differences in pitch range was demonstrated in New Zealand English by Daly \& Warren (2001). The speakers in their study read scripted sentences and stories which included instances of direct speech. Their findings confirmed speaker-sex stereotypes. In other words women had greater pitch ranges than men. This was particularly true in the story readings which contained dialogues, and were presumably closer to natural speech. When the dialogue data was converted to semi-tone values the women still had greater pitch ranges than the men. The findings of both Daly and Warren (2001) and Haan and van Heuven (1999) contrasted with those of Henton (1989). The reason for the difference in results appeared to lie in the text types used for analysis. Story telling encouraged women's usage of wider pitch ranges, whereas the reading of lists of statements did not. The studies which Henton reviewed, with the exception of one study by Graddol and Swann (1983), were notable for the fact that they did not contain dialogue tasks (Henton 1989).

\subsection{Pitch dynamism}

Study of pitch dynamism was the second phase of Henton's investigation of what might be acoustically involved in stereotypical female 'swoopiness'. Pitch dynamism in some form is also important to my exploration of a possible difference between the intonation of Taranaki and Wellington speakers of New Zealand English. Just as pitch dynamism is likely to be involved in 'swoopiness', so it is likely to be an important aspect of 'singsonginess'.

Crucial to cross-study comparison of pitch dynamism is similarity of operational definition. Henton defined pitch dynamism as, 'the degree of rapidity of changes in a speaker's pitch range from high points to low points and vice versa, in time' (Henton 1995:44). She analysed passages read by five men and five women selected for social homogeneity. She calculated the average rate in change in F0 for the ten speakers in 
Hertz, which she then converted to semitones. Using this measure she found no significant difference between male and female speakers with respect to pitch dynamism.

The survey undertaken by Daly and Warren (2001) mentioned above in connection with pitch range, also measured pitch dynamism. They used a similar methodology to that used by Henton (1995). Important differences in project design were the inclusion of a reading passage which contained direct speech and the employment of ERB measurements. Analysed in this way, female speakers were found to use more dynamic pitch than males as well as employing a greater pitch range.

In another study Warren and Daly focussed their attention on rises in pitch (Warren \& Daly 2000). They examined the size and rate of change of rises and the alignment of pitch movement against segmental aspects of utterances, in questions realised only by intonational means in the speech of young Pakeha women and men in Wellington. Females were found to use larger and more rapid rises which were aligned later with respect to text. The differences between men and women were found to be realisational as opposed to semantic.

\subsection{Other studies which confirm speaker stereotypes}

Many other studies of intonation have confirmed speaker stereotypes. I outline a few of these below. They are reviewed because of their relevance to my findings with respect to gender differences in intonation in Taranaki and Wellington.

A study by Nicola Woods (1992) of the intonation of Southern British English is of interest because it is one of few studies to analyse spontaneous speech. In this respect it more closely resembles my own research where material from conversational interviews was selected for analysis. In an examination of the intonation of spontaneous speech of twenty middle-class speakers of Southern British English (five young men, five young women, five boys and five girls) Woods focussed on pitch movement on nuclear syllables, pitch range and maximum pitch. Both impressionistic and instrumental techniques were employed. Whilst acknowledging that the relationship between pitch and fundamental frequency is not simple, she equated pitch with fundamental frequency when comparing pitch ranges. She found women's speech to be characterised by rising and high-falling 
nuclear tones and by a wide pitch range. In contrast level tones and a relatively narrow pitch range were what marked men's intonation. The finding regarding young women's preference for rising nuclear tones is consistent with that of Pellowe and Jones (1978) who found that young female speakers of Tyneside English and of RP favoured rising tones. Woods separated the category of rising tones into complex fall-rises and simple rises. She found no significant difference between men and women in the number of simple rises used but women used significantly more complex fall-rises than did men. A similar pattern is evident in the data I have collected in Taranaki and Wellington.

Woods' study was later criticised by Henton on the grounds that (i) because the author did not control for the sex of the interviewer (herself), her findings could be affected by 'listener-orientation adaptive pitch tuning' and (ii) the interlocuters were probably in 'information gathering', 'curious' and/or 'emphasising' modes, because this was presumably the first time the participants in the conversational dyads had met (Henton 1995:47). It could be argued, however, that, given that both men and women found themselves in the same predicament, both sexes had equal opportunity to express curiosity and/or empathy and in so doing could have chosen to use a larger number of rise-falls and high falling tones. Henton observed that it is necessary to consider "the speech situation, the sex of the interviewer, the sexes of conversational dyads, ... and the topic/content of the speech before concluding that certain intonational patterns are more favoured by one sex than the other' (Henton 1995:47).

Other researchers have found that females use a greater variety of intonational tunes than males. This was so for students in Bristol (Elyan 1978), and for children in Swedish day schools (Fichtelius et al 1980). Women speakers of American English used more complex intonation patterns when interacting with a female interviewer (Edelsky 1979), hence Henton's comment above about 'listener-orientation adaptive pitch tuning'. This contrasts, however, with the finding that Pakeha women in New Zealand used more HRTs than Pakeha men, regardless of the gender or ethnicity of the listener (Bell \& Johnson 1997).

Before describing my own methodology I will refer briefly to two studies of the intonation of New Zealand English which used a very different approach. 


\subsubsection{Psycholinguistic/experimental methodology}

Vermillion (2003) used an experimental approach to the study of dialectal variation in English intonation. She examined the tonal cues which listeners use to distinguish one variety of English from another. In an investigation of the cues which New Zealanders use to distinguish New Zealand English from Southern British Standard English (RP) it was found that the relative pitch height of final phrase boundaries was significant. An adult male speaker of RP British English was asked to read aloud a statement 'as naturally as possible'. This sentence was then digitally manipulated in order to assess which intonational variations may be used by listeners to identify New Zealand English (Vermillion 2003:20). Thirty university students listened to different manipulations of the sentence and rated them according to the degree to which they sounded as though they were uttered by a speaker of New Zealand English or by a British English speaker. Where there were rising accents at the end of phrases, higher pitch peaks were associated with New Zealand English speakers and in the case of falling accents at the end of phrases, the lower the pitch fell, the more likely the listeners were to claim that a New Zealander was speaking. Results of a further perception experiment indicated New Zealand English has relatively high pitch values within intonation phrases compared with British English speakers, with the above mentioned marked departures to either low or high phrase final boundaries. A production study (Vermillion 2004) showed speakers of New Zealand English realising wider contours than British English speakers, regardless of position within the intonation phrase.

Psycholinguistic/experimental methodology was used by Zwartz and Warren (2003) in . their study of how New Zealand listeners perceive differences between questioning intonation and statement HRTs. They reported that listeners hear differences in the alignment and shape of rising contours which signal to them whether the rises function as questions or statements. Question rises tend to be characterised by quick early starts and statement rises by later starts and the rise continues to the endpoint of the contour. No significant gender difference was found in this study. This contrasts with the findings reported in the production study of Warren \& Daly (2000). (See Section 4.2.2.4.3). 
My review of the relevant literature on dialectology, regional variation in New Zealand English, intonational variation, and methodologies used in the comparison of varieties of English intonation is now complete.

I conclude by restating the research questions to which I sought answers and outlining my reasons for asking these particular questions.

\subsection{Research questions}

Sociolinguistic methodology, drawing on social network, geolinguistic and ethnographic theories seemed most appropriate for my purposes and sociolinguistic principles are reflected in the questions addressed.

\section{Question 1: Is there regional variation in New Zealand English intonation?}

The first of my questions focuses on my principal area of concern, whether or not regional variation in New Zealand English, aside from the Southland variety, exists. It arose from curiosity as to the basis of lay opinions concerning regional variation in New Zealand English (See Chapter 1 and Section 3.1).

That regional variation may be emergent seemed a reasonable assumption given that a homogeneous New Zealand variety of English has been in existence for at least three generations. Australia, settled by English speaking people approximately fifty years before New Zealand, showed traces of regional diversification in the way English was spoken some twenty years ago (Bradley 1989). Presumably these changes would have started somewhat earlier than this. This being the case, one could expect that New Zealand English might be ripe for the development of regional variation. And indeed, Bauer and Bauer have found evidence of regional variation in playground language (see Sections 2.2 and 3.4).

Question 2: Does Taranaki English possess intonational features which distinguish it from the English spoken in Wellington? 
The second question introduces the two regions selected for comparison. Taranaki was selected firstly because folk perceptions of the English spoken in the area, particularly the notion that Taranaki English is 'sing-songy', suggested there might be something unique about Taranaki English intonation. Secondly, the area's relative isolation from the rest of New Zealand may have allowed for the development of variation. Wellington was selected in part because of the availability of two existing corpora of spoken English. In addition it was thought that the speech of Wellingtonians might represent a standard for New Zealand English, given the city's status as administrative capital of New Zealand, thus providing a contrast for possible regional variation in Taranaki. It could be anticipated that Wellingtonians' intonation might be characterised as 'generally speaking rather flat' as per Bauer's description (L.Bauer 1994:391).

Question 3: Are there intonational differences in the English spoken by male and female speakers in Taranaki and Wellington?

This question focuses on possible gender differences in the intonation of speakers from the two regions. A variety of studies, using widely different methodologies, have demonstrated the existence of gender differences in intonation patterns (see Section 4.2.2) so consideration of possible gender differences was important. In addition, if evidence of language change were found, gender differences in intonation patterns needed to be considered, given the different contributions men and women have made in the area of language change. (See Section 2.4.3 for the significance of gender in language change).

Question 4: Is there any evidence of change over time in the intonation of speakers from Taranaki and Wellington?

If evidence of regional variation were found I wanted to know if the variation was a recent phenomenon or if it had existed in earlier generations, hence my fourth question concerning change over time, and my decision to compare the intonation of speakers from two widely separated age groups.

Question 5: Are there intonational differences between urban and rurally oriented speakers in Taranaki and Wellington? 
Many New Zealanders have rural connections and it would be wrong to assume that, because an individual lives in an urban setting in New Zealand, they will automatically be urban in their orientation. I believed that this would apply to New Plymouth dwellers in particular (see Section 2.6.1). This being the case, it might be said that any variation I found between Wellington and Taranaki speakers was in fact an urban versus rural difference, and not a truly regional difference. I was anxious, therefore, to gauge the extent to which speakers from all locations were rural or urban in their orientation, and to check whether particular intonation features correlated with rural or urban orientation. In this way authentically regional differences could be separated out from rural/urban differences.

In the next chapter I describe the means by which I sought answers to the research questions. 
This research project was designed according to sociolinguistic principles developed by Labov in the United States, Milroy and Milroy and Trudgill in Great Britain (Labov 1972a, b, c, Milroy \& Milroy 1985, L.Milroy 1980, Trudgill 1974,1983) and adopted and refined by many others since. Central to the sociolinguistic paradigm is the notion that linguistic variation is to be expected, and linguistic variation can be understood, at least in part, if the social context in which it occurs is considered. Using this method independent social variables are correlated with linguistic variables in order to reveal the underlying structure in what might appear to be an otherwise chaotic language situation. This chapter describes the methods I used to examine the associations between social factors and patterns of intonation in the speech of people in two regions of New Zealand.

\subsection{The sample}

The aim of my project was to seek evidence of possible regional variation in New Zealand English intonation and the research sample was designed with this goal in mind. I chose two very different regions for comparison - Taranaki, a predominantly rural area having one city, New Plymouth, and a scattering of small towns and Wellington, the capital city of New Zealand. Random sampling of these areas would not have been appropriate given that I wished to control for social factors such as ethnicity and socioeconomic class which, if ignored, could potentially bias apparent regional effects. I therefore chose to use a judgement sample where I identified in advance the types of speaker to be studied and sought a quota of speakers who would fit specified social categories.

\subsubsection{Sample size}

In order to control for the social variables I was interested in I needed samples of speech from a minimum of sixty speakers, these speakers being divided into twelve cells (described below), with five speakers per cell. Sixty speakers was not only a minimum, it was also a maximum number, given that I was to be the sole interviewer and analyser and there were financial and time constraints to be considered. (As things transpired I ended up conducting forty of the interviews myself, the remaining twenty interviews being divided between two other interviewers (see Section 5.3 below)). 
The size of the corpus is in line with sociolinguistic surveys of its type. Much larger samples are required for surveying other kinds of social behaviour such as dietary preferences or television watching habits but it has been argued that smaller samples are appropriate for linguistic analysis.

\begin{abstract}
'A speech community sample need not include the large number of individuals usually required for other kinds of behavioural surveys. If people within a speech community indeed understand each other with a high degree of efficiency, this tends to place a limit on the extent of possible variation, and imposes a regularity (necessary for effective communication) not found to the same extent in other kinds of social behaviour' (Sankoff 1980:51-52).
\end{abstract}

Trudgill interviewed and analysed the speech of sixty people in Norwich (Trudgill 1974), Milroy analysed data from sixty speakers having interviewed seventy three people in Belfast (L.Milroy 1980), and Holmes et al used a sample of seventy five speakers in Porirua (Holmes et al 1991). Eckert (2000) selected for analysis sixty nine speakers from a total sample of two hundred students at a suburban Detroit high school. Her approach to sampling was somewhat different in that she used an ethnographic methodology, spending two years as a participant observer in the school gaining an understanding of the social structures of the institution and an empathy with its students. Because of this she was able to construct a judgement sample based on 'local' categories as opposed to predetermined categories. The subjects themselves contributed to the identification of social categories she should investigate, categorising themselves as either 'Burnouts' or 'Jocks' on the basis of their opposing ideologies and styles. 'Rather than testing hypotheses against predetermined categories, ethnography is, among other things, a search for local categories. Thus while survey fieldwork focuses on filling in a sample, ethnographic fieldwork focuses on finding what is worth sampling' (Eckert 2000:69). This level of participant observation was impractical for the present study. However my status as a semi-insider in Taranaki and an insider in Wellington (see Sections 5.4 and 5.5) compensated to some degree. It enabled me to locate potential subjects to fill my sample categories with relative ease and it certainly helped in the interviewing process.

Five persons per sample cell is generally considered an adequate number for sociolinguistic analysis provided the researcher defines the cells in terms of carefully considered local social categories (Feagin 2002:29). The nature of the analysis I undertook (see Section 5.9) precluded larger cells. 


\subsubsection{Composition of the sample}

In order to explore the question of whether speakers in Taranaki and Wellington had differing patterns of intonation, I constructed a sample which allowed for comparison across three social parameters: location, age and gender. I endeavoured to keep ethnicity and socioeconomic class stable for reasons to be discussed. In addition I was anxious to avoid confusion between possible regional differences and rural versus urban variation. To help clarify this situation speakers were rated according to a rural orientation index (see Section 5.2 below) so that their orientation scores could be correlated with linguistic trends. The rural orientation index was not used in determining the sample. It was employed in post hoc analysis. The selection of speakers was based on a combination of traditional demographic categories and on social network theory. The sample design is summarised in Table 5.1 below.

\begin{tabular}{|c|c|c|c|c|}
\hline & $\begin{array}{c}\text { South } \\
\text { Taranaki }\end{array}$ & New Plymouth & Wellington & Totals \\
\hline Old Males & 5 & 5 & 5 & 15 \\
\hline Old Females & 5 & 5 & 5 & 15 \\
\hline Young Males & 5 & 5 & 5 & 15 \\
\hline Young Females & 5 & 5 & 5 & 15 \\
\hline Totals & 20 & 20 & 20 & 60 \\
\hline
\end{tabular}

Table 5.1. The sample

\subsubsection{Location}

I selected for examination two Taranaki communities and Wellington was chosen to provide a regional contrast with these communities. The two Taranaki communities were New Plymouth, a coastal city to the west of Mount Egmont/Taranaki with a population of 50,000 , and the dairy farming community of South Taranaki centred around Opunake, a small rural centre on the South Coast of Taranaki. Wellington speakers were scattered throughout Greater Wellington from Porirua in the north to Lyall Bay in the south. 


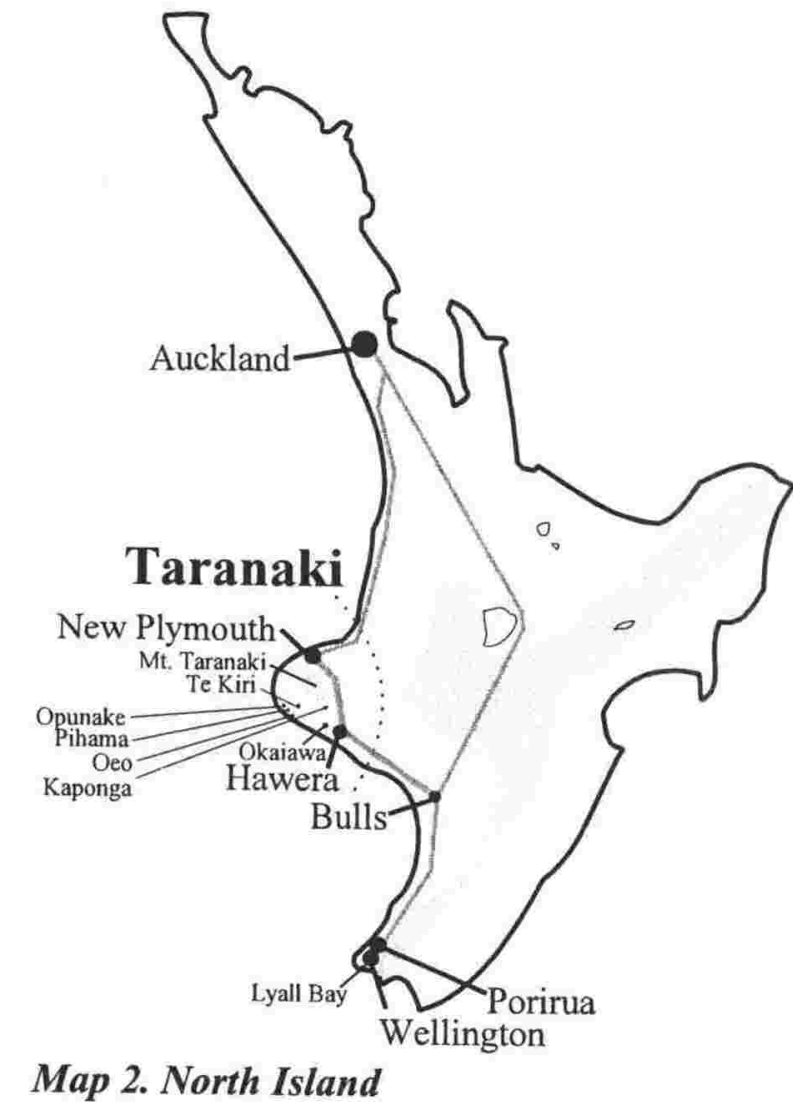

The communities were selected to enable me to explore possible geographic diffusion of intonational pitch patterns (see Section 2.5). New Plymouth is 355 $\mathrm{km}$ distant from Wellington. The two cities are joined by Highway 1 from Wellington to Bulls and Highway 3 from Bulls to New Plymouth. Opunake, the centre of the rural South Taranaki dairy farming district I surveyed, is $62 \mathrm{~km}$ of very winding, narrow road from New Plymouth on Highway 45 south of the mountain, or $115 \mathrm{~km}$ from New Plymouth via Hawera and Highway 3.

If there is a change in progress with regard to particular pitch patterns in New Zealand English intonation, the size of community populations may be a factor in determining the progress of the shift. It may be spreading via hierarchical diffusion. Callary (1975) and Trudgill (1983) say that hierarchical diffusion occurs where linguistic innovations begin in large population centres and then trickle down to centres with smaller populations. According to this scenario, speakers in Wellington and other larger cities in New Zealand would be most likely to display innovative intonation patterns. These patterns would be less evident in New Plymouth and least evident in the dairy farming community around Opunake.

Criteria for selection of speakers for the location cells were (1) they had been born in the location or they had moved there before the age of ten, (2) they still lived in the location and (3) they had spent at least $75 \%$ of their life in the location.

Most speakers selected for the Taranaki location cells were second, if not third or more generation Taranakians. At least one subject had ancestors who came to New Plymouth on one of the original six boats of the Plymouth Company which brought settlers from the 
South-West of England to Taranaki in the early 1840's. Most of the Wellington sample were also at least second generation Wellingtonians.

It is unlikely that physical location and population size alone will explain linguistic variation so other social factors were also explored.

\subsubsection{Age}

An important aspect of the present study was the investigation of possible language change in progress over time. Study of differences in the speech of people from different age groups can be used to make diachronic inferences about language change. This model is known as the 'apparent-time' model of language change. It 'rests on the assumption that the dialect a speaker learns as a child will remain with that speaker for life. Thus, other things being equal (eg. social class or dialect contact), differences among generations of adults will mirror actual diachronic developments in language. From this perspective, the speech of each generation is assumed to reflect the language as it existed at the time when that generation learned the language' (Wolfram et al 1999:8).

The speakers in the present study were taken from two widely separated age groups in order to examine the inter-generational differences expected of change in progress - young adults aged 20 - 35 and older people aged 70 years and over. Young adults, having moved away from childhood and the adolescent years in which age-grading of speech patterns is most likely, are at the stage where they establish personal preferences, including preferences in styles of speech which will, in all likelihood, remain relatively stable throughout their adult years. The older cohort could be expected to display the speech patterns they developed during the corresponding stage of their own lives. There are, however, as far as I know, no longitudinal studies which demonstrate that pitch patterns stay with speakers for life. Given the finding of Harrington et al (2000:927) that Queen Elizabeth II's pronunciation of some vowels has changed over her lifetime, it may well be that pitch patterns too do not remain constant. The assumption behind apparent time studies needs to be treated with due caution. 


\subsubsection{Gender}

In addition to age I was interested in the relationship between intonation patterns and gender. For the purposes of this study I assumed a simple correlation between gender, which is a cultural construct, and the biological sex of the speakers concerned, although I acknowledge that the two do not necessarily map directly on to each other. (See Sections 2.4.3 and 2.7 for discussion of gender as a sociolinguistic variable and as a cultural construct).

Comparison of the intonation of women and men was important for two reasons. Firstly, variation between women's and men's intonation patterns has frequently been described and analysed in the literature. For example, there are differences in pitch range (for American English, see Childers and Wu 1991; for British English, see Woods 1992; for New Zealand English, see Daly \& Warren 2001); in pitch dynamism (Daly \& Warren 2001); in percentage rate of HRT usage (for Australian English, see Guy et al 1986; for New Zealand English, see Britain 1992); in the size and rate of pitch rises, and their alignment against segmental aspects of utterances (Warren \& Daly 2000) (for more detail see Section 4.2.2). On the basis of these findings, I expected to find differences between the intonation patterns of women and men in the present project. Ignoring speaker gender as a factor could distort the description of the intonation patterns of the regions being examined. Secondly, it has been found that linguistic differences between women and men are important in understanding the process of language change. In numerous studies women have been reported as leading men in the use of innovative speech forms (Labov 1990, Holmes 1997b) (for more detail see Section 2.4.3). If there should be evidence of language change in the regions studied, examination of gender contrast could be useful in interpreting such change.

\subsubsection{Ethnicity}

Ethnicity is another social category which is prominent in variationist research. Ethnicity, like gender, is socially constructed. It is 'not about what one $i s$, but rather about what one does' (Fought 2002:444) and it 'is a subjective rather than an objective matter, and consequently difficult to quantify' (Boyce 1992:24). For this reason participants in my 
research project self-selected their ethnicity and in every case they identified as Pakeha (or European) New Zealanders.

Maori English is a variety of New Zealand English which has received considerable attention in the literature in recent years (Benton 1985, 1991; King 1993; Holmes 1997a; Warren \& Bauer 2004). It is distinguished by particular features of vocabulary, syntax and pronunciation (see Section 2.4.2). It has been demonstrated that exposure to the Maori language has some influence on the way that Maori New Zealanders speak English (Holmes 1997a). As the focus of my project was regional variation it was important that, as far as possible, I avoid possible confusion with ethnic, in this case, Maori, variation. The sample was therefore restricted to Pakeha New Zealanders who had had very little exposure to the Maori language.

\subsubsection{Social class}

Social class is another speaker variable commonly examined in sociolinguistic studies and it has proved highly productive from the time of the early work of Labov in New York (1966), to Trudgill's research in Norwich (1974) and in numerous other studies up to the present day (eg. Horvath 1985, Labov 1990, Haeri 1997). Social class as a concept has proven problematic however. It has been described as 'inherently fuzzy' (Chambers 2003:41), a description which is particularly apt for the situation as it pertains to New Zealand where occupational mobility is common. Middle-aged male doctors are likely to have worked in freezing works and shearing gangs to finance their medical studies, while it is not impossible for a housewife with a good idea, entrepreneurial flair and drive to become CEO of a major company. Higher education is regarded as desirable but it does not guarantee a high paying, high status job. Ash (2002) rightly says that tailoring the notion of social class to the particular community under study is important.

'If the researcher is truly engaged in the community, if he or she has talked and listened to its members enough to visit in their homes, to ask about their families, to know what topics are of burning local interest and concern, then he or she will learn how the members of the community regard each other and will tailor the formulation of all social variables to describe the community in its own terms' (Ash 2002:420). 
Eckert's (2000) ethnographic approach to the study of the speech of adolescents in a suburban high school in Detroit is a case in point. In this study students divided themselves into two fundamentally opposed social groups, Jocks and Burnouts (see Section 2.7.1). The Jocks were oriented towards middle class preoccupations and the Burnouts to working class ones.

'These contrasting orientations are displayed in everyday social practices such as dress, adornment, demeanor, use of leisure time and preferred hangout places, and the adolescents make use of the rich symbolic resource offered by language variability to construct styles which situate them socially in relation to others in the high school between the polar values of jocks and burnouts' (Milroy \& Gordon 2003:98).

Traditionally sociolinguistic survey studies have employed indices of socioeconomic status based on factors such as income, occupation, level of education, type of dwelling, residential area and father's occupation. Factors may be weighted depending on the researcher's view of their relative importance as indicators of the social class system in the community being studied. In New Zealand studies speakers have generally been allocated to one of two classes depending on whether they attended a state school or a private school (Gordon \& Maclagan 1990), and on the basis of occupation and level of education (Holmes et al 1991, Maclagan \& Gordon 1999). Bayard (1991) placed people on a social class continuum from 3 at the lower end to 13 at the upper end. Placement on the continuum depended on occupation, level of education and amount of private/boarding schooling.

Most New Zealand sociolinguistic researchers have utilised the Elley-Irving Scale index of male occupations (Elley and Irving 1972,1985) and the Irving-Elley index of female occupations (Irving and Elley 1977). Occupations were classified into six levels according to an equal weighting of income and educational level and were last revised using data from the 1981 census. A more complex method was used in the construction of the New Zealand Socio-economic Index-1996 of Occupational Status (NZSEI-96) (Davis et al 2003). It is based on 1996 census data and it updates and revises the New Zealand Socioeconomic Index of Occupational Status-1991 (NZSEI-91). Values for the occupations in the 1991 index equated to 'an optimally-weighted combination of income and educational variables, corrected for age, based on the assumptions of the model (ie. minimising the strength of the direct education-income link). These values represented 
occupational SES (socio-economic status) scores, which were finally scaled on a continuum from 10 - 90 to yield the NZSEI-91'. The scale was divided into six groups (level 1 being the highest status group and level 6 the lowest) in part to enable comparisons with the Elley-Irving socio-economic scale. Adjustments were made to the construction of the scale in the revised NZSEI-96 so that part-time workers could be incorporated, and index scores were adjusted to allow for the tendency of self-employed workers to understate their income. The relationship between income and expenditure on food for self-employed workers was compared with that for waged employees assuming that both the self-employed and employees would correctly report their food expenditure. The calculated ratios of expenditure to income were higher for self-employed individuals (with the exception of the group classified as professionals) than for waged individuals and the incomes of the self-employed were adjusted upwards accordingly. The adjustment affected agricultural workers in particular, moving them from level 5 on the scale to level 4.

In the present study I was anxious to avoid confusion of social class variation, which has been shown to exist in New Zealand English (Gordon \& Maclagan 1990, Holmes et al 1991, Bayard 1991, Batterham 1995), with regional variation, so I attempted to keep social class as stable as possible. In order to do so I checked the occupations of interviewees against the NZSEI-96 scale of occupational status. I elected to use occupation as a measure of social class because 'there is substantive evidence that supports the idea that an individual's position within the labour market is a key determinant of life chances, access to rewards and quality of life' (Rose 1995, cited in Galbraith et al 2003:18). It is also more socially acceptable to ask people about their work than it is to ask about other factors which might be relevant to their social status such as income. I chose this particular scale because (1) it is based on 1996 census material and most of the interviews for my research took place in the late 1990's, (2) 'it looks at how education translates into income via occupation' making allowances for age (Galbraith et al 2003:20), and (3) because it makes adjustments for part-time and self-employed workers. Given that a substantial number of my interviewees were self-employed this was important.

A social network technique was employed for the recruitment of participants (see Section 5.4). An advantage of this technique was that it worked well in keeping the variable of 
socio-economic status reasonably constant. The social networks of speakers tended to consist of others of comparable status and lifestyles. This was particularly so in the case of the rural cells, male and female, old and young, who were a notably homogeneous group. As farmers they were all on level 4 of the NZSEI. When the entire sample of sixty speakers was considered the mode occupational level was 4 , with the mean and median levels 4.5. The Wellington cells tended towards the more working class end of the scale, ie. occupational levels 5 and 6 , although the Wellington young men were more mixed with two men at level 3, a policeman and a psychiatric nurse. The New Plymouth samples were more heterogeneous with occupations ranging from level 2 to level 6 . The young women in particular were skewed towards the middle-class end of the scale. This cell consisted of two accountants (level 2), a florist running her own business (level 3), a nurse (level 3) and a polytechnic student who aspired to be a police officer (level 3). The fact that some of the New Plymouth sample tended towards the middle-class end of the scale is perhaps not surprising given that I had lived in New Plymouth, I would classify myself as middle-class, my friends were mostly middle-class, and these friends were my initial contacts who introduced me to people within their social circles. It was necessary to keep this bias in mind when variation in intonation was analysed.

Figure 5.1 shows the distribution of NZSEI scores among the participants in the three locations. 


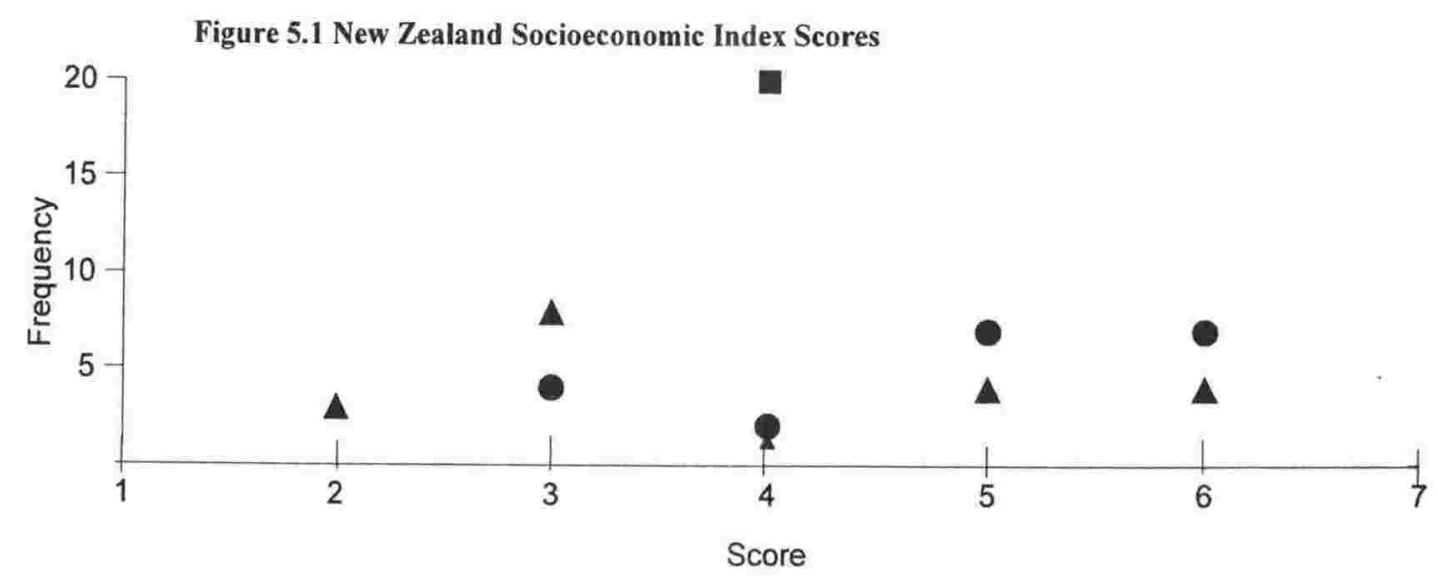

South Taranaki A New Plymouth Wellington

\begin{tabular}{|c|c|c|c|c|c|c|c|}
\hline NZEI Score & 1 & 2 & 3 & 4 & 5 & 6 & 7 \\
\hline South Taranaki & & & & 20 & & & \\
\hline New Plymouth & & 3 & 8 & 1 & 4 & 4 & \\
\hline Wellington & & & 4 & 2 & 7 & 7 & \\
\hline
\end{tabular}

\subsection{Rural Orientation Index}

I noted in Section 2.6.1 some of the changes which have taken place in rural Taranaki in recent years which have brought country people into closer contact with urban influences. Disentangling urban and rural threads in Taranaki was an issue for the research and I concluded that a social network approach could help separate participants with a more urban bent from those who had a distinctly rural orientation. This was an important distinction to make as I wished to avoid confusion between urban versus rural differences and possible regional variation.

I devised a network index which reflected the kinds of people a person interacted with, so that I could test assumptions about how an individual's linguistic behaviour would be constrained and shaped by their social contacts. I selected parameters for the index on the basis of what I knew about the areas concerned, and the people who lived there, from personal experience and from discussion with others who knew the areas intimately. The chosen parameters were: 
- residence

- $\quad$ kin

- occupation

- voluntary association

- schooling

- $\quad$ commercial transactions

Each of these had been adopted successfully by other researchers in other contexts in other parts of the world (see Section 2.6), but the weighting and detail of the criteria for the parameters were designed with local contexts in mind.

The criteria for each of the parameters are given below. Points were scored for each criterion as shown. Points could be scored for more than one criterion per parameter up to the limit stated. A participant scoring 0 points in total would be entirely urban in orientation and someone with 14 points would have maximally rural orientation.

Parameter 1: Residence. Range: 0 - 2.

Points and criteria:

(1) Informant currently lives on a farm or in a small rural community.

Pihama, Okaiawa, Oeo and Te Kiri in South Taranaki are typical of such communities. They consist of a handful of shops and businesses whose function it is to service the surrounding countryside.

(1) Informant has always lived on a farm or in a small rural community. This is based on the premise that residence in a rural community is necessary for integration into that community and the longer you live in a community the greater the pressure to conform to its social norms, including its speech norms.

(1) Informant lived on a farm until retirement.

Retired farmers who now lived in town scored a point because, not only had they spent the bulk of their lives on the farm, they still spent time on the farm which in most cases their sons and/or nephews were now working.

(.5) Informant has lived on a farm at some point in their life. Some inhabitants of New Plymouth had either lived on farms as children or were employed on farms at some point in their younger years. 
(.5) Informant has definite plans to live in the country in the future.

A small number of young people resident in New Plymouth expressed interest in living in the country at some stage in the future. They were given half a point if they had a stated goal for living in the country.

Parameter 2: Kinship. Range: 0 - 2.

Points and criteria:

(1) Informant's partner/spouse was brought up on a farm or in a small rural community.

(1) Members of the informant's extended family live on a farm or in a small rural community.

(.5) Member(s) of extended family has/have lived on a farm.

Parameter 3: Occupation. Range: 0 - 2.

Points and criteria:

(1) Informant is a farmer.

'Farmer' included farm owners who farm their own land, farm managers who farm someone else's land and sharemilkers (a sharemilker being a person who works another's dairy farm for a share of the profits, and who sometimes owns a herd of cows).

(1) Informant is a retired farmer.

'Retired' farmers in my sample had not stopped being farmers. Each of them had sons or nephews running the family business and the old farmers helped out on the farm as and when they could. In at least two cases this meant daily involvement.

(1) Informant is at least a second generation farmer.

The rural ethic will have been passed down through successive generations making it difficult for the individual to break from tradition.

Parameter 4: Voluntary association. Range 0 - 4.

Points and criteria:

(1) Most of informant's friends live in country.

(1 per activity, max.3) Informant is active in rural associations, clubs, sports, church. 
Voluntary association was heavily weighted because subjects were most likely to accommodate their speech to the speech of those they chose to mix with. A rurally oriented person would tend to have friends who lived in the country and would choose to participate in rural activities and join rural groups.

Parameter 5. Schooling. Range $0-2$.

Points and criteria:

(2) Informant was educated entirely in the country.

(1) Informant was educated partially in the country.

Most subjects in the South Taranaki rural sample were educated entirely in the country but two of the old men had had their primary schooling in small country schools and then went on to boarding school in town for their secondary schooling. One of them boarded at a Catholic school in Wellington because at the time there was no Catholic secondary school for boys in Taranaki. He told me he was one of about sixty boys from Taranaki. The pupils at the boarding school were a mixture of urban and rural boys. One might expect therefore that the rural peer influence would be diluted, hence the lower rural score. All subjects attended school. None lived so far from a school that they had to be educated by correspondence.

Parameter 6. Commercial transactions. Range 0 - 2 .

Points and criteria:

(1) Informant goes to a small rural town to conduct the bulk of their commercial transactions and to do their shopping.

(1) Informant goes to a small rural town once a week or more.

Subjects who lived on farms were asked which town they went to to conduct commercial transactions and do their shopping. If by 'town' they meant a small Taranaki rural town such as Opunake, they scored a point. If they went to a town like this once a week or more they scored another point. On the other hand, if by 'town' they meant New Plymouth, no points were scored, the implication being that the more one mixes with people of one's own kind, the more likely it is that one will speak like them. Subjects living in New Plymouth or Wellington scored no points as the bulk of their transactions took place in the city. 
Figure 5.2 shows the orientation scores of each speaker along the continuum of extremely urban to extremely rural orientation. The Wellington and New Plymouth groups display similar distributions at the urban end of the scale, ranging from 0 to 6 while, with the exception of one outlier, the South Taranaki sample has scores ranging from 10 to 14 . 


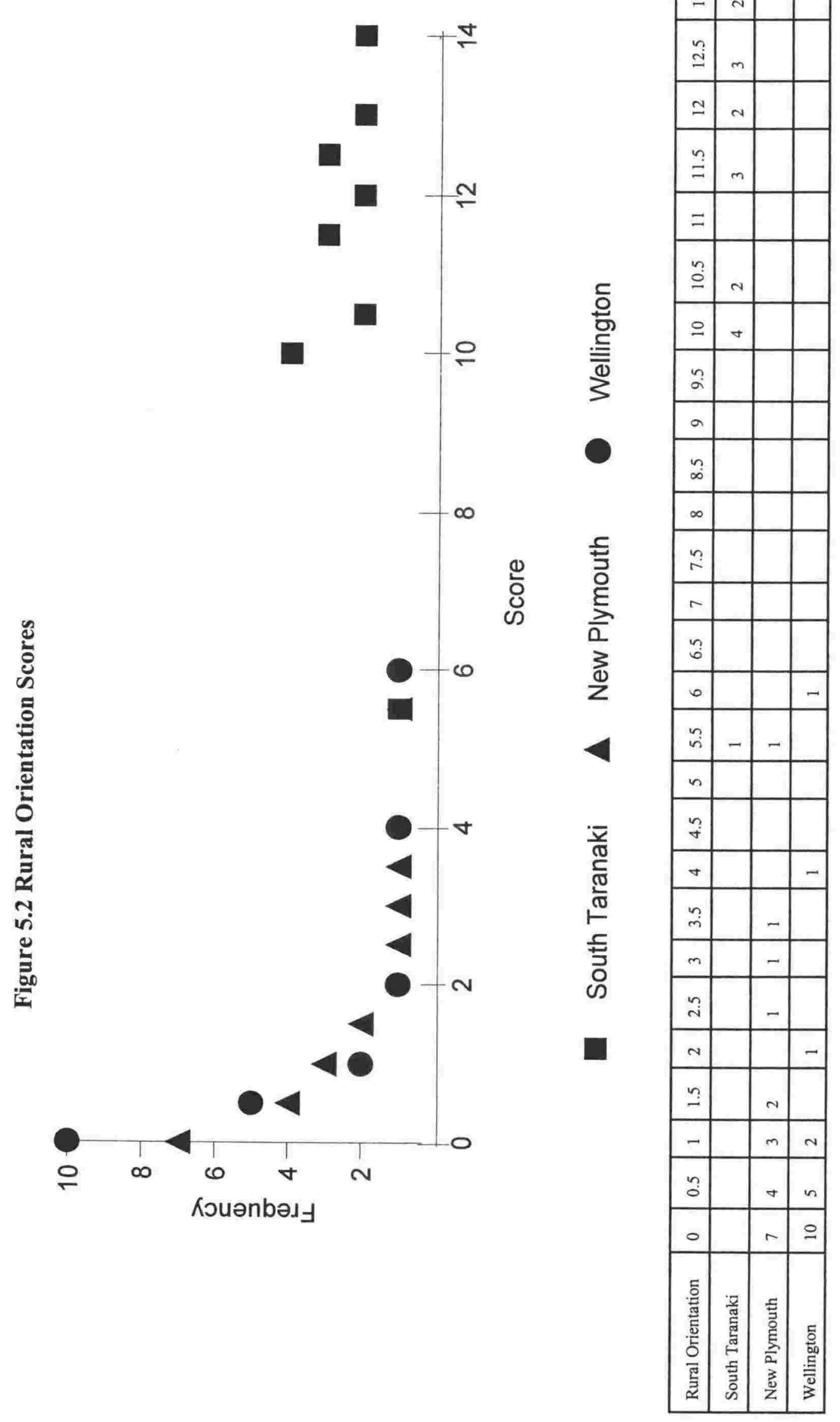




\subsection{The corpora}

I decided to use data from three corpora of spoken New Zealand English collected for three separate projects. This was largely because of the practical issues of the size of the database needed for my project (samples from sixty speakers) and the existence of time constraints. It was fortunate that excellent material had already been collected (1) for the sociolinguistic survey of the Porirua community conducted by Holmes, Bell and Boyce in the early 1990's and (2) for an oral history project entitled 'Coastal Voices of New Zealand' recorded by Dinah Priestley in the mid- to late 1990's.

\subsubsection{The Porirua Corpus}

Speech samples from ten women, five young and five elderly, from the Porirua corpus were included in my Wellington sample. Although technically a separate city from Wellington, Porirua forms part of the greater Wellington region. In addition to this, several of the Porirua women worked or had worked in Wellington city. These women were therefore considered suitable for my Wellington sample.

\subsubsection{The Oral History Corpus}

Speech samples from five elderly Wellington men and four of the elderly Taranaki rural women were obtained from the Oral History Archives of the Turnbull Library. This material was collected by Dinah Priestley for her oral history project on the Coastal Voices of New Zealand.

\subsubsection{The Taranaki Corpus}

The bulk of the material was collected by me over four years from 1998 to 2001 . This included all the Taranaki cells, excepting the four Taranaki rural elderly women mentioned above. It took a long time to collect this material as it required many weekend expeditions to Taranaki which is six hours drive away from Wellington where I live. I also recorded the speech of five young Wellington men. 


\subsection{Locating and contacting speakers}

Making contact with people and asking them to participate in sociolinguistic surveys can be a daunting prospect. The task can be eased, however, by utilising the social networks of study participants, using the technique variously known as the 'friend of a friend' or 'snowball' approach to data collection as advocated and adopted by Milroy and Milroy in their study of working-class communities in Belfast (L.Milroy 1980, Milroy \& Milroy 1985).

L.Milroy gained access to Belfast communities by using the status of a friend of a friend, introducing herself through mutually known individuals and entering networks of kith and kin. In this way she was successful in obtaining large quantities of relaxed, vernacular speech.

In a study of the speech patterns of rural migrants in the city of Bergen, Norway, Kerswill (1994) followed L.Milroy's procedure for obtaining contacts and was similarly successful. He wrote of his experience, 'The efficacy of the 'friends of a friend' method was striking. Once I had made the initial contacts, I mentioned these contacts when approaching people whose names I had been given. In almost every case, I received enthusiastic co-operation and cordial hospitality. In many cases, I was clearly regarded as a friend of a friend, even though my identity and purpose were known' (Kerswill 1994:66). He achieved these contacts after arranging to meet the chairperson of one of the rural migrant societies at one of their weekly folk-dance meetings. On that evening he arranged to meet with eight volunteers. After interviewing these people he interviewed sixteen more people who were friends or relatives of the earlier volunteers (Kerswill 1994:65).

An individual has 'first-order' contacts with whom they have direct contact. Each of the people in the first-order zone may be in contact with others whom the individual does not know, but with whom he or she could potentially come into contact via the people in the first-order zone. These more distantly connected people are 'friends of friends' or people in the individual's 'second-order' social network zone. 'Friends of friends' are extremely important people in most societies (Milroy 1980). According to the theory of 
exchange propounded by Boissevain (1974) the 'friend of a friend' relationship is thought to set up mutual rights and obligations. I chose to adopt the 'friend of a friend'. approach in obtaining survey subjects in the hope that I would find, as Kerswill did, that 'people would be more likely to agree to be recorded because of their obligation to our mutual contact, who would also act as a guarantor of my good faith' (Kerswill 1994:65).

In Taranaki I applied the methodology as follows. I talked initially to an assortment of contacts in the New Plymouth and rural South Taranaki regions and these people in turn put me in touch with their first order networks. My initial contacts were old friends from my years spent in New Plymouth, more recently acquired friends in South Taranaki and colleagues and students at Victoria University who hail from Taranaki. Having explained the aims of my project to them, my contacts, or network gatekeepers, gave me the names of family and friends who fitted the required social criteria and who might be able to help me. In some cases the gatekeepers contacted potential subjects for me and then let me know whether or not they were willing to help and, in other cases, I contacted the people myself, letting them know I was a friend of their friend or relative and seeking their consent to be interviewed. Very often, after a successful interview, subjects would give me the names of further friends and family members who could be interviewed. I found that subjects who were initially rather diffident about taking part in the project could have their anxieties alleviated by talking to their friend who had been interviewed previously.

The same procedure was followed for contacting the Wellington young men. Three of this group were already well known to me and my extended family put me in touch with the two additional people needed to fill the cell.

The benefits of the 'friend of a friend' approach cannot be overstated. One participant confided in me after a successful recording session, 'I would never have agreed to do this you know if G... (her uncle and my friend) hadn't talked to me first'. Another subject, much relieved, said afterwards, 'It's just like chatting with a friend really'. And indeed, that is exactly how it often felt for me. 
I was fortunate in managing to tap into a dense network of young friends in rural South Taranaki. Seven of the ten young people in the location sample were well known to each other. I needed more 'gate keepers' in New Plymouth to find the required number of subjects and fewer of the gate keepers' first order contacts knew each other. The methodology used led me to social networks which reflected the difference between the looser knit social networks typical of urban dwellers and the closer networks of rural New Zealand.

My first contact with potential speakers was usually via telephone although occasionally I had already met the person and talked to them. The 'friend of a friend' approach to filling my judgement sample meant that typically people were expecting a call from me and they had already been briefed about the nature of my project by their friend or relative whom I had interviewed previously. I was always honest about what the project involved. I would tell them I was interested in how people spoke in different parts of New Zealand, with a particular interest in the Taranaki and Wellington areas. I refrained, however, from telling them that my principle focus was intonation as I did not want them to become self conscious about this aspect of their speech.

\subsection{The interviewer}

The personal characteristics of the interviewer or interviewers are important when considering how to overcome the constraints inherent in a tape-recorded interview with a relative or complete stranger.

Saville-Troike (1986:111-112) maintains that, 'It is likely that only a researcher who shares, or comes to share, the intuitions of the speech community under study will be able to accurately describe the socially shared base which accounts in large part for the dynamics of communicative interaction'.

Many researchers have opted to use several interviewers in order to broaden the range of language available for study. Milroy cites Douglas-Cowie's study in 1978 of a Northern Irish village community which, 'demonstrated quite clearly the differences between the language addressed to an Ulster-Scots insider and an English outsider' and Viv Edwards 
who, in 1986, found, 'dramatically different patterns, depending on whether the fieldworker is black or white' (Milroy 1987a:64). A controlled experiment which included sociolinguistic interviews of an African-American teenager by an AfricanAmerican adult interviewer and a white adult interviewer resulted in the interviewee using a significantly greater percentage of African American Vernacular English features in the interview with the African American fieldworker (Rickford \&McNairKnox 1994). The researchers concluded that in their experiment 'style shifting [was] primarily a function of the race of the interviewer(s)' (Rickford \& McNair-Knox 1994:259).

For their social dialect investigation of language variation in the Porirua community, Holmes, Bell and Boyce employed four interviewers who lived, or had lived, in Porirua. Not only did the Porirua survey interviewers have community insider status, they were also matched with their interviewees for ethnicity and sex, the idea being to encourage relaxed, free running conversation and to avoid possible variation caused by crossethnic or cross-sex interviews (Holmes et al1991:40).

However, as Milroy observes, 'The best solution is not necessarily ... socially matching fieldworkers to subjects' (Milroy 1987a:81). In some communities attitudes to males and females need to be taken into account. Milroy describes the situation pertaining in her study of language variation in Belfast communities. 'The fieldworker had to be a woman. Women were much less likely to be attacked than men, and since male strangers were at that time viewed with considerable suspicion in many parts of Belfast, they were likely to be in some danger if they visited one place over a protracted period' (Milroy 1987b:44). A similar situation existed in inner-city Detroit when Walter F. Edwards was studying African American English. 'A householder in the area was much more likely to let a strange woman into his or her house than a strange male' (Edwards 1992:113). Edwards hired four females as interviewers, but only one proved to be very successful. She was 'remarkably fearless about working in the area and very obviously enjoyed conducting interviews' (Edwards 1992:113).

Wolfram and Schilling-Estes observe that, 'outsiders may also possess the personal characteristics that help make a person a good fieldworker. Thus, it is often the case that 
people with empathetic, non-threatening conversational styles end up getting better interviews than field workers who are carefully selected to match the status, age and gender characteristics of the interviewee' (Wolfram \& Schilling-Estes, 1998:244).

Having considered all of the above I decided I would examine the advantages of using one person, namely myself, as the single interviewer for most of the data collection in Taranaki and Wellington (ie. except for four interviews by Dinah Priestley and the ten Porirua Corpus interviews).

Had I opted to employ interviewers who matched subjects in terms of age, sex, ethnicity and home location, I would have needed a team of twelve interviewers all of whom would have required careful vetting for their ability to listen and encourage relaxed and natural conversation. Training in interviewing techniques would also have been necessary. This would have been a massive, time consuming and expensive undertaking with no guarantee that all interviewers would be equally effective.

Disadvantages in doing the interviewing myself might seem equally daunting. I could be classified as a middle-aged, middle-class, city dwelling woman having very little in common with either of the age groups to be interviewed (young adults and the elderly) or either of the Taranaki groups (New Plymouth and rural South Taranaki), although I shared the same Pakeha ethnicity as all the interviewees.

Having a single interviewer had the advantage, however, that the social situation in all the interviews was be consistent. I also had some historical background to give me an entry point to conversation with people in Taranaki. I had spent seven years of my early adulthood living in New Plymouth and I had had rural experience holidaying with farming relatives. In addition to this it seemed highly likely that a middle-aged woman would be considered non-threatening by both young and old, and male and female subjects.

In fact my semi-insider, semi-outsider status proved to be rather useful. My seven years in Taranaki gave me a genuine interest in the affairs of the region and it also gave me a degree of credibility amongst the locals. I was not seen as just another nosy parker 
university person. As someone who had returned to the area after some years away it seemed natural to be asking the sort of things I was asking and subjects responded generously.

My status as a Wellingtonian helped in the interviewing of the Wellington young men as did the fact that I already knew three of them well.

Dinah Priestley was the sole interviewer for her oral history project. She, like me, could be classified as a middle-aged, middle-class, Pakeha Wellingtonian. She is an experienced and highly competent interviewer. She approached her interviews in similar fashion to the Porirua field workers and myself.

The ten interviews which I selected for analysis from the Porirua survey were conducted by a young woman who was resident in the area. She was matched in age with the five young women interviewed but not with the five elderly women.

\subsection{Recording interviewees}

In most cases interviews were conducted in subjects' own homes, the idea being to minimise inconvenience to subjects and maximise the chances of relaxed, conversational speech, approximating as closely as possible the vernacular. I tried to do the recording in spaces where there were plenty of soft furnishings in order to reduce the likelihood of echo. Unfortunately this was not always possible. On occasion I recorded people at their place of work, in one instance in the office of a funeral parlour and in another in a room designed for patient interviews. In both cases the offices used were minimally furnished.

In most cases I conducted interviews in one sitting of sixty to ninety minutes duration. The advantage of making more than one visit was brought home to me, however, on the one occasion when I made a return visit. Half way through the first recording session the tape recorder failed. When I returned the next week with a replacement recorder the young woman being interviewed was noticeably more relaxed and conversation flowed easily. The fact that I had made a return trip to Taranaki from Wellington expressly to 
see her may have impressed her. She was also more familiar with me and the notion of being recorded. Unfortunately time constraints and distance meant I was unable to spend more time getting to know most of the interviewees. However, in spite of all the problems inherent in interviewing and tape recording people who were for the most part strangers to me, I managed to collect a substantial corpus of material suitable for prosodic analysis. A handful of Taranaki participants requested copies of their tapes such was their enthusiasm for the project. One elderly man wanted to keep a record of stories he had told me for his grandchildren and great grandchildren. A young woman was astounded at some of the things her partner had told me, ('You never told me about that!') and the couple wanted a record of it.

Wolfram (personal communication) recommended to me the practice of having three people present during an interview, thus altering the dynamics of the one-on-one interview where two strangers talking face to face could feel awkward. In the research which Wolfram conducted in North Carolina, pairs of interviewers were used (Wolfram, Hazen \& Schilling-Estes 1999). Advantages in doing this are that 'fieldworkers can work together to keep the discussion going; and there are fewer lulls in the conversation when one fieldworker needs to look at notes for the new questions. Also one fieldworker can monitor the recording equipment which is often a distraction in one-toone interviews' (Milroy \& Gordon 2003:66). For practical reasons I was the sole fieldworker in the interviews I conducted in Taranaki and Wellington, there was only one interviewer in the Porirua Survey interviews, and Dinah Priestley conducted her own recordings for her oral history project. However in several cases a third person, usually a partner or child, was present during recording in Taranaki and in some cases, in Porirua. I was told by a friend in Taranaki that one particular elderly woman whom I hoped to interview, was probably too shy to be recorded unless her husband could be present, so I interviewed them together. This was a very satisfactory arrangement with both partners coaxing and helping each other and, I think, enjoying the experience. On the whole, the presence of a third party tended to make the subject feel more secure and consequently relaxed, resulting in more casual sounding conversation. The disadvantages of occasional interruptions or extraneous noises off were therefore outweighed. There was, however, one exception. One young woman said she felt intimidated by her husband's presence and she asked him to 'Please go away!' 
Sensitivity to the dynamics of individual relationships is called for in the interviewer. I do not believe that the fact that, in some interviews, a third party was present, resulted in hugely variable data. The presence of a third person helped in situations where an interviewee was very reserved, while for most interviewees the presence of another person was not necessary for the encouragement of fluent conversation.

Much as I tried to keep extraneous sounds to a minimum there were many noises over which I had little or no control including: cicadas in late summer, the squawking of pet budgies, dogs barking, lawn mowers, washing machines, traffic noise, trains, a fork lift driving past the window, toddlers chatting and singing, chiming clocks (very common) and the ubiquitous telephone ringing.

A Sony professional WM-D6C walkman cassette recorder was used for recording in conjunction with a lapel microphone. Most people managed to ignore the presence of the microphone to the extent that they forgot it was attached to them if they were called away to answer the telephone or door. Some subjects had a tendency to absentmindedly fiddle with the cord as they talked but this does not appear to have adversely effected the sound quality of the recordings.

\subsection{Ethical considerations}

The University's Human Ethics Committee required that permission be obtained from participants before any recording was undertaken. Everyone was therefore asked to sign a form giving consent to be recorded and for the taped material to be placed in the Wellington Archive of Spoken New Zealand English for the use of linguistic researchers (see Appendix 1). I reassured participants before I began recording that their identity would be kept confidential and their name would not be attached to either tape recordings or transcripts. These would be identifiable by code only. Participants were also asked if they would like to receive a summary of my findings.

Similar permission had been obtained from Porirua project participants at the time of their being recorded. I wrote to participants in Priestley's oral history project and obtained permission to analyse their speech for my research. 
During the course of making the Taranaki recordings I encountered an ethical problem which I had not anticipated. In one or two of the interviews the tone veered towards that of a social therapy session and I felt obliged to switch off the recorder because I thought the subject matter was not entirely appropriate for this exercise. The situation was reminiscent of that in which Lesley Milroy found herself in Belfast where many recordings of a particular family 'resembled therapy sessions more closely than sociolinguistic field tapes. I sometimes felt that I was taking unfair advantage of the family's need to talk through their problems with a sympathetic outsider' (Milroy 1987a:90). This was very much how I felt on occasion.

\subsection{The interview}

Since participant observation of the type undertaken by Eckert (1988) and others was not possible for this project, I chose to collect data through the medium of sociolinguistic interviews. For their project, Holmes et al (1991) used an interview schedule administered by an interviewer in the interviewee's home, following the standard technique of most social dialect surveys which had been conducted until that time. Well known examples of such surveys include Labov's work in New York (Labov 1966), Trudgill's investigation of the speech of people in Norwich (Trudgill 1974), and Horvath's work in Sydney (Horvath 1985). More recent and local examples include the social dialect survey undertaken by Vine in Wanganui, a provincial town of New Zealand approximately midway between Wellington and New Plymouth (Vine 1995) and the sociolinguistic study of Aucklanders conducted by Batterham (Batterham 1995). My interview schedule, described below and attached as Appendix 2, was similar to that used by Holmes et al (1991) and also to the one used by Priestley who devised her oral history interview schedule with the help of Holmes ensuring comparability of data. Although not identical in format, the interviews from all three corpora were sufficiently similar in content and approach to provide data for analysis which was stylistically comparable.

The interview schedule I used included similar, though not identical, sections to those of the Porirua and oral history projects. Basic biographical information was sought, there were questions designed to elicit free flowing conversation and interviewees were asked 
to read scripted passages and word lists. Most important for my needs were the conversational sections and the biographical material. Also necessary were questions concerning speakers' rural or urban orientation, given that one of my aims was to investigate possible correlations between rural or urban orientation and patterns of pitch movement. Word lists and reading passages which were collected were not needed for this project but could provide the basis for future study of language variation. Wordlists were available for some of the Priestley interviewees, but her informants did not read the reading passage.

\subsubsection{Language questions}

The first section of the schedule focussed on what interviewees believed about regional variation in New Zealand English. They had been told that this was my research topic and were not surprised to be asked such questions. The questions received carefully considered responses. Taranaki respondents were well aware of a special Southland way of speaking, many people having had first hand contact with Southlanders. Both Taranaki and Southland are prime dairy farming areas and there is a degree of mobility between regions. Interestingly most people living in Taranaki maintained that they would not be able to tell if another person came from Taranaki simply by the way they spoke. This differed from what I found when I piloted my interview schedule with Taranaki born people who had moved to Wellington for job related reasons. This sample of two believed that there were discernible differences and that they probably could tell another Taranaki person by the way they spoke. Other Taranakians currently working in Wellington have also told me of feeling self conscious about their speech on first moving to Wellington. It would seem that people need to move outside their home region before becoming aware of their special way of speaking. Wellingtonians did not believe there was a special Wellington way of speaking. When asked about possible rural/urban differences most respondents referred to specifically rural lexical items, and to a rural tendency to use slangy speech. 


\subsubsection{British and American lexical items}

There followed a list of lexical items which was used in the Porirua survey (Holmes et al 1991) and in an earlier survey in Dunedin (Bayard 1987). Informants were asked which of two alternative words, meaning the same thing, they would use most of the time. One word in each pair was British and the other was its American equivalent. Again, this sort of question was not surprising in a language focussed interview. No formal analysis of this section has been undertaken.

\subsubsection{L-vocalisation}

Still in relatively formal vein, I included a word list and short reading passages devised by $\mathrm{B}$. Horvath to provide data for an Australasian regional survey of / $/$ / vocalisation (Horvath \& Horvath 2002). This section was included in the Taranaki corpus only and the material has not as yet been analysed.

\subsubsection{Rural/Urban orientation questions}

In the next section informants were asked questions designed to determine their position on the rural orientation index described in Section 5.2. Topics to do with schooling, commercial transactions, the whereabouts of kin, the amount of contact with them, voluntary associations (where friends lived, what social groups and clubs they belonged to) and aspirations for the future were covered. Questions to do with occupation and residency were covered in the demographic section at the end of the schedule.

\subsubsection{Word list}

The word list which included minimal pairs incorporated vowel and consonant sounds which might help distinguish possible regional varieties of New Zealand English. The list was similar to those used in the Porirua survey (Holmes et al 1991) and in Priestley's oral history project. Fortunately most speakers had little difficulty coping with the reading task. In the two cases where there was an obvious problem (one 
because of poor eye sight and the other from lack of confidence) I helped with the first page and did not give them the complete set to read. This material awaits analysis.

\subsubsection{General conversation}

By this stage in the interview I hoped that subjects would be accustomed to the tape recorder and me and would be sufficiently relaxed to talk relatively informally. They might also be relieved to have finished ploughing their way through a long and boring list of words and at last be able to move onto something else. From this point on my chief objective was to encourage fluent, relaxed conversation, minimising the 'observer's paradox' (Labov 1972c). Henceforth the interview took the form of sets of questions based around topics which might be of interest to interviewees, a technique not unlike the system of conversational modules described by Labov (1984). I did not stick rigidly to the list of questions and did not broach all topics with every speaker. Whilst endeavouring not to do too much of the talking myself, I did participate in the conversation, following Labov's advice, 'volunteering experience, responding to new issues, and following the subject's main interests and ideas wherever they [went]' (Labov 1984:36-37). Topics of conversation included childhood reminiscences, family relationships, the classic 'danger of death' question, local driving conditions and standards, work, and the state of the nation. Family relationships and the state of the nation were, on the whole, less productive than other topics and I therefore tended not to venture into this territory very often. Childhood reminiscences, standards of driving, and work were fruitful topics as was, in many instances, the 'danger of death' question. I believe I got good results to this question largely because, immediately before asking the question, I asked interviewees to read the 'danger of death' story written for the Porirua project. It appeared to jolt the memories of many people and they were happy to relate their own scary experiences in a natural and unselfconscious manner. On the other hand, in a few cases, the question elicited a laugh and, no, they had had very safe, sheltered lives to date (cross fingers). 


\subsubsection{Demographic information}

I decided to gather biographical information about interviewees at the end of the interview, partly because if I asked for it earlier, I risked setting up a more formal tone than desirable, and partly because by this stage in the interview much of the information I wanted had already been volunteered, thus reducing the number of tedious questions necessary. Information gleaned from this section was important for ensuring that informants fitted my non-linguistic criteria. Criteria of age, sex, ethnicity, socioeconomic class and residency needed to be satisfied. Other questions were designed to elicit information which could be useful in the interpretation of my findings. Into this category fell questions to do with the informant's parents' and partner's residential and occupational histories. I was also interested to know the extent of people's exposure to the Maori language. Interestingly, on occasion some of these straight-forward questions prompted quite loquacious responses.

\subsection{Analysis}

"when the fieldwork is finally completed, any sense of relief evaporates rapidly as the reality of analysis of all that data dawns" (Feagin 2002:36).

\subsubsection{Text type}

Analysis began with the selection, from the speech samples of each speaker, of passages which were suitable for intonation analysis. I opted for narrative speech samples for the reasons outlined below.

Ladefoged (1997:140) recommended that short narratives or other material containing longer stretches of speech be recorded in the field when data was required for the study of the rhythm and intonation of languages which are endangered. The same would be true for language varieties such as Taranaki English which are not necessarily endangered, but which have not as yet been thoroughly described. He suggested local folk tales or short autobiographical narratives might be suitable. In a comparison of the intonation of two Northern Australian languages Fletcher and Evans (2002) followed Ladefoged's advice and recorded and analysed two spontaneously produced narratives, 
one in Kundedjnjenghmi and the other in Dalabon. The researchers felt that the conventional experimental procedure of recording tokens inserted in carrier sentences or dialogues would not be adequate for eliciting the patterns of pitch prominence, boundary marking and timing which were the focus of their study.

It has been demonstrated that the High Rising Terminal (HRT), the steep rise in pitch at the end of a non-interrogative intonational phrase which is a salient feature of New Zealand English, is more likely to occur in narrative texts than in descriptive, explanatory or opinion-giving texts (Allan 1990, Britain 1992, Ainsworth 1994). Warren and Britain (2000) established that the structural elements in texts which appeal to hearers' understanding and empathy are most likely to carry HRTs and these elements are typical of narrative texts. The HRT is not in itself the focus of this research but the feature displays an interesting degree of pitch movement. Text which favours the production of this feature may display other dynamic patterns which could give rise to a perceived singsong quality in speech, although this still remains to be empirically tested. Whether or not this association exists, it is important that comparisons be made between texts which are as similar as possible. Since narratives formed part of all three corpora, and since there is already a suggestion in the HRT studies that narrative styles are more likely to show extensive pitch movements, it seemed appropriate to focus on these text types for present purposes.

Wherever possible I selected for analysis sections of speech data from the corpora which conformed with Labov's definition of narrative, where a minimal narrative is 'a sequence of two clauses which are temporally ordered' (Labov 1972b: 360). Fullyformed oral narratives in Labov's framework contain the following six elements: an abstract, orientation detail, complicating action recounting what happened, an evaluation which gives an indication as to what makes the story interesting, a resolution saying what happened in the end, and a coda signalling the end of the story. Not every narrative in my corpus contained all six elements but most contained more than the minimal two temporally ordered clauses.

Where fluent narrative sections of speech were difficult to find I occasionally used sections which might be termed 'factual reporting' such as childhood reminiscences, or 
descriptions of a typical day's work. Although not strictly speaking narratives, the passages selected were at least fluent and contained more than one clause. For the most part, however, narratives were abundantly available. The majority of speakers had interesting stories to tell in response to the 'danger of death' question. The question was positioned immediately after a reading passage which told the story of a person who got into trouble trying to get their sailing dinghy back to shore. This prompted the narration of numerous stories from people's pasts featuring lakes, rivers and the sea. The recreational preferences of many of the subjects were centred around aquatic sports fishing, diving, swimming, waterskiing, sailing and surfing - a watery focus which reflects the island status of New Zealand. The corpus contains harrowing tales of swimmers and surfboard riders being swept out to sea on rip tides and others being dumped by freak waves. In one a diver surfaced to see his support boat disappearing over the horizon. There is a handful of stories which concern the hazards of farming, particularly amongst the elderly, and one might well wonder at the standard of driving in New Zealand given the number of stories involving motor accidents. One of my favourite stories concerns a novice skier standing petrified at the top of a ski run who then opts to walk down the mountain rather than risk life and limb by skiing down.

Having selected passages for analysis my next task was to transcribe them.

\subsubsection{Transcription of data}

In selecting a transcription system appropriate to my needs I had to be mindful of practical considerations. I needed to be able to transcribe, on my own, a large amount of material. I decided that five minutes of conversational speech per speaker would provide an adequate sample for present purposes allowing sufficient time for each speaker to tell at least one, if not more stories in full and to demonstrate their normal intonational repertoire. All told this came to a period of approximately three hours of data needing close analysis (some 73,418 syllables in 15,358 intonation groups). Crystal (1969) found that a period of three hours of connected, informal, 'educated' English speech was sufficiently long to be representative of the wide range of prosodic features which he described. He listened to thirty speakers in all. 'The deciding matter in this question of length is practicality, in terms of the linguist's time. Transcribing the speech accurately 
to account for all the linguistic contrasts was a task which took well over a year - and this excludes the checking of the transcription by two other linguists' (Crystal 1969:13). The transcription of my data also took well over a year.

I decided on an analysis which was purely auditory because the intention was to examine a large amount of spoken material from a broad range of speakers and to give an indicative description of the intonation patterns revealed. My aim was to uncover any regional and/or social differences in intonation which might exist in New Zealand English. Acoustic analysis of such a volume of data was quite impractical, although acoustic analysis of specific features, eg rises in pitch used by different social groups, might be appropriate for subsequent research.

I employed a system of tonetic stress marks similar to those used by O'Connor and Arnold (1961) and Crystal (1969) where the shape of the tonetic stress marks reflected the pitch movement associated with stressed syllables. See Table 5.2 below for the diacritic marks used. The advantages of using such a system of notation were noted by Williams (1996:47):

'From the point of view of the transcriber ...the notation is ideal for use at speed, as only a few marks must be added to the text. The system is compact, relatively easy to print, and efficient for both transcriber and reader. It was originally formulated with the needs of foreign learners of English in mind (eg. O' Connor \& Arnold 1961), rather than for the expression of a particular intonational theory, and so was designed to be practical and easy to learn by non-specialists'.

I used a broad (systematic) set of categories for transcription based on the traditional British system. In using the broad transcription system devised by $\mathrm{O}^{\prime}$ Connor and Arnold for transcription of the intonation of British English I hazarded a guess that British structural rules applied to New Zealand English intonation. Given the British origins of New Zealand English (see Section 2.1.1) and historical connections with Britain this seemed a not unreasonable assumption.

A transcription system which focussed on pitch movement or lack of it was needed for my analysis and the system selected is explicit in marking tunes associated with nuclear pitch accents, indicating whether they rise or fall or do neither. An alternative 
descriptive framework such as the Autosegmental-Metrical approach (Pierrehumbert, 1980; Beckman \& Pierrehumbert 1986) sees movements in pitch as the result of tonal continuation from one tonal domain to another eg. a falling nuclear accent would be indicated by a high pitch accent on a prominent syllable (marked $\mathrm{H}^{*}$ ) and a low phrase accent (marked L-) at the end of an intonational unit called the intermediate phrase. The 'British' traditional method of O'Connor and Arnold (1961) and Crystal (1969) with its explicit focus on movement seemed most appropriate for present purposes.

\subsubsection{Auditory analysis}

The auditory analysis was undertaken as follows:

\subsubsection{Orthographic transcription}

Five minute sections of narrative text from each recording were orthographically transcribed using a Sony BM-77 transcribing machine with backspacing and slow playback facilities.

\subsubsection{Intonation group boundaries}

Intonation groups, the basic units of intonational structure, were identified (following Cruttenden 1997:29-37). The boundaries of intonational groups were sometimes clearly identifiable and sometimes less so. Wennerstrom (2001a), in a summary of previous discussions of what constitutes an intonational phrase (equivalent to an intonation group) says, that

'the ideal intonational phrase coincides with a cluster of linguistic features, any of which may be useful in its identification. It can be uttered within one breath; it is often set off by pauses; it gradually declines in pitch throughout its duration; it ends with a final lengthening, slower tempo, and possible changes in voice quality; it forms the domain of certain phonological rules; and it may coincide with syntactic constituents' (Wennerstrom 2001a:30).

With this ideal in mind, I identified the boundaries of the units by the presence of some or all of the following characteristics: a pause, lengthening of the final syllable with 
concomitant slowing of tempo, increase or decrease in volume, pitch discontinuity, terminal falls or rises in pitch, and anacrusis (speeding up of unstressed syllables at the beginning of an intonational group). Very often syntactic cues indicated intonation group boundaries and many boundaries coincided with changes in speaker turn.

Pauses were marked with a plus sign, + . A pause may serve as a turn holder while the speaker plans the rest of their utterance or it may indicate word finding difficulty. Pauses may also occur when the speaker is correcting a false start.

The following extract illustrates typical placement of intonation group boundaries. I have marked the boundaries as I heard them with a vertical bar ' 1 '.

so now all I do is ski and fish $\mid+$ the only one that can hurt me is myself $\mid$ now $\mid$ Figure 5.3. Placement of intonation group boundaries

\subsubsection{Identification of accent units}

Syllables which were rhythmically prominent, ie. stressed, and pitch prominent (accented) were auditorally identified. Pitch prominence could be expressed as moving pitch, as a step up or step down in pitch, or as a change in pitch trend (eg. from falling to rising, or from level to rising). 'Accent unit' is the term for the domain of a pitch accent which is linked to a prominent syllable. The realisation of a pitch accent is not limited to the prominent syllable itself, but can spread over syllables up to, but not including, the next pitch accent.

The following diagram indicates where accent units are located in the speech extract used above. Italics mark pitch prominent syllables and the underlined sections mark the domain of the numbered accent units.

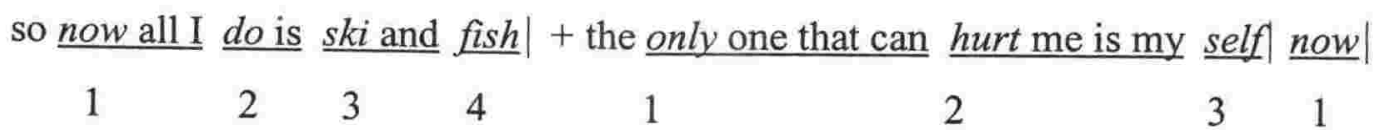

Figure 5.4. Location of accent units 


\subsubsection{Description of accent units}

Accent units within the intonation groups were marked according to whether they were rising, falling, or level in pitch. The most prominently accented syllable in each intonation group, ie. the one with the most marked pitch level or pitch movement and normally the last accented syllable in the group, was identified as the nuclear accent unit. Some nuclear accent units were characterised by a combination of both rising and falling pitch movement and were marked accordingly. This category of nuclear accent was called 'complex' and could include the following combinations of movement: risefall or fall-rise, and occasionally rise-fall-rise or fall-rise-fall. One speaker managed an extraordinary rise-fall-rise-fall-rise! There were also instances of compound nuclear accents where each movement, rising or falling, was clearly associated with a different prominent syllable.

Typically, identification of the nucleus was a straightforward task, with one accented syllable being clearly more prominent than others in the intonation group. However, given that the data being transcribed was informal, conversational speech, there were instances of speaker hesitations and false starts resulting in incomplete intonation groups which had no nucleus at all. In even more informal data, no doubt interruptions would also have been a feature of the conversations, resulting in incomplete intonation groups. But in these conversations the interviewer aimed to encourage free flowing, fluent speech and interruptions were kept to a minimum.

\subsubsection{Structure of intonation groups}

The section of the intonation group which extends from the first non-nuclear pitch accent up to, but not including, the nucleus is referred to as the 'head'. There may be a 'pre-head' or pre-onset which contains syllables within an intonation group which precede the first pitch accent. There is also often a nuclear tail which consists of an unspecified number of stressed or unstressed syllables following the nuclear accent and it continues the pitch movement of the nuclear accent until the end of the intonation group. 
The illustration below shows an intonation group with accent units marked for pitch movement ( $\diamond$ indicates a falling non-nuclear accent and \indicates a falling nuclear accent), and the underlining showing the placement of pre-head, head, nuclear accent and nuclear tail.

$\underline{\text { they sort of }} \times \underline{\text { do all the } \rtimes \text { pubs in }} \backslash \underline{\text { Ha }} \quad \underline{\text { wera }} \mid$
[pre-head] $\quad$ [head $\quad$ [nucleus] [nuclear tail]

Figure 5.5. Intonation group structure

\subsubsection{Declination}

Declination is 'the phenomenon whereby pitch (strictly speaking, fundamental frequency) is on average lower at the end of an intonation-group than at the beginning' (Cruttenden 1997:162). Evidence for its existence in RP is derived from carefully controlled sentences which were read aloud and subjected to precise acoustic measurements. The declination is represented by 'a slightly declining baseline and a more steeply declining top line, thus producing a narrowing of pitch range as the intonation-group progresses' (Cruttenden 1997:162). Cruttenden suggests that the patterns produced in this carefully controlled situation could be regarded as 'neutral' intonation patterns 'from which more expressive intonations in natural conversation may deviate' (Cruttenden 1997:162). Conscious of this 'neutral' or 'default' pattern for RP English, I auditorally assessed accented syllables which did not sit neatly on the declination line. If they started at a markedly higher pitch than the preceding accented syllable they were considered to show 'up-step', which was marked by an up arrow, $\uparrow$, if they started at a lower pitch than the preceding accented syllable they showed 'downstep', which was marked by a down arrow, $\downarrow$, and if they started at the same pitch as the preceding accented syllable they showed 'continuation' of the pitch level, which was marked by a horizontal arrow, $\rightarrow$. Used alone, on an unstressed syllable, the arrows marked a pitch pattern which was significantly above or below the expected pitch level. It is somewhat debatable whether or not the declination line typical of RP English should be regarded as the default pattern for New Zealand English. It was clearly present for some speakers in my corpus but less clearly so for others. Where the declination line appeared to be absent and the base-line was level in pitch I used the arrow symbols to 
mark pitch level above or below what might be expected, given my auditory assessment of what might be the speaker's normal pitch base-line. The issue of whether the base- . line declines or whether it is level is an important one in the description of New Zealand English intonation, but base-lines as such were beyond the scope of this project. My focus was on movement away from the base-line, whether declining or level.

\subsubsection{Prosodic features transcribed}

The following is the set of characters used to represent prosodic features in the texts:

\begin{tabular}{|c|c|}
\hline 1 & intonation group boundary \\
\hline$\backslash$ & falling nucleus \\
\hline$/$ & rising nucleus \\
\hline$\wedge$ & rise-fall nucleus (complex) \\
\hline V & fall-rise nucleus (complex) \\
\hline $1+1$ & $\begin{array}{l}\text { rise }+ \text { fall nucleus (compound - each pitch movement is } \\
\text { associated with a different prominent syllable) }\end{array}$ \\
\hline $1+1$ & $\begin{array}{l}\text { fall + rise nucleus (compound - each pitch movement is } \\
\text { associated with a different prominent syllable) }\end{array}$ \\
\hline- & level nucleus \\
\hline$>$ & falling non-nuclear accent \\
\hline$>$ & rising non-nuclear accent \\
\hline , & level non-nuclear accent \\
\hline . & stressed but unaccented \\
\hline$\uparrow$ & stepped up onset \\
\hline$\downarrow$ & stepped down onset \\
\hline$\rightarrow$ & level onset \\
\hline+ & pause \\
\hline
\end{tabular}

Table 5.2. Characters used to represent prosodic features 
A sample of approximately $50 \%$ of my auditory assessments was checked by one of my supervisors, Paul Warren, and a high degree of consensus was reached. Blind checks were also undertaken on sections of the transcriptions. My assessments did not vary greatly from one listening to another. A few adjustments were necessary but overall there was a high level of consistency.

The following is a sample section of transcribed text.

$$
\begin{aligned}
& \text { i was }+\backslash \text { diving } \mid+ \text { was only a \coupla } \searrow \text { years a } \vee \text { go } \mid \vee \text { actually } \mid+ \text { ๖out } \vee \text { here } \mid+ \\
& \backslash \text { and } \mid \mathrm{i} \text { 'd + \been on the } \backslash \text { bottom } \mid+ \text { 'getting } \backslash \text { crays } \mid+ \text { and i'd \got a \lot of } \\
& \backslash \text { crays [laughs] } \mid+\backslash \text { and } \mid+\succ \text { when } \mathrm{i}>\text { went to come } \uparrow^{-} \text {up } \mid+\succ \text { we have a }
\end{aligned}
$$

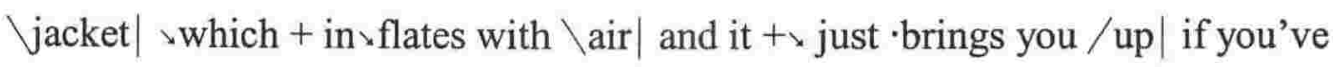

$$
\begin{aligned}
& \text { 'got a } \mid+ \text { like \generally| you can \swim up| 'but if you've + 'got a 'sack of } \\
& { }^{-} \text {crays } \mid \text { or }^{-} \text {whatever } \mid \text { and you've } \vee \text { quite \weighed } \mid+{ }^{\prime} \text { weighed } \wedge \text { down } \mid+\backslash \text { you } \mid \\
& + \text { just } \text { blow up your }+\cdot{ }^{-} \text {compen } \uparrow^{-} \text {sator } \mid \text { 'takes you to the } \uparrow^{-} \text {top } \mid \text { well } \mathrm{i}+ \\
& \backslash \text { kicked up } \mid \text { for the } \backslash \text { top } \mid+ \text { sblew up my \compensator } \mid+ \text { and + the } \triangleleft \text { little + } \\
& \text { ×valve at the \top here } \mid \text { was }+i^{\prime} d \times \text { pulled it to }{ }^{-} \text {bits } \mid \text { to }{ }^{-} \text {fix it } \mid \text { a }>\text { few days } \\
& \text { be } \backslash \text { fore } \mid+ \text { and } \mathrm{i} \rtimes \text { hadn't } \text { put it 'back to \gether } \mid+ \text { and it + de } \backslash \text { flated } \mid \text { and } \mathrm{i} \\
& \text { 'started to } \backslash \operatorname{sink} \mid+ \text { and then } \mathrm{i} \times \text { kicked my } \text { way back } \uparrow^{-} \text {up } \mid \text { and } \backslash \text { blew it } \mid \text { and } \\
& \backslash \text { blew it up } \mid \text { and } \mathrm{i} \backslash \text { realised } \mid \text { what would \happen } \mid+ \text { and the \guys| that were } \\
& \text { in the \boat } \mid \text { had } \backslash \text { gone } \mid+ \text { bout a } \ \text { kilometre down the }+\backslash \text { coast } \mid \text { to 'pick } \\
& \text { someone /else up| }
\end{aligned}
$$

\subsubsection{Quantitative analysis of data}

A minimum of 200 intonation groups per speaker were analysed.

\subsubsection{Length of intonation groups}

The number of syllables per intonation group was averaged for each speaker and the range of syllables per intonation group was 3.68 - 5.94, with an overall average of 4.78 syllables. The number of accent units (including nuclear accent units) per intonation 
group was also averaged for each speaker. The range per intonation group was 1.52 2.71 , with an overall average of 1.94 accent units.

It has been found that the average length of an intonation group varies according to the style of speech. The more formal the speech style, the longer the intonation group (Crystal 1969). Warren and Daly (2005 f.c.) reported 4.70 words per intonation group in a survey of New Zealand news readers' speech. Chafe (1994:63) divides intonation groups into three categories - 'fragmentary' (ie. incomplete), 'substantive' (conveying 'substantive ideas of events, states, or referents') and 'regulatory' (having 'regulatory functions in the sense of regulating interaction or information flow'. Utterances such as 'Well' and 'mhm' come into this category.) In the conversational sample he measured, regulatory intonation groups tended to be short, with a mean length of 1.36 words and substantive intonation groups were longer with a mean length of 4.84 words. In the conversational data in my corpus, speakers were composing what they wanted to say and relaying it almost simultaneously. Hesitation features such as pauses and false starts were evident while speakers organised their thoughts. There were also numerous instances of 'regulatory' units such as 'um', 'yeah' and 'mhm'. These units were included in my count. The consequently relatively short intonation groups were typical of informal speech styles.

\subsubsection{Changes in pitch direction per intonation group and per accent unit}

The first step in the analysis was to find a method of globally measuring changes in pitch direction that would allow for the measurement of differences between the sets of sample texts. I counted changes in pitch direction firstly in each intonation group and then in each accent unit. My count of changes in pitch direction included changes of direction within complex nuclei, changes from rising accent units to falling accent units in the head and from falling accent units to rising accent units in the head. Where there was a step up to a level or falling pitch accent, the step up was counted as a change in pitch direction and where there was a step down to a level or rising pitch accent, the step down was counted as a change in pitch direction. In passages of continuous speech, resetting of pitch upwards or downwards at the beginning of a new intonation group after a fall or rise at the end of the previous intonation group counted as a change of 
direction. Resetting of pitch at the beginning of a new intonation 'paragraph' was not counted as a change of pitch direction. Paragraphs in written speech have analogues in spoken speech. There are prosodic markers, particularly in organised or rehearsed speech styles such as news-reading, or story telling, which indicate the introduction of new subject matter. Tench (1996:23) describes a typical intonation paragraph in RP English as follows: 'the first onset syllable of the initial intonation unit of the new item is high and then comes a gradual descent in the general pitch level of the following units until the lowest point is reached with the final unit.' The descent in pitch level in New Zealand English may not be as pronounced as in RP but new subjects are nevertheless clearly marked intonationally. Speakers tend to expand their pitch range at the onset of a new topic and contract the range at its conclusion.

The number of changes of pitch direction per intonation group and per accent unit was averaged for each speaker.

Figure 5.6 below illustrates the counting of changes of pitch direction in a sample text. The asterisks mark where the pitch changes direction from down to up and from up to down.

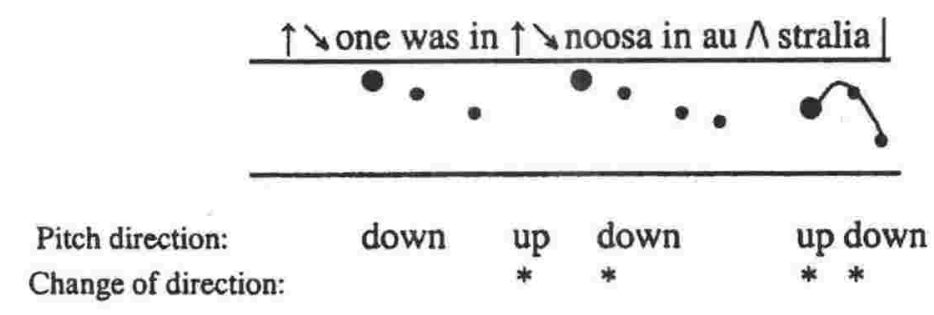

Figure 5.6 Changes of pitch direction in an intonation group

\subsubsection{Nuclear accents}

My attention turned next to the analysis of nuclear accents. The nucleus is the most prominent and salient accent in the intonation group and could therefore be expected to make a major contribution to the perception of intonation. Pitch movements associated 
with nuclear accents largely determine the tune of the intonation group (Cruttenden 1997). Analysis of broad tune types could reveal patterns which might relate to an impression of sing-songy or flat speech.

Percentages of nuclear accents which were rising, falling, level and complex were calculated.

\subsubsection{Non-nuclear accents}

I looked next at non-nuclear accents because I wanted to see if a preference for moving pitch or for level pitch would extend from nuclear accents to other accent units. I calculated percentages of level and falling non-nuclear accents. There were very few rising non-nuclear accents $(0.23 \%$ overall as compared to $36.75 \%$ falling non-nuclear accents and $63.01 \%$ level non-nuclear accents).

\subsubsection{Falling accents with boosted onsets (nuclear and non-nuclear)}

I then narrowed my focus further by investigating the manner in which each falling accent was approached or 'attacked'. I selected falling accents because speakers used more falling accents than other non-level accents. The count of falling accents included nuclear and non-nuclear falling accents. The manner in which speakers approached falling accents varied. The starting point of downward pitch movement was usually slightly above that of the preceding unaccented syllable, but sometimes there was a noticeable step up to it (transcribed as $\uparrow \backslash$ or $\uparrow \searrow$ ), sometimes the onset was level with the previous unaccented syllable (transcribed as $\vec{\backslash} \backslash$ or $\vec{y}$ ) and occasionally there was a noticeable downwards step to the onset of the fall in pitch (transcribed as $\downarrow \backslash$ or $\downarrow$ ). There were instances of stepped up onsets to falls which were insufficiently boosted to be transcribed as $\uparrow \backslash$. Such cases were marked as standard falls $(\backslash)$.

I calculated the percentage of falling accents which had a noticeably stepped up onset, working on the assumption that if speech is characterised by a high percentage of falling accents which have boosted onsets, the effect will be of considerable pitch movement. The listener may well perceive the speech as being 'sing-songy'. 
Calculating the percentage of falling accents with boosted onsets in speakers' intonation is not unlike the method used by Wolfram and Thomas (2002) for distinguishing intonational differences between African Americans and European Americans. They compared the frequency of high pitch accents in connected speech. A high pitch accent was defined as 'a stressed syllable whose pitch was higher than that of the immediately preceding stressed syllable' and the marking of high pitch accents was conducted impressionistically (Wolfram \& Thomas 2002:155). They found that African Americans in Hyde County, where the research was undertaken, showed more high pitch accents in their speech than their European American neighbours and that the ethnic difference appeared to be a long-standing one. Their results were consistent with research findings that African Americans show a wider pitch range than European Americans (e.g. Tarone 1973: Hudson \& Holbrook 1981, 1982). Falling accents with boosted onsets are a type of 'high pitch accent' as described above and they too prove to be a useful tool in distinguishing between dialects, or in this case, incipient dialects.

\subsubsection{Level accents with boosted onsets (nuclear and non-nuclear)}

Raised pitch can be realised either as an upwards movement in pitch, or as a level accent with a noticeably stepped up onset. I calculated the percentage of level accents which . had noticeably stepped up onsets because use of this pitch pattern could contribute to an impression of 'sing-songy' intonation.

By globally measuring changes in pitch direction and then narrowing the focus to the pitch movement present in particular types of accent unit I constructed an index which could be loosely described as a 'singsong' index, by which I could measure the difference between sample texts. Details of the differences found are described in the next chapter.

\subsubsection{Statistical analysis}

In order to examine the potential influence of Location, Age and Gender on the above features of intonation, a multiway analysis of variance (ANOVA) was performed for each variable. This procedure was appropriate because all factors at once were taken 
into consideration. 'While computing the effect of one independent variable, it [ANOVA] explicitly controls for the effect of all other known independent variables' (Guy 1993: 237) and the procedure also examines possible interactional effects among variables. Had I examined each factor individually the results produced would have been less accurate and important information missed. As it transpired, there was considerable interaction amongst the independent variables as can be seen in Chapter 6 and the implications of these interactions are explored in Chapter 7.

Having described in some detail the methodology employed in this project I turn now to the major findings of my research. 
In this chapter I describe in more detail the measurement of 'sing-songyness', or 'pitch dynamism,' of speakers' intonation. My measure of 'pitch dynamism' was the number of times on average speakers changed pitch direction within intonation groups and accent units, the relative proportion of pitch accents characterised by movement, and the proportion of pitch accents having boosted onsets. I list the intonational features studied and the social factors considered, giving reasons as to why each was selected for analysis. I then describe how analysis of variance was undertaken and the results of the analysis are outlined. The implications of the results will be discussed in Chapter 7 .

\subsection{Dependent variables}

The dependent variables selected for analysis consisted of seven features relating to pitch movement within intonation groups. The features and the rationale for their inclusion are outlined below:

(1) average number of changes of pitch direction per intonation group

This variable was selected to provide a global measure of how often speakers changed pitch direction in their speech. A description of how changes in pitch direction were counted is given in Section 5.9.4.2.

\section{(2) average number of changes of pitch direction per accent unit}

I reasoned that the impression of 'sing-songyness' would depend on what kind of accent units were present and how many there were per intonation group. Because there was potential variation in the number of accent units per intonation group, it was necessary to be sure that the first measure, the number of times a speaker changed pitch direction per intonation group, was not being unduly influenced by differences in phrasing. I therefore looked at the phrasing at a more local level to see if there was a parallel pattern between variables (1) and (2). I had no clear expectation that there would be great differences between speakers in the length of their intonation groups because texts selected for analysis were of a similar type. (See Section 5.9.1 for description of text type). 
(3) percentage of nuclear accents with moving pitch

Nuclear accents, because of their prominence, contribute in large part to the listener's perception of the character of a speaker's intonation. They determine the tune of an intonation group (see Section 5.9.4.3). Nuclear accents characterised by pitch movement, whether falling, rising or a mixture of both, were of interest because one could expect intonation characterised by a lot of pitch movement to sound more 'singsongy' than intonation which had a high proportion of level nuclear accents.

\section{(4) percentage of complex nuclear accents}

Complex nuclear accents were of particular interest in this study because each accent by definition contains at least one change of pitch direction, from falling to rising pitch, or from rising to falling pitch. Intonation characterised by a lot of pitch movement might be expected to contain a higher percentage of complex nuclear accents than would intonation characterised by minimal pitch movement.

\section{(5) percentage of non-nuclear accents with movement}

Although not as salient as nuclear accents, non-nuclear accents also contribute to the tune of an intonation group and I was interested to see if a preference for moving pitch or level pitch would extend to other accent units. A nuclear accent which has moving pitch is not necessarily preceded by non-nuclear accents characterised by movement and level nuclear accents may be preceded by non-nuclear accents which are characterised by movement. I selected non-nuclear accents with pitch movement as a dependent variable for the same reason I chose nuclear accents with movement.

(6) percentage of falling accents (nuclear and non-nuclear) having boosted onsets The way in which a speaker attacks accents may have an effect on a listener's perception of that speaker's intonation. If speech is characterised by a high percentage of falling accents which have boosted onsets the effect will be of considerable pitch movement, utilising more of the speaker's pitch range. This may contribute to an impression of 'sing-songy' intonation. Hence my interest in falling accents with boosted onsets. 
(7) percentage of level accents (nuclear and non-nuclear) having boosted onsets Level accents with boosted or stepped up onsets were selected as dependent variables because, although there is no pitch movement in the accent itself, the onset amounts to a change in pitch direction. It is not unlike a rising accent in this respect. A high percentage of level accents with boosted onsets could contribute to an impression of 'sing-songy' intonation.

The dependent variables were entered into analysis of variance (ANOVA), with independent variables as specified below. Since they dealt with proportional data, the proportion scores corresponding to the percentages in dependent variables (3) - (7) were subjected to arcsine transform $(2 \operatorname{arcsine} \sqrt{ } \mathrm{p})$ in order to convert the binomial distribution into a normal distribution.

\subsection{Independent variables}

A total of three independent variables were included in the analyses. These were:

(A) Location - (i) South Taranaki dairy farming community (henceforth referred to as 'South Taranaki', (ii) New Plymouth or (iii)Wellington

(B) Gender - male or female

(C) Age - old or young

The above factors were selected as independent variables because they best addressed the research questions posed in Section 4.3. They were the design factors selected in my sampling procedure (see Section 5.1). 
Table 6.1 shows the complete data coverage.

\begin{tabular}{|c|c|c|c|c|}
\hline & $\begin{array}{c}\text { South } \\
\text { Taranaki }\end{array}$ & New Plymouth & Wellington & Totals \\
\hline Old Males & 5 & 5 & 5 & 15 \\
\hline Old Females & 5 & 5 & 5 & 15 \\
\hline Young Males & 5 & 5 & 5 & 15 \\
\hline Young & 5 & 5 & 5 & 15 \\
Females & & & & 60 \\
\hline Totals & 20 & 20 & 20 & \\
\hline
\end{tabular}

Table 6.1. The sample

For exploration of any significant main effects of Location, post hoc analyses (Fishers Protected LSD) were carried out comparing pairs of means (eg. Wellington and South Taranaki, or Wellington and New Plymouth).

\subsection{Results for dependent variables}

Results are presented below for each of the dependent variables (1) - (7).

Figures referred to in the text are presented on pages 128-137, 137. The figures are presented by factor so that attention is drawn to commonalities in the social patterning for different intonational features.

(1) average number of changes of pitch direction per intonation group

The dependent variable here was the average number of changes of pitch direction (CoD) per intonation group.

The ANOVA showed significant main effects of Location $(F[2,48]=18.54, p<0.001)$ and Age $(\mathrm{F}[1,48]=28.40, \mathrm{p}<0.001)$ but not of Gender $(\mathrm{F}[2,48]=2.19)$. The interaction of Location and Gender was significant $(\mathrm{F}[2,48]=8.88, \mathrm{p}<0.001)$ as was the interaction of Location, Gender and Age $(F[2,48]=12.73, \mathrm{p}<0.001)$. These effects are shown in 
Figures 6.1, 6.11, 6.16 and 6.21. It is clear from Figure 6.1 that the significant effect of Location results from differences between South Taranaki and New Plymouth, and New Plymouth and Wellington. Individual comparisons in the post hoc tests showed that both South Taranaki and New Plymouth speakers used significantly more changes of pitch direction than Wellington speakers $(\mathrm{p}<0.001, \mathrm{p}<0.005$ respectively). In addition South Taranaki speakers used more than New Plymouth speakers $(\mathrm{p}<0.01)$.

The main effect of Age (see Figure 6.11) results from a greater incidence of changes in pitch direction for the older age group.

The interaction of Location and Gender (Figure 6.16) arises because the effect of Location is present for the males only, South Taranaki males using more changes in pitch direction than New Plymouth males who in turn use more than Wellington males. Another way of looking at this is that the difference between males and females is much more marked for South Taranaki than either of the other groups.

The complex interaction of Location, Gender and Age is shown in Figure 6.21. We see that the effect of Location is different for each of the four groups - old males, old females, young males and young females. The old South Taranaki males have higher scores than the old males of New Plymouth and Wellington; the old females of South Taranaki and New Plymouth have higher scores than the old females of Wellington; the young males of South Taranaki and New Plymouth have higher scores than the young. males of Wellington; and there is little difference between the young female groups, though the Wellington females have slightly higher scores than the South Taranaki and New Plymouth females. The effect of Age - the old using more changes of pitch direction than younger speakers - is apparent for all pairings of old and young except for the New Plymouth males and the Wellington females where there is very little difference. The old South Taranaki males stand out as having the highest scores and the young Wellington males stand out as having the lowest scores.

\section{(2) average number of changes of pitch direction per accent unit}

The dependent variable here was the average number of changes of pitch direction per accent unit. 
The ANOVA showed significant main effects of Location $(F[2,48]=18.23, \mathrm{p}<0.001)$, Gender $(\mathrm{F}[1,48]=4.13, \mathrm{p}<0.05)$ and Age $(\mathrm{F}[1,48]=6.41, \mathrm{p}<0.05)$. There were also significant interactions of Location and Gender $(F[2,48]=11.19, \mathrm{p}<0.001)$, and of Location, Gender and Age $(F[2,48]=13.72, p<0.001$. These effects are shown in Figures $6.2,6.7,6.12,6.17$ and 6.22. Figure 6.2 shows that, as with the previous variable, the significant effect of Location results from differences between South Taranaki and New Plymouth, and between New Plymouth and Wellington. Post hoc tests showed that both the South Taranaki and New Plymouth speakers used significantly more changes of pitch direction per accent unit than did Wellington speakers (both at the level of $\mathrm{p}<0.001$ ). Within Taranaki the South Taranaki speakers used significantly more than the New Plymouth speakers $(\mathrm{p}<0.05)$.

The main effect of Gender (see Figure 6.7) results from a greater incidence of changes of pitch direction per accent unit for male speakers than for female speakers.

The main effect for Age (see Figure 6.12) results from a greater incidence of changes of pitch direction per accent unit for older speakers than for younger speakers.

As with the previous variable the interaction of Location and Gender (see Figure 6.17) arises because the Location effect is present with the males only and the difference between males and females is much more marked for South Taranaki than either of the other groups. The counts for the New Plymouth males and females are identical for this variable.

The complex interaction of Location, Gender and Age is shown in Figure 6.22. As with the first variable, the effect of Location was different for each of the four groups: the old South Taranaki males had higher scores than the old New Plymouth and old Wellington males; the old South Taranaki and old New Plymouth females had higher scores than the old Wellington females; the young South Taranaki men had the highest scores for their age group, closely followed by the young New Plymouth males and the young Wellington males had the lowest scores; the young females had similar scores though the young Wellington females had slightly higher scores than the young South Taranaki and young New Plymouth females. Again, as with the first variable, the old had higher 
scores than the young in all pairs of old and young except in the case of New Plymouth males and Wellington females. Here the New Plymouth males, old and young, had similar scores while the Wellington young females had higher scores than the Wellington old females. Once again the South Taranaki old males had the highest scores of all cell groups and the Wellington young males had the lowest scores. There was an effect of Gender - males having higher scores than females - amongst the old and young of South Taranaki, and the old of Wellington. The young of Wellington showed a different gender pattern with the young Wellington females having higher scores than the young Wellington males. There were less marked and less consistent patterns across the old and young New Plymouth groups.

\section{(3) percentage nuclear accents with moving pitch}

The dependent variable here was the percentage of nuclear accents characterised by moving pitch. Analysis of variance was performed on arcsine transformed proportion data $(2 \operatorname{arcsine} \sqrt{ } \mathrm{p})$.

The ANOVA showed significant main effects of Location $(F[2,48]=13.74, \mathrm{p}<0.001)$ and Age $(F[1,48]=25.46, p<0.001)$, but not of Gender $(F[1,48]=0.49)$. The interaction of Location and Gender was also significant $(F[2,48]=8.13$, $\mathrm{p}<0.001)$ as was the interaction of Location, Gender and Age $(F[2,48]=13.17, \mathrm{p}<0.001)$. These effects are shown in Figures 6.3, 6.13, 6.18 and 6.23. Once again it is clear from Figure 6.3 that the significant effect of Location results from differences between South Taranaki and New Plymouth, and New Plymouth and Wellington. Post hoc tests showed that both the South Taranaki and New Plymouth speakers used significantly more nuclei with moving pitch than the Wellingtonians ( $\mathrm{p}<0.001$ and $\mathrm{p}<0.005$ respectively). In addition the South Taranaki speakers used significantly more nuclei with moving pitch than New Plymouth speakers $(\mathrm{p}<0.05)$.

The main effect of Age (see Figure 6.13) results from a greater incidence of nuclei with moving pitch for the older speakers.

As with the previous variables the interaction of Location and Gender (see Figure 6.18) arises because the Location effect is present with the males only. 
Figure 6.23 shows the interaction of Location, Gender and Age. As with the first two variables, the effect of Location was different for each of the four groups - old males, old females, young males and young females. Location patterned for each group in a similar fashion to the way in which it patterned for the first variable (average changes of pitch direction per intonation group). The old South Taranaki males had higher scores than the old New Plymouth and old Wellington males; the old South Taranaki and New Plymouth females had higher scores than the old Wellington females; the young South Taranaki and New Plymouth males had higher scores than the young Wellington males;

the Wellington young females had marginally higher scores than the South Taranaki and New Plymouth young females. The effect of Age - the older speakers using more nuclear accents with moving pitch than the younger speakers - was present for the South Taranaki and New Plymouth females and for the Wellington males. Age seemed to have little effect on the South Taranaki and New Plymouth males, and the Wellington females.

\section{(4) percentage complex nuclear accents}

The dependent variable here was the percentage of nuclear accents which were complex, ie. those which were characterised by falling then rising pitch or rising then falling pitch. Analysis of variance was performed on arcsine transformed proportion data $(2 \operatorname{arcsine} \sqrt{ } \mathrm{p})$.

The ANOVA showed significant main effects of Gender only $(F[1,48]=9.83$, $\mathrm{p}<0.005)$. The effects of Location and Age were not significant $((\mathrm{F}[2,48]=1.25)$, $(F[1,48]=3.61)$ respectively) and nor was the interaction of Location, Gender and Age $(\mathrm{F}[2,48]=0.18)$.

The main effect of Gender (Figure 6.8) results from a greater incidence of complex nuclei for the women.

\section{(5) percentage non-nuclear accents with moving pitch}

The dependent variable here was the percentage of non-nuclear accents characterised by moving pitch. Analysis of variance was performed on arcsine transformed proportion data $(2 \arcsin \sqrt{ } \mathrm{p})$. 
The ANOVA showed significant main effects of Location $(F[2,48]=14.95, \mathrm{p}<0.001)$ and Gender $(\mathrm{F}[1,48]=21.70, \mathrm{p}<0.001)$, but not of Age $(\mathrm{F}[1,48]=0.69)$. The interaction of Location and Gender was also significant $(F[2,48]=16.26, p<0.001)$ as was the interaction of Location, Gender and Age $(F[2,48]=11.20$, p $<0.001)$. These effects are shown in Figures 6.4, 6.9, 6.19 and 6.24. Figure 6.4 shows that the significant effect of Location results from differences between Taranaki locations and Wellington. Post hoc tests showed that both South Taranaki and New Plymouth speakers used significantly more non-nuclear accents with moving pitch than Wellingtonians (both at the level of $\mathrm{p}<0.001)$. The South Taranaki speakers did not use significantly more moving nonnuclear accents than the New Plymouth speakers $(\mathrm{p}<0.171)$.

The main effect of Gender (see Figure 6.9) results from a greater incidence of nonnuclear accents with moving pitch for the men.

The interaction of Location and Gender (Figure 6.19) arises again because the Location effect applies only to the males and because there is a gender difference in South Taranaki only.

The interaction of Location, Gender and Age is shown in Figure 6.24. As with the first three variables, the effect of Location was different for each of the four groups - old males, old females, young males and young females. Location patterned for each group in a similar fashion to the way in which it patterned for the second variable (average changes of pitch direction per accent unit). The old South Taranaki males used more non-nuclear accents with moving pitch than the old New Plymouth and old Wellington males; the old New Plymouth females used more than the old South Taranaki females, who used more than the old Wellington females; the young South Taranaki males had higher scores than the young New Plymouth males and the young Wellington males had the lowest scores; the young Wellington females had higher scores than the young South Taranaki and New Plymouth females. For this variable there is a gender effect - males having higher scores than females - for four of the male/female pairs. There are two exceptions to this pattern. These are the old New Plymouth speakers and the young Wellington speakers. In both these cases the females have higher scores than the males. 
(6) percentage of falling accents (nuclear and non-nuclear) having boosted onsets The dependent variable here was the percentage of falling accents (both nuclear and non-nuclear) which had boosted onsets. Analysis of variance was performed on arcsine transformed proportion data $(2 \operatorname{arcsine} \sqrt{ } \mathrm{p})$.

The ANOVA showed significant main effects of Location $(F[2,48]=5.27, \mathrm{p}<0.01)$ and Age $(F[1,48]=63.13, p<0.001)$, but not of Gender $(F[1,48]=0.33)$. The interaction of Location and Gender was also significant $(F[2,48]=3.63, \mathrm{p}<0.05)$ as was the interaction of Location, Gender and Age $(F[2,48]=5.99, \mathrm{p}<0.005)$. These effects are shown in Figures 6.5, 6.14, 6.20 and 6.25. It is clear from Figure 6.5 that the significant effect of Location results from the difference between the South Taranaki speakers and the Wellingtonians. The post hoc tests showed that the South Taranaki speakers used significantly more falling accents with boosted onsets than did the Wellingtonians $(\mathrm{p}<0.005)$. Differences between New Plymouth and South Taranaki speakers were not significant $(\mathrm{p}<0.121)$ and nor were differences between New Plymouth speakers and the Wellingtonians $(\mathrm{p}<0.101)$.

The main effect of Age (see Figure 6.14) results from a greater incidence of falling accents with boosted onsets for the older speakers.

Once again Location and Gender (Figure 6.20) interacted such that the Location effect was present only for the men with very little difference amongst the women. And the difference between men and women was much more marked for South Taranaki than either of the other groups.

Figure 6.25 shows the interaction of Location, Gender and Age. The Location effect South Taranaki $>$ New Plymouth $>$ Wellington - was present for this variable amongst the old males, the old females and the young males, but the order was reversed for the young female group. The age effect - old speakers having higher scores than young speakers - was present for all the old/young pairs. The young South Taranaki males, however, were much closer to the old South Taranaki males than were the other young speakers to older members of their Location and Gender matched groups. 
(7) percentage of level accents (nuclear and non-nuclear) having boosted onsets The dependent variable here was the percentage of level accents (nuclear and nonnuclear) having boosted onsets. Analysis of variance was performed on arcsine transformed proportion data $(2 \operatorname{arcsine} \sqrt{ } \mathrm{p})$.

The ANOVA showed a significant main effect of Location $(F[2,48]=6.57, \mathrm{p}<0.005)$, of Gender $(F[1,48]=53.45, \mathrm{p}<0.001)$ and of Age $(F[1,48]=20.26, p<0.001)$. The interaction of Location, Gender and Age was also significant $(F[2,48]=3.89, p<0.05)$. These effects are shown in Figures 6.6, 6.10, 6.15 and 6.26. It is clear from Figure 6.6 that the significant effect of Location results from differences between the Taranaki locations and Wellington. Individual comparisons in the post hoc tests showed that the South Taranaki and New Plymouth speakers used significantly more level accents with boosted onsets than Wellington speakers ( $\mathrm{p}<0.001$ and $\mathrm{p}<0.05$ respectively). There was no significant difference between South Taranaki and New Plymouth speakers.

The main effect of Gender (see Figure 6.10) results from a greater incidence of level accents with boosted onsets for the women.

The main effect of Age (see Figure 6.15) results from the fact that the elderly speakers had a higher incidence of level accents with boosted onsets than the younger speakers.

The interaction of Location, Gender and Age is shown in Figure 6.26. For this variable it is only the old females who clearly reflect the overall effect for Location - South Taranaki $>$ New Plymouth $>$ Wellington. The effect of Gender - in this instance females having higher scores than males - is present for all male/female pairs of groups with the exception of the old Wellington males and females who have very similar scores. 
Figure 6.1 Average changes of pitch direction per intonation group

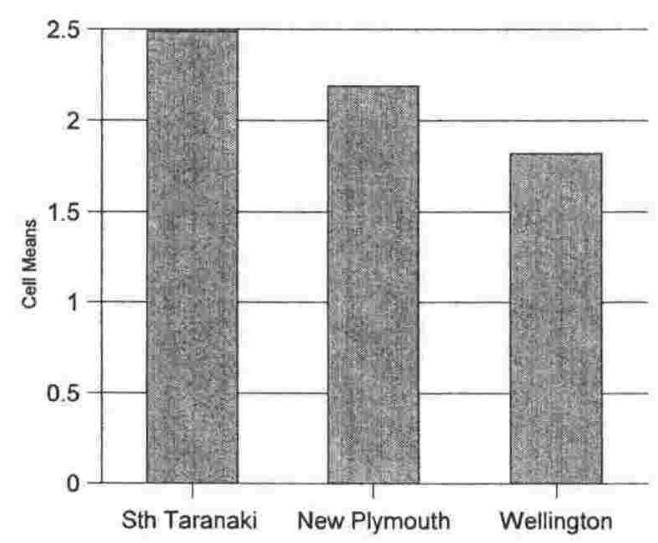

\begin{tabular}{|c|c|c|}
\hline & Mean & sd \\
\hline Sth Taranaki & 2.49 & 0.54 \\
\hline New Plymouth & 2.19 & 0.47 \\
\hline Wellington & 1.82 & 0.54 \\
\hline
\end{tabular}

Figure 6.3 Percent of nuclear accents with moving pitch

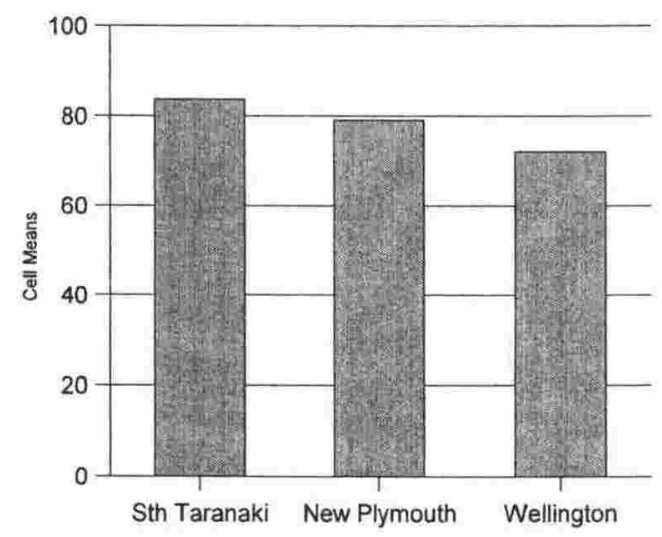

\begin{tabular}{|c|c|c|}
\hline & Mean & sd \\
\hline Sth Taranaki & 83.72 & 8.50 \\
\hline New Plymouth & 79.09 & 9.95 \\
\hline Wellington & 72.14 & 12.39 \\
\hline
\end{tabular}

Figure 6.2 Average changes of pitch direction per accent unit

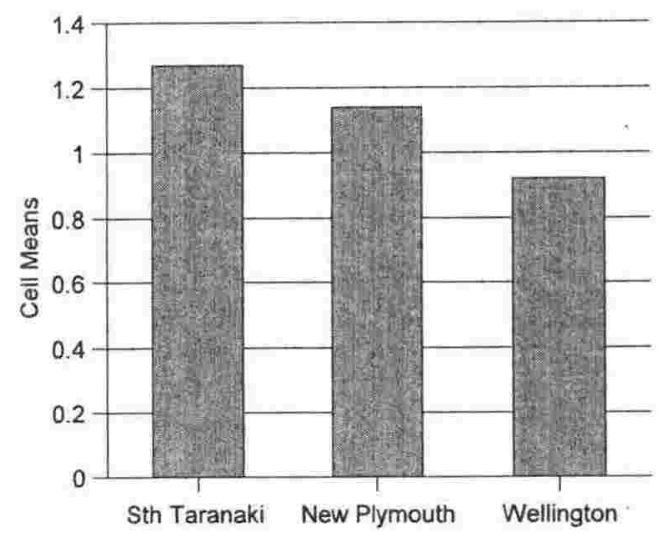

\begin{tabular}{|c|c|c|}
\hline & Mean & sd \\
\hline Sth Taranaki & 1.27 & 0.28 \\
\hline New Plymouth & 1.14 & 0.23 \\
\hline Wellington & 0.92 & 0.27 \\
\hline
\end{tabular}

Figure 6.4 Percent of non-nuclear accents with moving pitch

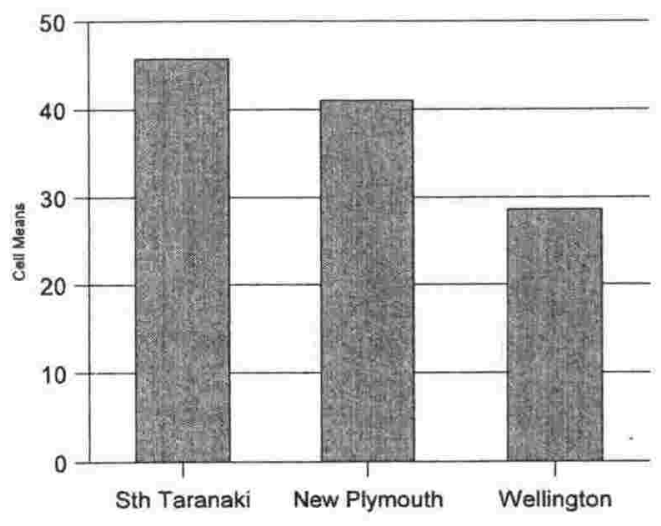

\begin{tabular}{|c|c|c|}
\hline & Mean & sd \\
\hline Sth Taranaki & 45.79 & 19.42 \\
\hline New Plymouth & 41.03 & 12.46 \\
\hline Wellington & 28.62 & 14.24 \\
\hline
\end{tabular}


Figure 6.5 Percent of falling accents with boosted onset

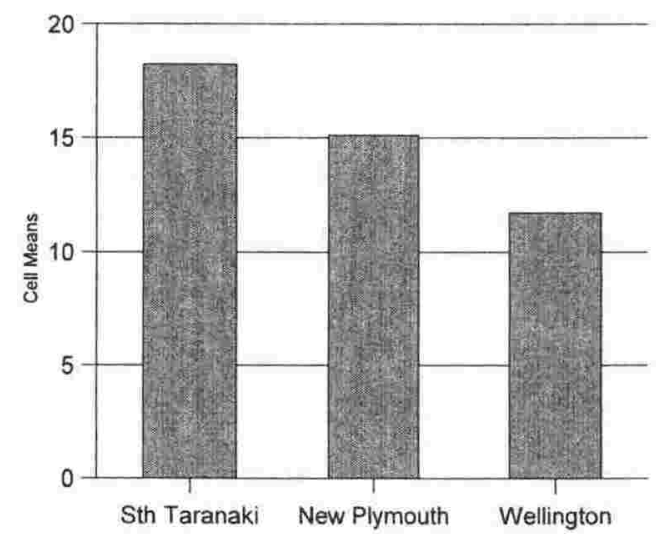

\begin{tabular}{|c|c|c|}
\hline & Mean & sd \\
\hline Sth Taranaki & 18.23 & 10.45 \\
\hline New Plymouth & 15.11 & 10.18 \\
\hline Wellington & 11.72 & 7.14 \\
\hline
\end{tabular}

Figure 6.6 Percent of level accents. with boosted onset

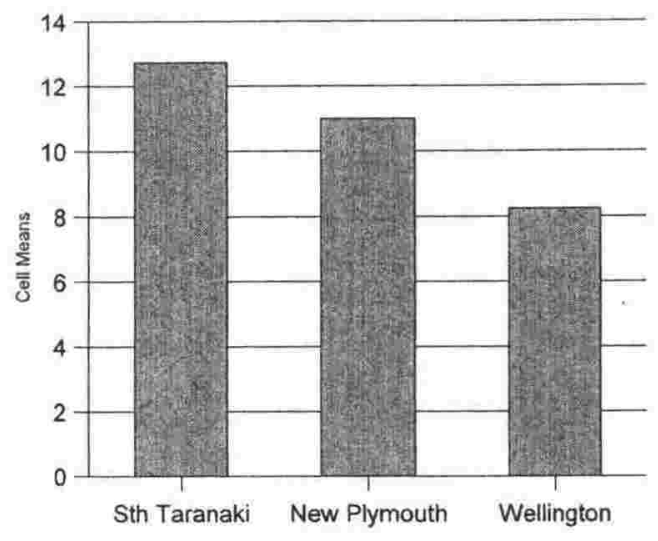

\begin{tabular}{|c|c|c|}
\hline & Mean & sd \\
\hline Sth Taranaki & 12.73 & 6.32 \\
\hline New Plymouth & 11 & 6.41 \\
\hline Wellington & 8.24 & 3.76 \\
\hline
\end{tabular}


Figure 6.7 Average changes of pitch direction per accent unit

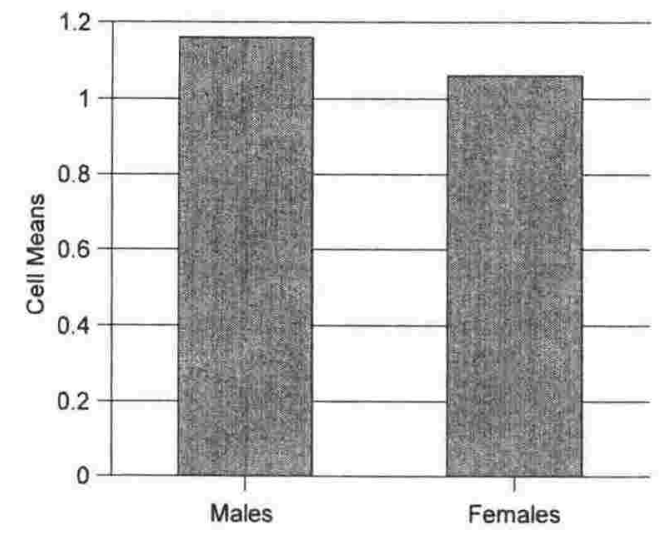

\begin{tabular}{|c|c|c|}
\hline & Mean & sd \\
\hline Males & 1.16 & 0.34 \\
\hline Females & 1.06 & 0.23 \\
\hline
\end{tabular}

Figure 6.9 Percent of non-nuclear accents with moving pitch

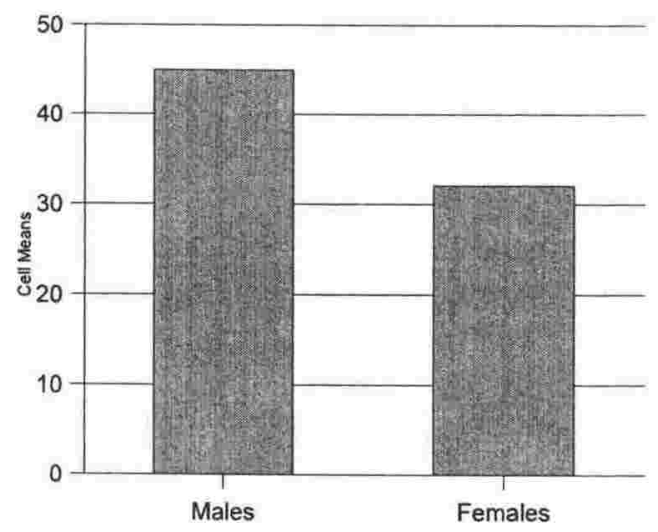

\begin{tabular}{|c|c|c|}
\hline & Mean & sd \\
\hline Males & 44.91 & 18.76 \\
\hline Females & 32.05 & 12.35 \\
\hline
\end{tabular}

Figure 6.8 Percent of complex nuclear accents

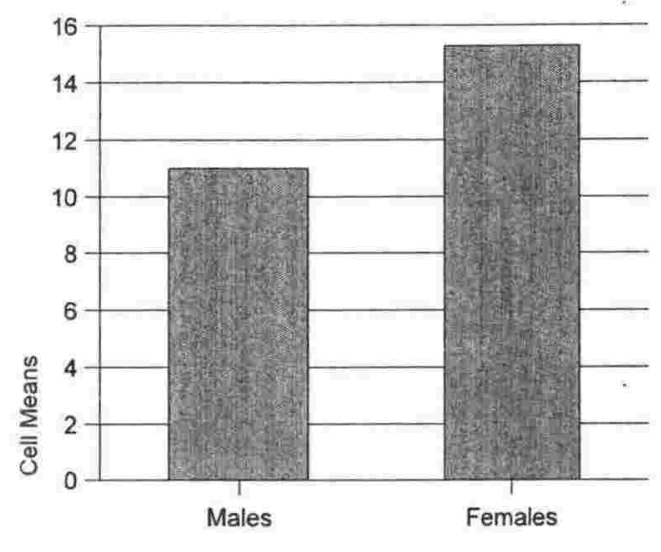

\begin{tabular}{|c|c|c|}
\hline & Mean & sd \\
\hline Males & 11.01 & 5.48 \\
\hline Females & 15.28 & 5.77 \\
\hline
\end{tabular}

Figure 6.10 Percent of level accents with boosted onset

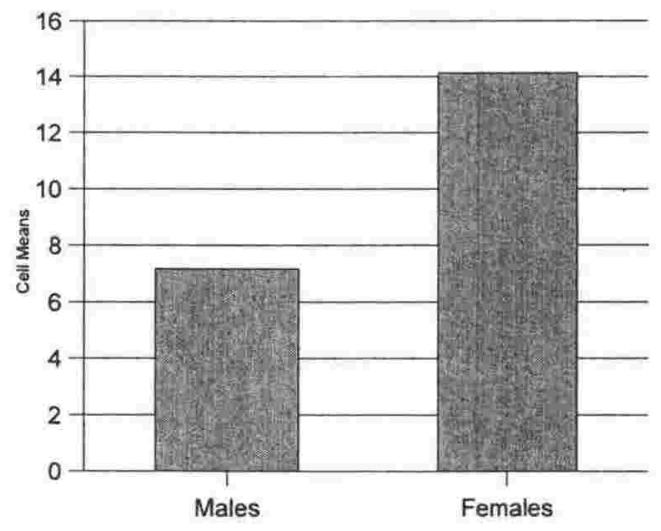

\begin{tabular}{|c|c|c|}
\hline & Mean & sd \\
\hline Males & 7.18 & 4.02 \\
\hline Females & 14.13 & 5.32 \\
\hline
\end{tabular}


6.3.3 Significant Main Effects of Age

Figure 6.11 Average changes of direction per intonation group

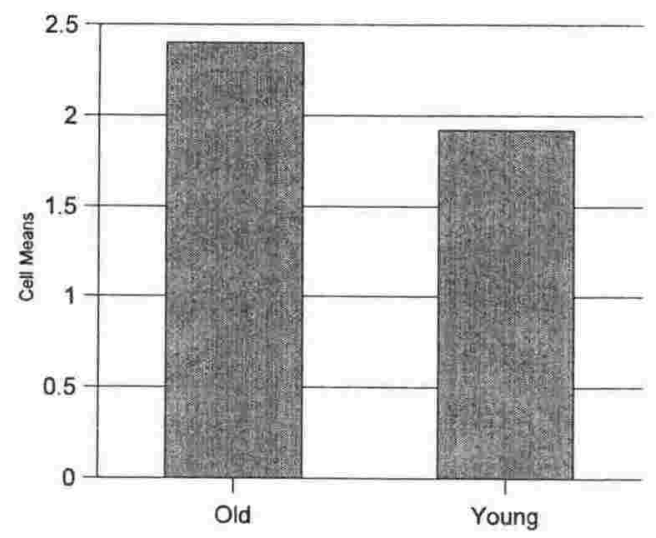

\begin{tabular}{|c|c|c|}
\hline & Mean & sd \\
\hline Old & 2.4 & 0.49 \\
\hline Young & 1.92 & 0.56 \\
\hline
\end{tabular}

Figure 6.12 Average changes of direction per accent unit

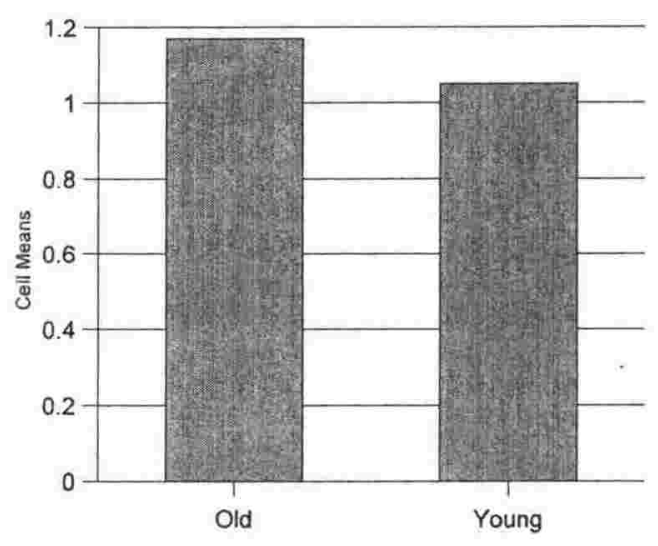

\begin{tabular}{|c|c|c|}
\hline & Mean & sd \\
\hline Old & 1.17 & 0.28 \\
\hline Young & 1.05 & 0.31 \\
\hline
\end{tabular}

Figure 6.13 Percent of nuclear accents with moving pitch

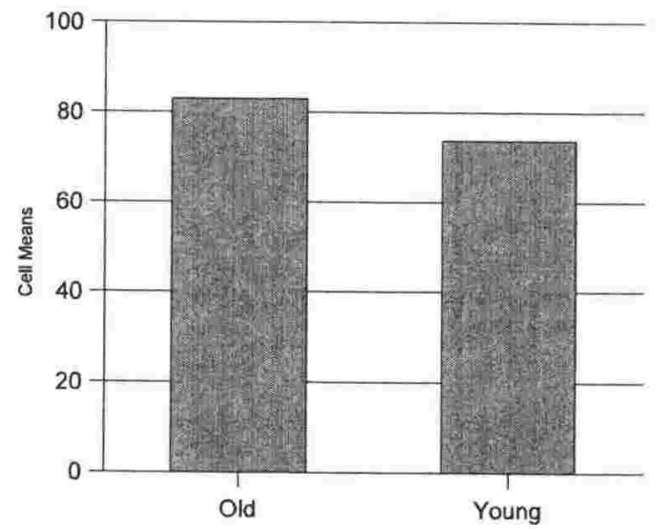

\begin{tabular}{|c|c|c|}
\hline & Mean & sd \\
\hline Old & 82.98 & 7.88 \\
\hline Young & 73.65 & 12.35 \\
\hline
\end{tabular}


Figure 6.14 Percent of falling accents with boosted onset

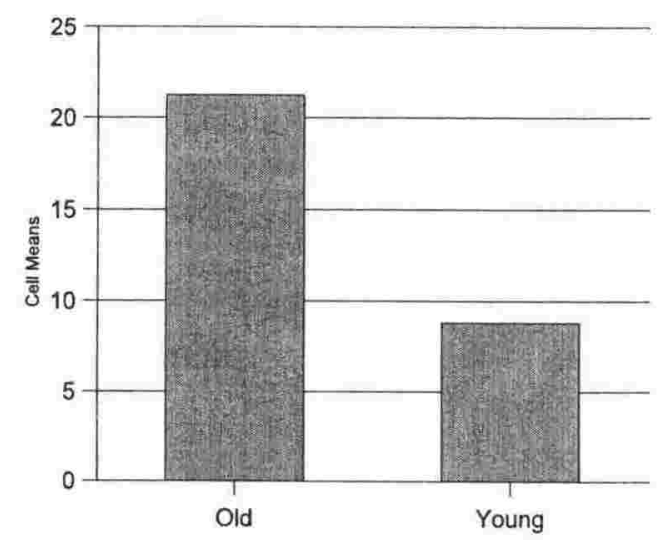

\begin{tabular}{|c|c|c|}
\hline & Mean & sd \\
\hline Old & 21.23 & 7.65 \\
\hline Young & 8.81 & 7.01 \\
\hline
\end{tabular}

Figure 6.15 Percent of level accents with boosted onsets

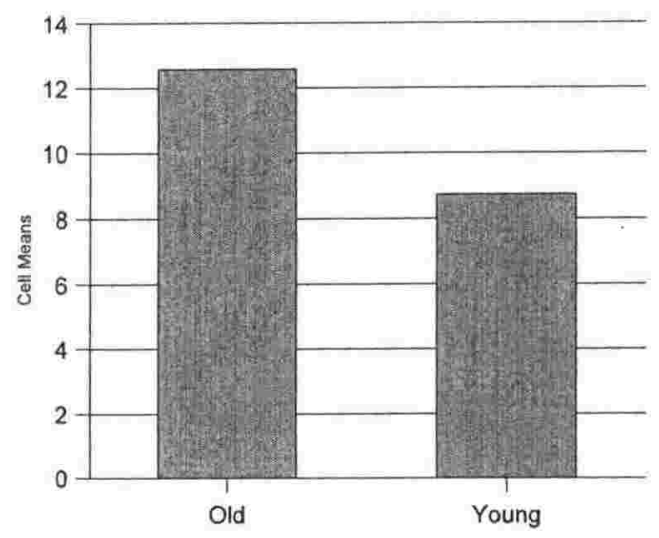

\begin{tabular}{|c|c|c|}
\hline & Mean & sd \\
\hline Old & 12.57 & 5.17 \\
\hline Young & 8.74 & 5.92 \\
\hline
\end{tabular}




\subsubsection{Significant Interactions of Location and Gender}

Figure 6.16 Average change of pitch direction per intonation group

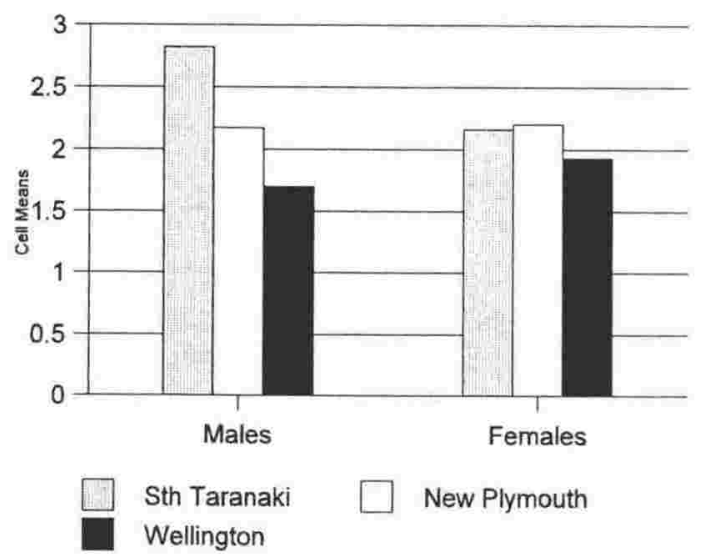

\begin{tabular}{|c|c|c|}
\hline Mean (sd) & Males & Females \\
\hline South Taranaki & $\begin{array}{c}2.82 \\
(0.34)\end{array}$ & $2.16(0.50)$ \\
\hline New Plymouth & $\begin{array}{c}2.17 \\
(0.33)\end{array}$ & $2.20(0.60)$ \\
\hline Wellington & $\begin{array}{c}1.70 \\
(0.73)\end{array}$ & $1.93(0.24)$ \\
\hline
\end{tabular}

Figure 6.18 Percent of nuclear accents with moving pitch

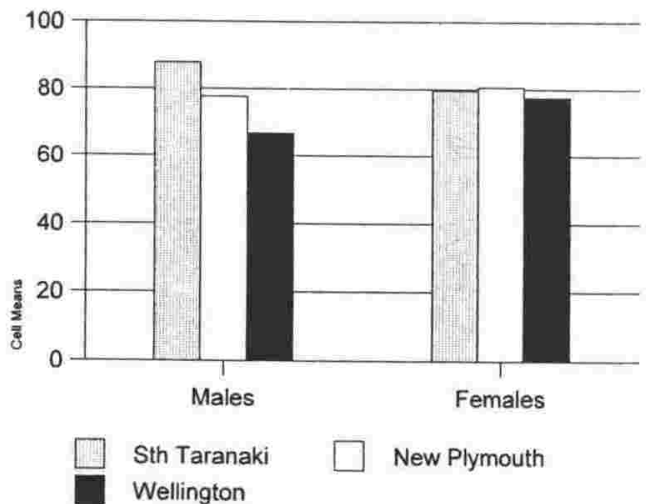

\begin{tabular}{|c|c|c|}
\hline Mean (sd) & Males & Females \\
\hline South Taranaki & $87.83(4.71)$ & $79.62(9.65)$ \\
\hline New Plymouth & $77.64(8.81)$ & $80.54(11.25)$ \\
\hline Wellington & $66.76(15.39)$ & $77.51(4.80)$ \\
\hline
\end{tabular}

Figure 6.17 Average change of pitch direction per accent unit

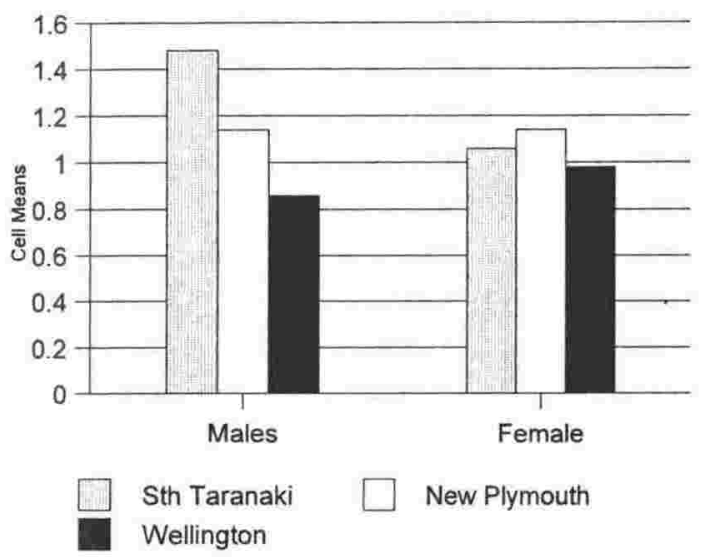

\begin{tabular}{|c|c|c|}
\hline Mean (sd) & Males & Females \\
\hline South Taranaki & $\begin{array}{c}1.48 \\
(0.18)\end{array}$ & $1.06(0.20)$ \\
\hline New Plymouth & $\begin{array}{c}1.14 \\
(0.19)\end{array}$ & $1.14(0.27)$ \\
\hline Wellington & $\begin{array}{c}0.86 \\
(0.31)\end{array}$ & $0.98(0.22)$ \\
\hline
\end{tabular}

Figure 6.19 Percent of non-nuclear accents with moving pitch

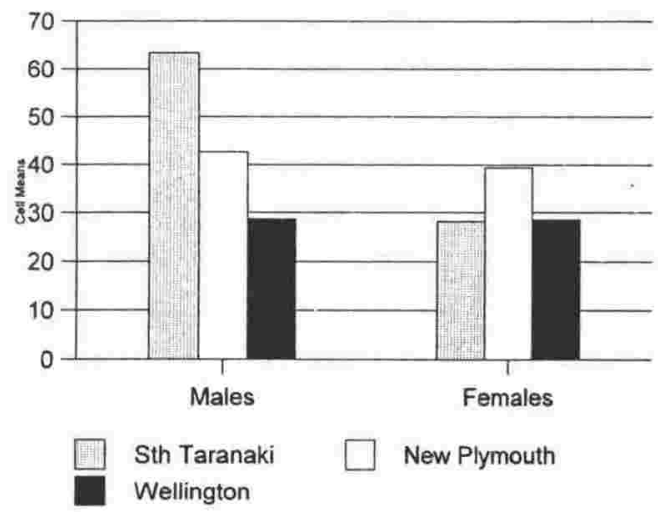

\begin{tabular}{|c|c|c|}
\hline Mean (sd) & Males & Females \\
\hline South Taranaki & $63.35(8.80)$ & $28.23(5.78)$ \\
\hline New Plymouth & $42.62(11.73)$ & $39.43(13.57)$ \\
\hline Wellington & $28.75(15.66)$ & $28.49(13.52)$ \\
\hline
\end{tabular}


Figure 6.20 Percent of falling accents with boosted onset

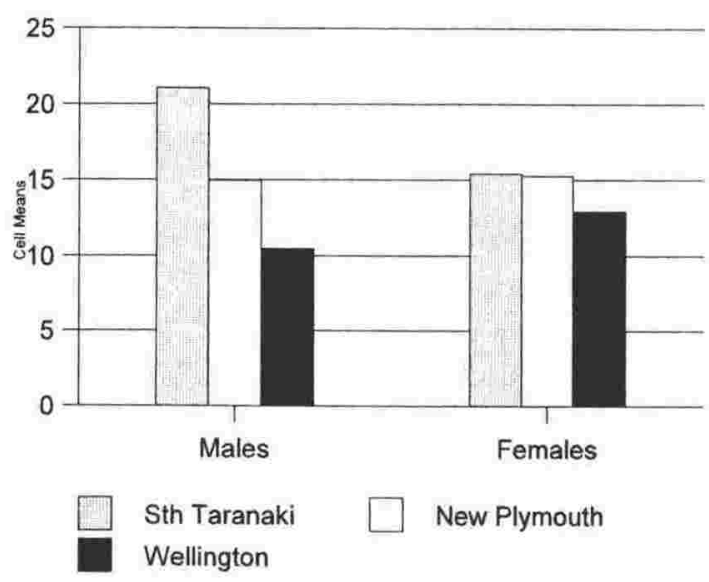

\begin{tabular}{|c|c|c|}
\hline Mean (sd) & Males & Females \\
\hline South Taranaki & $21.05(7.77)$ & $15.41(12.36)$ \\
\hline New Plymouth & $14.95(9.25)$ & $15.27(11.54)$ \\
\hline Wellington & $10.48(8.50)$ & $12.97(5.66)$ \\
\hline
\end{tabular}






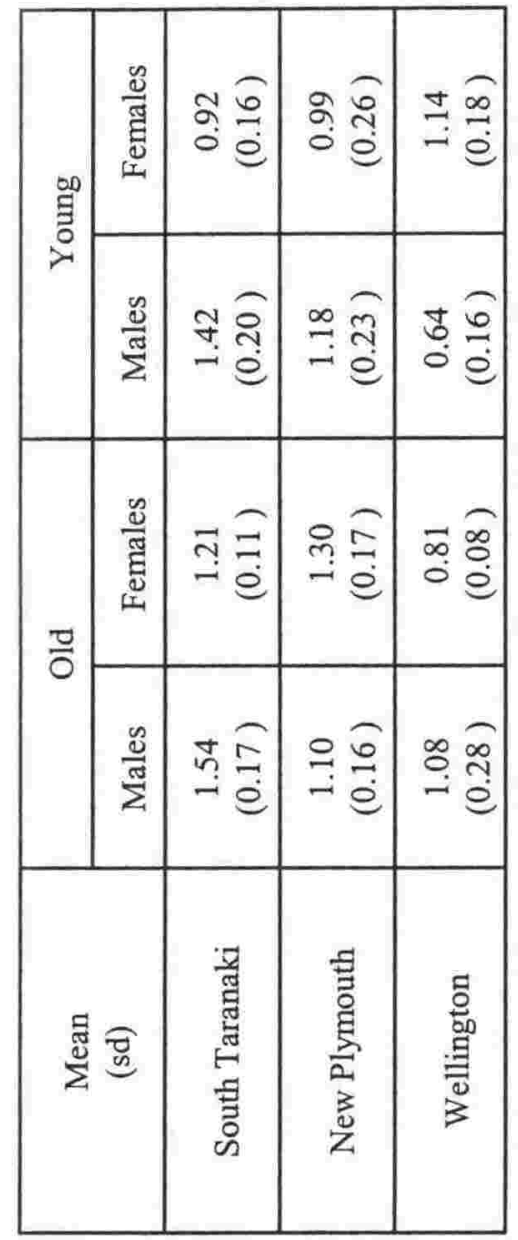

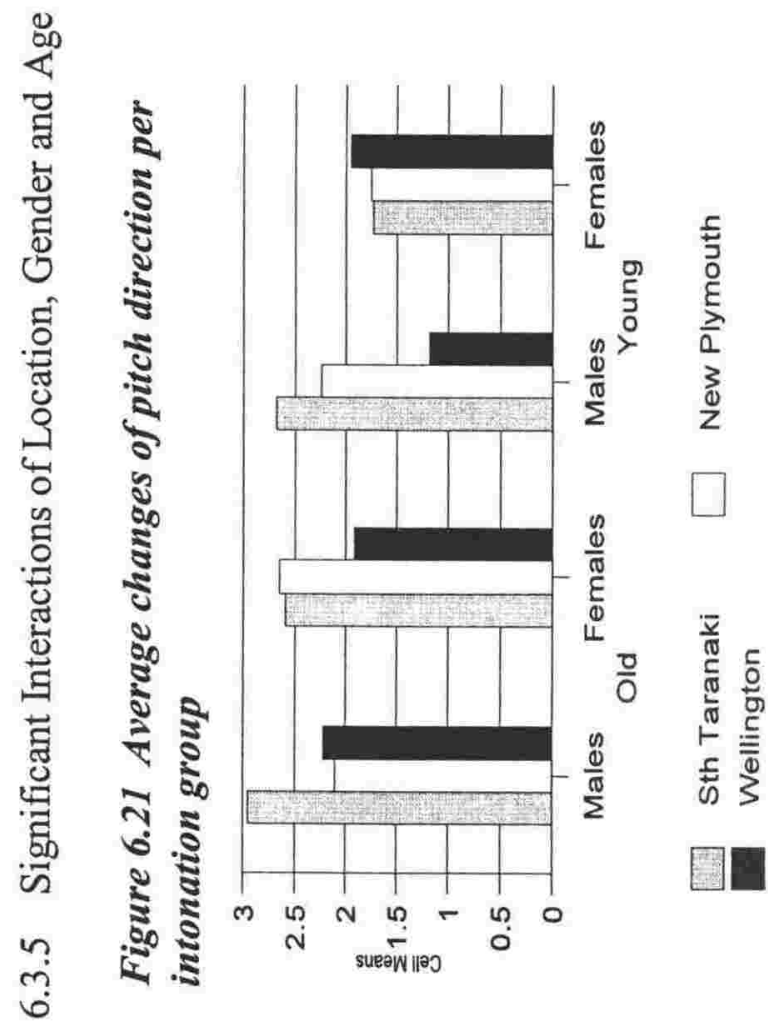

\begin{tabular}{|c|c|c|c|c|}
\hline \multirow{2}{*}{ 章 } & 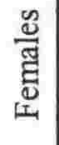 & ঙ્ఠ & $\stackrel{n}{=}$ & 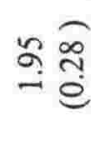 \\
\hline & 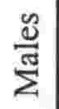 & ¿̊. & ন̃ & $\stackrel{\infty}{=}$ तે \\
\hline \multirow{2}{*}{ 믐 } & 施 & ते & $\begin{array}{l}\tilde{b} \\
i \\
\stackrel{n}{e}\end{array}$ & $\vec{a} \tilde{-}$ \\
\hline & $\frac{\mathscr{\omega}}{\tilde{m}}$ & 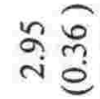 & त्ञ & స̃ \\
\hline \multicolumn{2}{|c|}{ 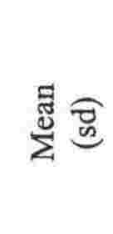 } & 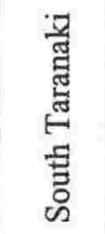 & 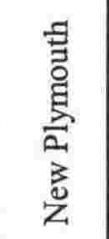 & $\begin{array}{l}\frac{\mathrm{g}}{\mathrm{o}} \\
\stackrel{\mathrm{g}}{\mathrm{e}} \\
\stackrel{0}{3}\end{array}$ \\
\hline & & & & \\
\hline
\end{tabular}



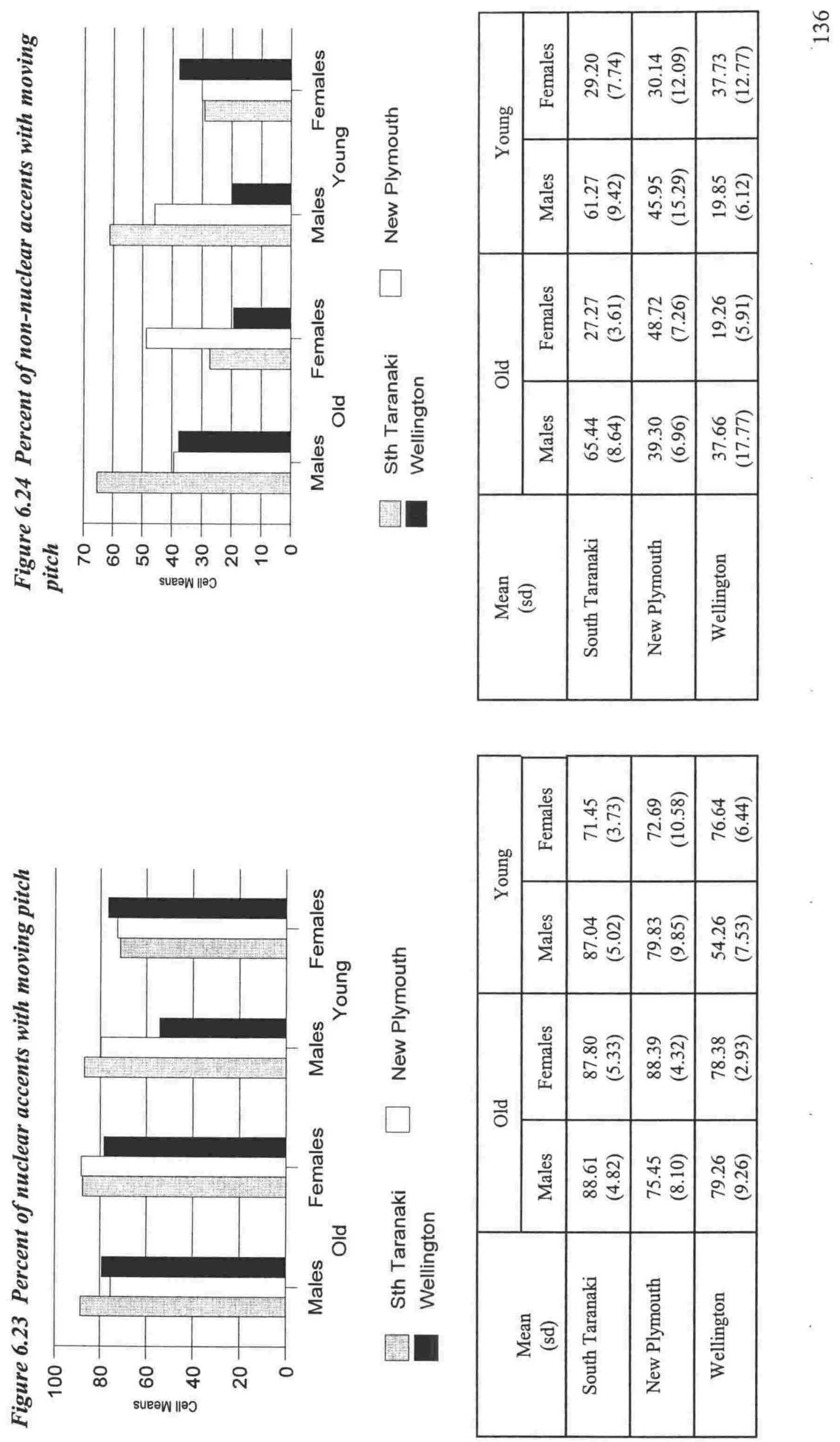

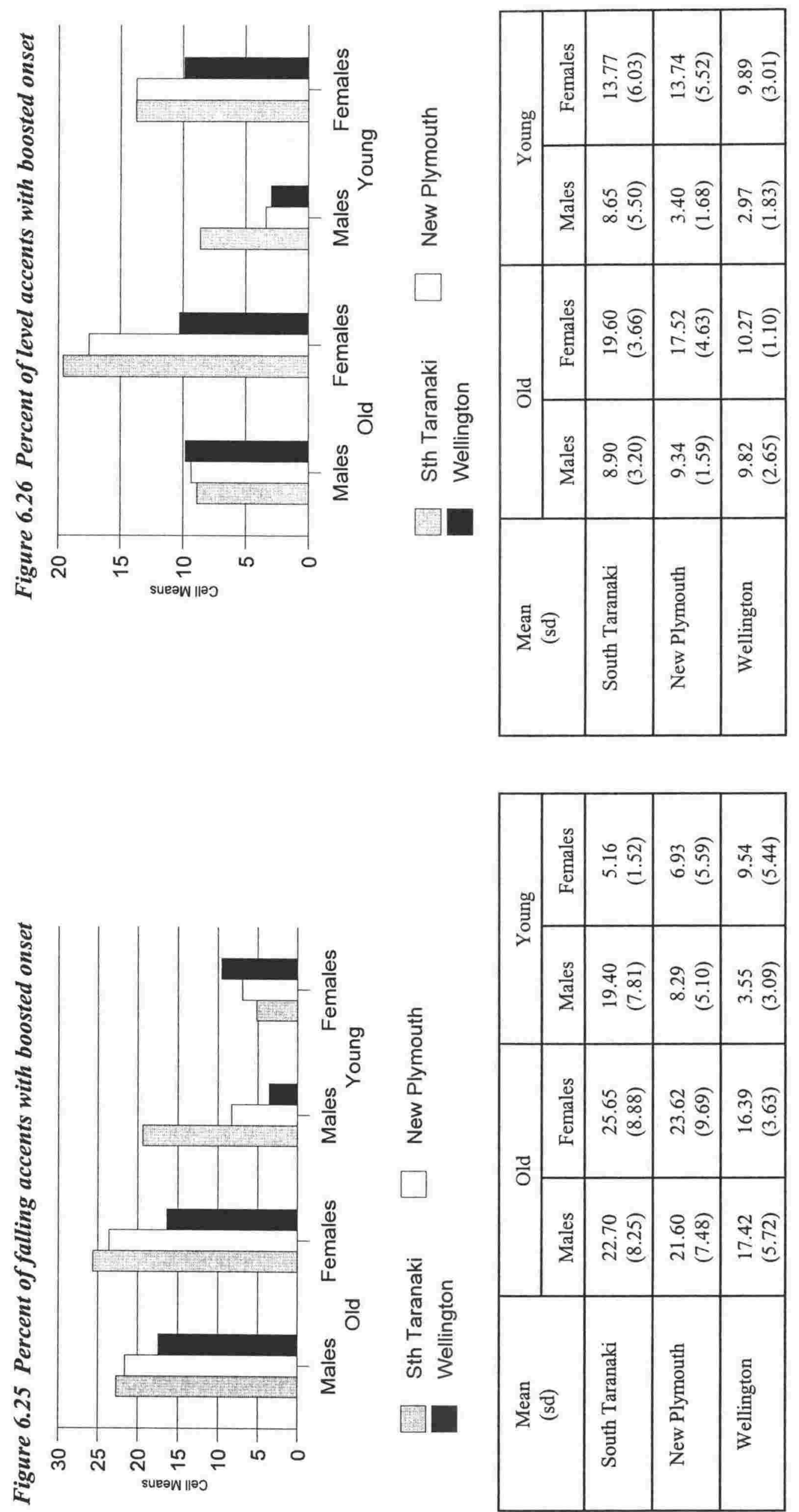

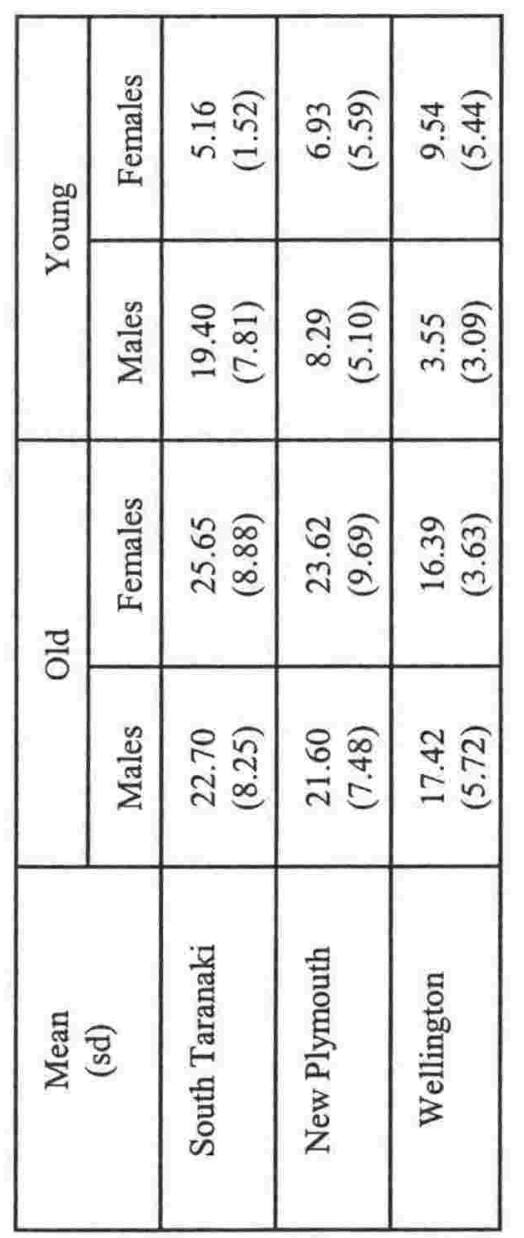



the data with the following results. The rural orientation index correlated positively with changes of pitch direction per intonation group $(r=0.40, p<0.001)$, changes of pitch direction per accent unit $(\mathrm{r}=0.36, \mathrm{p}<0.005)$ and use of accents with moving pitch, both nuclear $(\mathrm{r}=0.35, \mathrm{p}<0.005)$ and non-nuclear $(\mathrm{r}=0.32, \mathrm{p}<0.01)$. There was no significant correlation with complex nuclei, falling accents with boosted onsets or level accents with boosted onsets.

The implications of the results outlined in this chapter are discussed in the following chapter which attempts to bring together all my findings on variation in the intonation of speakers from Taranaki and Wellington. 


\section{CHAPTER SEVEN: DISCUSSION}

\subsection{Introduction}

In the preceding chapter I outlined the primary results of this study by describing the variation associated with each of the intonational features being examined. For purposes of presentational clarity, I kept to a minimum attempts to interpret my findings. Having looked at each feature individually, I now approach the results from a broader perspective, drawing links between individual findings and relating them to insights gained from other studies.

I begin my discussion by focussing on the research questions listed in Section 4.3 and ascertaining to what extent I am able to answer them. My results show that the situation is a complicated one. I will answer the questions by looking at the main effects revealed by my analysis, and at the same time noting the complex interactions between variables. I then address the question of what supporting evidence is needed for my finding that regional variation exists in New Zealand English. Finally I provide a critical discussion of the methodology used to find answers to the questions.

\subsection{Research questions}

The complex interactions outlined in Chapter 6 illustrate how difficult it is to give straight answers to the research questions posed. I shall attempt to clarify the situation by extracting from my results three general rules for pitch dynamism and noting a series of apparent exceptions to these rules. I emphasis here that these 'rules' are purely descriptive and have no regulatory function. By analysing the exceptions I illustrate how the rules interact with each other. The rules and exceptions are discussed in the context of the research questions. Explanations for the exceptions are posited. I hope in this way to show that the situation I have described is less chaotic than might at first appear. Exceptions can sometimes provide us with useful clues as to what underlies linguistic change. 


\subsubsection{Rules for pitch dynamism}

Analysis of all samples in the study showed that as a rule:

(i) Speakers in Taranaki locations showed more pitch dynamism than Wellingtonians.

(ii) Male speakers showed more pitch dynamism across the intonation group as a whole whereas female speakers showed more dramatic pitch movement, especially in features associated with the nucleus.

(iii) Older speakers showed more pitch dynamism than younger speakers.

\subsubsection{Exceptions to the rules}

(i) Exceptions to the first rule were the young dairy farming women in South Taranaki and the young women of New Plymouth who had pitch dynamism patterns more like Wellingtonians than like their fellow Taranakians.

(ii) Exceptions to the second rule were the young men of Wellington who had very low pitch dynamism scores for all features and the elderly women of Taranaki (both the dairy farming women of South Taranaki and the women of New Plymouth) who had high pitch dynamism scores for all features.

(iii) Exceptions to the third rule were the young men of Taranaki, and the young dairy farming men of South Taranaki in particular. The young women of Wellington were also unusual in that for some variables they had higher counts than the elderly Wellington women.

\subsubsection{Regional variation}

Question 1: Is there regional variation in New Zealand English intonation?

My results show that there is evidence of regional variation in New Zealand English intonation, but the picture is complicated by the interaction of regional differences with factors such as gender, age, and rural or urban orientation. A clearer answer to this first research question emerges only after these factors have been discussed. The question will be revisited in Section 7.2.18 below. 


\subsubsection{Location}

Question 2: Does Taranaki English possess intonational features which distinguish it from the English spoken in Wellington?

Rule (i) above, namely that speakers in Taranaki locations showed more pitch dynamism than Wellingtonians, relates most obviously to Research Question (2) and it suggests that this question can be answered in the affirmative. It appears at first sight that Taranaki English does possess intonational features which distinguish it from the English spoken in Wellington. My findings confirm that, of those surveyed, most people living in Taranaki locations displayed more pitch movement than most Wellingtonians. This was demonstrated by the Taranaki speakers' greater use of changes of pitch direction per intonation group and per accent unit. Consistent with this finding was the fact that people from Taranaki locations had a greater tendency than the Wellingtonians to use accents, both nuclear and non-nuclear, which were characterised by moving pitch. Adding to the effect of greater pitch movement amongst speakers from Taranaki is the finding that the people in Taranaki locations showed a greater tendency to use boosted accents (both falling and level) than did the Wellingtonians.

The order from most frequent to least frequent use of all the intonational features indicating dynamism under scrutiny (with the exception of complex nuclei), was the South Taranaki dairy farming community, New Plymouth, then Wellington (see Figures 6.1-6.5). It should be noted though that the differences between each of the locations were not necessarily statistically significant. In the case of non-nuclear accents with moving pitch and accents with boosted onsets the differences between the dairy farmers and New Plymouth were not significant. And in the case of falling accents with boosted onsets the difference between New Plymouth and Wellington was not significant.

The finding that overall there was more pitch variation in the speech of most Taranaki speakers surveyed than in the speech of most Wellingtonians surveyed suggests that Taranaki English does possess intonational features which distinguish it from the English spoken in Wellington. But the fact that not all Taranaki speakers share the same preference for pitch variation suggests that a change with respect to these linguistic 
features might be underway. The change could be the result of 'hierarchical' diffusion (Callary 1975, Trudgill 1983) whereby a linguistic innovation begins in a larger population centre and then trickles down to smaller centres. In this case the linguistic innovation consists of a comparative lack of pitch variation. According to the theory of hierarchical diffusion the tendency towards flatter intonation would have started in the centre with the biggest population, Wellington, then moved to New Plymouth, the next most populous centre, and thence to the more sparsely populated South Taranaki dairy farming community. The results described above suggest that such a pattern of diffusion is taking place.

The hierarchical model of diffusion appears more appropriate in this instance than either the cultural hearth model, which focuses on the speech locality in which an innovation first appears and from which it spreads more widely, or the core-periphery model with its focus on change spreading from the rapidly growing periphery to the more slowly growing older core (Horvath \& Horvath 1997).

As noted in Section 2.5, proponents of geolinguistic theory such as Britain (1991) and Horvath and Horvath (2002) emphasise the need to examine the effects of 'place' as opposed to 'space' in order to understand the geographic distribution of linguistic features, 'place' referring to 'the ensemble of sociolinguistic conditions within a speech locality', and 'space' to the physical relationship between speech localities (Horvath \& Horvath 2002:63). The need to look beyond physical space, or in my terminology 'location', is clearly evident when the speech behaviour of individual groups of speakers within my corpus is examined.

Consideration of the way in which Gender and Age interacted with Location with respect to the features being studied shows that it cannot necessarily be said that because someone comes from Location $\mathrm{x}$ their speech is likely to be characterised by particular intonational features. There was a significant interaction of Location, Gender and Age for all features except complex nuclei. In other words, whether or not a speaker is likely to have particular intonation patterns depends not only on their Location but also on their Gender and their Age. A speaker might be from the South Taranaki dairy farming community, but if they were male they were likely to have high scores for pitch 
movement and if they were female their scores would be lower. In addition to this an elderly dairy farming man was likely to have more pitch movement than a young dairy farming man, and an elderly dairy farming woman was likely to have more pitch movement than a young dairy farming woman. There was not much difference overall between male and female speakers in New Plymouth but when the age of speakers was considered it was clear that elderly New Plymouth women had more pitch movement than both elderly and young New Plymouth men and considerably more than young New Plymouth women. In the case of Wellington speakers, the men had intonation characterised by less pitch movement than the women, but when the age of the speakers was considered as well as their gender, the elderly Wellington men were shown to have more pitch movement than Wellington women both young and old. The Wellington young men had the lowest pitch movement scores of all groups.

This is potentially very confusing. But for the most part the different sample groups do conform to Rule (i) for Location, the exceptions being as stated above, the young women of Taranaki, whose intonation is notable for its relative evenness of pitch. The young women's behaviour, however, is in line with Rule (ii) relating to Gender and Rule (iii) relating to Age.

\subsubsection{Gender}

Rule (ii) that male speakers showed more pitch dynamism across the intonation group as a whole than female speakers whereas female speakers showed more dramatic pitch movement, especially in features associated with the nucleus, relates to Research Question 3.

Question 3: Are there intonational differences in the English spoken by male and female speakers in these regions?

Analysis of the intonational features surveyed indicated some differences between the men and the women in the sample. In some respects the men showed more pitch variation than did the women. The men in the sample changed pitch direction more frequently per accent unit than did the women. They also used more non-nuclear accents 
characterised by moving pitch than the women. On the other hand level accents with boosted onsets and complex nuclear accents were clearly favoured by women. Counts for changes of direction per intonation group showed no significant gender difference, and there was no significant male or female preference for nuclei with moving pitch, or for falling accents with boosted onsets. This may be because men and women are using different means of marking changes in pitch. This applies to rises in particular, women having higher counts than men for boosting as opposed to moving pitch.

These results are interesting in that a different gender pattern might be predicted on the basis of stereotypical descriptions of female intonation (admittedly American female intonation) of the type listed by Henton (1989:299): 'high-pitched', 'shrill', 'overemotional' 'swoopy'; or by McConnell-Ginet (1983:555): 'more dynamic than men's, displaying wider ranges of pitches, more frequent and rapid shifts in pitch, and more frequently ending with a non-falling terminal than men's.' Such characterisation would predict that the women might favour more pitch movement than the men. It does not appear from my results that this was necessarily the case except that boosting might be considered to be more dramatic and rapid than moving pitch. Using my measure of pitch variation it was apparent that, where there was a significant gender difference, it tended to be the men who had more pitch movement than the women.

With respect to two of the features examined, however, the women tended towards McConnell-Ginet's stereotype that their intonation 'more frequently end[s] with a nonfalling terminal than men's' (McConnell-Ginet 1983:555). The two features I refer to are level accents with boosted onsets and complex nuclear accents, the latter including fall-rise accents. These features amount to upwards change in pitch direction and could be described as 'non-falling terminals' (for 'terminal' read nuclear accent). They often serve a similar function to the High Rising Terminal (HRT) which has been shown to be associated more with female than male speech (see Section 4.2.2.3.2). Although data were not specifically analysed for HRTs they were clearly present in the intonation of many speakers. It is my impression that in my data HRTs tend to be preceded by level sections of intonation, and falling terminals by falling accents. The pattern of falls is characterised by more changes in pitch direction since each falling accent starts at a higher pitch level than the end of the preceding falling accent. The women were shown 
to use fewer non-nuclear accents with moving pitch than the men, which is consistent with their preference for level accents with boosted onsets and complex fall-rise nuclei which sometimes functioned as HRTs. I make no claims, however, that speakers with intonation characterised by a lot of pitch movement up and down did not also produce HRTs. Complex fall-rise nuclei and level accents with boosted onsets are perhaps not good indicators of 'sing-songyness' if they are commonly preceded by level accents.

The same caution for the main effect of Gender applies as with the main effect of Location. It does not necessarily follow that because a speaker in the corpus is male or female they are likely to have a particular set of intonational features. Where they live and how old they are is also important. Of all the features, complex nuclei alone appeared to be affected by a single variable. Women, whether from Taranaki or Wellington, whether old or young, used more complex nuclei than men. This is possibly an example of the phenomenon described by Edelsky (1979) as 'listener-orientation adaptive pitch tuning'. Edelsky found that women speakers of American English used more complex intonation patterns when interacting with a female interviewer. The three interviewers of women in the present project were all women. Unless the interviews were repeated with men doing the interviewing there is no way of knowing if the female interviewees were adapting their pitch to the pitch patterns of the interviewer.

The complex way in which Location and Age interact with Gender can be seen in Figures 6.21 - 6.26 and the interactions are described in Section 6.3. Of particular interest here are the exceptions to Rule (ii). The young men of Wellington had the lowest of all the scores on the pitch dynamism scale in spite of the general rule that males showed more pitch dynamism than females across the intonation group as a whole. Their scores, however, were completely in tune with Rule (i) for Location and Rule (iii) for Age. The elderly women of Taranaki did not conform to Rule (ii) either, their pitch dynamism scores being at the high end of the scale unlike most of their gender. But, as with the young Wellington men, their scores were in keeping with the rules for Location and Age. 


\subsubsection{Age}

The next research question deals with the issue of age and is linked to Rule (iii) that older speakers showed more pitch dynamism than younger speakers. Answering this question will provide some indication as to what older intonation patterns were like and how newer patterns sound.

Question 4: Is there any evidence of change over time in the intonation of speakers from Taranaki and Wellington?

The results of my analysis provide clear evidence of change over apparent time in the intonation of speakers from Taranaki and Wellington. There was more pitch variation amongst the elderly than among the young of both regions. The elderly speakers changed pitch direction more frequently per intonation group and per accent unit than did the younger speakers. They also used more nuclear accents with moving pitch, and more accents, both falling and level, with boosted onsets. It is noteworthy that the highest scores for four of the features studied (changes of pitch direction per intonation group and per accent unit, and percentage of accents with moving pitch, both nuclear and non-nuclear) belonged to the elderly men of South Taranaki, in other words the NORMs, or 'nonmobile, older, rural males', preferred by the traditional dialect geographers (see Section 2.3). If dynamic pitch is conservative, then these men appear to have the most conservative intonation patterns.

Only two of the seven intonational features examined failed to show a significant difference between the old and the young speakers. These were non-nuclear accents with moving pitch and complex nuclei.

However, in spite of the main effect of Age on the five variables listed above, there was an interaction with Age, Location and Gender such that for most variables there was little difference between the elderly and young men of New Plymouth, and the complex pattern for Wellington women can be seen in Figures 6.21 - 6.26, wherein sometimes the young women had higher scores than the elderly women, sometimes it was the other way round and at other times there was little difference between the two groups. 
(I explore possible reasons for this behaviour in Section 7.2.10). Youth, it seems, does not guarantee less pitch movement. Once again it depends on where a speaker lives and whether they are male or female. This was particularly apparent where the young dairy farming men of South Taranaki were concerned. Although their speech was characterised by less pitch movement than that of the elderly dairy farming men, they were still amongst the highest scorers for most variables studied. They may provide an exception to Rule (iii) for Age, but they nevertheless conform to Rule (i) for Location and Rule (ii) for Gender. The other group I have listed as an exception to Rule (iii) are the young women of Wellington. They are less exceptional than the young dairy farming men given that, generally speaking, their intonation could be said to be less dynamic than that of most elderly people. I highlight them because they nevertheless demonstrated considerable pitch movement relative to the elderly women of Wellington on two of the features studied, i.e. changes of pitch direction per accent unit and nonnuclear accents with moving pitch. In this respect they broke Rule (iii) for Age. Their scores tend towards the middle of the spectrum for most features but on the whole they conform with the rules for Location and Gender.

\subsubsection{Explanations for exceptional cases}

Having observed how the three rules interact, I will now explore the apparently exceptional cases further, seeking explanations for their existence in sociolinguistic and social network theories. During the course of the discussion reference will be made to all of the sample groups, each of them having an important part to play in the account, but particular note will be made of the exceptional groups listed above. I begin with an examination of the noticeable contrast between the pitch patterns of the young dairy farming men and women of South Taranaki.

Table 7.1 below shows that the young dairy farming men had higher scores than the young dairy farming women for five of the seven intonational features studied. The women had more level accents with boosted onsets (possibly indicating more rapid and dramatic change in pitch) and similar amounts of complex nuclei, but in all other respects the young men had intonation which was characterised by more pitch movement than the young women's. 
The final column for the first two features in the table shows the significance level of $t$ test analysis comparing data for males and females. The final column for the remaining five features shows the significance level of chi-square analysis comparing data for males and females.

\begin{tabular}{|l|c|c|c|}
\hline & \multicolumn{2}{|l|}{$\begin{array}{l}\text { Sth Taranaki } \\
\text { Males }\end{array}$} & $\begin{array}{l}\text { Sth Taranaki } \\
\text { Females }\end{array}$ \\
\hline CoD/int. group & 2.68 & 1.72 & $\mathrm{p}<0.001$ \\
\hline CoD/accent unit & 1.41 & 0.91 & $\mathrm{p}<0.01$ \\
\hline$\%$ nuclei moving & 87.16 & 71.39 & $\mathrm{p}<0.001$ \\
\hline$\%$ complex nuclei & 13.63 & 13.77 & $\mathrm{~ns}$ \\
\hline$\%$ non-nuc moving & 61.73 & 29.25 & $\mathrm{p}<0.001$ \\
\hline$\%$ falls boost onset & 19.59 & 5.31 & $\mathrm{p}<0.001$ \\
\hline$\%$ level boost onset & 8.7 & 13.23 & \\
\hline
\end{tabular}

Table 7.1. Differences between young South Taranaki males and females.

\subsubsection{Social networks}

The differences in the intonation patterns favoured by the young men and women in question could appear somewhat puzzling at first, particularly if we look at the closeknit South Taranaki dairy farming community under scrutiny here in the light of the social network theory developed within sociolinguistics by Milroy and Milroy (1985). As noted in Section 2.6, rural communities have traditionally been characterised by the 'dense' and 'multiplex' social networks which the Milroys identified amongst working class people of Belfast. In such settings a strong sense of solidarity is often found and pressure exerted on members to conform to social norms, including mainstream linguistic values. Husbands and wives in South Taranaki typically worked together as business partners on their farms. Childcare was shared by both partners. One young couple described how their preschool children played in a caravan parked alongside the cowshed, freeing up both parents at milking time. Several of the young men commented 
that the amount of time they spent with their young families was one of the advantages of their rural lifestyle over life in town. Most of the speakers in the sample mixed with each other socially and one of the men and one of the women were married to each other. According to social network theory these close network ties should correlate with similar scores on the measure of pitch dynamism, but this was not the case.

\subsubsection{Language markets}

Careful scrutiny of the speakers' employment histories provided clues as to the possible source of the gender differences identified. In the biographical section of the conversational interviews I conducted, interviewees were asked for details of their schooling and their employment, historical as well as current. All interviewees had been brought up on dairy farms in South Taranaki, had attended primary schools in the region followed by attendance at Opunake High School. All had spent the early years of their adulthood away from the area and had returned to take up dairy farming in their midtwenties. On leaving high school the men attended polytechnic in New Plymouth, or in one instance Massey University in Palmerston North, to obtain agricultural and/or trade certificates/diplomas and they worked in New Plymouth as tradesmen for a few years. The women on the other hand moved to New Plymouth and worked in offices, banks or hair dressing salons. The women's jobs could be described as service jobs involving a lot of contact with people from all walks of life whereas the men's jobs could be described as practical, and everyday contact would probably have been predominantly with men in similar employment. This situation is not unlike that described by Nichols (1983) in a study she undertook of a Gullah-speaking African American island community in South Carolina. She found that in general the women of the island spoke a variety of English which more closely resembled standard English than the variety spoken by the men. This was because the men worked in manual jobs on the mainland which required physical skills and did not depend on the way they spoke, whereas the women worked in service jobs connected with the seasonal tourist industry which entailed interaction with a wide spectrum of speakers and standard language was called for. Eckert and McConnell-Ginet (2003:286) refer to this situation as 'gendered jobs in the language market'. 'Like the right friends, clothes, manners, haircuts and automobiles,' they say 'the "right" linguistic variety can facilitate access to positions 
and situations of societal power and the "wrong" variety can block such access' (Eckert \& McConnell-Ginet 2003:271). In this case one of the language markets demanded vernacular or local language and the other required standard or global language.

The years of early adulthood may have been critical in the development of differing intonational patterns amongst the men and women of South Taranaki. The young women may have accommodated their pitch patterns to match those of the young women they were working with in New Plymouth. The intonation of the young New Plymouth women was notable for a similar lack of pitch dynamism. These women, like the dairy farming young women, were employed in service jobs such as accounting, nursing, and floristry. The young men, mixing mostly with each other or with men like themselves, maintained the intonation patterns they had grown up with. The young men of New Plymouth had lower pitch dynamism scores than the young dairy farming men, but they too had higher scores than the young women of their area. So why is it that the young women of Taranaki had scores which were similar to the Wellingtonians' scores? And why is it that, for the most part, their intonation did not conform with the stereotypical female patterning of intonation as outlined by McConnell-Ginet (1983:555)? It most certainly could not be accused of being 'swoopy', one of the descriptors which features in Henton's list of stereotypically female intonation traits (Henton 1989:299).

\subsubsection{Changes old and new}

For answers to these two questions we need to consider Rule (iii) that generally speaking older speakers showed more pitch dynamism than younger speakers. Analysis of data from the two widely separated age groups provided me with a kind of apparenttime window onto the diachronic development of change in intonation patterns. In other words intonation characterised by a comparative lack of pitch dynamism is the more innovative form because it is favoured by the young speakers in the sample and not by the elderly speakers. This would appear to conflict with the fact that the HRT, a particularly dynamic intonational feature, is also favoured by younger speakers (Britain 1992). (But note my comments regarding a possible connection between HRTs and level intonation in Section 7.2.5 above. Note also Warren and Daly's findings regarding 
women's preference for rapid, sudden movements in HRTs (Warren \& Daly 2005 f.c.). Such movement would be distinct from sing-song patterns which entail more regular pitch movement up and down). It appears that the young women in the Taranaki sample have adopted the more innovative level intonation and the young men have not.

This behaviour is perhaps not so surprising if we turn to the findings of other sociolinguistic researchers. Recall Labov's conclusion based on a very wide range of research into dialectology that, while women have been shown to lead in linguistic changes which are new and dynamic, they have also been shown to lag behind men in the use of variables representing older changes (Labov 1990). Recall also Woods' (1997) illustration of this generalisation in her study of gender-related variation and linguistic change in the development of New Zealand English in the Otago region of New Zealand. Her analysis revealed three distinct stages in the diachronic development of New Zealand English as spoken in Otago with women being the first to adopt innovative features which were then adopted by men over time, at which point women had a tendency to revert to earlier forms (see Section 2.4.3). Recent work by Warren (2005) indicates the same pattern may be present in New Zealand English intonation data which he has been analysing. Analysis showed a generational difference in the use and shape of rising intonation patterns. He found evidence that 'the norm for NZE is a late rise onset, that earlier rises were first introduced by female speakers, predominantly for questions, and that this pattern was subsequently taken up by males' (Warren 2005:20). Woods suggested that where it is found that men are leading linguistic change, it tends to be in situations of geographic restriction and comparative lack of contact with speakers of different varieties. Labov's (1972a) classic Martha's Vineyard study (see Sections 2.4 .3 and 2.7.2) proved this point. The men of the community led in a language change which was clearly not the result of dialect mixing but rather the adoption of a form associated with conservative usage on the island. In another classic study Milroy and Milroy (1993) found that 'strictly localised' variants were most frequently used by men in their Belfast study and 'supralocal' forms were favoured by women. The same was found to be true of men and women in Newcastle (Milroy 1999). In this study women were found to be more advanced in terms of dialect levelling in that they characteristically converged on a limited range of general Northern English vowel variants, eliminating more locally marked variants retained by men. 
The situation of the young dairy farming men in South Taranaki could in some regards be compared with that of the men in Labov's study of Martha's Vineyard (Labov 1972a). The middle-aged fishermen of Martha's Vineyard showed a strong tendency to maintain the linguistic features typical of the older generation of fishermen in the region. This was interpreted by Labov as a linguistic response to socio-economic changes in the community. On Martha's Vineyard there had been a downturn in the fishing industry and a decline in farming and dairying with a consequent increasing reliance on tourism and summer holidaymakers for income. The linguistic response amongst the men to these changes was to demonstrate their pride in being different to the incoming flood of socio-economically privileged mainlanders by maintaining the linguistic features typical of the older generation of fishermen. The socio-economic history of the young dairy farmers in Taranaki in no way resembles that of the Martha's Vineyard fishermen in Labov's study. I draw the comparison because of the similar social isolation of the young Taranaki men and because of the pride they expressed in being from the 'Naki'. All had had a taste of the world outside South Taranaki and all had subsequently chosen to return home. All said they enjoyed their work and life-style. None had any desire to live elsewhere. These young men may be subconsciously using older, local intonation patterns as a badge of local identity.

The young women's response to a seemingly similar situation was to adopt the linguistic norms of society outside the farming community of South Taranaki, accommodating to the speech patterns of the young women they mixed with in New Plymouth. The intonation of the young women in New Plymouth was in turn very different to that of the women of their grandmothers' generation who had very dynamic pitch movement, more in keeping with the stereotypical intonation described by Henton and McConnellGinet. This was possibly symptomatic of the more traditionally 'feminine' role they might have played in society. The intonation of the young women in Taranaki more closely resembled that of their urban sisters in Wellington. The gender pattern of the younger age group in Wellington showed a reversal of the situation present in Taranaki. In Wellington it was the young men who favoured less dynamic pitch movement. In fact they had the most level intonation of all groups measured. It is tempting to interpret the pattern of change from more dynamic to less dynamic pitch movement as being similar to that pointed out in numerous contexts by Labov (1990) and demonstrated by Woods 
(1997) in Otago with regards to the MOUTH diphthong (see Section 2.4.3). Women may have led the change from dynamic pitch to flatter intonation in Wellington and they continue to do so in Taranaki. The pattern in Wellington may have become a more established variant and the men have adopted it, the women meantime having reverted in part to an earlier norm. Not only is their intonation characterised by more pitch movement than the young men's, for two of the variables the young women have higher scores than the elderly women of Wellington. With no hard evidence on this issue to date however, this needs to be a subject for future research.

\subsubsection{1 'Standard' versus 'non-standard' intonation}

A case can be made that the young women in Taranaki are acting out the role which New Zealand women have long been playing in adopting innovative features which lead to changes in the standard accent (see Section 2.4.3). By looking at women's usage it may be possible to predict what New Zealand English will sound like in future. If this is so, it would be reasonable to assume that the future standard for New Zealand English will be, if it is not already, the flattish intonation preferred by the young women of Taranaki. The distinctiveness of Taranaki's intonation currently rests with the young rural men who, for now at least, express their staunchness and pride in being from the 'Naki' via their dynamic pitch movement.

\subsubsection{Social status}

Another approach which can be taken when considering the comparative lack of pitch variation of the young South Taranaki dairy farming women and the relatively dynamic intonation of their menfolk is to view the difference from the perspective of social status and prestige. It may be that the women who work alongside men in equal partnerships on their farms have unconsciously rejected speech traits which they see as stereotypically feminine. Stereotypically feminine intonation patterns of the type listed by Henton and McConnell-Ginet would be just as inappropriate in the cow shed as high heeled shoes. This may imply that they wish to sound like men. But which men? Certainly not the dairy farming men with whom they associate most. And their intonation is not as level as that of the young men of Wellington. It is more likely that 
their model is not men's intonation at all but the intonation of their sophisticated city sisters in New Plymouth and Wellington. It is interesting to note that the pattern of men having more pitch movement than women in South Taranaki is not new. The same pattern exists, albeit to a lesser extent, among the elderly men and women of the area. (For one feature in particular, non-nuclear accents with movement, the elderly women's scores are considerably lower than the elderly men's). The wives of farmers have traditionally had an important part to play in the running of farms and it may be that overly 'feminine' behaviour in such contexts has always been disfavoured.

\subsubsection{Non-conformity, social mobility and innovation}

Female innovators have been described by Labov $(2001,2002)$ as tending to be upper working class, skilled individuals who have a wide network of contacts outside their local communities as well as a dense network of local ties. They are observed to have a history of resistance to repressive authority, to be socially upwardly mobile and to be well respected within their local social networks. 'The history of our leaders of linguistic change is a history of nonconformity, and their sociolinguistic position is a display of nonconformity' (Labov 2001:410).

The Taranaki sample provided at least one example of such an individual. One young woman grew up in what is known by locals to be the 'roughest' part of New Plymouth, attended local schools, then went on to university where she qualified as an accountant. Her work has taken her overseas to conferences. As well as strong local networks she has national and international contacts. She has demonstrated social mobility and would be one of the highest achievers in the sample. If we examine her count for falling accents with boosted onsets, the feature which I claim is possibly most diagnostic of 'sing-songyness' (see Section 7.3.2), we find that she has the lowest count of all the Taranaki speakers $(2.51 \%)$. Scrutiny of the whole sample, including Wellington speakers, shows only two speakers with lower scores. Both of these are young Wellington men - one with a score of $1.03 \%$ and the other with a score of 0 . The young Taranaki women did not all have such non-conformist backgrounds, but the influence of the few that did could have been powerful. 


\subsubsection{Gender socialisation}

Looking at the issue from the perspective of gender socialisation throws further light on possible reasons for the differences between the men and women in the sample. Men and women draw on different resources to construct their social identities and this can be reflected in their speech.

'Men must stick to a narrow path and they must not innovate because they fear the consequences of any behaviour, including sociolinguistic behaviour, which sets them apart from their peers. Women, on the other hand, are free to use the symbolic resources of phonological variation for purposes other than indexing gender and to use innovatory forms without fear of the consequences' (Milroy 1999: 375).

So one possible explanation for the difference is that the young dairy farming men, who perhaps feel constrained by peer norms, use the conservative, localised, intonational variants and the young women feel free to use more innovative, supralocal variants.

\subsubsection{Impact of socio-economic and ideological changes}

To state the obvious, language is constantly changing. As noted in Section 2.7.2, four decades on from Labov's study of the speech of Martha's Vineyard, researchers have returned to the region and found that earlier linguistic patterns have undergone changes in the intervening years (Blake \& Josey 2003). Blake and Josey argued that the changes were linked to socio-economic restructuring and resulting ideological changes taking place on the island. The locals' allegiance to the traditional way of life has diminished and there has been a decline in the linguistic marking of opposition to non-local populations. Changes in the socio-economic and cultural environment of rural South Taranaki will undoubtedly occur over the coming years just as they have in Martha's Vineyard. Dairy farming in New Zealand is becoming less and less a family affair. The recent recruitment campaign on New Zealand television for careers in dairy farming is unprecedented in my life time. Opening up the South Taranaki rural community to more outsiders may result in shifting allegiances amongst the local community and there may be linguistic responses to the impact of the changes. It is not impossible that the current difference between the intonation patterns of the men and women of the area will be less 
obvious in future. The young men of Taranaki may well follow the lead of the women of the area and decide it is 'cool' to adopt the supralocal pitch patterns of their urban counterparts in Wellington. On the other hand, they may choose to continue to express their 'Naki-ness' by means of their dynamic intonation, just as the young men of the Cajun English speaking community in rural areas of Louisiana have been shown to display their 'Cajun-ness' through language (Dubois \& Horvath 2000), and members of the Lumbee Native American Indian community have been shown to emphasize their . cultural and ethnic distinctiveness through their dialect of English (Wolfram \& Dannenburg 1999).

\subsubsection{Summary of explanations}

In summary, I posit the following explanations for the linguistic behaviour of the groups of speakers highlighted as being exceptions to the three rules listed in Section 7.2.1.

The young women on South Taranaki dairy farms do not conform with the rule for Location because, having spent three or four years of their early adulthood working in service jobs in New Plymouth, they have accommodated their speech to that of people outside South Taranaki, the young women of New Plymouth in particular. Secondly, because of their status as equal partners in their dairy farming businesses, they have subconsciously rejected stereotypically feminine speech patterns such as 'swoopy' intonation because such patterns might suggest an imbalance of power in relation to the menfolk of the region.

The young women of New Plymouth do not conform with the rule for Location because during their working day they are exposed to the speech of other more mobile New Zealanders and they accommodate their speech to patterns which they see as being new and 'cool', patterns which are features of the English spoken elsewhere in New Zealand. In doing so, they are taking on the role that New Zealand women have traditionally played in the setting of new standards for speech.

The young men of Wellington do not conform with the rule for Gender because, living as they do in Wellington, which the locals maintain is the cultural as well as the 
administrative capital of New Zealand, they have adopted the unemotional sounding pitch patterns which are an aspect of the accepted prestige accent of the young people of New Zealand. It is possible that the women of the area were instrumental in the establishment of this pattern and have now reverted in part to the earlier pattern of more pitch movement.

The elderly dairy farming women have less pitch movement than the elderly dairy farming men (except in the case of accents with boosted onsets where the elderly women have more) but more than the other men's groups. It could be said then that as a whole they do not conform with the rule for Gender. This is because they have remained faithful to the Taranaki tradition with which they are most familiar, of favouring intonation characterised by a lot of pitch movement.

The elderly women of New Plymouth do not conform with the rule for Gender because they too have maintained the old Taranaki dynamic intonation patterns. Their pitch dynamism scores are higher than their menfolk's. Their intonation patterns are more in keeping with stereotypes of female intonation patterns, possibly reflecting traditional societal mores with regard to women's position in relation to men's. The lives of all the elderly Taranaki women surveyed are notable for their lack of geographical mobility. With one or two exceptions they have lived their entire lives in New Plymouth or South Taranaki.

The young dairy farming men of South Taranaki do not conform with the rule for Age because, by holding on to older, local intonation patterns they are expressing their pride in being from the 'Naki'. Their dynamic intonation is an expression of their distinctiveness.

As stated above, the young women of Wellington do not conform with the rule for Age for two of the variables studied. This may be because, the standard for flatter intonation patterns having been established in Wellington, the women are now reverting to older patterns which are characterised by more pitch movement. 


\subsubsection{Rural versus urban orientation}

I turn now to the fifth research question which is concerned with how speakers' orientation to town or country correlates with the intonational features studied. This is an important question because it may help clarify the extent to which the regional differences I have found are truly regional as opposed to rural versus urban distinctions.

\section{Question 5: Are there intonational differences between urban and rurally oriented speakers in Taranaki and Wellington?}

As reported in Section 6.5, linear regression scores showed positive correlations between rural orientation scores and scores for pitch movement. Not surprisingly, people with the highest rural orientation scores lived on farms, or had spent most of their lives on farms. People with the lowest rural orientation scores lived in the cities of New Plymouth and Wellington. The index shows that some individuals who lived in cities, both New Plymouth and Wellington, had more rural connections than other city dwellers and had scores which reflected this. Conversely not all of the farmers were completely rural in their orientation. The fact that New Plymouth and Wellington speakers had similarly low scores overall on the rural orientation scale suggests that where there were significant intonational differences between New Plymouth and Wellington speakers, the differences were authentically regional, and not simply rural versus urban differences. New Plymouth speakers used significantly more changes of pitch direction per intonation group and per accent unit than Wellingtonians. They also used more accents characterised by moving pitch than Wellingtonians. These differences would appear to be genuinely regional.

There was no correlation between scores on the rural orientation index and counts of falling accents with boosted onsets. But there was a significant difference between speakers from the South Taranaki dairy farming community and Wellingtonians with respect to this feature. People with rural orientation might use the feature as much or as little as might people with urban orientation, yet speakers from one region favoured it more than speakers from another region, suggesting further evidence of regional variation. 


\subsubsection{Regional variation revisited}

Having studied the complicating factors which interact with regional variation I now return to the first research question which was:

\section{Is there regional variation in New Zealand English intonation?}

In this study I have provided evidence that most of the speakers surveyed in Taranaki had speech characterised by more pitch dynamism than the speech of most of the speakers surveyed in Wellington. I cannot claim that a particular intonation pattern is special to one of the regions studied in the way that Bauer and Bauer could say that a particular playground expression was unique to one of the dialect regions they identified in New Zealand (Bauer \& Bauer 2000a,b,2001,2002a,b,2003) or in the way that nonprevocalic /r/ is thought to be unique to the Southland/South Otago region of New Zealand. All of the intonational features studied in the present project were present to some degree in both Taranaki and Wellington. The difference lay in the degree to which the features were present in the speech of people from the two regions. Analysis of the interactions of Location, Gender and Age provided useful clues as to changes which the features studied are undergoing in the regions. Study of the relationship between pitch dynamism and rural versus urban orientation indicated to what extent the intonational differences found are regional as opposed to rural versus urban.

Having provided evidence of regional variation in New Zealand English intonation I now address the question of how this finding relates to the work of Bauer and Bauer on regional variation in the playground language of New Zealand school children. (See Sections 2.2 and 3.2).

A northern, a central and a southern region emerged from the Bauers' study. Taranaki fitted for the most part into the northern region and Wellington belonged to the central region. A claim was made that Wellington formed a subregion within the much larger central region, whereas Taranaki did not constitute a subregion in its own right. The findings suggested, however, that strong internal ties existed within Taranaki. There were also strong similarities between Taranaki and the King Country immediately to the 
north. The researchers did not seek evidence of matching regional variation in adult speech. But the important role which children, particularly those verging on adolescence, the age at which the children in the playground language survey were interviewed, play in the development of new dialects has been noted by Kerswill and Williams in the United Kingdom (Kerswill \& Williams 2000) and by Hickey in New Zealand (Hickey 2003). (See Section 2.1.4). There is a strong possibility that, given evidence for the existence of regional variation in the speech of children in New Zealand, matching adult variation may be emerging, if it is not already present.

I have shown that there is a difference between Taranaki and Wellington intonation patterns but I have not provided proof of a uniquely Taranaki or a uniquely Wellington way of speaking. For evidence of this, comparison with the intonation of other regions is needed. It is possible that a study of the intonation of a northern region might show similarities with Taranaki intonation, indicating that the regional boundaries for children's language may extend to adult intonation patterns. (Comparison with King Country speakers could be of particular interest here, given the Bauers' comments about resemblances between Taranaki and King Country children's choice of playground expressions. It seems highly likely that there are historical family and community networks between the two predominantly rural regions which might well result in linguistic similarities). It is equally possible that the intonation patterns of Wellingtonians are similar to those of other speakers in the central region identified by the Bauers.

Given the sociolinguistic evidence outlined above, however, I suspect the most likely scenario is that the flatter intonation favoured by most of the Wellingtonians in the sample is the 'standard' shared by other New Zealanders. It is my impression (completely untested) that their intonation is similar to the intonation of most New Zealanders. I suspect, in other words, that Wellington, with its relatively mobile population, a feature which it shares with other capital cities, does not constitute a separate dialect region. Taranaki, on the other hand, may be, or may have been in the past, a separate region with respect to its intonation patterns. Study of the pitch dynamism scores of the elderly speakers in the sample can give us some idea of how far back in time the regional differences in intonation extend. It has been demonstrated that, 
generally speaking, elderly speakers have more pitch dynamism than younger speakers in the sample. It is also the case that for three of the features studied (namely changes of pitch direction per intonation group and per accent unit, and nuclear accents with moving pitch) the elderly dairy farming men and women of South Taranaki and the elderly women of New Plymouth had higher counts than the other elderly speakers surveyed. In the case of falling accents with boosted onsets, elderly men and women of both South Taranaki and New Plymouth had higher counts than elderly Wellington speakers, male and female. In the case of level accents with boosted onsets which were favoured by women more than men, the elderly South Taranaki and New Plymouth women had notably higher scores than the elderly Wellington women. All of this suggests that intonational differences between the two regions are not new. What it does not tell us, however, is whether or not the elderly Taranaki speakers' high level of pitch dynamism is shared by elderly speakers from other regions of New Zealand. This is beyond the scope of the present study. Until comparisons are made with other regions it will not be possible to say we have conclusive proof of the existence of a Taranaki regional dialect. At this point I can only rely on my impression that the intonation of elderly Taranaki speakers is distinctive for its high level of pitch dynamism compared with the intonation of most other New Zealanders, not just Wellingtonians. And if the young men of South Taranaki are able to maintain the dynamic pitch patterns they currently share with their local elders in the face of other New Zealanders' more level intonation patterns, in time this aspect of their speech may become more salient than at present, and a more distinctively Taranaki dialect may yet emerge. Regional differences are likely to develop in a colonial variety of English as it matures (Bauer \& Bauer 2002a:173). Regional variation has been observed in the speech of our neighbours in Australia (Bradley 1989; Horvath \& Horvath 2002). Australia was settled by English speakers from 1788 , which is approximately fifty years prior to New Zealand's settlement by English speakers. 'If dialectal divergence has been observed in Australia for at least twenty years, it must have started well before that' (Bauer \& Bauer 2002a:173). If the Australian model for the timing of dialectal divergence is anything to go by then we might expect to see the emergence of regional variation in New Zealand English about now. And it appears, from the evidence of Bauer and Bauer, that New Zealand English may be sufficiently mature for this to have occurred. 
If a New Zealand-wide study of intonation were to be undertaken and intonation characterised by a lot of pitch movement up and down proved to be a particularly Taranaki trait, questions could be asked about the origins of this difference. Given the observation by Walters (2003) that intonational features may be the most enduring features of speech where there are competing dialects or where one language or dialect is giving way to another, and given the lack of any other evidence of dialectal difference, it would be reasonable to assume that dynamic pitch movement in Taranaki is the last remnant of an input dialect. At this point in New Zealand's history one could only hazard guesses as to what that input dialect might be. Influence from the dialect spoken by the English speaking settlers from the South West of England seems unlikely at this stage. It is not impossible that the early twentieth century influx of dairy farming labour from Switzerland to South Taranaki may have had some influence on the speech patterns of the area. One of the young South Taranaki men interviewed was a third generation dairy farmer in the region, with Swiss ancestry on both sides of his family. His father spoke only Swiss German until he went to school. Kaponga in South Taranaki is popularly known as the Swiss 'capital' of New Zealand. The following extraordinary statement by 'A Britisher' is an extract from correspondence in the Hawera Star of June 1916 concerning the recent introduction of compulsory military service (quoted in Arnold 1997):

'This new law applies only to British subjects, and the consequences will be that the farm lands will in many instances, and the artisan employment also, pass into the hands of Swiss, or as I prefer to call them, aliens. They (the Swiss) are becoming far too numerous, and unless steps are taken to prevent it, will ere a few years oust the British - who by national right and by right of present-day conquest or preservation own the country - and become firmly implanted in our nation and indelibly stamped in national affairs'.

If anxious sentiments such as these were being expressed by the locals, it seems the Swiss may have been present in sufficient numbers at the time to have had some influence on the language being spoken.

During the course of this project lay people talked of various possible influences on the speech of Taranaki people aside from that of the Swiss dairy farming immigrants. Other suggestions included the possible influence of a sizeable group of Polish immigrants. 
There are a number of families of Irish origin in the area and it was suggested to me that there could be some influence from the dialect of Maori spoken in the Taranaki region.

Discussion of the possible source or sources of differences in the intonation of Taranaki speakers requires an open mind and considerably more research into sociohistorical and related linguistic factors than was possible for the present project.

\subsection{Methodological issues}

Finally, having discussed the implications of my results, I add a methodological note on issues which emerged in the course of my research. Specifically, I look at the usefulness of the index I devised for degrees of pitch movement, the relative indexicality of intonational features chosen for examination, my use of narrative texts for intonational analysis and the issue of where the intonational differences I discovered fit in Ladd's taxonomy of intonational differences.

\subsubsection{Index of pitch movement}

The first question to be discussed is whether the 'sing-song' or 'pitch dynamism' index I devised for measuring the quantity and quality of pitch movement in the intonation of speakers was successful. I believe that this was the case. It proved to be an effective tool in differentiating between speakers and groups of speakers whose intonation was characterised by a lot of pitch movement, (in other words 'sing-songy' intonation), and those with more level intonation.

It could be argued that the method used was too subjective. However, $50 \%$ of the texts were checked by a second person and blind checks were carried out on substantial portions, as a result of which only minor alterations were deemed necessary, suggesting that the method was reliable.

I informally tested the validity of the index on two occasions by playing two speech samples to two different classes of third year students of linguistics at Victoria University of Wellington and then asking them to comment on whether they thought one 
of the speakers had more pitch movement than the other. They confidently claimed that the young Taranaki dairy farming man in the sample had more 'bouncy' intonation than the young Taranaki dairy farming woman. The young man with the 'bouncy' intonation had on average 3.02 changes of pitch direction per intonation group and 1.59 changes of pitch direction per accent unit, while the young woman with the 'flatter' intonation had on average 1.25 changes of pitch direction per intonation group and 0.66 changes of pitch direction per accent unit.

The patterning of variable (1) the average number of changes of pitch direction per intonation group appeared to mirror variable (2) the average number of changes of pitch direction per accent unit. If a speaker had a high count of changes of pitch direction per intonation group they also had a high count of changes of pitch direction per accent unit and, conversely, if they had a low count for one variable they had a low count for the other. It is perhaps questionable whether variables (1) and (2) are in fact independent of one another. There was also a good degree of consistency between high counts of accents with moving pitch and high counts of changes of pitch per intonation group and per accent unit. Patterns for accents with boosted onsets did not mirror the other patterns quite so consistently but analysis of these features was certainly useful, particularly in discerning gender patterns. The same could be said for the analysis of complex nuclei which was not useful in differentiating between speakers of different age or locality but played a significant part in differentiating female intonation patterns from male intonation patterns.

\subsubsection{Relative indexicality of features}

Averaging the number of times a speaker changed pitch direction in each intonation group and then in each accent unit provided me with a global measure of changes in pitch direction. Analysis of nuclear accents gave an indication of whether speakers favoured tunes which were characterised by pitch movement. And analysis of the manner in which accents were approached, whether with a boosted step up in pitch, or with a more standard onset, provided a narrower focus on the amount of pitch movement present. 
Of the seven intonational features studied it is my impression that a preference for falling accents with boosted onsets may be the best indicator of 'sing-songyness' because it features a change in pitch direction which is highly salient and it exploits more of the speaker's usual pitch range. A global count of changes in pitch direction is helpful, as is knowing what kinds of tunes a speaker favours. However, a speaker might have intonation characterised by a lot of changes in pitch direction, and a lot of moving pitch accents, yet their intonation may nevertheless sound flat if their overall pitch range is narrow. A falling accent with a boosted onset involves a noticeable step up from the speaker's normal pitch range and movement back down again. So the effect is of more pitch movement than normal. It is likely that someone whose speech contains a generous number of these pitch accents may sound more 'sing-songy' than others. Comparison of speakers' pitch ranges might substantiate this impression. Testing listeners' perceptions of the relative 'sing-songyness' of firstly, speech containing both high counts of changes in pitch direction and a high percentage of falling accents with. boosted onsets, and secondly, speech containing high counts of changes in pitch direction but few if any falling accents with boosted onsets would also be instructive. Analysis of variance with respect to this feature showed main effects of Location and Age and interactions of Location, Gender and Age. Elderly speakers clearly preferred the feature, (of the young, only the South Taranaki dairy farming men favoured it), and it was more characteristic on the whole of Taranaki speakers than of Wellingtonians. The elderly South Taranaki women had the highest scores with the other Taranaki elderly groups not far behind.

I also contend that complex fall-rise nuclei and level nuclei with boosted onsets may not be good indicators of 'sing-songy' speech. As indicated in Section 7.2.5, both these features can function as HRTs. Although data were not specifically analysed for HRTs, I gained the impression whilst transcribing intonation patterns that intonational phrases ending with HRTs were often, though not always, preceded by level accents. So speech containing a high percentage of fall-rise nuclei and level nuclei with boosted onsets may have fewer changes of pitch direction, and sound less 'sing-songy' than speech containing a high percentage of falling accents. 


\subsubsection{Use of narrative texts}

My use of narrative texts for analysis was motivated largely because speakers tend to be at their most fluent when telling stories; they are likely to be emotionally engaged in their subject matter and to be focussed on what they are saying as opposed to how they are saying it. However, it could be argued that pitch dynamism, or lack of it, is merely an indication of an individual's storytelling ability. I was aware that, whilst telling stories, speakers can manipulate their prosody in order to convey emotion and attitude. They may, for example, lengthen the stressed vowels of key words, and exaggerate volume and pitch (Wennerstrom 2001a:206). It might be said that prosodic manipulation is an aspect of 'good' storytelling in that it can make a story sound more interesting to the listener. A preference for pitch dynamism and exaggerated pitch movement in the form of falling accents with boosted onsets might indicate that the storyteller is doing a good job. This being the case it would seem that most of the Taranaki speakers in the sample were better storytellers than most of the Wellingtonians and elderly people were better storytellers than most of the young speakers. I believe this to be quite untrue. As Wennerstrom points out 'Variation in how extreme a prosodic display can be depends on the norms of the speech community, the circumstances surrounding the storytelling event, and the individual's own creative choices' (Wennerstrom 2001b:218). She cites an example of someone conveying a series of rather shocking events unemotionally and within a narrow pitch range. 'Deadpan style invests a certain power in the teller', she says, and 'he is able to tell calmly of arrests and other "demonic" acts as if they are nothing unusual in his worldly experience'. The story telling style of the young men of Wellington was notable for its lack of pitch variation, while at the same time the situations being described were often full of danger and the stories were far from dull. Perhaps these young men were deliberately suppressing emotional display to achieve a 'worldly aura' as was the young man in Wennerstrom's study. In their world, unemotional sounding speech, characterised by minimal pitch movement is 'cool'. A 'good' story does not necessarily correlate with maximal pitch variation and I still maintain that my choice of narrative texts was quite appropriate for the task at hand. 
7.3.4 Ladd's taxonomy of intonational differences

Finally, note that it is in the nature of the data presented here that it cannot readily address the issue of where the differences I found belong in Ladd's taxonomy of intonational differences (see Section 4.1). My approach was essentially descriptive. Greater control of the collection and analysis of data is needed in order to determine whether observed differences are in fact semantic, systemic or realisational. Further detailed study in this area of intonational analysis is needed.

In the next chapter I look at what conclusions can be drawn from my research findings and I suggest some future directions for research in this area. 


\section{CHAPTER EIGHT: CONCLUSIONS}

I return now to the quotations with which I introduced this thesis. Can we conclude that the Taranaki speakers quoted in the introduction are correct in thinking that their speech is different to that of other New Zealanders, Wellingtonians in particular? I am not in a position to answer this question with a definite 'Yes' or 'No' as I have not analysed the intonation of these particular individuals. But, having undertaken the research described in previous chapters, comparing the intonation of Taranakians who chose to stay in Taranaki, and the intonation of Wellingtonians, I can now assert with more confidence that there is likely to be something different about their way of speaking. It appears that the folk impression that there is something different about the Taranaki accent is not without basis in fact. In particular Dinah Priestley's perception of a 'sing-songy' quality to the speech of the elderly Taranaki women provided a useful starting point to this investigation of exactly what makes the speech of Taranaki different.

In this chapter I summarise the contents of the thesis, highlight its major findings and conclusions, then indicate directions for future research in the area.

\subsection{Summary}

Chapter 1 provided an introduction to the thesis. It was observed that until recently, there had been little scientific research into regional variation in New Zealand English and that examination of New Zealand English intonation was also a relatively new field of study. My reasons for selecting Taranaki and Wellington as regions for comparison were outlined.

In Chapter 2 I considered how dialects are formed, with particular reference to the formation of New Zealand English. British dialects spoken in New Zealand in the nineteenth century were briefly reviewed. Theories of dialect mixture and Lass's Law of Swamping (Lass 1987) were outlined, and the important role children play in the development of new dialects was emphasised. I then examined methodologies used by dialectologists to establish the existence of linguistic variation and the reasons for such 
variation. I looked firstly at traditional dialect geography and then at social dialectology, including social network theory, geolinguistics, social constructionism and ethnography.

Chapter 3 surveyed approaches taken to research on regional variation in New Zealand English and outlined the results of these studies. The survey began with the folk linguistic study undertaken by Pamela Gordon (1997) which explored the views of New Zealanders on the subject of regional accents in New Zealand. Studies of lexical, grammatical and phonological variation were also reviewed. Evidence pointed in most cases to either social class or ethnic variation and not to regional variation. However, Bartlett (1992, 2003), Bauer and Bauer (2000a,b, 2001, 2002a,b, 2003), and possibly Batterham (2000) and Allan and Stark (2000) provided evidence of traces of regional variation in New Zealand English.

Chapter 4 provided background material for the study of intonation. My reasons for choosing to look at intonation as a possible area of regional variation in New Zealand English were outlined. I looked at Ladd's (1996) typological framework for intonational variation, and at impressionistic, sociolinguistic and psycholinguistic/experimental methodologies used by researchers for the comparison of varieties of English intonation. The literature on HRTs was reviewed, HRTs having occupied centre stage in the study of New Zealand English intonation to date. I also outlined research undertaken on gender comparisons of intonation. Several gender studies made reference to the male/female stereotypes of intonation patterns cited by McConnell-Ginet (1983) and Henton (1989), (eg. Warren \& Daly 2000, Daly \& Warren 2001, Vermillion 2003). Finally, I formulated the research questions which underpin my thesis, and I justified the questions asked on the basis of material contained in the preceding literature review.

In Chapter 5 I described and justified firstly, the sociolinguistic method I used for seeking evidence of possible regional variation in New Zealand English intonation; secondly, the method used for transcribing patterns of pitch movement; thirdly, the intonational features selected for analysis; and finally, the statistical analysis undertaken.

In Chapter 6 the primary results of the thesis were listed and the variation associated with each of the intonational features was examined. 
The first principal finding was that, in general, most Taranaki speakers in the sample showed more pitch dynamism than most Wellingtonians, exceptions being the young women of Taranaki who had pitch patterns more like Wellingtonians than like their fellow Taranakians. The South Taranaki dairy farming sample had higher pitch dynamism scores than the New Plymouth sample who in turn had higher scores than the Wellington sample, suggesting that the intonation patterns were undergoing change as a result of hierarchical diffusion. The more level intonation patterns characteristic of Wellingtonians appear to be spreading to less populated centres.

The second principal finding was that, for some features, male speakers showed more pitch dynamism than females. In this respect the young men and women did not conform to stereotypical male/female patterns whereby men's intonation is characterised by less pitch dynamism than women's. Exceptions in my sample were the young men of Wellington who had very low pitch dynamism scores and the elderly women of Taranaki who had high pitch dynamism scores.

The third principal finding was that, overall, the elderly speakers in the sample showed more pitch dynamism than the younger speakers, exceptions being the young men of Taranaki, and the young dairy farming men of South Taranaki in particular. The young women of Wellington were also unusual in that for some variables they had higher pitch dynamism scores than the elderly Wellington women.

In Chapter 7 I attempted to interpret the results, drawing links between the different findings outlined in Chapter 6, and relating them to insights gained from other studies.

An interesting question raised by the data was the difference between the intonation patterns of the young men and women of South Taranaki. Careful scrutiny of social networks and the 'language markets' to which speakers subscribed showed that all the young people belonged to strong local networks but that the young women had come into contact with wider networks in their late teens and early twenties. Consequent differences in the kind of face to face interactions with others which the men and women would have experienced could account for differences in intonation patterns. The women would have been exposed to the newer, more level intonation patterns of 
the young women of New Plymouth who were in turn exposed to similar patterns amongst young people in the wider community. The Taranaki young women appear to have accommodated their speech to that of their peers in the city.

The way in which Gender and Age interacted with Location suggested that the move towards fairly level intonation patterns may have reached completion in Wellington, with the young men in the sample having the lowest scores for pitch dynamism, the Wellington women having established the standard at an earlier date. My interpretation is that the young women of Taranaki seemed to be accommodating to this standard, while the young men of the area were maintaining the older intonation patterns, and in so doing, proudly displaying their Naki-ness.

It was also suggested that in South Taranaki the young women, who were equal partners in the dairy farming businesses they ran with their menfolk, may have subconsciously rejected intonation patterns which could be seen as stereotypically feminine. These women may belong to the category of female linguistic innovators described by Labov (2001) as non-conformists who have strong local networks, are highly skilled and respected in their communities, and who are upwardly mobile socially.

Another possibility is that perhaps the young dairy farming men, feeling constrained by peer norms, used more conservative, localised intonational variants while the women felt free to use the more innovative, supralocal variants.

It is acknowledged that changes in the socio-economic and cultural environments of the regions studied are inevitable and that such changes may well result in shifting allegiances amongst local communities. This in turn could result in complex linguistic responses to the impact of change. Only time will tell if the young men will continue to emphasise their Taranaki identity by means of their dynamic intonation .

The index of rural orientation proved helpful in separating genuinely regional differences from rural versus urban differences. High rural orientation scores correlated positively with high scores for pitch movement. This might suggest that the differences I found between Wellington and Taranaki were simply town versus country differences. 
However, the fact that New Plymouth and Wellington speakers had similarly low scores on the rural orientation scale suggests that where there were significant intonational differences between New Plymouth and Wellington speakers, the differences were authentically regional. New Plymouth speakers used significantly more changes of pitch direction per intonation group and per accent unit, and more accents characterised by moving pitch than Wellingtonians. These differences appear to be genuinely regional, and not simply rural versus urban differences. The way in which falling accents with boosted onsets patterned suggested further evidence of regional variation. It was found that people with rural orientation might use falling accents with boosted onsets as much or as little as might people with urban orientation, yet speakers from one region, South Taranaki, favoured this feature more than speakers from another region, Wellington. The regional factor appears to be operating separately from the rural factor here.

Evidence of differences in the degree of pitch dynamism present in the intonation of the Taranaki and Wellington speakers supports claims about regional variation in New Zealand English intonation, but it does not in itself prove the existence of a uniquely Taranaki or a uniquely Wellington way of speaking English. For evidence of this, comparison with the intonation of other regions in New Zealand is needed.

In conclusion, whilst acknowledging that my research findings are indicative only, they nevertheless provide a solid platform for future research into regional and social dialectology in New Zealand English. In the next section I outline some of the directions which such research could take.

\subsection{Future directions}

\subsubsection{Regional comparisons}

Research into the intonation of other regions is essential not only for support for the notion that Taranaki English might be unique, it is also needed as evidence that the intonation of Wellingtonians may constitute a 'standard' for New Zealand English intonation. Comments by Bauer and Bauer (2003) suggest that a comparison with the 
intonation of King Country speakers could be interesting. Comparison with Southland could also be instructive. Like Taranaki, Southland is relatively isolated, has a thriving dairy farming industry, some heavy industry, a provincial city and a scattering of small rural towns. Importantly its people are very proud to identify as Southlanders and it is known to have at least one phonological feature unique to the region. It would also be interesting to know how the intonation of Wellingtonians compares with that of Aucklanders, Auckland being by far the largest population centre in New Zealand. Over $25 \%$ of the country's population live in the area. In their study of playground language, Bauer and Bauer observed a particularly strong boundary between the northern region to which Auckland belongs and the central region which has Wellington at its centre. It would be interesting to know if the same divide exists for patterns of intonation.

\subsubsection{Possible sources of difference}

For clues as to the possible origins of a uniquely Taranaki English further research into the socio-historical background of the region is needed. For example, information about the numbers of Swiss immigrants to the region, when they arrived, exactly where they settled, which dialects they spoke, and some clues as to the nature of the intonation patterns they brought with them would be useful. A comparison of the intonation patterns of the dialect of Maori spoken in the Taranaki region with the intonation of other regional dialects of Maori would be interesting, as would a study of the intonation of English spoken by Maori in Taranaki. If, as Walters observed in his study of Welsh English, intonational features may be the most enduring features of speech where one language or dialect is giving way to another, Taranaki English intonation could contain traces of Swiss German or Taranaki Maori.

\subsubsection{Trajectory of change}

Analysis of the intonation of speakers selected from the Mobile Disc Recording Unit tapes made by the National Broadcasting Corporation of New Zealand between 1946 and 1948 could provide useful information about earlier patterns of intonational variation in Taranaki and Wellington. And analysis of today's middle-aged speakers' 
intonation patterns would provide a yet clearer picture of the trajectory of change in intonation.

Future monitoring of the intonation patterns of young adults in the two regions studied would indicate whether or not intonation characterised by a lot of pitch dynamism will remain a feature of Taranaki English and whether Wellington English will continue to be characterised by minimal pitch dynamism.

\subsubsection{Acoustic analysis}

My intuition that speech containing a generous number of falling accents with boosted onsets will sound more sing-songy than speech characterised by falling accents with standard onsets could be tested by (a) obtaining an exact acoustic measurement of speakers' pitch range, measurements being taken from the end of an accent preceding a falling accent to the onset of the falling accent and (b) testing listeners' perceptions of the relative 'sing-songyness' of firstly, speech containing both high counts of changes in pitch direction and a high percentage of falling accents with boosted onsets, and secondly, speech containing high counts of changes in pitch direction but few if any falling accents with boosted onsets.

I would also like to undertake acoustic analysis of intonation groups containing HRTs to test my intuition that HRTs tend to be (though they are by no means always) preceded by level pitch accents. Such a finding would be consistent with the findings of Warren and Daly (2005 f.c.), and Zwartz and Warren (2003) that rises in New Zealand English HRTs are generally late and dramatic.

More controlled data collection and analysis would allow for categorisation of the above intonational differences as semantic or realisational. 


\subsubsection{Gender differences in intonation}

The finding that the women in this sample used more complex pitch accents than the men, irrespective of their age and location, suggests that closer analysis of what kinds of complex nuclei are being used by whom, and in what contexts, could add to our knowledge of what distinguishes women's and men's intonation patterns.

\subsubsection{Lexical variation}

Comments made by some interviewees suggested that there might be lexical items unique to the Taranaki region and I believe future research into possible regional variation should encompass lexical variation. When I began thinking about the present project the expression Naki was used only by Taranaki locals and its meaning was confined to the local rugby team. Since then it has spread to the wider community and has become common currency throughout New Zealand for 'Taranaki.' Examples of specifically Taranaki expressions are Opahappening for Opunake and Taradise for Taranaki (Peter Little, personal communication). Then there are distinctly local ways of pronouncing several Taranaki place names. The way in which one says, for example, Oakura, Hawera or Auroa Road quickly identifies the speaker as a local or an outsider. To these lexical items can be added the two playground expressions which Bauer and Bauer found to be almost exclusively used in Taranaki: twigs for declaring a truce and pinner meaning something is easy. I am convinced a wider survey focussed on word usage would produce interesting findings.

\subsection{Contribution of this thesis to social and regional dialectology}

In summary, this thesis contributes to the fields of social and regional dialectology in New Zealand in the following ways:

- it makes a useful addition to work currently being undertaken on the description of New Zealand English intonation;

- it introduces a mechanism for differentiating between speakers whose intonation is characterised by a lot of pitch movement and speakers with more level intonation; 
- it contributes to the field of geolinguistics, the concepts of both 'space' and 'place' having played an important part in the interpretation of results;

- it introduces an index for measuring the degree to which speakers are rural or urban in their orientation;

- it contributes to our understanding of differences between rural and urban varieties of New Zealand English;

- it pioneers sociolinguistic research into the speech of people from Taranaki;

- $\quad$ and last, but not least, it pioneers the study of regional variation in New Zealand English intonation. 


\section{APPENDICES}

Appendix 1

\section{VICTORIA UNIVERSITY OF WELLINGTON}

CONSENT TO PARTICIPATION IN RESEARCH

NAME OF PROJECT: REGIONAL VARIATION IN NEW ZEALAND

ENGLISH

NAME OF PERSON

RECORDED:

NAME OF

INTERVIEWER:

\section{DATE OF}

INTERVIEW:

\section{PLACE OF \\ INTERVIEW:}

I have been given an explanation of this research project and I understand what it is about.

I have had an opportunity to ask questions and have them answered to my satisfaction.

I agree that the recording and the transcript of my interview may be held by the Wellington Archive of Spoken New Zealand English and may be used for linguistic research. 
I understand that only linguistic researchers will be allowed to listen to the recording and it will be used only for genuine linguistic research purposes.

I understand that published results will not use my name and that no opinions will be attributed to me in any way that will identify me.

$\square \quad$ I would like to receive a summary of the results of this research when it is completed.

I agree to take part in this research.

\section{Signature:}


Appendix 2

\section{INTERVIEW SCHEDULE}

(The schedule was adjusted for Wellington interviewees where appropriate.)

I am interested in hearing about what it is like to live in Taranaki today compared to what it used to be like and I am also interested in how people talk around here

I want to be able to remember everything you say so I'd like to use a tape recorder to help me remember what you tell me.

I will be asking questions about yourself and your background to help me understand why people talk differently and I will also ask you questions about the words people in this area use and the way they talk.

The information you give me will be confidential. My fellow researchers and I will be the only people who will ever hear the tapes and I will not put your name on the tape.

If you have any questions I will be happy to answer them.

\section{Section 1. Language Questions}

1. A lot of people write letters to the newspapers complaining about the way in which people speak in New Zealand. Do you like the way New Zealanders speak?

2. Do you think people in town speak differently to the way people in the country speak? If yes, - In what ways do they sound different?

-What do you think about the way country people speak?

3. Do you think New Zealanders speak differently in different parts of New Zealand? If yes, - Where do they speak differently?

- Can you describe their speech for me please. 
( Prompt possible areas - East Cape, Northland, the South Island, the West Coast, Southland)

4. Can you tell if someone comes from Taranaki by the way they speak?

If yes ask How can you tell?

Are there any special words or phrases they use?

Any special swear words or anything like that?

\section{Section 2. Lexical Items}

There are sometimes two words used in New Zealand for the same thing - like radio/wireless. I am interested in finding out which word people in this area use most of the time.

- Do you use the word lift or elevator?

Both/any other?

- Do you use the word lorry or truck for a big motor vehicle?

Both/any other?

- Do you use jersey or sweater or jumper?

All/any other?

- Would you say go to the pictures or go to the movies?

Do you ever use flicks?

Both/any other?

- Do you use the word biscuits or cookies?

Both/any other?

- Do you use the word flashlight or torch?

Both/any other? 
- Do you talk about trousers or pants?

Both/any other?

- Do you use the word serviette or napkin?

Both/any other?

- Do you use the word car bonnet or hood?

Both/any other?

- Which do you say, fill the car with gas or fill the car with petrol?

(Check if they say gas that they are not talking about CNG or LPG)

Do you ever use benzine?

Do you know anyone who uses benzine?

Both/any other?

- Do you use the word $\underline{\text { tin }}$ or $\underline{\text { can? }}$

(Check tin of food (eg baked beans) vs can of drink (eg beer)

- Do you use the word footpath or sidewalk or pavement?

\section{Section 3: Word List 1}

Before doing this section check that the interviewee has no trouble with reading.

Now I'd like you to read aloud some words for me.

This isn't a test of any kind. I am just interested in how people in this area pronounce these words, so just read them as naturally as you can and not too fast.

Give them 6 words on cards first.

(6 words - each on a separate card:

must, eat, howled, hour, during, enthusiasm) 
If they struggle or make an excuse (eg. I have lost my glasses) just leave it at that and say "That's fine",

Move to general conversation and keep it short.

dance

noodle

girl

doll

giraffe

pull

mask

foul

bald

felt

needle

advance

pearl

plant 


\section{owl}

halt

grasp

toil

toll-booth

\section{field of wild flowers}

school

\section{Section 4: Reading Passages}

Now I'd like you to read some passages aloud onto the tape. They have some words in them that I'm interested in. Could you please just read them as you would normally, but not too fast.

Give the interviewee the reading passages on cards.

Please read the passages below clearly and not too fast.

When I was small we used to get a little bottle of milk at school every day. It was cold when it was delivered. But sometimes it sat in the hall where it was hot and by the time we got it, it smelled awful. I'll always remember that smell. It was horrible. 
Have you seen that Arnold Schwarznegger film called Junior? Well, I'll tell you about it. As usual, he's the incredible hulk, but he's also full of fun and plays the fool a lot. He had me rolling in the aisle. The girls all fall madly in love with him. I think he's real cool but my friend Sal thinks I'm a dill because I'm such a celebrity freak.

III

It's a dreary dull day. It's rainy and cool. I take my raincoat from the hall cupboard and walk through the puddles to look at the new foal. I whistle for her and she comes bounding up the hill. Her ears wiggle ecstatically when I give her an apple and some celery.

IV

Sometimes I help deliver Meals on Wheels to old people. I feel sorry for some of them. Their lives are dull and lonely and some of them only get visits from the local school girls or someone like me. I go without fail because they rely on me. The food isn't that great. They boil the vegetables till they're soft and mushy. I don't find it very exciting myself.

Mrs Nile is one of my favourites. She told me a long story the other day about how she wants to sell her car to a gentleman friend called Malcolm. She likes to haggle over the sale so she hasn't made a deal yet. I think her goal is to keep him around - she's a bit fickle. Poor Mal!

\section{Section 5: Rural Orientation}

1. Where did you go to primary school? secondary school? 
2. How far did you have to travel from home to get to school?

3. Did you go to university or polytech or somewhere else for job training after you left school?

If yes, Where did you go?

4. Where do you usually go to do your shopping? banking? visit the doctor and dentist?

5. How often do you go to town?

6. Do you have relatives living in Taranaki too? eg. parents, grandparents, brothers, sisters, cousins, uncles, aunts?

7. If yes Whereabouts do they live?

8. How often do you see them? Every day? Once a month? Once a year? Hardly ever?

9. Where do most of your friends live? In the town? or in the country?

10. What sorts of things do you like to do on your free time?

Prompt as necessary. Any sports? Hobbies?

11. Do you belong to any local clubs or associations? Which ones?

12. Do you go to a local church?

13. What would you say are the benefits of living in the country?

13. What would you say are the benefits of living in town?

14. (For those who live in the country) - What do you think of townies? (For those who live in town) - What do you think of country people? 
15. Where do you plan to retire?

16. (Depending on answer to 15 ) Would you consider living in the country?

\section{Section 6: Word List 2}

Now I've got another list of words for you to read. This is a rather long list. I know it will be a bit boring for you but it will be very useful for me.

Please read through the words nice and slowly.

READ ACROSS. READ SLOWLY.

SCAN LINE BEFORE READING.

$\begin{array}{llll}\text { gulf } & \text { golf } & \text { street } & \\ \text { peering } & \text { pairing } & \text { women } & \\ \text { doll } & \text { dole } & \text { dolt } & \text { menu } \\ \text { fire } & \text { fireman } & \text { fire engine } & \text { fewer } \\ \text { tower } & \text { towers } & \text { towering } & \text { tour } \\ \text { cure } & & & \text { owed } \\ & \text { curing } & \text { see } & \text { often } \\ \text { batted } & & & \\ \text { bassume } & \text { battered } & \text { do } & \\ \text { sense } & \text { presume } & \text { woman } & \\ & & & \end{array}$




\begin{tabular}{|c|c|c|c|c|}
\hline nuclear & student & sing & sick & \\
\hline boring & boar & board & bored & stupid \\
\hline city & seedy & water & & \\
\hline rule & gruel & seek & quarter & \\
\hline fault & fort & here & & \\
\hline tune & dune & there & marae & \\
\hline Pete & pit & pot & pat & issues \\
\hline put & pet & secretary & & \\
\hline cut & putt & me & & \\
\hline baddy & daddy & Luke & kiwi & \\
\hline bee & bay & buy & boy & nuisance \\
\hline no & now & new & & \\
\hline boot & boat & bout & got & \\
\hline ferry & fairy & nothing & & \\
\hline pert & port & part & invasion & \\
\hline pull & pool & pill & Paul & Maori \\
\hline telly & tally & meal & & \\
\hline
\end{tabular}




\begin{tabular}{|c|c|c|c|c|}
\hline dill & dull & known & & \\
\hline reel & real & Scrooge & & \\
\hline poor & pour & pore & paw & me \\
\hline groan & grown & moan & mown & go \\
\hline weather & whether & each & temporary & \\
\hline beer & bear & bo & bough & ate \\
\hline hear & hair & pooch & government & \\
\hline fear & fair & cheer & chair & tree \\
\hline spear & spare & share & kauri & \\
\hline really & rarely & milk & fool & \\
\hline dunce & dance & chance & full & \\
\hline
\end{tabular}

\section{Section 7: General Conversation}

I'd like to talk for a minute about your childhood in Taranaki and your family.

\section{Childhood:}

What were you like as a child?

Do you remember any particular friends you had?

What sort of things did you do together?

Can you tell me about any games you used to play? At home? At your friends' places? At school? 
What did you like doing most? Least?

Do you remember the house you grew up in?

Can you walk me through it, describing it to me room by room? and the garden? was there a garden?

How did you get on with your parents as a child?

What was their attitude to education? religion? alcohol? cigarettes?

\section{Family/Relationships}

[These question are dependent on the nature of the person's family eg. Do they have children?]

Do you get together with other family members for Christmas?

What did you do on Christmas Day last year?

Where were your children born?

Are they/ were they good kids or do they/ did they get up to mischief? How do you/ did you keep them in line?

Are they like you? How? What sort of personalities do they have?

Do you remember your first girl/boy friend? What were they like?

How did you meet your wife/husband/partner?

\section{Section 8: Reading Passage 2}

Now we have another reading passage.

Give the interviewee the reading passage on the card.

Please read the passage below clearly and not too fast. 
Last summer we went touring around the East Cape area in our old van. We towed our boat behind us. One day we stopped at a small bay for a bite to eat. I checked the water, topped up the oil, and followed the family down to the beach. "The sea is just great for swimming," said Carl. During lunch I decided to sail around a little island about half a mile off shore. Carl was sleepy and the girls were playing in a pool with their dolls, so I went alone.

It took about an hour with a fairly strong wind to get all the way around the island. By then I could see the shore again and I started to feel rather pleased with myself. That was when things began to go wrong.

The breeze which had blown me out so fast was getting stronger. I pulled in the sail tight, but the boat was so light that I was being blown out to sea. At first there had been plenty of people around, but now the sea was almost empty and there was no-one within hearing distance. I howled till my voice gave up, but it was a waste of time.

I was wearing only shorts and a T-shirt and the wind was cruel. The swell grew bigger but I tried not to panic. I said to myself, "Carl knows I'm out here. He'll get help." I decided to take down the sail and row, but still nothing happened. I made scarcely any progress. The wind got even fiercer and the sky grew dark. I was in real trouble and I felt awful. I began to pray.

I don't usually believe in miracles but that's how I felt about what happened next. A motor boat appeared round the island heading straight towards me. One of the men in it threw me a rope. "Catch pal," he called. I tied it to a wire hoop on the hull and they towed me back to shore. A woman had spotted me through her binoculars. She saw I was in trouble and sent the boat out to get me.

And where was Carl? Well he'd driven round to the next bay. He thought I must have sailed in there by mistake. Lucky I hadn't waited for him to rescue me! 


\section{Section 9: General Conversation 2}

\section{Danger of Death}

Have you ever found yourself in a situation like the one in the reading passage where you thought, "This is it. I'm going to die."?

Could you tell me about that?

\section{$\underline{\text { Roads/Driving }}$}

You hear in the media about some pretty awful things happening on the roads in Taranaki. I'd like to talk about this for a bit.

What do you think of the standard of driving in Taranaki?

Do you think old/young people are better drivers?

Are there any roads which are particularly dangerous in this area?

Are there any dangerous spots you'd warn people about?

Have ever seen a bad accident around here? What happened?

\section{$\underline{\text { Work }}$}

Let's move onto a less gloomy subject. Work. Let's talk about work.

Can you tell me about a typical day at your work? When do you have to start your day? When does it finish?

What are the main things that you have to do?

(For farmers) What changes have you seen in the farming scene in the past few years? What do you think farming will be like in the $21^{\text {st }}$ century?

What other sort of changes have you noticed in the past few years? 


\section{State of the Nation}

And what do you think of the state of the nation generally? Education? Health system? Are things improving? Deteriorating?

\section{Section 10: Demographic Information}

Finally some questions about you -

\section{A. Residential History}

1. How long have you lived in Taranaki?

2. Depending on answer to Q1

Were you born in Taranaki?

or (a) And where were you born?

(b) At what age did you come to live in Taranaki?

3. Have you spent more than 12 months total away from Taranaki in the last three years? If yes, please state year(s) and time spent away from Taranaki in that (those) years.

4. How long in total have you spent away from Taranaki in your life?

5. What places did you live in for at least 3 years before you turned 20 ?

6. Where else have you lived for at least 10 years?

7. Have you ever lived overseas for 3 or more years?

If yes, please state years and time spent overseas.

8. Are or have you been married or in a long term relationship?

9. If yes to Q6 
Where was your wife/husband/partner born?

If overseas When did s/he come to New Zealand?

Where did s/he live before they were 20 ?

10. Where was your mother born?

If overseas When did she come to New Zealand?

11. Which language did your mother speak first at home?

12. Where was your father born?

If overseas When did he come to New Zealand?

13. Which language did your father speak first at home?

B. Gender, Age, Ethnicity

10. Which gender is the speaker? F or M. Circle the appropriate letter.

11. Which of these age groups do you belong to?

Show interviewee the card and circle appropriate group below

$\begin{array}{ll}20-24 & 25-29 \\ 30-34 & 35-39 \\ 40-44 & 45-49 \\ 50-54 & 55-59 \\ 60-64 & 65-69 \\ 70-74 & 75-79 \\ 80-84 & 85-89 \\ 90 \text { years and over }\end{array}$

12. Which ethnic group do you identify with?

13. Which ethnic group does your wife/husband/partner identify with? 
14. Is/was your mother Maori? Of European ancestry? Other?

15. Is/was your father Maori? Of European ancestry? Other?

16. Can you speak Maori?

17. If no to Q16 Have you ever learnt Maori?

C. Education and Occupation

18. How old were you when you left school?

19. Did you pass any school exams?

Specify (eg. School Certificate, University Entrance, Matriculation. The highest qualification the person obtained.)

20. Have you passed any exams since you left school?

Specify (eg. trade certificate, apprenticeship, secretarial, university. The highest qualification the person obtained.)

21. Are you working in paid employment at present?

Circle answer Yes No

If yes What is your current job?

If no Have you ever had a paid job?

If yes What was it?

22. Is your wife/husband/partner working in paid employment at present?

Circle answer Yes No

If yes What is their current job?

If no Have they ever had a paid job? 
If yes What was it?

23. What does/ did your father do for a living?

24. Do you know what your father's father did?

25. What about your mother? What does/did she do for a living?

26. Do you know what your mother's mother and father did?

THE END 
Abercrombie, David. 1967. Elements of General Phonetics. Edinburgh: Edinburgh University Press.

Ainsworth, Helen. 1993. Rhythm in New Zealand English. Unpublished BA (Honours) paper. Victoria University of Wellington.

Ainsworth, Helen. 1994. The emergence of the high rising terminal contour in the speech of New Zealand children. Te Reo 37: 3-20.

Akenson, Donald H. 1990. Half the World From Home. Perspectives on the Irish in New Zealand, 1860-1950. Wellington: Victoria University Press.

Allan, Scott. 1990. The rise of New Zealand intonation. In Allan Bell and Janet Holmes (eds.) New Zealand Ways of Speaking English. Clevedon: Multilingual Matters.

Allan, Scott \& Donna Starks. 2000. Accent on Auckland. The University of Auckland News October 2000.

Arnold, Rollo. 1997. Settler Kaponga 1881 - 1914: A Frontier Fragment of the Western World. Wellington: Victoria University Press.

Ash, Sharon. 2002. Social class. In J.K.Chambers, Peter Trudgill \& Natalie SchillingEstes (eds.) The Handbook of Language Variation and Change. Blackwell: Oxford.

Bailey, Guy, Tom Wikle, Jan Tillery \& Lori Sand. 1993. Some patterns of linguistic diffusion. Language Variation and Change 5: 359-390.

Barber, Charles. 1993. The English Language: A Historical Introduction. Cambridge: Cambridge University Press.

Bartlett, Christopher. 1992. Regional variation in New Zealand English: The case of Southland. New Zealand English Newsletter 6:5-15.

Bartlett, Christopher. 2003. The Southland variety of New Zealand English: Postvocalic $/ \mathrm{r} /$ and the BATH vowel. Unpublished $\mathrm{PhD}$ thesis. University of Otago, Dunedin.

Batterham, Margaret. 1995. "There is another type here": some front vowel variables in New Zealand English. Unpublished doctoral dissertation. La Trobe University, Victoria, Australia.

Batterham, Margaret. 2000. The apparent merger of the front centring diphthongs EAR and AIR - in New Zealand English. In Allan Bell and Koenraad Kuiper (eds.) New Zealand English. Wellington: Victoria University Press. 111-145. 
Bauer, Laurie. 1986. Notes on New Zealand English Phonetics and Phonology. English World-Wide 7 (2):225-258.

Bauer, Laurie.1994. English in New Zealand. In R. Burchfield (ed.) The Cambridge History of the English Language, Volume 5: English in Britain and Overseas: Origin and Development. Cambridge: Cambridge University Press. 382-429.

Bauer, Laurie. 1997. Attempting to trace Scottish influence on New Zealand English. In Edgar W. Schneider (ed.) Englishes Around the World 2, Studies in Honour of Manfred Görlach. Amsterdam/Philadelphia: John Benjamins Publishing Company. 257-272.

Bauer, Laurie. 1999. On the origins of the New Zealand English accent. English WorldWide. 20:2, 287-307.

Bauer, Laurie. 2000. The dialectal origins of New Zealand English. In Allan Bell \& Koenraad Kuiper (eds.) New Zealand English.Wellington: Victoria University Press. 40-52.

Bauer, Laurie \& Winifred Bauer. 2000a. The influence of the Maori population on NZ dialect areas. Te Reo 43, 39-61.

Bauer, Laurie \& Winifred Bauer. 2000b. Nova Zelandia est omnis divisa in partes tres. New Zealand English Journal 14: 7-17.

Bauer, Laurie \& Winifred Bauer. 2001. New Zealand English or New Zealand Englishes? English in Aotearoa. 43: 59-76.

Bauer, Laurie \& Winifred Bauer. 2002a. Can we catch regional dialects developing in colonial English?: The case of New Zealand. English World-Wide 23:2, 169193.

Bauer, Laurie \& Winifred Bauer. 2002b. The persistence of dialect areas. Te Reo 45: $37-44$.

Bauer, Laurie \& Winifred Bauer. 2003. Playground Talk: Dialects and Change in New Zealand English. Wellington: School of Linguistics and Applied Language Studies, Victoria University of Wellington.

Bauer, Laurie \& Paul Warren. 2004. New Zealand English: Phonology. In B. Kortmann, E.W. Schneider, K. Burridge, R. Mestrie \& C. Upton (eds.) A Handbook of Varieties of English: A Multimedia Reference Tool (Vol.1, pp. 580-602). Berlin: Mouton de Gruyter.

Baugh, John.1993. Adapting dialectology: the conduct of community language studies. In Dennis R. Preston (ed.) American Dialect Research. Amsterdam/Philadelphia: John Benjamins Publishing Company. 
Bayard, Donn. 1987. Class and change in New Zealand English: a summary report. Te Reo, 30: 3-36.

Bayard, Donn. 1989. "Me say that? No way!": the social correlates of American lexical diffusion in New Zealand English. Te Reo. 32: 17-60.

Bayard, Donn. 1990. 'God help us if we all sound like this': Attitudes to New Zealand English and other English accents. In Allan Bell and Janet Holmes (eds.) New Zealand Ways of Speaking English. Clevedon: Multilingual Matters, 67-96.

Bayard, Donn. 1991. Social Constraints on the phonology of New Zealand English. English Around the World. Ed. Jenny Cheshire. Cambridge: Cambridge University Press. 169-185.

Bayard, Donn. 1995. Kiwitalk: Sociolinguistics and New Zealand Society. Palmerston North: Dunmore Press.

Bayard, Donn and Christopher Bartlett. 1996. "You must be from Gorrre": attitudinal effects of Southland rhotic accents and speaker gender on NZE listeners and the question of NZE regional variation. Te Reo 39: 25-45.

Bayard, Donn, Ann Weatherall, Cynthia Gallois \& Jeffery Pittam. 2001. Pax Americana? Accent attitudinal evaluations in New Zealand, Australia and America. Journal of Sociolinguistics 5/1: 22-49.

Beckman, Mary \& G. Ayers Elam. 1994/1997. Guide to ToBI Labelling Version 3.0. http://ling.ohiostate.edu/Phonetics/E_ToBI/etobi_homepage.html

Beckman, Mary \& J. B. Pierrehumbert. 1986. Intonational structure in Japanese and English. Phonology 3, 255-309.

Bell, Allan. 1997. Those short front vowels. New Zealand English Journal. 11: 3-13.

Bell, Allan \& Gary Johnson. 1997. Towards a sociolinguistics of style. University of Pennsylvania Working Papers in Linguistics 12: 223-248.

Bennett, J.A.W. 1970. English as it is spoken in New Zealand. In W.S.Ramson (ed.) English Transported, Essays on Australian English. 69-83.

Benton, Richard A. 1985. Maori, English and Maori English. In John B. Pride (ed.) Cross-Cultural Encounters. Melbourne: River Seine. 110-120.

Benton, Richard A. 1991. Maori English: A New Zealand Myth? In Jenny Cheshire (ed.) English Around the World 187-199. Cambridge: Cambridge University Press.

Blake, Renee \& Meredith Josey. 2003. The /ay/ diphthong in a Martha's Vineyard community: What can we say 40 years after Labov. Language in Society 32: 451-485. 
Bloomfield, Leonard. 1933. Language. New York: Holt.

Boissevain, Jeremy. 1974. Friends of Friends: Networks, Manipulators and Coalitions. Oxford: Basil Blackwell.

Borowsky, Toni \& Horvath, Barbara. (In press) L-Vocalisation in Australian English.

Bortoni-Ricardo, Stella Maris. 1985. The Urbanisation of Rural Dialect Speakers. Cambridge: Cambridge University Press.

Boyce, Mary. 1992. Maori language in Porirua: a study of reported proficiency, patterns of use and attitudes. Unpublished MA thesis, Victoria University of Wellington.

Bradley, David. 1989. Regional dialects in Australian English phonology. In Peter Collins \& David Blair (eds.) Australian English. The Language of a New Society.. St Lucia: University of Queensland Press. 260-270.

Brend, Ruth. 1975. Male-female intonation patterns in American English. In Barrie Thorne and Nancy Henley (eds.) Language and Sex, Difference and Dominance. Massachusetts: Newbury House Publishers, Inc. 84-87.

Britain, David. 1991. Dialect and space: a geolinguistic study of speech variables in the Fens. Unpublished PhD dissertation, Essex University, Colchester.

Britain, David. 1992. Linguistic change in intonation: the use of high rising terminals in New Zealand English Language Variation and Change. 4: 77-104.

Britain, David. 1997. Dialect contact and phonological reallocation: "Canadian Raising" in the English Fens. Language and Society 26:1, 15-46.

Britain, David \& Newman, John. 1992. High rising terminals in New Zealand English. Journal of the International Phonetic Association 22:1/2.

Brown, Gillian, Karen Currie \& Joanne Kenworthy.1980. Questions of Intonation. London: Croom Helm.

Callary, Robert. 1975. Phonological change and the development of an urban dialect in Illinois. Language in Society 4: 155-169.

Cassidy, Steve. 2001. Emu and ToBI. http://emu.sourceforge.net/emu-tobi.shtml

Chafe, Wallace. 1994. Discourse, Consciousness and Time. Chicago: The University of Chicago Press.

Chambers, J.K. 1992. Dialect acquisition. Language 68:3, 673-705.

Chambers, J.K. 1993. Sociolinguistic dialectology. In Dennis R. Preston (ed.) American Dialect Research. Amsterdam/Philadelphia: John Benjamins Publishing Company. 
Chambers, J.K. 1995. Sociolinguistic Theory. Oxford: Blackwell.

Chambers, J.K. 1998. Myth 15: TV makes people sound the same. In Laurie Bauer \& Peter Trudgill (eds.) Language Myths. London: Penguin Books. 123-131.

Chambers, J.K. 2003. Sociolinguistic Theory. ( $2^{\text {nd }}$ edition) Oxford: Blackwell.

Chambers, J.K \& Trudgill, Peter. 1980. Dialectology. Cambridge: Cambridge University Press.

Chambers, J.K. \& Trudgill, Peter. 1998. Dialectology. (2 $2^{\text {nd }}$ edition) Cambridge: Cambridge University Press.

Cheshire, Jenny. 1982. Variation in an English Dialect: A Sociolinguistic Study. Cambridge: Cambridge University Press.

Cheshire, Jenny, Paul Kerswill \& Ann Williams. 2005 f.c. On the non-convergence of phonology, grammar and discourse. In P. Auer, F. Hinskens and P. Kerswill (eds.) Dialect Change: Convergence and Divergence in European Languages. Cambridge: Cambridge University Press.

Childers, D. \& K.Wu. 1991. Gender recognition from speech: Part II: Fine analysis. Journal of the Acoustical Society of America, 90: 1841-1856.

Ching, Marvin. 1982. The question intonation in assertions. American Speech 57: 95107.

Couper-Kuhlen, Elizabeth \& Selting, Margret. 1996. Prosody in Conversation, Interactional Studies. Cambridge: Cambridge University Press.

Cruttenden, Alan. 1995. Rises in English. In J. Windsor Lewis (ed.) Studies in General and English Phonetics: Essays in Honour of Professor J. D. O'Connor. London and New York: Routledge. 155-173.

Cruttenden, Alan. 1997. Intonation. Cambridge: Cambridge University Press.

Cruttenden, Alan. 2001. Mancunian intonation and intonational representation. Phonetica 58:53-80.

Crystal, David. 1969. Prosodic Systems and Intonation in English. Cambridge: Cambridge University Press.

Crystal, David. 1995. Documenting rhythmical change. In J. Windsor Lewis (ed.) Studies in General and English Phonetics: Essays in Honour of Professor J. D. O'Connor. London and New York: Routledge. 174-179.

Currie, K.L. 1979. Intonation systems in Scottish English, unpublished $\mathrm{PhD}$ thesis, University of Edinburgh. 
Daly, Nicola \& Paul Warren. 2001. Pitching it differently in New Zealand English: speaker sex and intonation patterns. Journal of Sociolinguistics 5/1 85-96.

Dalziel, Raewyn. 1991. Emigration and kinship, migrants to New Plymouth 1840-1843. The New Zealand Journal of History 25(2): 112-128.

Davis, Peter, Philippa Howden-Chapman \& Keith McLeod. 1997. The New Zealand socioeconomic index: a census-based occupational scale of socioeconomic status. In Peter Crampton \& Philippa Howden-Chapman (eds.) Socioeconomic Inequalities and Health. Wellington: Institute of Policy Studies, Victoria University of Wellington 131-148.

Davis, Peter, Gabrielle Jenkin \& Pat Coope. 2003. New Zealand Socio-economic Index 1996: An update and revision of the New Zealand Socio-economic Index of Occupational Status. Wellington: Statistics New Zealand Te Tari Tatau.

Davis, Rhona. 1977. "New Zild". Two letters to the NZ Listener, 30 April and 18 June. Reproduced in Gordon \& Deverson (1985:61-2).

Deverson, Tony and Elizabeth Gordon. 1998. New Zealand English and English in New Zealand. Auckland: New House Publishers Ltd.

Dorian, Nancy. 1994. Varieties of variation in a very small place: social homogeneity, prestige norms, and linguistic variation. Language. 70:4, 631-698.

Douglas-Cowie, E., R. Cowie and J. Rahilly. 1995. The social distribution of intonation patterns in Belfast. In J. Windsor Lewis (ed.) Studies in General and English Phonetics: Essays in Honour of Professor J. D. O'Connor. London and New York: Routledge 180-186.

Dubois, Sylvie. 1995. Field methods in four Cajun communities. In Albert Valdman (ed.) French and Creole in Louisiana. New York: Plenum. 47-70.

Dubois, Sylvie \& Barbara Horvath. 2000. When the music changes, you change too: gender and language change in Cajun English. Language Variation and Change 11: $287-313$.

Durkin, Mary. 1972. A study of the pronunciation, oral grammar and vocabulary of West Coast school children. Unpublished MA thesis. Christchurch: University of Canterbury.

Eckert, Penelope. 1988. Adolescent social structure and the spread of linguistic change. Language in Society 17 (2): 183-207.

Eckert, Penelope. 1989. Jocks and Burnouts: Social Identity in the High School. New York: Teachers College Press.

Eckert, Penelope. 2000. Linguistic Variation as Social Practice: The Linguistic Construction of Social Identity in Belton High. Oxford: Blackwell. 
Eckert, Penelope \& Sally McConnell-Ginet. 1992. Think practically and look locally: Language and gender as community-based practice. Annual Revue of Anthropology 21: 461-490.

Eckert, Penelope, \& Sally McConnell-Ginet. 2003. Language and Gender. Cambridge: Cambridge University Press.

Edelsky, Carole. 1979. Question intonation and sex roles. Language in Society 8, 1532.

Edwards, Walter F. 1992. Sociolinguistic behaviour in a Detroit inner-city black neighbourhood. Language in Society 21: 93-115.

Elley,W.B. \& J.C.Irving. 1972. A socio-economic index for New Zealand based on levels of education and income from the 1966 census. New Zealand Journal of Educational Studies 7 (2) 153-167.

Elley, W.B. \& J.C.Irving. 1985. The Elley-Irving socio-economic index 1981 census revision. New Zealand Journal of Educational Studies 20:2 115-128.

Elyan, O. 1978. Sex differences in speech style. Women Speaking 4, 4-8.

Feagin, Crawford. 2002. Entering the community: fieldwork. In J.K.Chambers, Peter Trudgill \& Natalie Schilling-Estes (eds.) The Handbook of Language Variation and Change. Oxford: Blackwell. 20-39.

Fichtelius, Anna, Irene Johansson \& Kerstin Nordin. 1980. Three investigations of sexassociated speech variation in day school. In Cheris Kramarae (ed.) The Voices and Words of Women and Men. Oxford: Pergamon Press. 219-225.

Fletcher, Janet \& Nicholas Evans. 2002. An acoustic phonetic analysis of intonational prominence in two Australian languages. Journal of the International Phonetic Association 32(2), 123-140.

Fletcher, Janet, Esther Grabe \& Paul Warren. 2005. Intonational variation in four dialects of English: the high rising tone. In Sun-Ah Jun (ed.) Prosodic Typology and Transcription - A Unified Approach. Oxford: Oxford University Press. 390409.

Fought, Carmen. 2002. Ethnicity. In J.K.Chambers, Peter Trudgill \& Natalie SchillingEstes (eds.) The Handbook of Language Variation and Change. Oxford: Blackwell. 444-472.

Fromkin, Victoria \& Robert Rodman. 1983. An Introduction to Language. New York: Holt, Rinehart and Winston.

Gal, Susan. 1979. Language Shift: Social Determinants of Linguistic Change in Bilingual Austria. New York: Academic Press. 
Galbraith, Christine, Gabrielle Jenkin, Peter Davis \& Pat Coope. 2003. Users' Guide to the New Zealand Socio-economic Index 1996. Wellington: Statistics New Zealand Te Tari Tatau.

Gardner, William J. 1999. Where they Lived: Studies in Local, Regional and Social History. Christchurch: Regional Press.

Giddens, Anthony. 1984. The Constitution of Society. Cambridge: Polity Press.

Gordon, Elizabeth, Lyle Campbell, Jennifer Hay, Margaret Maclagan, Andrea Sudbury and Peter Trudgill. 2004. New Zealand English: Its Origins and Evolution. Cambridge: Cambridge University Press.

Gordon, Elizabeth \& Tony Deverson. 1985. New Zealand English. Auckland: Heinemann.

Gordon, Elizabeth \& Tony Deverson. 1998. New Zealand English and English in New Zealand. Auckland: New House Press.

Gordon, Elizabeth \& Margaret Maclagan. 1985. A study of the 'ear/air' contrast in New Zealand English. The New Zealand Speech-Language Therapists' Journal 40: 16-26.

Gordon, Elizabeth \& Margaret A. Maclagan. 1990. A longitudinal study of the EAR/AIR contrast in New Zealand English. In Allan Bell \& Janet Holmes (eds.) New Zealand Ways of Speaking English Clevedon, Avon: Multilingual Matters. 129-148.

Gordon, Matthew. 2001. Small-Town Values and Big-City Vowels: Northern Cities Shift in Michigan. Publication of the American Dialect Society, no. 84, Duke University Press.

Gordon, Pamela. 1997. What New Zealanders believe about regional variation in New Zealand English: a folklinguistic investigation. New Zealand English Journal. 11: 14-23.

Grabe, Esther. 2002. Variation adds to prosodic typology. In B. Bel \& I. Marlin (eds.) Proceedings of the Speech Prosody 2002 Conference. Aix-en-Provence: Laboratoire Parole et Langage. 127-132.

Grabe, Esther, Francis Nolan \& Brechtje Post. 1997. English Intonation in the British Isles: The IViE Corpus. http://www.phon.ox.ac.uk/esther/ivyweb/ (Created 1997, accessed 25 February 2004).

Grabe, Esther \& Brechtje Post. 2002. Intonational variation in the British Isles. In B. Bel \& I. Marlin (eds.) Proceedings of the Speech Prosody 2002 Conference. Aix-en-Provence: Laboratoire Parole et Langage. 343-346. 
Grabe, Esther, Brechtje Post \& Francis Nolan. 2000. Modelling intonational variation in English, the IViE system. Proceedings of Speech Prosody 2000 Conference. Krakow, Poland.

Graddol, David \& Joan Swann. 1983. Speaking fundamental frequency: Some physical and social correlates. Language and Speech 26: 351-366.

Graham Jeanine.1981. Settler society. In W.H. Oliver \& B.P. Williams (eds.) The Oxford History of New Zealand. Wellington: Oxford University Press. 112-139.

Gumperz, John. The Speech Community. In International Encyclopedia of the Social Sciences. London: MacMillan, 381-6.

Guy, G.R. 1993. The quantitative analysis of linguistic variation. In Dennis Preston (ed.) American Dialect Research. Amsterdam and Philadelphia: Benjamins, 223-49.

Guy, Gregory, Barbara Horvath, Julia Vonwiller, Elaine Daisley \& Inge Rogers. 1986. An intonational change in progress in Australian English. Language in Society 15: $23-52$.

Guy, Gregory \& Julia Vonwiller. 1984. The meaning of an intonation in Australian English. Australian Journal of Linguistics 4/1: 1-17.

Guy, Gregory \& Julia Vonwiller. 1989. The high rising tone in Australian English. In Peter Colins and David Blair (eds.) Australian English: the Language of a New Society. St Lucia, Queensland: University of Queensland Press. 21-34.

Haan, Judith \& Vincent J. van Heuven. 1999. Male vs. female pitch range in Dutch questions. Proceedings of the $14^{\text {th }}$ International Congress of Phonetic Sciences. San Francisco, 1581-1584.

Haeri, N. 1997. The Sociolinguistic Market of Cairo: Gender, Class and Education. London \& New York: Kegan Paul International.

Hall, Moira. 1976. An acoustic analysis of New Zealand vowels. Unpublished MA thesis, Auckland, University of Auckland.

Halliday, M.A.K. 1967. Intonation and Grammar in British English. The Hague: Mouton.

Harrington, Jonathan, Sallyanne Palethorpe \& Catherine Watson. 2000. Does the Queen speak the Queen's English? Nature 408 (December 21/28): 927.

Henton, Caroline. 1989. Fact and fiction in the description of female and male pitch. Language and Communication 9,4: 299-311.

Henton, Caroline. 1995. Pitch dynamism in male and female speech. Language and Communication 15,1: 43-61. 
Hermes, Dik J., \& Joost C. van Gestel. 1991. The frequency scale of speech intonation. Journal of the Acoustical Society of America 90: 97-103.

Hickey, Raymond. 2003. How do dialects get the features they have? On the process of new dialect formation. In Raymond Hickey (ed.) Motives for Language Change. Cambridge: Cambridge University Press. 213-239.

Hirst, Daniel \& Albert di Cristo 1998. A survey of intonation systems. In Daniel Hirst \& Albert di Cristo (eds) Intonation Systems. Cambridge: Cambridge University Press.

Hockett, Charles F. 1958. A course in Modern Linguistics. New York: MacMillan.

Hogstad, Kirsti. 1995. Regional Variation in New Zealand English? Unpublished MA thesis. Denmark: Fynsk Universitetsstøtte.

Holmes, Janet. 1994. New Zealand flappers: an analysis of T voicing in New Zealand English. English World-Wide 15:2 195-224.

Holmes, Janet. 1995a. Time for /t/: initial/t/ in New Zealand English. Australian Journal of Linguistics 15: 127-156.

Holmes, Janet. 1995b. Two for /t/: flapping and glottal stops in New Zealand English. Te Reo 38: 53-72.

Holmes, Janet. 1996. Losing voice: is final/z/ devoicing a feature of maori English? World Englishes 15: 193-205.

Holmes, Janet. 1997a. Maori and Pakeha English: some New Zealand social dialect data. Language in Society 26:65-101.

Holmes, Janet. 1997b. Setting standards: sound changes and gender in New Zealand English. English World-Wide 18:1 107-142.

Holmes, Janet. 1997c. Women, language and identity. Journal of Sociolinguistics 1:2 195-223.

Holmes, Janet \& Helen Ainsworth. 1996. Syllable-timing and Maori English. Te Reo 39: $75-84$.

Holmes, Janet \& Helen Ainsworth. 1997. Unpacking the research process: investigating syllable-timing in New Zealand English. Language Awareness 6: 32-47.

Holmes, Janet \& Allan Bell. 1988. Learning by experience: notes for New Zealand social dialectologists. Te Reo 31, 19-49.

Holmes, Janet \& Bell, Allan. 1991. New Zealand English. In Jenny Cheshire (ed.) English around the World: Sociolinguistic Perspectives. Cambridge: Cambridge University Press. 153-168. 
Holmes, Janet \& Allan Bell. 1992. On shear markets and sharing sheep: the merger of EAR and AIR diphthongs in New Zealand English. Language Variation and Change 4: 251-273.

Holmes, Janet, Allan Bell \& Mary Boyce. 1991. Variation and Change in New Zealand English: A Social Dialect Investigation. Project report to the Social Sciences Committee of the Foundation for Research, Science and Technology. Wellington: Victoria University of Wellington.

Horvath, Barbara M. 1985. Variation in Australian English: The Sociolects of Sydney. Cambridge: Cambridge University Press.

Horvath, Barbara M. \& Ronald J. Horvath. 1997. The geolinguistics of a sound change in progress: /1/ vocalisation in Australia. In Miriam Meyerhoff, Charles Boberg and Stephanie Strassel (eds.) Working Papers in Linguistics: A Selection of Papers from NWAVE 25. Philadelphia: University of Pennsylvania. 105-124.

Horvath, Barbara M. \& Ronald J. Horvath. 2001. A multilocality study of a sound change in progress: The case of $/ 1 /$ vocalization in New Zealand and Australian English. Language Variation and Change 13: 37-57.

Horvath, Barbara M. \& Ronald J. Horvath. 2002. The geolinguistics of /1/ vocalization in Australia and New Zealand. Journal of Sociolinguistics 6/3, 319-346.

Hudson, Amelia I. \& Anthony Holbrook. 1981. A study of reading fundamental vocal frequency of young black adults. Journal of Speech and Hearing Research 24: 197-201.

Hudson, Amelia I. \& Anthony Holbrook. 1982. Fundamental frequency characteristics of young black adults: Spontaneous speaking and oral reading. Journal of Speech and Hearing Research 25: 25-28.

Hudson, R. A. 1996. Sociolinguistics. ( $2^{\text {nd }}$ ed.) Cambridge: Cambridge University Press.

Hundt, Marianne. 1996. New Zealand English in Relation to British English and American English: A Corpus-Based Study in Morphosyntactic Variation. $\mathrm{PhD}$ thesis. Freiburg: Albert-Ludwigs-Universitat.

Irving, J.C. \& W.B. Elley. 1977. A socio-economic index for the female labour force in New Zealand. New Zealand Journal of Educational Studies 12 (2) 154-163.

James, Eric, Christopher Mahut \& George Latkiewicz. 1989. The investigation of an apparently new intonation pattern in Toronto English. Information Communication (Speech and Voice Society and Phonetics Laboratory, University of Toronto) 10: 11-17.

Jarman, Eric \& Alan Cruttenden. 1976. Belfast intonation and the myth of the fall. Journal of the International Phonetic Association 6: 4-12. 
Johnstone, Barbara. 1996. The Linguistic Individual. Self-Expression in Language and Linguistics. New York: Oxford University Press.

Johnstone, Barbara. 1999. Uses of southern speech by contemporary Texas women. In Ben Rampton (ed.) Journal of Sociolinguistics. Special Issue on Styling the Other. 4(3):505-522.

Johnstone, Barbara \& Judith Mattson Bean. 1997. Self-expression and linguistic variation. Language in Society 26: 221-246.

Kerswill, Paul. 1994. Dialects Converging, Rural Speech in Urban Norway. Oxford: Clarendon Press.

Kerswill, Paul. 1996. Children, adolescents and language change. Language Variation and Change 8: 177-202.

Kerswill, Paul. 2001. Koineization and accommodation. In Jack K. Chambers, Peter Trudgill \& Natalie Schilling-Estes (eds.) The Handbook of Language Variation and Change. Malden, MA: Blackwell. 669-702.

Kerswill, Paul \& Ann Williams. 2000. Creating a New Town koine: Children and language change in Milton Keynes. Language in Society 29, 65-115.

King, Jeanette. 1993. Maori English: a phonological study. New Zealand English Newsletter 7:33-47.

King, Jeanette. 1999. Talking Bro: Maori English in the university setting. Te Reo 42: 20-38.

Kirk, John \& Sanderson, Stewart \& Widdowson, J.D.A. 1985. Studies in Linguistic Geography. London: Croom Helm.

Labov, William. 1966. The Social Stratification of English in New York City. Washington DC: Centre for Applied Linguistics.

Labov, William. 1972a. Sociolinguistic Patterns. Philadelphia: University of Pennysylvania Press.

Labov, William. 1972b. Language in the Inner City. Philadelphia: University of Pennsylvania Press.

Labov, William. 1972c. Some principles of linguistic methodology. Language in Society 1/1: 97-120.

Labov, William. 1984. Field methods of the project of linguistic change and variation. In John Baugh and Joel Sherzer (eds.), Language in Use: Readings in Sociolinguistics. Englewood Cliffs: Prentice-Hall. 28-53. 
Labov, William. 1990. The intersection of sex and social class in the course of linguistic change. Language Variation and Change 2: 205-254.

Labov, William. 2001. Principles of Linguistic Change. Volume 2: Social Factors. Massachusetts, Oxford: Blackwell Publishers.

Labov, William. 2002. Driving forces in linguistic change. Proceedings of the 2002 International Conference on Korean Linguistics, 2 August, 2002, Seoul National University.

Labov, William \& J. Waletzky. 1967. Narrative analysis: oral versions of personal experience. In J. Helms (ed.) Essays on the Verbal and Visual Arts. Seattle: University of Washington Press. 12-44.

Ladd, D. Robert. 1996. Intonational Phonology. Cambridge: Cambridge University Press.

Ladd, D. Robert \& G. Lindsay. 1991. Theoretical consequences of Glaswegian intonation, paper presented at the York meeting of the Linguistics Association of Great Britain.

Ladefoged, Peter. 1997. Instrumental techniques for linguistic phonetic fieldwork. In William J. Hardcastle \& John Laver (eds.), The Handbook of Phonetic Sciences. Oxford: Blackwell Publishers.

Lakoff, Robin. 1975. Language and Woman's Place. New York: Harper and Row.

Lass, Roger. 1987. The Shape of English: Structure and History. London: J.M. Dent \& Sons.

Leek, Robert \& Bayard,Donn. 1995. Yankisms in Kiwiland, from zed to zee: American lexical and pronunciation incursions in Dunedin (1984-1985) and Auckland (1990). Te Reo 38: 105-125.

Lippi-Green, Rosina L. 1989. Social network integration and language change in progress in a rural alpine village. Language in Society 18: 213-234.

Local, John K. 1986. Patterns and problems in a study of Tyneside intonation. In Catherine Johns-Lewis (ed.) Intonation in Discourse. London: Croom Helm.

Local, J.K., J. Kelly \& W.H.G. Wells. 1986. Towards a phonology of conversation: turn-taking in Tyneside English. Journal of Linguistics 22: 411-437.

Local, J.K., W.H.G. Wells \& M. Sebba. 1985. Phonology for conversation: phonetic aspects of turn delimitation in London Jamaican. Journal of Pragmatics 9: 309330.

Lyons, John, ed. 1970. New Horizons in Linguistics. Harmondsworth: Penguin. 
Macalister, John. 1999. Trends in New Zealand English: Some observations on the presence of Maori words in the lexicon. New Zealand English Journal 13: 3849.

Macalister, John. 2000. The changing use of Maori words in New Zealand English. New Zealand English Journal 14: 41-47.

Macalister, John. 2002. Maori loanwords and New Zealand humour. NZ Words 6, 3-4.

Macalister, John. 2003. The presence of Maori words in New Zealand English. Unpublished $\mathrm{PhD}$ thesis. Victoria University of Wellington.

Macaulay, Ronald K.S. \& G.D. Trevelyan. 1973. Language, Education and Employment in Glasgow. Report to the Social Science Research Council. Edinburgh: Scottish Council for Research in Education.

Maclagan, Margaret A. 2000. How long have women been leading language change? In Janet Holmes (ed.), Gendered Speech in Social Context: Perspectives from Gown and Town. Wellington: Victoria University Press. 87-98.

Maclagan Margaret \& Elizabeth Gordon. 1999. Data for New Zealand social dialectology: the Canterbury Corpus. New Zealand English Journal 13: 50-58.

McClure, J. Derrick. 1980. Western Scottish intonation: a preliminary study. In Linda R. Waugh \& C.H. van Schooneveld (eds.) The Melody of Language. Baltimore: University Park Press. 201-218.

McConnell-Ginet, Sally, 1983. Intonation in a man's world. In Barrie Thorne, Cheris Kramarae and Nancy Henley (eds). Language, Gender and Society. Massachusetts: Newbury House Publishers. 69-88.

McGregor, Robert. 1980. The social distribution of an Australian English intonation contour. Working papers of the Speech and Language Research Centre, School of English and Linguistics, Macquarie University 2: 1-26.

McKinnon, Malcolm. 1997. New Zealand Historical Atlas. Auckland: David Bateman.

Meyerhoff, Miriam. 1991. Grounding and overcoming obstacles: the positive politeness motivations of High Rise Terminals. Manuscript.

Meyerhoff, Miriam. 1994. Sounds pretty ethnic, eh?: A pragmatic particle in New Zealand English. Language in Society 23: 367-388.

Milroy, James \& Lesley Milroy. 1985. Linguistic change, social network and speaker innovation. Journal of Linguistics 25: 339-384.

Milroy, James \& Lesley Milroy. 1993. Mechanisms of change in urban dialects: The role of class, social network and gender. International Journal of Applied Linguistics 3: 57-77. 
Milroy, Lesley. 1980. Language and Social Networks. Oxford: Blackwell.

Milroy, Lesley. 1987a. Observing and Analysing Natural Language. A Critical Account of Sociolinguistic Method. Oxford: Basil Blackwell, Inc.

Milroy, Lesley. 1987b. Language and Social Networks.(2nd ed.) Oxford: Basil Blackwell.

Milroy, Lesley, 1999. Women as innovators and norm creators: The sociolinguistics of dialect levelling in a northern English city. Engendering Communication:

Proceedings of the fifth Berkeley Women and Language Conference. Berkeley, California: Berkeley Women and Language Group. 361-76.

Milroy, Lesley \& Matthew Gordon. 2003. Sociolinguistics: Method and Interpretation. Oxford: Basil Blackwood.

Mitchell, A.G. \& A. Delbridge. 1965. The Speech of Australian Adolescents. Sydney: Angus and Robertson.

Nichols, Patricia C. 1983. Linguistic options and choices for black women in the rural south. In Barrie Thorne, Cheris Kramerae and Nancy Henley (eds.) Language, Gender and Society. Rowley, MA: Newbury House.

Niedzielski, Nancy \& Dennis R. Preston. 1999. Folk Linguistics. New York: Walter de Gruyter.

Nolan, Francis \& Kimberley Farrar. 1999. Timing of FO peaks and peak lag. Proceedings of the $14^{\text {th }}$ International Congress of Phonetic Science, San Francisco. 961-964.

Norrick, Neal R. 2000. Conversational Narrative: Storytelling in Everyday Talk. Amsterdam: John Benjamins Publishing Company.

O’Connor, J.D. \& G.F.Arnold. 1961. Intonation of Colloquial English: A Practical Handbook. London: Longman.

Ochs, Elinor. 1993. Constructing social identity: A language socialization perspective. Research on Language and Social Interaction 26 (3): 287-306.

Orsman, Harry (ed.). 1997. A Dictionary of New Zealand English: A Dictionary of New Zealandisms on Historical Principles. Auckland: Oxford University Press.

Paddock, Harold. 1981. A Dialect Survey of Carbonear, Newfoundland. Urbana: American Dialect Society.

Pellowe, John \& Val Jones. 1978. On intonational variability in Tyneside speech. In Peter Trudgill (ed) Sociolinguistic patterns in British English. Edward Arnold: London. 101-121. 
Peppe, Sue, Jane Maxim \& Bill Wells. 2000. Prosodic variation in Southern British English. Language and Speech 43 (3): 309-334.

Pierrehumbert, J.B. 1980. The phonology and phonetics of English intonation. Unpublished doctoral dissertation. Cambridge, Massachusetts, USA: Massachusetts Institute of Technology.

Preston, Dennis. 1989. Perceptual Dialectology: Nonlinguists 'Views of Areal Linguistics. Dordrecht: Foris.

Quirk, R., J. Svartvik, A.P. Duckworth, J.P.L. Rusiecki \& A.J.T. Colin. 1964. Studies in the correspondence of prosodic to grammatical features in English. In H.G. Lunt (ed.) Proceedings of the Ninth International Congress of Linguists, The Hague: Mouton. 679-91.

Rickford, John R. \& Faye McNair-Knox. 1994. Addressee- and topic influence style shift: A quantitative sociolinguistic study. In Douglas Biber and Edward Finegan (eds.) Sociolinguistic Perspectives on Register. New York: Oxford University Press. 235-276.

Rickford, John R. \& John McWhorter. 1997. Language contact and language generation: Pidgins and Creoles. In Florian Coulmas (ed.) The Handbook of Sociolinguistics. Oxford:Blackwell.

Robertson, Shelley. 1996. Maori English and the bus-driving listener: a study of ethnic identification and phonetic cues. Wellington Working Papers in Linguistics 8:54-69

Rose, D. 1995. A Report on Phase 1 of the ESRC Review of the OPCS Social Classification. Essex: Economic and Social Research Council.

Samarin, William J. 1971. Salient and substantive pidginization. In Dell Hymes (ed.) Pidginization and Creolization of Languages. Proceedings of a conference held at the university of the West Indies, Jamaica, April 1968.

Sankoff, Gillian. 1980. A quantitative paradigm for the study of communicative competence. In Gillian Sankoff (ed.) The Social Life of Language. Philadelphia: University of Pennsylvania Press. 47-79.

Saville-Troike, Muriel. 1986. The Ethnography of Communication. Oxford: Basil Blackwell.

Schilling-Estes, Natalie. 1999. Reconsidering rural dialects: A historic and ethnographic approach. Paper presented at the $10^{\text {th }}$ International Conference on Methods in Dialectology, Memorial University of Newfoundland, St Johns Canada , 2-6 August.

Shaw, Bernard. 1941. Pygmalion: a romance in five acts. Harmondsworth: Penguin. 
Shuy, Roger W., Walt Wolfram \& William K. Riley. 1967. Linguistic Correlates of Social Stratification in Detroit Speech. Cooperative Research Project No.6 1347. East Lansing, Michigan: Michigan State University.

Shuy, Roger W., Walt Wolfram \& William K. Riley, 1968. Field Techniques in an Urban Language Study. Washington D.C.: Centre for Applied Language Studies.

Siegel, Jeff. 1985. Koines and koineization. Language in Society 14:357-378.

Siegel, Jeff. 1993. Introduction: controversies in the study of koines and koineization. International Journal of the Sociology of Language 99: 5-8.

Sinclair, Keith. 2000. A History of New Zealand. Auckland:Penguin Books.

Statistics New Zealand. 1996 Census of Population and Dwellings, Regional Summary.

Stuart-Smith, Jane. 1999. Glasgow: accent and voice quality. In Paul Foulkes \& Gerard J. Docherty (eds.) Urban Voices: Accent Studies in the British Isles. London: Arnold. 203-

Sudbury, Andrea. 2001. Falklands Island English: a southern hemisphere variety? English World-wide 22: 55-80.

Tarone, Elaine E. 1973. Aspects of intonation in Black English. American Speech 48: 29-36.

Taylor, Ben. 1986. Gay men, femininity and /t/ in New Zealand English. Wellington Working Papers in Linguistics 8: 70-92.

Taylor, Rowan. 2000. Child's play. New Zealand Listener October 14: 26-27.

Tench, Paul. 1990. The pronunciation of English in Abercrave. In Nikolas Coupland (ed.) English in Wales: Diversity, Conflict and Change. Clevedon: Multilingual Matters Ltd. 130-141.

Tench, Paul. 1996. The Intonation Systems of English. London: Cassell.

Thomas, Beth. 1989. Differences of sex and sects: linguistic variation and social networks in a Welsh mining village. In Jennifer Coates \& Deborah Cameron (eds.) Women in their Speech Communities, 51-60.

Thorne, Barrie, Chris Kramerae \& Nancy Henley (eds). 1983. Language, Gender and Society. Rowley, MA: Newbury House.

Tielen, M.T.J. 1989. Fundamental frequency characteristics of middle aged men and women. Proceedings, Institute of Phonetic Sciences, University of Amsterdam, $13,45-58$. 
Tielen, M.T.J. 1992. Male and female speech: an experimental study of sex-related voice and pronunciation characteristics. PhD thesis, University of Amsterdam, CIP-Gegvens Koninklijke Bibliotheek, Den Haag.

Toolan, Michael J. 1988. Narrative: A Critical Linguistic Introduction. London: Routledge.

Trudgill, Peter. 1974. The Social Differentiation of English in Norwich. London: Cambridge University Press.

Trudgill, Peter. 1983. On Dialect: Social and Geographical Perspectives. Oxford: Basil Blackwell.

Trudgill, Peter. 1986. Dialects in Contact. Oxford: Basil Blackwell.

Trudgill, Peter. 1989. Interlanguage, interdialect and typological change. In Susan Gass et al (eds) Variation in Second Language Acquisition: Psycholinguistic Issues.

Trudgill, Peter. 1998. The Dialects of English. Oxford: Blackwell.

Trudgill, Peter. 1999. The chaos before the order: New Zealand English and the second stage of new-dialect formation. In Ernst Hakon Jahr (ed.) Language Change: Advances in Historical Linguistics. Berlin, New York: Mouton de Gruyter. 197207.

Trudgill, Peter. 2004. New-Dialect Formation: The Inevitability of Colonial Englishes. Oxford: Oxford University Press.

Trudgill, Peter, Elizabeth Gordon \& Gillian Lewis. 1998. New-dialect formation and southern hemisphere English: the New Zealand short front vowels. Journal of Sociolinguistics 2:1, 35-51.

Trudgill, Peter, Elizabeth Gordon, Gillian Lewis \& Margaret Maclagan. 2000.

Determinism in new-dialect formation and the genesis of New Zealand English. Journal of Linguistics 36:2, 299-318.

Trudgill, Peter \& Jean Hannah. 1985. International English. A Guide to Varieties of Standard English. London: Edward Arnold.

Turner, G.W. 1966. The English Language in Australia and New Zealand. London: Longmans.

Turner, G.W. 1970. New Zealand English Today. In W.S.Ramson (ed.) English Transported, Essays on Australasian English. 84-101.

Urry, John. 1985. Social Relations, space and time. In Derek Gregory and John Urry (eds) Social Relations and Spatial Structures. Basingstoke: MacMillan Publishers Ltd. 20-48. 
Vermillion, Patricia. 2002. The ups and downs of Kiwis: an experiment investigating tonal cues which are used to identify NZE intonation. Presented at The Language and Society Conference, 20-22 November 2002, University of Waikato, Hamilton, New Zealand.

Vermillion, Patricia. 2003. The ups and downs of Kiwis: An experiment investigating tonal cues used to identify NZE intonation. Wellington Working Papers in Linguistics. Volume 15. Wellington: Victoria University of Wellington.

Vermillion, Patricia. 2004. Defining the Kiwi tune - localised pitch range: An experiment comparing New Zealand English and (RP) British English pitch range. Presented at The Language and Society Conference, 2-3 September 2004, Massey University, Palmerston North, New Zealand.

Vine, Bernadette. 1995. 'Anyway we're not British': A social dialect study of two features of the speech of thirty Pakeha women from Wanganui. MA thesis, Victoria University of Wellington.

Walters, J.Roderick. 2003. "Celtic English": Influences on a South Wales valleys accent. English World-Wide 24:1 63-87.

Warren, Paul. 1998. Timing patterns in New Zealand English rhythm. Te Reo 41: 8093.

Warren, Paul. 2005. Patterns of late rising in New Zealand - intonational variation or intonational change? Language Variation and Change 17 (2).

Warren, Paul \& Laurie Bauer. 2004. Maori English: Phonology. In B. Kortmann, E. Schneider, K. Burridge, R. Mesthrie \& C. Upton (eds.) A Handbook of Varieties of English: A Multimedia Reference Tool (Vol.1, pp. 614-624) Berlin: Mouton de Gruyter.

Warren, Paul \& David Britain. 2000. Intonation and prosody in New Zealand English. In Allan Bell and Koenraad Kuiper (eds.) New Zealand English. Wellington: Victoria University Press. 146-172.

Warren, Paul \& Nicola Daly, 2000. Sex as a factor in rises in New Zealand English. In Janet Holmes (ed.) Gendered Speech in Social Context: Perspectives from Gown and Town. Wellington: Victoria University Press. 99-113.

Warren, Paul \& Nicola Daly, 2005 f.c. Characterizing New Zealand English intonation: broad and narrow analysis. In Allan Bell, Ray Harlow \& Donna Starks (eds.) Languages of New Zealand. Wellington: Victoria University Press.

Wells, Bill \& Sue Peppe. 1996. Ending up in Ulster. In Elizabeth Couper-Kuhlen \& Margret Selting (eds.) Prosody in Conversation. Cambridge: Cambridge University Press. 101-130.

Wells, J.C. 1982. Accents of English. Cambridge: Cambridge University Press. 
Wells, William H.G. 1989. Pre-final focus accents in English: a comparative study of two varieties. In David Bradley, Eugenie J.A. Henderson \& Martine Mazoudon (eds.) Prosodic Analysis and Asian Linguistics: to Honour R.K. Sprigg.

Canberra: Pacific Linguistics. 17-32.

Wennerstrom, Ann. 2001(a). The Music of Everyday Speech. New York: Oxford University Press.

Wennerstrom, Ann. 2001(b). Intonation and evaluation in oral narratives. Journal of Pragmatics 33, 1183-1206.

Williams, Ann \& Paul Kerswill. 1999. Dialect levelling: change and continuity in Milton Keynes, Reading and Hull. In Paul Foulkes \& Gerry Docherty (eds.) Urban Voices. London: Arnold. 141-162.

Williams, Briony. 1996. The formulation of an intonation transcription system for British English. In G. Knowles, A.Wichman \& P.Alderson (eds.) Working with Speech. London: Longman.

Windsor Lewis, Jack, (ed.) 1995. Studies in General and English Phonetics, Essays in Honour of J.D.O'Connor. London and New York: Routledge.

Wolfram, Walt.1991. Dialects and American English. Englewood Cliffs, N.J.: Prentice Hall.

Wolfram, Walt. 1997. Dialect in society. In Florian Coulmas (ed.) The Handbook of Sociolinguistics. Oxford: Blackwell. 107-126.

Wolfram, Walt \& Clare Dannenburg. 1999. Dialect identity in a tri-ethnic context: the case of Lumbee American Indian English. English World-Wide 20:2 179-216.

Wolfram, Walt, Kirk Hazen \& Natalie Schilling-Estes, 1999. Dialect Change and Maintenance on the Outer Banks. Publication of the American Dialect Society, 81. Tuscaloosa: University of Alabama Press.

Wolfram, Walt \& Natalie Schilling-Estes, 1998. American English. Massachusetts: Blackwell Publishers.

Wolfram, Walt \& Erik R. Thomas. 2002. The Development of African American English: Evidence from an Isolated Community. Oxford: Blackwell.

Wolfson, Nessa. 1982. The conversational historical present in American English narrative. Topics in Sociolinguistics 1. Dordrecht: Foris.

Woods, Nicola J. 1992. It's not what she says, it's the way she says it: the influence of speaker-sex on pitch and intonational patterns. Manuscript. 
Woods, Nicola J. 1997. The formation and development of New Zealand English: interaction of gender-related variation and linguistic change. Journal of Sociolinguistics. 1:1, 95-125.

Zwartz, Joel. 2002. Lateness of rise as a factor in listener interpretation of HRTs. Unpublished Honours paper, Victoria University of Wellington, Wellington, New Zealand.

Zwartz, Joel \& Paul Warren. 2003. This is a statement? Lateness of rise as a factor in listener interpretation of HRTs. Wellington Working Papers in Linguistics Volume 15. Wellington: Victoria University of Wellington. 